\title{
Evaluation of disease management programmes for chronically ill
}

Citation for published version (APA):

Steuten, L. M. G. (2006). Evaluation of disease management programmes for chronically ill. [Doctoral Thesis, Maastricht University]. Datawyse / Universitaire Pers Maastricht.

https://doi.org/10.26481/dis.20060223ls

Document status and date:

Published: 01/01/2006

DOI:

10.26481/dis.20060223ls

Document Version:

Publisher's PDF, also known as Version of record

\section{Please check the document version of this publication:}

- A submitted manuscript is the version of the article upon submission and before peer-review. There can be important differences between the submitted version and the official published version of record.

People interested in the research are advised to contact the author for the final version of the publication, or visit the DOI to the publisher's website.

- The final author version and the galley proof are versions of the publication after peer review.

- The final published version features the final layout of the paper including the volume, issue and page numbers.

Link to publication

\footnotetext{
General rights rights.

- You may freely distribute the URL identifying the publication in the public portal. please follow below link for the End User Agreement:

www.umlib.nl/taverne-license

Take down policy

If you believe that this document breaches copyright please contact us at:

repository@maastrichtuniversity.nl

providing details and we will investigate your claim.
}

Copyright and moral rights for the publications made accessible in the public portal are retained by the authors and/or other copyright owners and it is a condition of accessing publications that users recognise and abide by the legal requirements associated with these

- Users may download and print one copy of any publication from the public portal for the purpose of private study or research.

- You may not further distribute the material or use it for any profit-making activity or commercial gain

If the publication is distributed under the terms of Article $25 \mathrm{fa}$ of the Dutch Copyright Act, indicated by the "Taverne" license above, 
EVALUATION OF

DISEASE MANAGEMENT PROGRAMMES

FOR CHRONICALLY ILL 
(C) Lotte Steuten, Maastricht, 2006 ISBN 9052785134

Layout en druk: Datawyse / Universitaire Pers Maastricht

De druk van dit proefschrift is mede mogelijk gemaakt door GlaxoSmithKline. 


\section{EVALUATION OF \\ DISEASE MANAGEMENT PROGRAMMES FOR CHRONICALLY ILL}

\section{PROEFSCHRIFT}

Ter verkrijging van de graad van doctor aan de Universiteit Maastricht op gezag van de Rector Magnificus, Prof. mr. G.P.M.F. Mols, volgens het besluit van het College van Decanen in het openbaar te verdedigen op donderdag 23 februari 2006 om 16.00 uur

door 


\section{PROMOTORES}

Prof. dr. C. Spreeuwwenberg

Prof. dr. G.G. van Merode

\section{CO-PROMOTOR}

Dr. H.J.M. Vrijhoef

\section{BEOORDELINGSCOMMISSIE}

Prof. dr. C.D.A. Stehouwer (voorzitter)

Prof. dr. mr. R.P.T.M. Grol

Prof. dr. D.L. Kodner (New York University)

Prof. dr. A.P.W.P. van Montfort (Erasmus Universiteit Rotterdam)

Prof. dr. R. de Wit 


\section{CONTENTS}

CHAPTER 1| General Introduction

CHAPTER 2| Assessing the Methodological Quality of Disease Management Evaluation Studies

CHAPTER 3 Disease Management within its Organisational Context

CHAPTER 4| Are we Measuring what Matters in Health Technology Assessment of Disease Management?

CHAPTER 5 / COPD as a multi-component disease

CHAPTER 6. Assessment of Asthma and COPD Disease Management Programmes

CHAPTER 7 | A Disease Management Programme for Patients with Diabetes Mellitus is Associated with Improved Quality of Care Within Existing Budgets

CHAPTER 8 A Probabilistic Decision Model to Assess the Long-term Cost Utility of a Disease Management Programme for Patients with Asthma

CHAPTER 9| General discussion

CHAPTER 10| Summary-Samenvatting

Dankwoord

Curriculum Vitae

List of publications 


\section{GENERAL INTRODUCTION}

Parts of the introduction have been published in:

- Tijdschrift voor Gezondheidswetenschappen 2004;82(2):118-20 en

- Tijdschrift voor Gezondheidswetenschappen 2005;83(5):305-6. 


\section{INTRODUCTION}

This dissertation focuses on the evaluation of disease management programmes for chronically ill. Chronic diseases are currently the main cause of death and disability worldwide. Chronic, non-communicable conditions, including stroke, cancer, diabetes and respiratory diseases, account for $59 \%$ of the 57 million deaths annually and almost one third of the global burden of disease [1]. Meeting the complex needs of a growing group of patients with a chronic condition is one of the greatest challenges that healthcare faces today [2].

Disease management programmes for chronically ill are proposed as a means to improve quality of care and mitigate healthcare costs [2-4]. The assumption is that better care today will result in better health and less expensive care in the future [2].

The main purpose of this research is to assess if organising care in accordance with principles of disease management improves quality of care within existing budgets. Effects and resource implications of disease management programmes for patients with diabetes, asthma or chronic obstructive pulmonary disease (COPD) are evaluated. Principles of Health Technology Assessment (HTA) and decision-analysis are applied to explicitly support decision-making with regard to disease management.

\section{Chronic disease and care delivery}

The term 'chronic disease' connotes all impairments or deviations from normal which have one or more of the following characteristics: they are permanent, leave residual disability, are caused by non-reversible pathological alteration, require special training of the patient for rehabilitation and may be expected to require a long period of supervision, observation, or care [5]. Despite clinical differences across specific chronic conditions, each illness confronts patients and their families with the same spectrum of needs: to alter their behaviour; to deal with the social and emotional impacts of symptoms, disabilities, and approaching death; to take medicines; and to interact with medical care over time [6]. Herewith, all chronic conditions place similar demands on healthcare systems [7].

Evidence shows that present models of care delivery are not sufficiently equipped to address these demands. This results in the majority of patients with a chronic disease being inadequately treated [8]. The cause of this deficiency in healthcare is sometimes called the 'tyranny of the urgent' [9], referring to the situation in which acute symptoms and concerns of patients dominate the less urgent need to bring chronic illness under optimal control. In a system designed for acute rather than chronic care, care delivery for patients with a chronic disease is often fragmented and patients are not adequately taught to care for their own illnesses. All too often, healthcare for a chronically ill patient is characterized by an uninformed passive patient interacting with an unprepared practice team $[3,9]$, resulting in sub optimal care delivery in 
terms of effectiveness and efficiency. Instead, chronically ill patients are assumed to benefit from planned, regular interactions with their caregivers, focusing on function and prevention of exacerbations and complications. Interactions should include systematic assessments, attention to treatment guidelines, and behaviourally sophisticated support for the patient's role as self-manager. In order to optimise processes of care and self care behaviour of patients, it is proposed that interactions must be linked through time by clinically relevant information systems and continuous monitoring, initiated by medical practice [2].

\section{Disease management programmes for chronically ill}

In Western countries, new healthcare models for chronically ill patients were introduced in the 1990s in response to the pressure on quality and costs of chronic care. These models originated from the overlapping approaches of integrated care (United States) and shared care (Western Europe). In the Netherlands, shared care acted as a precursor of the concept of disease management that was introduced in 1997 [10]. Several definitions of disease management were formulated $[11,12]$, while a diversity of disease management initiatives arose.

In this study the, by now widely accepted, definition of the Disease Management Association of America (DMAA) was adopted. The DMAA defined disease management as 'a system of co-ordinated healthcare interventions and communications for populations with conditions in which patient self care efforts are significant' [13]. Disease management supports the physician or practitioner/patient relationship and plan of care, emphasizes prevention of exacerbations and complications by utilising evidence based practice guidelines and patient empowerment strategies, and evaluates clinical, humanistic and economic outcomes on an ongoing basis with the goal of improving overall health. Disease management components include 1) population-identification processes, 2) evidence based practice guidelines, 3) collaborative practice models to include physician and support-service providers, 4) patient self management education, 5) process and outcomes measurement, evaluation and management, and 6) routine reporting/feedback loops [13]. It is acknowledged that there are many different programmes in terms of their comprehensiveness and focus. The so-called 'full-service' disease management programmes, comprising all components of disease management, can be distinguished from 'disease management support services", that are less comprehensive [13]. This distinction is important. when interpreting and comparing the effects of programmes. 


\section{Disease management programmes for patients with diabetes mellitus, asthma or COPD in the region of Mastricht}

In 2001 , a shared care programme for patients with stable diabetes mellitus type 2 was expanded to a comprehensive disease management programme for all patients with diabetes mellitus (type 1 and 2) within the region of Maastricht. In the same year, a similar programme was developed for patients with asthma or COPD. The region of Maastricht comprises circa 120.000 inhabitants, 90 general practitioners (GPs) and one hospital. The programmes aim to include all patients that are currently diagnosed (or will be diagnosed) with diabetes, asthma or COPD.

In the region of Maastricht more than 3000 people are diagnosed with diabetes while it is recognised that at least $35 \%$ of patients with diabetes are undiagnosed so far [14]. In addition, the number of diabetics is expected to rise with $35.7 \%$ between 2000 and 2020 , as a result of improved detection methods and an increasing number of people. suffering from overweight [15]. With regard to the prevalence of asthma and COPD, it is estimated that approximately 8,000 people in the region of Maastricht have one of these conditions [16]. Based on demographic developments, the absolute number of patients with asthma will rise with $6.7 \%$ between 2000 en 2020 , as compared to an increase of $39.7 \%$ for patients with COPD [17].

With more than 11,000 people in the region of Maastricht being diagnosed with either diabetes, asthma or COPD, the burden of these conditions on the regional healthcare system is considerable. By implementing disease management programmes for patients with any of these conditions it is aimed to improve quality of care within the existing budget restraints.

Within the programmes, the six components of disease management, as distinguished by the DMAA, are addressed to a certain extent. The population of patients diagnosed with either asthma, COPD or diabetes, is identified through databases of GPs and the database of the hospital. Also, patients that are 'suspected' to suffer from any of these conditions, as based on medication use or medical history, are selected from the databases. A collaborative practice team is formed by a medical specialist, GP and nurse specialist. Tasks and responsibilities of each type of care provider are described in a multidisciplinary protocol. Evidence based guidelines form the basis of this protocol, outlining the programme in detail. Medical specialists and GPs are encouraged to adhere to the (inter) national treatment guidelines, while the protocol for care delivery by the nurse specialist is based on the Dutch guidelines for GPs. Were appropriate, care is transferred to the lowest level possible. For the nurse specialists this means that they independently perform diagnostic and therapeutic activities, while using their nursing skills to enhance patient education and promotion of self management. Since they are hosted by the hospital, but meet patients in the office of the GP, they function as a liaison between primary and secondary care. Processes and outcomes of care are monitored by the integrated care department of the hospital that co-ordinates the programme. Data from the electronic patient 


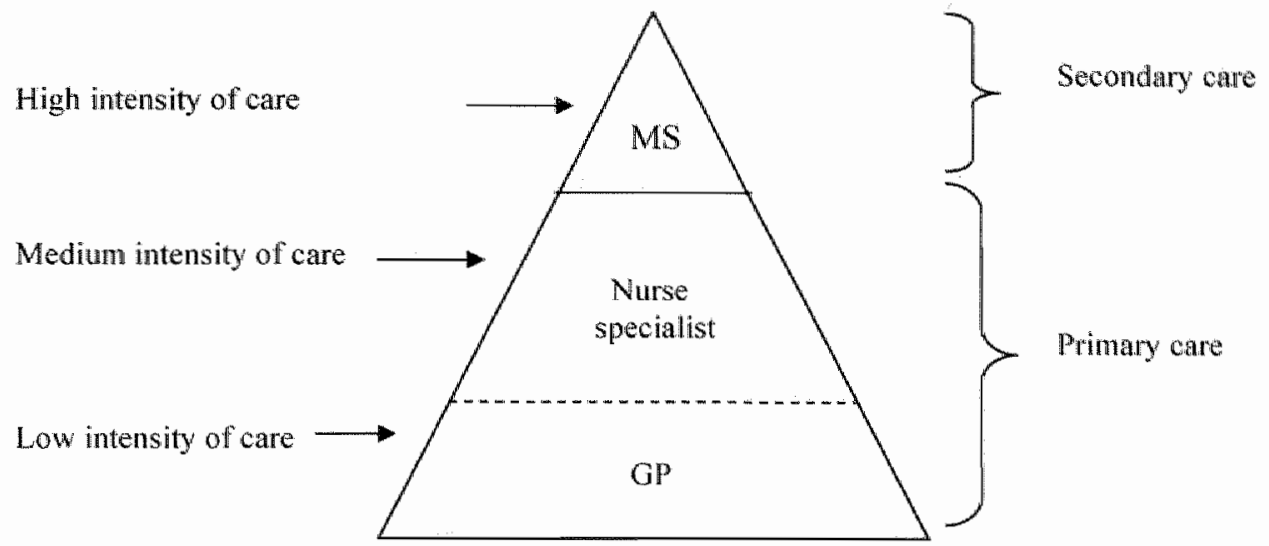

Figure 1: Outline of the "Mastricht" disease management progranmes.

record systems are used as steering information to manage the programme and to provide structural feedback towards care providers.

In practice, the programmes were operated as follows. Patients identified from any of the databases were approached for participation in one of the programmes. Those who agreed to participate were invited for an initial consultation that was carried out by the nurse specialist within the GP's office. During this consultation the nurse specialist assessed the health status of the patient, registered symptoms and complaints, interpreted laboratory and test results (e.g. HbA1c, spirometry) and performed physical examination when necessary. Based on these data, the collaborative practice team confirmed or reconsidered the diagnosis. Disease severity and. required intensity of care were classified in accordance with the guidelines, lading to a proposal concerning the assignment of the patient to either medical specialist, GP or nurse specialist. If patients agreed with this proposal, those requiring high intensity of care were assigned to the medical specialist (MS). Patients requiring medium intensity of care, received quarterly outpatient appointments from the nurse specialist within the office of the GP. Patients requiring low intensity of care are assigned to the GP (see Figure 1). Nurses and GPs regularly discussed patients that were seen by the nurse in the office of the GP. Once a week, the nurse reported to the medical specialist.

\section{Decision-making with regard to disease management}

In the US, disease management programmes have rapidly expanded in the belief that they would inprove patient outcomes at lower costs. In Western Europe, the concept of disease management has also gained attention quite fast. Nevertheless, it is 
questioned if disease management programmes actually fulfil the expectations. Recently, the US Central Budgetary Office published a report stressing, "to date there is insufficient evidence to conclude that disease management programmes can generally reduce the overall cost of healthcare services" ${ }^{2}[18]$. Substantial uncertainty exists conceming the impact of programmes on costs and outcomes of care, both in short and long term $[4,18,19]$. Decision-making on (further) implementation of programmes is hindered by this.

The uncertainty around costs and effects of programmes has several causes, as for example, limited availability of data depending on the interest of stakeholders, heterogeneity of programmes and methodological challenges in evaluating comprehensive disease management programmes in daily practice. First of all, many programmes are implemented without critical evaluation of their actual value $[20,21]$. When a programme is to be evaluated, this is often carried out "in house" and for internal management purposes only. Depending on the type of organisation and the stakeholders that support the programme, data that are considered useful from their perspective are collected. These data are not necessarily useful for other parties interested in disease management programmes. Physicians, for example, might be interested in other parameters than insurance companies or policy makers. In addition, decision-making with regard to disease management programmes suffers from the so-called "not invented here" syndrome. This syndrome can be described as a persistent corporate or institutional culture that either intentionally or unintentionally avoids using previously performed research or knowledge, because the research and developed knowledge was not originally executed 'in-house' [22]. However, it is recognised that heterogeneity of programmes and methodological limitations of studies attempting to assess the net value of disease management programmes, often provide a very good reason for not using previously collected information for decision-making purposes.

The substantial differences that exist between design and contents of disease management programmes might be explained by differences in healthcare systems and organisational context in which programmes are developed and operated. Also, the way programmes are implemented might vary due to differences in management and incentive structures within healthcare systems [23]. In the Netherlands, as opposed to the US for example, most disease management programmes are gradually introduced. Various combinations of disease management components are implemented on different locations, all with their own regional organisational structure. Failure to recognise the variation in programme contents, patient populations, processes and evaluated outcomes of care, may lead to inappropriate conclusions about the cost effectiveness of disease management programmes [24]. Organisational contingency theories, which assume that there is no single best way to organise and that any one way of organising is not equally effective under all conditions [25], point out that to be able to generalise research findings it is necessary to have insight in the way disease 
management programmes are embedded within regional healthcare structures: 23]. To study this empirically, variation in organisational structures, wherein programmes are implemented, is required. Since both disease management programmes under study are operated in the same setting, this prerequisite was not met. Therefore, this issue has been addressed by reviewing the literature comparing effects of programmes that are employed in different organisational settings.

Finally, there are methodological challenges that need to be discussed. Although most of these challenges are not unique for HTA of disease management, the complexity of diseases on which programmes are focused and the multifactorial nature of the programmes itself, lead to specific difficulties when attempting to evaluate programmes in a rigorous way and, in the meanwhile, support decision-making in daily practice. So far, research has shown the efficacy of each of the specific disease management components within controlled research settings [26-28]. However, the cost effectiveness - the benefit in real clinical practice - of the programmes as a whole has herewith not been proven $[18,29]$. As many interventions, disease management programmes are not meant for a specifically standardised population of patients, but for the total population of, for example, asthmatics, in a certain region. As a result, the target population of a disease management programme is likely to be rather heterogeneous, including patients with varying disease severity, complications and often co morbidity. From a methodological point of view, heterogeneity within study populations increases the potential of confounding and should preferably be avoided, for example, by excluding patients with a particular disease severity or co morbidity from the studly. However, this would decrease the value of study results for purposes of decision-making, since care providers and policy makers do not have the luxury of ignoring certain patient groups when deciding whether or not to spend money on disease management programmes that will affect the total population of patients. Also, relatively large patient groups need to be followed for several years since the largest benefits and potential cost savings are expected to occur in the long term due to the nature and course of chronic diseases. Finding a comparable patient population that during the total follow-up of the study will not be exposed to any of the components of the disease management programme and lives in an environment with similar healthcare structures as the experimental region is difficult if not impossible and unethical [29]. This leads to the situation that assessing the cost effectiveness of disease management programs within daily practice can hardly be performed in accordance with the current golden standard of science: the (double-blind) randomised controlled trial [30]. As a result, conclusions with regard to cost effectiveness are often based on short-term before-after studies, without critical reflection on potentiall treats to validity resulting from, for example, 'regression to mean' or other phenomena [31]. As long as a consistent analytical framework for the evaluation of clinical and economic outcomes is lacking, comparison of reported results is often impossible [32]. Given the lack of evidence that disease management programmes 
reduce costs of healthcare services $[4,18,19]$, while the incremental effectiveness of different programmes is hard to compare $[4,32]$, decision uncertainty with regard to allocation of scarce resources is substantial. The application of HTA is proposed as a means to reduce this uncertainty, given its specific features with regard to scope and purpose of research as outlined below.

\section{BACKGROUND OF METHODS APPLIED IN THIS RESEARCH}

Principles of HTA and decision-analytic modelling were applied to evaluate the short- as well as the long-term impact of the programmes on processes and outcomes. of care.

\section{Health Technology Assessment}

The term Health 'Technology Assessment (HTA) was first used in the United States Congress in 1967. HTA is a broad concept with many facets and vague borders, differing from country to country. Therefore, it is crucial to keep the context in which HTA is applied in mind. The healthcare system of a country reflects its history, culture, values and preferences. The same applies to HTA, which is influenced by that healthcare system.

Under pressure of rising healthcare expenditures, rapid technological change and the necessity to rationalise healthcare technology, the field of HTA has grown fast within the last decade, especially in Western Europe. However, most people dealing with HTA were not academics involved in scientific, comparative analysis. Also, there was hardly any pressure to develop conceptual clarity of HTA. Instead, HTA was applied in the demanding everyday business of supporting policy makers and industries to solve difficult problems [33].

In 1999 the Dutch Advisory Council on Health Research (RGO) established the "Platform HTA". It defined HTA as "scientific research towards a healthcare technology focusing on medical effectiveness and at least one other aspect of healthcare, as for example costs, organisational aspects or quality of care, with the explicit aim to provide input to decision-making in policy and practice'. Technology must be understood in the broadest sense of the word here. Not only medical instruments or medication are meant, also organisational arrangements or counselling are captured by this term [34].

The most profound form of HTA is the economic evaluation, in which effectiveness or efficacy as well as costs are compared between two (or more) interventions competing for scarce resources. Several forms of economic evaluation exist, among which cost effectiveness and cost utility analysis are the most well known. Although these terms are often used interchangeably, the two are not alike. Cost effectiveness 
analysis refers to an analysis in which costs and the number of occurrences of apecific desired outcome are assessed in each intervention (e.g. costs per successful hip surgery), while analyses that employ utilities as a measure of the value of programme effects are termed cost utility analysis. The results of cost utility analysis are typically expressed in terms of cost per quality-adjusted life year (QALY) gained, by undertaking one programme instead of another or instead of 'usual care'. Utillity analysis is viewed as a particularly useful technique since it allows for quality of life adjustments to a given set of programme outcomes, while simultaneously providing a generic outcome measure for comparison of costs and outcomes of different programmes. The generic outcome (QALY) is employed by adjusting the length of time that is affected by the health outcome, by the utility value (on a scale of 0 to 1) of the resulting level of health status [35]. Although it is not always possible to predict what form the final analysis will take, as this may depend on the results of an associated clinical evaluation, it was proposed to apply cost utility analysis to compare the costs and consequences of the disease management programme with "usual care" and herewith support decision-making with regard to allocation of scarce resources.

\section{Decision-analysis}

Recently a decision-analytic framework for the evaluation of healthcare programmes has been presented [36-38]. The framework suggests that the adoption decision should be based on the expected (mean) net benefits $[39,40]$ of the technology, given the existing information and irrespective of whether the difference is statistically significant [37]. The net benefit framework exploits econometric techniques to reformulate the cost effectiveness problem while avoiding reliance on cost effectiveness ratios and their associated statistical difficulties. The incremental cost effectiveness ratio (ICER) provides a point estimate of the mean cost per unit of effect gained by the intervention under study. This value, being the ratio of two differences that each may not have a normal distribution, has an unknown sampling distribution and is difficult to interpret. The value of the ICER itself does not give sufficient information for decision-making without knowledge on which quadrant of the cost effectiveness plane the estimate falls. Whille it is trivial to check which situation has produced the ICER estimate, care must be taken when constructing confidence intervals so that ratios with similar signs but different interpretations are not grouped together. A programme's net benefit is calculated by subtracting the additional cost from the additional effect, valued in euros (net monetary benefit), or by subtracting the additional cost, valued in effect units, from the additional effect (net health benefit). The decision rule in the net benefit framework is that the new intervention should be implemented only when net benefit is positive. In contrast to the ICER, where the variance is not defined, the variance of net benefit estimated from sample mean costs and effects in each trial arm is simply a linear combination of two 
asymptotically nomall variables. The confidence interval of the net benefit statistic can be determined in the standard fashion. However, the advantages of the net benefit approach come with a potential drawback, that is, the net benefit statistic is a function of the maximum willingness-to-pay for an additional effect (lambda), which is unknown to the analyst in most cases. This forces explicit consideration of this value of lambda. By some economists, however, this is considered a strength, since it emphasizes the importance of sensitivity analysis to examine different values of lambda [41].

\section{Handling uncertainty in economic evaluations}

Considerable uncertainty exists with regard to valid economic evaluations. This uncertainty can be distinguished in wariability, stochasticity and unfamiliarity, which has consequences for the way to handle uncertainty [42]. Firstly, several aspects of the underlying methodological framework are still debated among health economists, as for example the way in which productivity losses should be captured in cost utility analysis $[43,44]$. This uncertainty can be characterised as unfamiliarity. The relative impact of this uncertainty on results informing a decision can be estimated by sensitivity analysis [42]. Secondly, there is always uncertainty surrounding the data inputs such as clinical effects, health-related quality of life and resource use. This uncertainty contains both unfamiliarity and stochasticity. A distributional function can be estimated to reflect this stochasticity and its impact on decision uncertainty [42]. Thirdly, uncertainty can exist with regard to the composition of the (study) population. This is variability and can only be dealt with by performing further research [42]. Finally, uncertainty exists with regard to the assumptions that may be used [45]. This, again, is unfamiliarity that is to be dealt with by sensitivity analysis [42]. A number of alternative methods of sensitivity analysis are available to handle and express uncertainty caused by unfamiliarity and stochasticity. Sensitivity analysis involves a systematic examination of the infuence of uncertainties in the variables and assumptions employed in an evaluation on the estimated results.

\section{Modelling in economic evaluations}

The use of decision-analytic modelling to estimate the costs and consequences of healthcare technologies is becoming widespread $[46,47]$. Models can be used for several purposes including the synthesis of data from various sources and extrapolation of findings beyond the follow-up of an empirical trial [48]. They provide an insight into the working of a system and can be used to predict outcomes of a change. This is particularly useful when the system is very complex or when experimentation is not possible [49], for example dne to the complexity and comprehensiveness of the intervention. Given the desire not to overload randomised clinical trials with enor- 
mous amounts of data collection and to increase the generalisability of the andysis. trials may not be the ideal vehicle for all data collection necessary for economic and$y$ sis and decision-making [48]. In addition, economic evaluations will most likely be concerned with lifetime costs and consequences, while many evaluations are based on much shorter time horizons, usually mirroring the clinical data collection in the trials. Using available epidemiological and natural history data, models can be used to extrapolate costs and consequences over the desired time horizon [48]. Although there are some drawbacks on the use of models, for example the fact that they always simplify the complexity of daily practice and are sometimes considered as 'black boxes', modelling has become an important tool within HTA.

A particular type of model that is now frequently used in economic evaluation is the Markov model. Markov models have a long history of use in health service decision-making, including clinical, epidemiological and health economics applicam tions. The way in which Markov models simply and intuitively handle both costs and outcomes simultaneously is one of their strengths. Markov models are often employed to represent stochastic processes, that is, random processes that evolve over time [48]. Since these models are particularly suited to modelling chronic diseases, a Markov model has been developed to assess the long-term cost utility of the asthma disease management programme.

\section{RESEARCH}

To assess if organising care in accordance with principles of disease management improves quality of care within existing budgets, the effects and resource implications of two disease management programmes for either diabetes or asthma and COPD are studied in the region of Mastricht. These progranmes are considered good cases to study disease management since they contain all components of disease management to a certain extent. Additionally, the programmes are implemented on a large scale (i.e. region-wide) and incorporated in daily practise which makes it possible to study their effectiveness rather than their efficacy, which is considered more useful for decision-making. Although studying two programmes in one region may be considered of limited use to answer questions regarding cost effectiveness of disease management programmes in general, it should be recognised that no amount of positive observations is ever sufficient to test and prove a theory. However, one example that proves the opposite, is logically conclusive. This also shows the contemporary nature of conclusions of any experiment or research: there will always be a chance that the hypothesis will be falsified by an experiment proving the opposite [50]. 


\section{Research questions}

The study presented in this dissertation addresses several research questions that are described within the next seven chapters. To avoid repetition, the major research topics covering the specific research questions, will be described here in a more general form.

The first topic concerns methodological challenges that arise when assessing the impact of disease management programmes for purposes of decision-making. Attention is paid to 1) criteria for methodological quality of HTA of disease management programmes, 2) structure, process and outcome indicators that should be assessed given the aim(s) and type of programmes and 3) the application of decision-analytic methods to support decision-making with regard to disease management for chronically ill in both short and long term. Secondly, the potential impact of organisational structures on design and performance of disease management programmes is explored. Finally, it is assessed to what extent the disease management programmes for diabetes, asthma and COPD, as implemented in the region of Maastricht, reach their aims, both in short and long term.

\section{Research hypothesis}

Several hypotheses with regard to the methodology of Health Technology Assessment of disease management and the impact of disease management programmes on. effectiveness and efficiency of care, underpin this research.

First of all, it was hypothesized that given the comprehensive and complex nature of disease management interventions and the explicit goal of HTA to support decision-making, existing instruments for assessing methodological quality of studies would not necessarily address the 'right' methodological issues from an HTA point of view.

Secondly, based on contingency theories it was hypothesized that differences between disease management programmes could be explained by variations within the organisational context in which they were developed and implemented. In addition, we expected that the potential effectiveness and efficiency of the programmes would be influenced by variances in programme design. The contingency assumption is that variation between programmes is necessary to reach optimal effectiveness and efficiency of care, given differences in organisational context and available technology. With regard to these differences in programmes, we expected that the explicit aim(s) of the programme under study as well as the type of programme, as defined by its contents, would have guided the choice for indicators used in the evaluation of disease management programmes. It was hypothesised that, although probably not formalised, an analytic framework for evaluating disease management programmes would exist. 
With regard to programme design, it was recognised that the assignment of parlents to one specific care provider, based on disease severity as defined by current dassificaltion systems, was probably sensitive to changes in this system. In the last couple of years, increasing evidence arose suggesting that in order to assess disease severity of COPD more thoroughly, not only respiratory but also systemic expressions, as muscle depletion, weight loss and dyspnoea, should be included in the classification system [51,52]. It was hypothesised that the use of a multidinensional grading system, including these aspects, would influence the distribution of disease severity within a population of COPD patients and herewith the assignment of patients to care providers. This would have several implications for prevention, medical treatment and non-medical treatment as well as estimations of healthcare utilisation. Based on previous evidence with regard to disease management components [21,53-55] it was hypothesised that programmes would lead to improvements in quality of care without increasing healthcare costs. More specifically, it was expected that closer adherence to clinical guidelines and improvements in disease specific knowledge and self management abilities of patients would in the short term lead to an increase in resource utilisation (specifically with regard to medication and routine follow-up consultations), and increased patient satisfaction. In the long term, prevention of exacerbations and complications, as the result of improved disease control, would lead to an increase in thealth-related quality of life while mitigating healthcare costs.

\section{Research methods and design}

Given the different nature of the research questions, various methods have been applied to answer them. Since the methodological research questions requited an overview of the current practice in HTA of disease management, systematic literaw ture reviews have been perfomed to answer these questions. To address the organsational issues also a systematic literature review has been undertaken. Although these research objectives might optimally be investigated by (international) comparative research, this approach was chosen to get a better appreciation of the subject and generate sensible hypotheses to direct this type of research before actually starting a large scale empirical research. Finally, pre-post test designs were applied to assess the impact of the disease management programmes on processes and outcomes of care. Ideally, this type of question is studied by means of a randomised controlled trial ( $\mathrm{RCT}$ ) in order to demonstrate a causal relationship between the intervention and the outcomes and reduce the likelihood of bias in effect estimates, herewith safeguarding intemal validity. However, as pointed out before, several reservations exist with regard to the feasibility of employing this type of rigorous designs to daily practise, while external validity of results from R CTs is limited [56]. The pre-post test design was applied as the next best approach since the programmes were imple- 
mented region-wide (excluding the possibility of control groups within the region) and a 'fair' comparison region could not be found. In all potential comparison regions, imnovations were being implemented that would bias the measure of usual care, as for example the introduction of shared care arrangements or self management interventions. Finally, a probabilistic decision-analytic Markov model was developed to estimate the cost and effects of the disease management for patients with asthma in the long term. Except for data on asthma mortality, all data inputs for the model were taken from the empirical study. For details on the research methods and study designs, readers are referred to the comesponding chapters within this thesis.

\section{Operationalisation and instrumentation}

The disease management programmes under study aim to improve quality of care within the existing budget restraints. Previous studies already suggested that a mixture of indicator types may be more usefull in assessing quality of care from various stakeholder perspectives, and that attention should be paid to conceptualisation and operationalisation of quality of care indicators [57]. The paradigm of Donabedian, distinguishing structure, processes and outcomes of care, was therefore used as a starting point for the operationalisation of quality of care [58]. According to Donabedian, structure indicators are defined as the physical and organisational properties of the settings in which care is provided. Process encompasses all that is done to and for a population of consumers and patients, such as preventive services and measures, diagnosis, treatment, and palliative care. Outcomes are the end results of care, that are changes in patient or population health status, life expectancy, quality of life, and healthcare costs [58]. Within this dissertation the impact of disease management programmes on several processes and outcomes of care is assessed while healthcare structures are considered to influence the design and performance of the programmes.

Effectiveness and efficiency are regarded as attributes of quality in healthcare. Effectiveness is defined as the ability to attain the greatest improvements in healthere now achic vable by the best care. Efficiency is defined as the amount of resources needed to achieve a certain goal [59]. Based on previously established objectives in the care for chronically ill, a set of indicators with regard to quality of life was proposed by the Dutch Organisation for Scientific Research [60]. With this set, including clinical parameters, health status, self care behaviour and patient satisfaction, as well as health-related quality of life, effectiveness has been assessed. In order to assess efficiency of care, the outcomes were related to resource utillisation.

Clinical parameters and health status have been used to assess if the programmes affected disease control and consequently the occurrence of exacerbations or complications. Self care behaviour and disease specific knowledge were measured to investigate if care delivery within the programme promoted patient self manage- 
ment. Patient satisfaction was assessed to find out if the care as delivered was appreciated by the patients. Health-related quality of life was considered as an overall effect measure and used to calculate QALYs. In addition, process indicators were measured to assess if the disease management programme affected adherence to clinical guidelines and to investigate if clinical pathways changed as a result of the introduction of the programme. Survival was not considered as an outcome of the empirical study, since study design, length of follow-up and the size of the patient population were not considered suitable to assess a potential impact on this parameter. Resource use was measured to calculate both direct and indirect costs of care (e.g. medical costs and productivity losses). Both generic as well as disease specific instruments have been used in the studies. For details about instruments used, readers are referred to the chapters addressing the empirical studies that all. include a section in which instrumentation has been described further.

\section{OUTLINE OF THE THESIS}

The results of the systematic reviews are described in chapters 2,3 and 4. In chapter 2 the results of the systematic review towards the suitability of existing instruments to assess methodological quality of disease management evaluation studies is presented and a new instrument to assess HTA of disease management is proposed. The aim of this chapter is to introduce an HTA perspective on research methodology when complex, comprehensive interventions as disease management are considered. Within chapter 3 the results of a systematic literature review towards the components and organisational context of disease management programmes throughout the world are presented. Chapter 4 presents a taxonomy of indicators currently used to assess disease management programmes. In addition, a framework for H'TA of disease management is proposed that guides the choice for indicators to be measured when evaluating disease management programmes, taking the aim(s) and types of programmes into account.

The results of the empirical studies are described in chapters 5,6,7 and 8. In chapter 5 it is described how the distribution of COPD disease severity in primary care looks like and to what extent a multidimensional staging system to classify disease severity would influence this distribution. The impact of the disease management programme for patients with asthma or COPD on processes and outcomes of care is reported in chapter 6 . Within this chapter it is also described if changes in the end results of care can be predicted from process and intermediate outcomes. The results of the diabetes disease management programme on clinical parameters, self care behaviour, health-related quality of life and resource use are described in chapter 7. In chapter 8 the development as well as the results of the Markov model, assessing the 
long-term cost utility of the disease management programme for patients with asthma, has been described.

A summary and discussion of the main findings are presented in Chapter 9 . In this chapter also recommendations for effective and efficient organisation of care for chronically ill are presented as well as directives for further (methodological development of) HTA of disease management.

\section{REFERENCES}

1. World Health Organization. Chronic diseases and health promotion. Geneva: World Health Organization, 2005. http://www who.int/chp/en/ Last accessed: July 20, 2005.

2. Wagner EH. Chronic disease management: what will it take to improve care for chronic illness? Eff Clin Pract 1998;1:2-4.

3. Bodenheimer T, Wagner EH, Grumbach K. Improving care for patients with chronic illness. IAMA 2002;288:1775-9.

4. Ofman JJ, Badamgarav E, Henning JM et all. Does disease management improve clinical and economic outcomes in patients with chronic diseases? A systematic review. Am J Med 2004 Aug $1 ; 117(3): 182-92$.

5. Timmreck TC (ed). Dictionary of health services management ( $2^{\text {nd }}$ edition). Owings Mills Maryland, USA: National Health Publishing, 1986.

6. Wagner EH, Groves T. Care for chronic diseases. BMJ 2002;325:913-4.

7. Epping-Jordan JE, Pruitt SD, Bengoa R, Wagner EH. Improving the quality of care for chronic conditions. Qual Saf Health Care 2004;13:299-305.

8. Institute of Medicine. Crossing the Quality Chasm: a new health system for the $21^{\text {st }}$ century. Washington, DC: National Academies Press, 2001.

9. Wagner EH, Austin BT, Von Korff M. Organizing care for patients with chronic illness. Millbank Q 1996;74:511.44.

10. Vrijhoef HJM, Spreeuwenberg C, Eijkelberg IMJG, WolffenbuttelBHR, Van Merode GG. Adoption of a disease management model for diabetes in the region of Maastricht. BMJ $2001 ; 323: 983-5$.

11. Stuurgroup Scenario's Gezondheidszorg. Managed care en disease management in Nederland. Deel 1 - een eerste verkenning door partijen. Zoetermeer: STG, 1997. [in Duth]

12. Spreeuwenberg $C$, Pop P. In: Spreeuwenberg C. Pop P, Beusmans GHIM et al. Handboek transmunale zorg. Maarsen: Elsevier Gezondheidszorg, 2000:17-35. [in Dutch]

13. Disease Management Associntion of America. www dmaa org Last accessed: July 20, 2005.

14. Baan CA. Feskens EJM. Diabates mellitus samengevat. In: Volksgezondheid Toekonst Verkenning , Nationaal Kompas Volksgezondheid. Bilthoven: RIVM 2003. www.nationaalkompas.nl Last accessed: July 25, 2005. [iw Dutch]

15. Gijsen R, Baan CA, Feskens EJM, Poos MJJC. Neent het antal mensen met diabetes mellitus toe of af In: Volksgezondheid Toekomst Verkenning, Nationaal Kompas 
Volksgezondheid. Bilthoven: RIVM 2004. www.nationaalkompas.nl Last iccessed J thy 25 ; 2005. [in Dutch]

16. Boezen HM, Postma DS, Smit HA. Astma en COPD samengevat. In: Volksgezondheid Toekomst Verkenning, Nationaal Kompas Volksgezondheid. Bilthowen: RIVM 2003. www.nationaalkompas.nl Last accessed: July 25, 2005. [in Duth]

17. Boezen HM, Postma DS, Smit HA, Gijsen R, Poos MJ]. Neemt het aantal mensen met asthma of COPD toe of aP? In: Volksgezondheid Toekomst Verkenning, National Kompas Volksgezondheid. Bilthoven: RIVM 2004. www nationalkompas.nl Last accessed: July 25 , 2005. [in Duth]

18. Holtz-Eakin D. An analysis of the literature on disease management programmes. Congressional Budget Office, U.S. Congress, Washington DC 2004. www.cbo.gov Last accessed: July 14, 2005.

19. Knight $\mathrm{K}$, Badangarav E, Henning JM et al. A systenatic review of diabetes disease management programs. Am J Manag Care 2005;11(4):242-50.

20. Kesteloot K. Disease management. A new technology in need of critical assessment. Int J Technol Assess Health Care 1999;15(3):506-19.

21. Schrijvers $G$, Spreeuwenberg C, Van der Laag, et al, Disease Management in de Nederlandse context. Utrecht: Igitur, Utrecht Publishing \& Archiving Services, 2005. [in Dutdh]

22. Katz \& Allen. Investigating the Not Invented Here (NIH) Syndrome: a look at the performance, tenure and communication patterns of 50 R\&D project groups. R\&D Management 1982;12:7-19.

23. Macq J. Trials should inform structures and processes needed for tailoring interventions. BMJ 2005,330:665-6.

24. Ouwens $M$, Wollerheim $H$, Hermens R, Hulscher M, Grol R. Integrated care programmes for chronically ill patients: a review of systematic reviews. Int $\mathrm{J}$ Qual in Health Care $2005 ; 17(2): 141-6$.

25. Wan TH, Wang BL. Integrated healthcare networks" performance: a growth curve modelling approach. Health Care Manag Sci 2003;6:117-24.

26. Weingarten $\mathrm{SR}$, Henning JM, Badamgarav E, et al. Interventions used in disease management programmes for patients with chronic illness - which ones work? Meta-analysis of published reports. BMJ 2002;235:925-37.

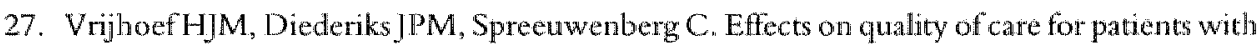
NIDDM or COPD when the specialised nurse has a central role: a literature teview. Patient Educ Couns 2000;41(3):243-50.

28. Vrijhoef HJM, Diederiks JPM, Spreeuwenberg C, Wolffenbutrel BHR. Substitution model with central role for nurse specialists is justified in the care for stable type 2 diabetic outpatients. J Adv Nursing 2001;36:1-10.

29. Steuten LMG, Van Merode GG, Spreeuwenberg C, VrijhoefHJM. Brug tussen onderzoek en beleid: toepassing van Health Technology Assessment op disease management. TSG 2004;82:118-20. [in Dutch]

30. Van Weel C, Knotmerus JA. Evidence based interventions and comprehensive treatment. The Lancet 1999;353:916-8. 
31. Linden $\mathrm{A}$, Adams $\mathrm{J}$, Roberts $\mathrm{N}$. An assessment of the total population approach for evaluating disease managenent progtam eftectiveness. Disease Management 2003;6:93-102.

32. Villagra V. Strategies to control costs and quality: a focus on outcomes research for disease management: Med Care 2004:42(4 Suppl):III24-30.

33. Banta D. The development of Health Technology Assessment. Health Policy $2003: 63: 121-32$.

34. Platform HTA. Stimulering HTA in Nederland. Raad woor Gezondsheidsonderzoek, Den Hagg, 2001. [in Duth]

35. Drummond MF, O'Brien B, Stoddart GL, Torrance GW. Methods for the economic evaluation of health care programmes. New York: Oxford University Press 1997.

36. Claxton K, Neumana Py, Araki S, Weinstein MC. Bayesian walue-of-information analysis. An application to a policy model of Alzheimer's disease. Int J Technol Assess Health Care $2001 ; 17(1): 38-55$.

37. Claxton $K$. The irrelevance of inference: a decision making approach to the stochastic evaluation of health care technologies. J Health Econ 1999;18:341-346.

38. Claxton $\mathrm{K}$, Posnett J. An economic approach to clinical trial design and research prionity setting. Health Econ 1996;5:513-524.

39. Stinnett AA, Mullahay J. Nethealth benefits: a new framework for the analysis of uncertainty in cost in costmeffectiveness analysis. Med Decis Making. 1998;18:S65-S80.

40. Tambour $M$, Zethraeus $N$, Johannesson $M$. A note on confidence intervals in cost-effectiveness analysis. Int J Tech Assess Health Care 1998;14(3):467-71.

41. Hoch JS, Briggs AH, Willan AR. Something old, something new, something borrowed, someting blue: a framework for the marriage of health econometrics and cost-effectiveness analysis. Health Econ 2002;11:415-30.

42. Van Merode GG, Groothuis S, Hasman A. Enterprise planning for hospitals. Int J Med Inform $2004 ; 73(6): 493-501$.

43. Weinstein MC, Siegel JE, Garber AM, et al. Productivity costs, time costs and health-related quality of life: a response to the Erasmus group. Health Econ. 1997;6:505-10.

44. Brouwer WBF, Koopmanschap MA, Rutten FFH. Productivity costs in cost-effectiveness analysis: numerator or denominator: a further discussion. Health Econ. 1997;6:511-14.

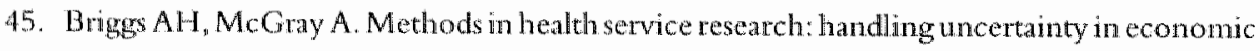
evaluations of healthcare interventions. BMJ 1999;319:635-8.

46. Buxton MJ, Drummond MF, van Hout BA, et al. Modelling in economic evaluation: an unavoidable fact of life. Health Econ 1997;6:217:27.

47. Eddy DM. Technology assessment: the role of mathematical modelling. In: Mosteller $\mathbb{F}$, editor. Assessing medical technologies. Washington, DC: National Academy Press, $1985: 144-53$.

48. Briggs A. Sculpher M. An introduction to Markov modelling for economic evaluation. Phamacoeconomics 1998;13(4):397-409.

49. Fone D, Hollinghurst $S$, Temple $M$, et al. Systematic review of the use and value of computer and simulation modelling in population health and health care delivery. $J$ of Public Health Med $2003 ; 25(4): 325-335$. 
50. Popper KR. Logik der Forschung. Viema: Julins Springer Verlag. 1935.

51. Wouters EF, Creutzberg EC, Schols AM. Systemic effects in COPB Chest $2002 ; 121: 1275-1305$.

52. Celli BR, Cote $\mathrm{CG}_{*}$ Marin JM, Casanova C, Montes de OCa M, Mendez RA, et al. The body-mass index, airflow obstruction, dyspnoea, and exercise capacity index in chronic obstructive pulmonary disease. NEJM 2004;350;10:1005-12.

53. Vrijhoef HJM. Is it justifiable to theat chronic patients by nurse specialists? Exaluation of effects on quality of care. Dissertation, Uniwersiteit Maastricht, Matstricht 2002.

54. Norris SL, Nichols PJ, Caspersen CJ et al. The effectiveness of disease and case management for people with diabetes: a systematic review. Am J Prev Med 2002;22(45):15-58.

55. Drummond $N$, Abdalla M, Buckingham JK, etal. Integrated care for asthma: a clinical, social and economic evaluation. BMJ 1994;308:559-64.

56. Ovretveit J. Evaluating health interventions. An introductin to evaluation of health treatments, services, policies and organizational interwentions. Buckingham, Philadelphia: Open University Press, 1998.

57. Arah OA, Klazinga NS, Delnoij DMJ, Ten Asbroek AHA, Custers T. Conceptual framework for health systems performance: a quest for effectiveness, quality, and improvement. Int J Qual Health Care 2003;15:377-398.

58. Donabedian A. The role of outcomes in quality assessment and assurance. Qual Rev Bull 1992;18:356-60.

59. Donabedian $\mathrm{A}$. The definition of quality and approaches to its assessment. Ann Arbor, Mich: Heaith Administration Press, 1980.

60. Driessen S, Casparie AF, Van den Bos GAM. Uitkomstindicatoren voor kwaliceitsbewaking -en bevordering in de zorg voor chronisch zieken. The Hague: Dutch Organisation for Scientific Research (NWO), study 4 from research programme Quality of Care. fin Dutch] 


\section{ASSESSING THE METHODOLOGICAL QUALITY OF DISEASE MANAGEMENT EVALUATION STUDIES}

L.M.G. Steuten, H.M.M. Vrijhoef, G.G. Van Merode, J.L, Severens, C. Spreetwenberg

Based on paper published in: Journal of Clinical Epidemiology, 2004;57:881-88. 


\begin{abstract}
Systematic reviews aim to summarise the evidence in a particular topic area, giving attention to the identified methodological quality of published research. Since research in a specific area may be susceptible to specific biases, it is assumed that the methodological quality of Health Technology Assessment (HTA) of disease management cannot properly be measured with the existing methodological quality assessment instruments. The purpose of this study is to describe to what extent existing instruments are useful in assessing the methodological quality of HTA of disease management. An inventory is made of the problems that arise when assessing the methodological quality of six HTAs of disease management with three different instruments. Problems concern the items that are related to the study design, criteria for selection and restriction of patients, baseline and outcome measures, blinding of patients and providers and the description of (co) interventions. Based on these findings a new instrument is proposed and validated. This instrument proves to be a reliable instrument for methodological quality assessment of HTA of disease management in comparison with the other three instruments.
\end{abstract}




\section{INTRODUCTION}

Since comprehensive disease management programmes have been attracting considerable interest in industrialised countries [1], several evaluations of this type of innovations have been published $[2,3,4,5,6,7]$. Some of the evaluations focus mainly on clinical effects or the costs of the innovation $[3,4,7]$, where other studies focus on quality of care and process outcomes $[2,4]$. Different designs have been used and variation in follow-up periods was seen $[5,6]$. This shows that disease management evaluation studies are performed in many different ways.

Disease management can be defined as a system of co-ordinated healthcare interventions and communications for populations with conditions in which patient self-care efforts are significant [8]. Components that reflect the ideal or "full service" disease management programme (DMP) include: (1) population identification processes, (2) evidence based practice guidelines, (3) collaborative practice models to include physician and support service providers, (4) patient self management education, (5) process and outcomes measurement, evaluation and management, (6) routine reporting and/or feedback loop $[1,8]$. When the evaluation of DMPs is focused on clinical outcomes and at least one other aspect of healthcare as, for example costs, organisational aspects or quality of care, and provides input to decision making in policy and practice, the study is regarded as Health Technology Assessment (HTA) of disease management $[9,10]$. The methodological assessment of HTAs of disease management is a major point of interest since the information gained from methodological quality assessment is crucial in determining the strength of inferences and in assigning grades to recommendations generated with a review $[11,12]$. Existing methodological quality assessment instruments (further mentioned as "instruments") are usually based on individual aspects or components of study design, conduct and analysis, for which there is theoretical evidence of bias. There are many generic instruments and scales available and all these instruments should have been developed according to the principles of creating measurement scalles $[13,14]$. However, most instruments have not been developed rigorously and the available instruments tend to focus on specific types of study designs [15]. As different checklists and scales emphasise different dimensions of methodological quality, variation in these tools may produce differing results for the same studies [16].

In the perspective of methodological quality assessment, HTA of disease management has some specific characteristics. Different study designs are used in conducting this type of evaluation research, multiple outcome parameters are measured, follow-up periods are relatively long and the interventions are complex as well as population based. Since the available instruments tend to focus on specific types of study designs [15] and because research in a particular area may be susceptible to specific biases [17], it is assumed that the methodological quality of HTA of disease management cannot properly be assessed with the existing instruments. 
The purpose of this study is to describe to what extent existing instruments are usefol in assessing the methodological quality of HTA of disease managenuent. Two research questions are studied: 1) what kind of problems occur when assessing the methodological quality of HTAs of disease management with existing instruments and 2) how should the methodological quality of HTAs of disease management be assessed, taking into account the specific characteristics of disease management?

\section{METHODS}

An inventory is made of the problems that arise when assessing the methodological quality of HTAs of disease management interventions with three different instruments. These are the EPOC instrument, the Quality Index and the SRTG instrument $[18-20\rceil$.

\section{Studies}

From a previously published systematic review [21] a data set of six studies [2-7] (four controlled before-after studies [CBA, 2-4,6], one randomised controlled trial [RCT, 5 ], and one interrupted time series [ITS, 7]) was randomly selected after reading all full text articles. The review assessed the effects of different disease management interventions, targeted at health professionals or the structure in which they deliver care, on the management of patients with diabetes mellitus in primary care, outpatient and community settings.

\section{Description of existing instruments}

The threa instruments mentioned [ $18-20]$, were chosen because they are commonly used and differ from each other concerning 1) their scope, 2) their quality construct, 3) the number of items checked and 4) the scoring techniques applied. In using these three different instruments, a large range of methodological quality aspects was tested for its relevance and usefulmess for HTA of disease management.

\section{The Effective Practice and Organization of Care (EPOC) instmment}

The Cochrane Effective Practice and Organization of Care group uses the EPOC-list to assess the methodological quality of studies towards interventions designed to improve professional practice and the delivery of effective health services [18]. This includes various forms of continuing education, quality assurance, informatics, financial, organisational and regulatory interventions that can effect the ability of healthcare professionals to deliver services more effectively and efficiently. Seven standard criteria are used to assess the methodological quality of studies. Each 
criterion is scored as 'done', 'not clear' or 'not done'. The EPOC-list is dividedinto three parts, with each part assessing another type of study design [18].

\section{The Quality Index}

The Quality Index can be used to assess both randomised and non-randomised studies. It provides an overall score for study quality as well as a profile of scores for the quality of reporting, internal validity (bias and confounding), external validity and power [19].

The checklist consists of 27 items that are either scored as 'yes (1)/ no $(0)$ ', as 'yes (2) / partially (1) / no $(0)$ ', or as 'yes (1) / no (0)/ unable to determine $(0)$ ".

\section{SRTG: Structured Reporting of Randomised Controlled Trials}

The Standards of Reporting Trials Group consisted of 30 investigators who are either experienced in developing scales to assess quality, or in designing, conducting, and analysing RCTs. They identified four content areas, which are 1) participant assignment, 2) masking, 3) participant follow-up and 4) statistical analysis. Based on a modified Delphi-process the investigators identified 24 items they felt to be essential [20]. The items were scored as 'yes', 'no' or 'unable to determine'.

\section{Assessment of the methodological quality}

The assessment of the studies was performed independently by two of the authors (LMGS/ HJMV) using the original guidelines for assessment of the three instruments. For every instrument, each item was individually assessed for its relevance and usefulness in assessing the methodological quality of the selected studies. Based on this assessment, an inventory was made of the problems that occur when assessing the methodological quality of this kind of studies using the three instruments. Based on these outcomes a modified instrument (further mentioned as the HTA-DM instrument) for methodological quality assessment of HTA of disease management was developed.

\section{Development of a methodological quality assessment instrument for HTA of disease management}

The HTA-DM instrument was developed according to the guidance of Kahn etal. [11]:

1. Defining the quality construct: the quality dimensions that are measured with this instrument are internal validity, external validity and statistical considerations.

2. Defining the scope and purpose of quality assessment: (quasi-) experimental studies, controlled observational studies and observational studies without control group are considered for review. The purpose of methodological 
quality assessment of HTA of disease managernent is to determine a methodological quality threshold, to determine the strength of inferences, and to assess grades to recommendations generated with the review.

3. Developing the instrument: relevant quality items were considered and a system for their scoring was developed. The HTA-DM instrument consists of:

- generic items: items related to features of the study design, which can be obtained from the literature;

- specific items: items related to specific features of the review's subject area;

- methodological items: items covering subject specific methodological issues;

- clinical items: items covering subject specific clinical issues.

4. Assessing the measurement properties of the instrument: the validity and reliability of the HTA-DM instrument were assessed in a pilot phase before applying the instrument to selected studies in a review.

\section{Measuring validity and reliability of the HTA-DM}

The HTA-DM instrument was tested for its validity and reliability on another set of 32 HTAs [22-53] of disease management that, based on their contents, were selected for another systematic review (by the same authors) about the organisational characteristics of disease management.

\section{Statistical methods}

Quality Scores (QSs) were calculated for each study. For studies scored with the Quality Index the original weighting was used. For studies scored with the SRTG and the EPOC instrument an equal weight of one point for each item was applied. To compare the HTA-DM instrument with the other instruments, the QSs were presented as percentage of the maximum score. In addition, the mean QSs were calculated. In order to assess ranking differences, Spearman rank correlation coefficients were calculated between the H'TA-DM instrument and the existing instruments, using SPSS 10.1 for Windows. Prior to analysing the data a correlation coefficient of $r \geq 0.7$ was defined as high, $0.7>r \geq 0.5$ as moderate and $r<0.5$ as low.

Interrater reliability was analysed by calculating kappa values per item. Kappa values between 0.41 and 0.60 are defined as 'moderate', kappa values between 0.61 and 0.80 as 'substantial' and kappa values between 0.81 and 1.00 as "almost perfect'[54]. Test-retest reliability in terms of intra-class correlation coefficients was determined by scoring all 32 studies again after four weeks. Respondent burden of all four instruments was measured in terms of the average amount of time needed to assess one paper. 


\section{Description of problems}

The assessment of items of the three instruments resulted in numerous problems according to their usefulness and/or relevance (Table 1). The problems concem the study design (RCT versus observational studies), criteria for selection and restriction of patients, baseline and outcome measures (several parameters are necessary), blinding of patients and providers (which is impossible in disease management) and the description of complex, multifaceted interventions and avoidance of co interventions.

Table 1: Description of problens

\begin{tabular}{|c|c|}
\hline Irem & Problen: \\
\hline Sndy design & 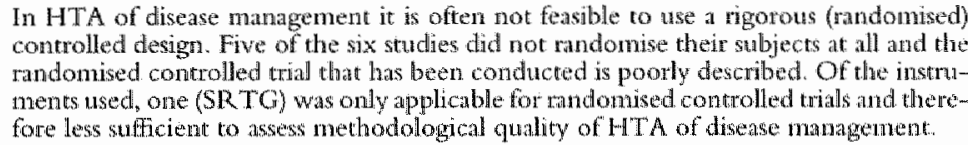 \\
\hline
\end{tabular}

Criteria for selection Disease management intervertion are population based, e g. they are expected to focus and restriction on all people with a specific disease. Therefore exclusion criteria are as important as inclusion criteria if, for purposes of scientific research, patients are excluded from the study. lin all six studies, inclusion criteria were described; no study described the exclusion criteria.

Prognostic Disease management interverotions are often complex and are expected to have effect on comparability at baseline several structure process and outcome ind cators. Therefore, always more than one (type of) baseline characteristic is presented in HTH of disease management. The used instruments ask for an 'owerall judgnent' of prograstic comparability berween sudy groups. However, with exception of the EPOC-list, the instments do not of ar a rellable way to

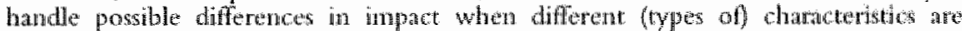
presented. Furthermore, not only patient-related data should be presented, also dat on care providers involved are important, since disease management intervemtions interfore in the primary care process as a whole. In five studies no clear 'ovetull juctgment' could be given for this item. "Ths criterion is irrelewart when no control group is used.

Blinded assessment of outcomes

Reliable onteome measures

Buinding of care prontiders
The used instruments ask for an 'overall judgment' of the blinded assersment of outconnes. However, with exception of the $\mathrm{EPOC}$ list the instrunents do not offer a retable way to Handle posible differences in impact when different (types of) outeomes are presented. as structure and process otatcomes, which are an important part of H A of disease arnarage ment. In frec of the six studies some outcomes were blindly assersed, some were not or it was not kearly stated; it two sudies all outcomes were blindly ansessed.

The used instruments focus on outcome nue astures. Surtucture and process masures are an inportant part of HTA of disease management, but are not explicitly thetstoned in the used instruments. In three studies process outcomes arti presented

In all three instruments, blinding of care providers is an item. This item is irrelewant for HTA of disease management. The perfornance of a care provider in a disease management program differs from his normal performance. Therefore it is impossible to blind care providers in HTA of disease managenent.

in none of the studies care providers were blinded. 


\begin{tabular}{|c|c|}
\hline Inew & Problew \\
\hline Slinding of patients & 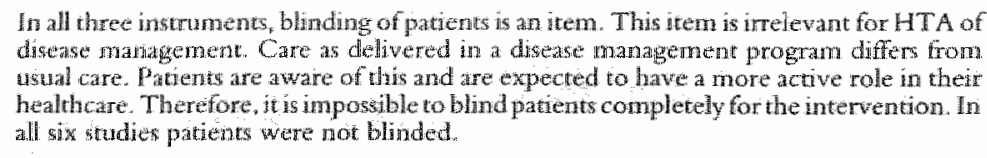 \\
\hline 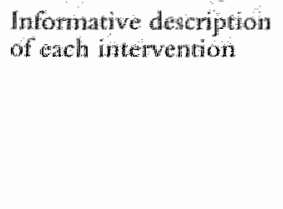 & 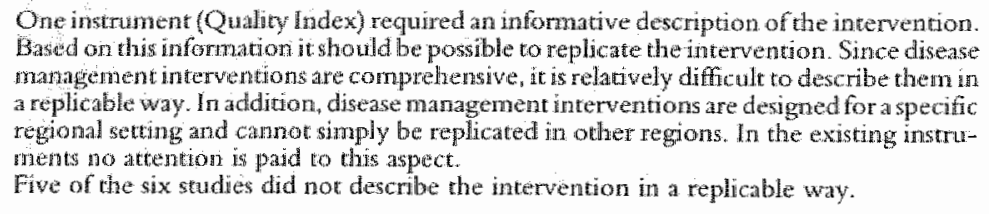 \\
\hline $\begin{array}{l}\text { Co interventions } \\
\text { avoidod }\end{array}$ & 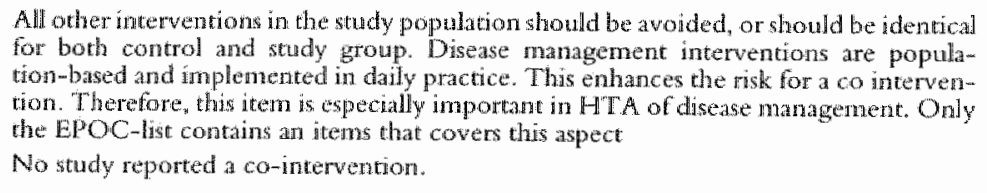 \\
\hline $\begin{array}{l}\text { Adecumare follow mp } \\
\text { period }\end{array}$ & 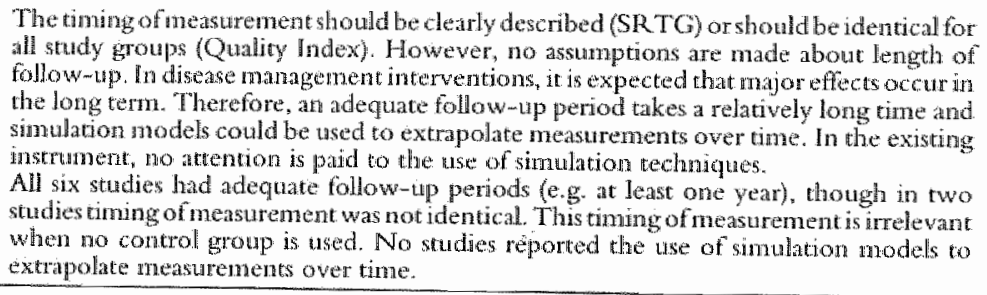 \\
\hline
\end{tabular}

\section{HTA-DM instrument}

The HTA-DM instrument (Appendix 1) results from the problems described above. The instrument includes four components (study population, description of intervention, measurement of outcomes, and data-analysis/presentation of data) and contains fifteen criteria.

\section{Differences in QSs between the existing instruments and the HTA-DM instrument}

The EPOC scores vary between 0 and 4 out of 7 points $(0 \%-71 \%)$, the scores on the SR TG vary between 1 and 18 points out of 24 points $(4 \%-75 \%)$, the scores on the QI vary between 4 and 21 points out of 27 points $(15 \%-78 \%)$ and the scores obtained with the HTA instrument vary between 7 and 15 out of 20 points $(35 \%-75 \%)$. Mean QSs per instrument are $45( \pm 15.6) \%$ on the SRTG, $47( \pm 15.9) \%$ on the EPOC instrument, $53( \pm 11.1) \%$ on the HTA-DM instrument and $56( \pm 15.7) \%$ on the Quality Index. 
Table 2: Quality scores as percentage of the maximum deteminimg hexardnical canking of stouties. [QS (ranking position)]

\begin{tabular}{|c|c|c|c|c|}
\hline Author & $\begin{array}{l}\text { EPOC } \\
\text { ingtrument }\end{array}$ & $\begin{array}{l}\text { SRTG } \\
\text { instrument }\end{array}$ & $\begin{array}{l}\text { Quality } \\
\text { Index }\end{array}$ & $\begin{array}{l}\text { HATA DM } \\
\text { instrumene }\end{array}$ \\
\hline Auber (1998) & $57(2)$ & $63(3)$ & $78(1)$ & 75011 \\
\hline Drummond (1994) & $57(2)$ & $67(2)$ & $74(2)$ & $70(2)$ \\
\hline Vrijhoer (2001) & $57(2)$ & $50(5)$ & $67(5)$ & $70(2)$ \\
\hline Vrijhoef (2001) & $43(3)$ & $46(6)$ & $74(2)$ & $70(2)$ \\
\hline Piette $(2000)$ & $57(2)$ & $75(1)$ & $71(3)$ & $65(3)$ \\
\hline Dougherty (1999) & $57(2)$ & $63(3)$ & $74(2)$ & $65(3)$ \\
\hline Hoskins (1993) & $57(2)$ & $46(6)$ & $7 *(2)$ & $65(3)$ \\
\hline DICET $(1994)$ & $57(2)$ & $42(7)$ & $74(2)$ & $65(3)$ \\
\hline Sinith (2001) & $29(4)$ & $33(9)$ & $56(8)$ & $65(3)$ \\
\hline Lahdemsuo (1996) & $71(1)$ & $67(2)$ & $63(6)$ & $60(4)$ \\
\hline Levetan $(1995)$ & $71(1)$ & $54(4)$ & $67(5)$ & $60(4)$ \\
\hline Muilhliauser (1991) & $57(2)$ & $50(5)$ & $59(7)$ & $55(5)$ \\
\hline Donohoe 2000$)$ & $43(3)$ & $63(3)$ & $70(4)$ & $55(5)$ \\
\hline Munroe $(1997)$ & $43(3)$ & $50(5)$ & $52(9)$ & $55(5)$ \\
\hline Bratton (2001) & $71(1)$ & $42(7)$ & $63(6)$ & $50(6)$ \\
\hline Berringer (1991) & $57(2)$ & $50(5)$ & $48(10)$ & $50(6)$ \\
\hline McCulloch (1998) & $57(2)$ & $29(10)$ & $44(11)$ & $50(6)$ \\
\hline Omman $(1994)$ & $43(3)$ & $42(7)$ & $52(9)$ & $50(6)$ \\
\hline Sidorov $(2002)$ & $43(3)$ & $38(8)$ & $52(9)$ & $50(6)$ \\
\hline Abouriek (1994) & $29(4)$ & $50(5)$ & $52(9)$ & $50(6)$ \\
\hline Tschopp (2002) & $57(2)$ & $63(3)$ & $52(9)$ & $45(7)$ \\
\hline Rossiter (2000) & $57(2)$ & $46,6)$ & $48(10)$ & 450 \\
\hline Lucas (2001) & $57(2)$ & $38(8)$ & $44(11)$ & $45(7)$ \\
\hline Zimmer (2000) & $43(3)$ & $46(6)$ & $33(13)$ & $45(7)$ \\
\hline Van aten Arend (2000) & $29(4)$ & $46(6)$ & $63(6)$ & $45(7)$ \\
\hline Overland $(1999)$ & $29(4)$ & $46(6)$ & $59(7)$ & $45(7)$ \\
\hline Fricdman $(1998)$ & $43(3)$ & $17(11)$ & $41(12)$ & $40(8)$ \\
\hline Rutten $(2001)$ & $29(4)$ & $42(7)$ & $52(9)$ & $40(8)$ \\
\hline Mayo (1996) & $29(4)$ & $33(9)$ & $44(1)$ & 40) $(8)$ \\
\hline Chion (2001) & $29(4)$ & $13(12)$ & $15(15)$ & $40(8)$ \\
\hline McCulloch (2000) & $0(5)$ & $4 \cdot(13)$ & $19(14)$ & $40(8)$ \\
\hline Thorell (1994) & $57(2)$ & $38(8)$ & $44(11)$ & $35(9)$ \\
\hline Mean QS & $47 \pm 16.0)$ & $45 i \pm 15.6)$ & $56 \pm 15.7$ & $53( \pm 11.1)$ \\
\hline
\end{tabular}

\section{Hierarchical ranking of studies}

Table 2 shows the hierarchical ranking of studies based on their QSs. A high value for the Spearman ranking correlation between the HTA-DM instrument and the Quality Index ( 0.850 ) was found. A moderate correlation was found between the 
HTA-DM instrment and the SRTG (0.606) while a low correlation was found between the HTA-DM instrument the EPOC instrument (0.441). The discriminating power of the EPOC instrument was found relatively low, while the Quality Index showed the highest discriminating power.

\section{Interrater and test-retest reliability}

The intermater reliability of the HTA-DM was good ( $\mathrm{r}=0.91)$. The analysis shows that for 16 items the kappa values vary between 0.81 and 0.97 (e.g. 'almost perfect'), for three items the kappa value is 1.000 while the kappa value of item 9 is $0.78(\mathrm{eg}$. substantial). Test-retest reliability in terms of the intra-class correlation is very good $(r=0.93)$.

\section{Respondent burden}

The average amount of time needed to assess the methodological quality of one paper after reading its full text is $13( \pm 5.6)$ minutes for the $S R T G_{n} 17( \pm 4.8)$ minutes for the Quality Index, $8( \pm 3.3)$ minutes for the EPOC list and $11( \pm 5.2)$ minutes for the H'TA-DM instrument.

\section{DISCUSSION}

To estimate effects of bias on the results of a study, the methodological quality of studies has to be assessed. Differences in methodological quality across studies may indicate that the results of some studies are more biased than those of others. Therefore, assessment of methodological quality of studies being reviewed is regarded as one of the key components of a systematic review [15]. In this study, the usefulness of thee existing instruments for assessing methodological quality of HTAs of disease management has been examined and, resulting from this, an instrument to assess methodological quality of HTA of disease management was constructed and validated.

In most existing instruments, items concerning study design strongly focus on (randomised) controlled trials. However, disease management interventions comprehend relatively large changes that interfere in real life [55]. Therefore, it is often not feasible to conduct a rigorous (andomised) controlled design and more pragmatic research designs have to be applied. In this perspective it is important to notice that RCTs should rank high in hierarchy only when they are well conducted and that well-conducted quasi-experimental and observational studies should also be considered [12]. Tha RCT of Osman [39], for example, scored relatively low on three of the four instruments in terms of absolute QSs, while the non-randomised 
study of Hoskins [28] scored relatively high on three of the four instruments. Criteria for selection and restriction of patients are of major importance since disease management interventions are population-based. Therefore, every adjustment in this for scientific reasons should be mentioned.

The major problem with the items related to baseline and outcome measurement is that they do not provide a reliable way to give an "overall judgment" when more (types of) baseline characteristics and outcomes are presented. For example, in HTA of disease management not only patient characteristics are relevant, but also characteristics of the primary care providers [56]. Structure and process outcomes are important aspects of HTA of disease management, because interventions interfere in the structure as well as the process of care as delivered to a specific population of chronically ill. With the existing instruments it is not possible to distinguish between studies that do present structure and process outcomes and studies that do not. The items "blinding of care providers" and "blinding of patients" are irrelevant in assessing the methodological quality of HTA studies of disease management. Care providers play an active role in executing disease management interventions and therefore cannot be blinded for there own performance. Also, care as delivered in a DMP differs from 'usual care' [57]. More attention is paid to prevention and patient education and the role of the nurse specialist is enhanced compared with "usual care". Patients are aware of this and are empowered to play a more active role in healthcare. For this reason, blinding of patients is impossible.

The item concerning 'informative description of each intervention' is extremely important in HTA of disease management, because of the comprehensiveness and the complexity of disease management interventions. Moreover, disease management interventions are designed for a specific regional setting and cannot be replicated in other regions without adapting the intervention to specific characteristics of that region. Furthermore, in the existing instruments no assumptions are made concerning the minimum length of follow-up, while it is expected that the major effects of disease management interventions occur in the long term [55], i.e., at least after five years.

With its more specific characteristics, the HTA-DM instrument should meet the difficulties mentioned. Regarding the study design, the scope of the HTA-DM instrument not only comprehends (quasi-) experimental studies, but also controlled and uncontrolled observational studies, as pre-post test designs and ITSs.

In the HTA-DM instrument the distinction between different (types of) baseline and outcome measurements has been made. Items concerning 'blinding of care providers' and 'blinding of patients' are discarded. Further, the item 'description of the intervention' is stated more explicitly and one item was added about description of specific characteristics of the region in which the intervention was executed. The follow-up period in the HTA-DM instrument is enhanced and the instrument has been expanded with an itern concerning the use of simulation models. 
When comparing the mean QSs of the three existing instruments with the HTA-DM instrument, it appears that the mean QSs of the EPOC and the SRTG instrument are lower. This might be explained by the fact that these instruments solely focus on RCTs. However; the mean QS of the HTA-DM is lower compared with the Quality Index, which might partly be explained by the fact that studies are more critically assessed regarding HTA methodology using HTA-DM instrument. In order to determine which studies should be included in systematic reviews and meta-analyses, the hierarchical ranking of studies is important [58]. The ranking differences between the HTA-DM instrument and respectively the EPOC instrument and the SRTG instrument are probably due to the differences in scope. Therefore, the EPOC and the SRTG instrument are considered less useful in assessing methodological quality of HTAs of disease management. Ranking correlation between the HTA-DM instrument and the Quality Index is high. This shows that the reliability of both instruments is comparable, but can also indicate that the HTA-DM instrument is just another version of the Quality Index and therefore redundant. However, when comparing other reliability criteria, the HTA-DM shows a higher test-retest reliability than the Quality Index ( $r=0.93$ versus $r=0.88$ ), kappa values are higher for the HTA-DM $(r=0.91$ versus $r=0.75)$ and the respondent burden is lower. The HTA-DM seems a reliable instrument when applied to HTAs of disease management, while the Quality Index can be used to assess methodological quality in other research areas that are less susceptible to specific biases.

The differences between the correlation coefficients show that the value of methodological quality assessment in a systematic review procedure depends on the validity and reliability of the instruments that are used. The reliability of most instruments is unknown [58], so further research should be performed on this topic. In this perspective the reliability of the individual criteria of the HTA-DM instrument and the sensitivity of the QSs for these criteria should be explored further. With regard to the QSs presented, is has to be stressed that originally the EPOC instrument is a checklist, not a scoring instrument. This might have affected the findings. In addition to this, the application of QSs as summary scores for identifying high quality studies for systematic reviews and meta-analyses can be discussed. Jüni et al $[16,17]$, stress that the methodological quality aspects should be identified a priory and assessed individwally, since the scale used to assess trial quality can influence the interpretation of meta-analytic studies. Although widely recommended, the method of assessing and incorporating the quality of trials in systematic reviews and meta-analysis is still a matter of ongoing debate. 


\section{CONCLUSION}

Systematic reviews require an assessment of the methodological quality of selected studies. For the purpose of assessing the methodological quality of HTAs of disease management, a tailor-made instrument was developed and validated. This so-called HTA-DM instrument shows to be a reliable instrument with regard to hierarchical ranking, test-retest reliability and interrater reliability, when applied to HTAs of disease management. The HTA-DM instrument is useful for both (randomised) controlled and observational designs as ITSs and pre-post test designs.

\section{REFERENCES}

1. Wagner EH, Austin BT, Von KorffM. Organizing care for patients with chronic illness. Millbank Quarterly 1996;54:56-8.

2. Branger PJ, Van 't Hooft A, Van der Wouden JC, Moorman PW, Van Bemmel]. Shared care for diabetes: supporting communication between primary and secondary care. International Journal of Medical Informatics 1999;53:133-142.

3. Sonnaville de J, Bouma M, Colly LP, Devillé W, Wijkel D, Heine RJ. Sustained good glycaemic control in NIDDM patients by implementation of structured care in general practice: 2-year follow-up study. Diabetologia 1997;40:0334-1340.

4. Day JL, Metcalfe J, Johnson P. Benefits provided by an integrated education and clinical diabetes centre: a follow-up study. Diabetic Medicine 1992;9:855-859.

5. Halbert RJ, Leung KM, Nichol JM, Legorreta A. Effect of multiple patient reminders in improving diabetic retinopathy screening. Diabetes Care 1999;22:752-755.

6. Peters AL, Davidson M. Application of a diabetes managed care program: the feasibility of using nurses and a computer system to provide effective care. Diabetes Care 1998;21: 1037-1043.

7. Rith-Najarian S, Branchaud C, Beaulieu O, Gohdes D, Simonson G, Mazze R. Reducing lower-extremity amputations due to diabetes. Jonmal of Family Practice 1998:47:127-132

8. www dmaa org Last accessed: September 1, 2005.

9. Banta HD. Introduction to the EUR-ASSESS report. Intl. J. of Technology Assessment in Health Care 1997;13:133-43.

10. Struyvenberg A, Benneker H. Advies Medical Technology Assessment. Rijswijk: RGO, 1998 (in Dutchi).

11. Khan KS, Ter Riet G, PopayJ, KleijnenJ. Study quality assessment. In: Khan KS, Ter Rjet $G$, Glanville J, Sowden AJ, Kleijnen J, eds. Undertaking systematic reviews of research on effectiveness. New York: NHS Center for Reviews and Dissemination, 2001:vol 2.

12. Kesteloot K. Disease management. A new te chnology in the need of critical assessment. International Journal of Technology Assessment in Health Care 1999; 15:506-519. 
13. Dowrs $S$, Black $N$. The feasibility of creating a checklist for the assessment of the methodologicall quality both of randomized and non mandomized studies of heath care interventions. Joumal of Epideniological Communify Health 1998;52:377-384.

14. Jadad AR, Moore RA, Carroll D, et al. Assessing the quality of reports of randonized clinical trials. Controlled Clinical Trials 1996;17:1-12.

15. Moher D, Jadad AR, Nichol G, Penman M, Tugwell P, Walsh S. Assessing the quality of randomized controlled trials. Controlled Cinical Trials 1995;16:62-73.

16. Jïni P, Witschi A, Bolsch R, Egger M. "The hazards of scoring the quality of clintcal trials for meta-analysis. JAMA 1999;282:1054-60.

17. Juni P, Alman DG, Egger M. Assessing the quality of controlled dinical trials. British Medical Journal $2001,323: 42-46$.

18. Bero LA, Grilli R, Grimshaw JM, Mowatt G, Oxman AD, Zwarenstein M. Cochrane Effective Practice and Organization of Care Group. The Cochrane Library 2002.

19. Downs $S, B$ ack $N$. The feasibility of creating a checklist for the assessment of the methodological quality both of randomised and non-randomised studies of health care interventions. Journal of Epidemiological Community Health 1998;52:377-384.

20. Standards of Reporting Trials Group. A proposal for structured reporting of randomized trials. JAMA 1994;272:1926-31.

21. Renders CM, Valk GD, Grifhin S, Wagner EH, Van Eijk JThM, Assendelft W. Interventions to improve the management of diabetes mellitus in primary care, outpatient and community settings (Cochrane Review). The Cochtane Library 2002:136.

22. Aubert RE, Herman WH, Waters J, et al. Nurse case Management to improve glycemic control in diabetic partients in a HMO. Ammals of Internal Medicine 1998;129:605-612.

23. Drummond $N$, Adbdalla $M$, Buckingham JK, et al Integrated care for asthma: a clinicall, social, and economic evaluation. BMJ 1994;308:559-64.

24. Vrijhoef HJM, Diederiks JPM, Spreeuwenberg C, Wolffenbuttel BHR, Van Wilderen LJGP. The nurse specialist as main care-provider for patients with type 2 diabetes in a primary care setting: effects on patient outcomes. International Joumal of Nursing Studies $2001.39: 4.41-451$.

25. VrijhoefHJM, Diederiks JPM, Spreetwenberg C, Wolffenbuttel BHR. Substitution model with central role for nurse specialist is justified in the care for stable type 2 diabetic ontpatients. Journal of Advanced Nursing 2001;36:1-10.

26. Piette JD, Weinberger M, McPhee SJ. The effect of automated calls with telephone nurse follow-up on patient-centered outcomes of diabetes care. Medical Care 2000;38:218-30.

27. Dougherty $G$, Schiffrin $A$, White D, Soderstrom $L$, Sufrategui M. Home-based management can achieve intensification cost-effectively in type I diabetes. Pediatrics 1999;103;122-8.

28. Hoskins PL, Fowler M, Constantino J, Forrest DK. Turtle JR. Sharing the care of diabetic patients between hospital and general practitioners: does it work? Diabetic Medicine $1993 ; 10: 81-86$

29. Diabetes Integrated Care Evaluation Team. Integrated care for dabetes: clinical, psychosocial, and economic evaluation. BMJ 1994;308:1209-12. 
30. Smith S, Byne G, Shannon WF, et al. The North Dublin Shared Care (DiSC)tropect a profle of current diabetes care in Ireland. Irish Medical Joumal 2001;94:1-8.

31. Lahdensuo $A$, Haahtela $T$, Herralla J, et al. Randomised comparison of guided self management and craditional treatment of asthma over one year. BMJ 1996;312:748-752.

32. Levetar CS, Salas JR, Wilets IF, ZumoffB. Impactof endocrine and diabetes tean consultation on hospital length of stay for pacients with diabetes. The American Journal of Medicine $1995 ; 99: 22-28$.

33. Mühthauser I, Richter B, Krant D, Weske G, Worth H, Berger M Evalluation of a structured treatment and teaching programma on asthma. Joumal Jntern Med 1991:230:157-64.

34. Donohoe ME, Fletton JA, Hook A, et al. Improving foor care for people writh diabetes mellitus - a randomized controlled trial of an integrated care approach. Diaberic Medicine 2000;17:581-587.

35. Munroe WP, Kunz K, Dalmady-Israel C, Potter L, Schonfeld WH. Economic evaluation of phamacist involvement in disease mantgement in a conmunity pharmacy setting. Clinical Therapeutics 1997;19:113-23.

36. Bratton DL, Price M, Gavin L, et al Impact of a multidisciplinary day program on disease and healthcare costs in children and adolescents with severe asthma: a two year follow-up study. Pediatric Pulmonology 2001;31:177-89.

37. Berringer $R$, Shibley MCH, Cary CC, Pugh CB, Powers PAG, Rafi JA. Outcomes of a Community Pharmacy-Based Diabetes Monitoring Program. I Am Pham Assoc $1991 ; 39: 791-7$.

38. McCulloch DK, Price MJ, Hindmarsh M, Wagner EH. A population-based approach to diabetes management in a primary care setting: early results and lessons learned. Effective Clinicall Practice 1998;1:12-22.

39. Osman LM, Abdalla MI, Beattie JAG, et al. Reducing hospital adnuission through computer education for asthma patients. BMJ 1994;308:568-571.

40. Sidorov J, Shull R, Tomcavage J, Girolami $S$, Lawton $N$, Harris R. Does diabetes disease management save money and improve outcomes? Diabetes Care 2002;25:684-9

41. Abourizk NN, O'Conno: P. Crabtree BF, Schnatz JD. An outpatient model of integrated diabetes treatment and education: functional, metabolic, and knowedge outcomes. The Diabates Educator 1994;20:416-21.

42. Tschopp JM. Frey JG, Pemet R, et al. Bronchal asthna and self-management education: implementation of guidelines by an interdisciplinary programme in a health network. Swiss Med Wkly 2002; 132:92-97.

43. Rossiter LF, Whitehurst-Cook MY, Small RE, et al. The impact of disease management on outcomes and cost of care: a study oflow income asthma patients. Inquiry 2000;37:188-202.

44. Lucas DO, Zimner LO, Paul JE, Jones D, Liao W, Lashley J. Two-Year results from the asthma self-management program: longrerm impact on health care services, costs, functional status, and productivity. Journal of Asthma 2001;38:321-30.

45. Zimmer LO Almond MJ, Jones D, etall. One-year outcomes from a computer-based disease managemetn program; the individualized asthma care training progran (IACT). Disease Management 2000;3:65-73. 
46. Van den Arend IM, Stok RP, Rutten GEHM, Schrijwers G. Education integrated into structured general practice care for type 2 diabetic paticnts results in sustained improvement of disease knowledge and self-care. Diaberic Medicine 2000;17:190-197.

47. Overland, Mira $M$, Yue DK. Diabetes management shared care of shared neglect. Diabetes Res Clin Practice 1999;44:123-28.

48. Friedman MM, Gleeson M, Kent MJ, Foris M, Rodriguez DJ. Managenent of diabetes in the Lovalace Health Systenos ${ }^{*}$ EPISODES OF CARE program. Effective Clinical Practice $1998 ; 1: 5-11$.

49. Rutten GEHM, Maajen J, Valkenburg ACH, Blankestijn JG, De Valk HW. The Utrecht Diabetes Project: telemedicine support improves GP care in Type 2 diabetes. Diabetic Medicine $2001 ; 18: 4.59-63$.

50. Mayo PH, Weinberg BJ, Kramer B, Richman J, Seibert-Choi OS, Rosen MJ. Results of a program to improve the process of inpatient care of adult asthmatics. Chest 1996;110:48-52.

51. Chiou ST, Lin HD, Yu NC, et al. An initial assessment of the feasibility and effectiveness of implenenting diabetes shared care system in. Taiwan - some experiences from I-Lan County. Diabetes Res Clin Practice 2001;54:567-S73.

52. McCulloch DK, Price M, Hindmarsh M, Wagner EH. Improvement in diabetes care using an integrated population based approach in a primary care setting. Disease Management 2000;3:75-82.

53. Thorell B, Olsson L, Svardsudd K. Implementation of a structured care programma for diaberes mellitus in a defined population in Mid-Sweden. Diabetic Medicine $1994: 11: 458-464$

54. Schouten H.JA. Klinische statistiek. Houten/Diegem: Bohn Stafleu Van Loghum, 1999.

55. Spreawenberg C. Managed care en disease management. Medisch Contact 1999;54:56-58 (in Dithl).

56. Steuten LMG, Vrijhoef HJM, Spreeuwenberg C, Van Merode GG. Participation of general. practitioners in distase management: experiences from the Netherlands. Intemational Joumal of Integrated Care 2002,2.

57. Vrijhoef HJM, Sprecuwenberg C, Eijkelberg IMJG, Wolfferbuttel BHR, Vata Merode $G$. Adoption of disease management model for diabetes in the region of Maastricht. British medical Journal 2001;323:983-985.

58. Streiner DL, Nomm GR. Health Measurements Scales: a practical guide to their development and use. Oxford University Press, 2001. 


\section{APPENDIX 1: \\ HTA-DM INSTRUMENT FOR ASSESSING THE METHODOLOGICAL QUALITY OF HTA OF DISEASE MANAGEMENT}

\section{Study population}

1. Are the criteria for selection clearly described?

$\frac{\text { Yes }}{\text { No }} \frac{1}{0}$

2. Are the criteria for restriction clearly described?

$\frac{Y e s}{\text { No }} \frac{1}{0}$

3a. Was the allocation concealed? (for controlled designs)

The unit of allocation is by institution, team or professional and any (random) allocation process is described explicitly OR the unit of allocation is by patient or episode of care and there was some form of centralized (randomised) allocation scheme, an on-site computer system or sealed opaque envelopes.

Yes $\frac{1}{\text { No }}$

3b. Is the intervention independent of other changes? (for uncontrolled designis) This should be answered yes if the scudy demonstrates that the intervention occurred independently from other changes.

Nos $\frac{1}{0}$

4a. Are the relevant baseline characteristics comparable? (for controlled designs) This should be answered yes if structure, process and/or outcome characteristics of patients AND characteristics of care providers are measured prior to the intervention, and substantial differences were present in less than $50 \%$ of the measurements across study groups.

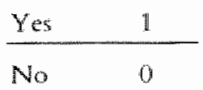


4b. Are there sufficient data points? (for uncontrolled designs)

This should be stated yes if there are sufficient data points concerning structure, process and/or outcome characteristics of patients AND characteristics of care providers, to enable statistical inference, and the sources and methods of data collection are the same before and after the intervention.

Yes $-\frac{1}{0}$

5. Is there an accurate description of drop-outs?

This should be stated yes if the number of drop-outs and the reasons for withdrawall are described.

$\frac{\text { Nes }}{\text { No }}-\frac{1}{0}$

\section{Intervention}

6. Is the intervention described accurately?

- Is the type of the intervention described?

Types of disease management interventions are, for example, organizational, educational, -or professional disease management, or a mixture of these.

$\begin{array}{ll}\text { Yes } & 1 \\ \text { No } & 0\end{array}$

- Is the intensity/frequency of the intervention described?

$\frac{\text { Yes }}{\text { No }} \frac{1}{0}$

- Are characteristics of the region/institution in which the intervention is imple-mented described?

Characteristics are, for example, size of the region, rural or urban environment and eventual preceding (research)projects related to the intervention.

$\frac{Y e s}{\text { No }} \frac{1}{0}$

7. Are co-interventions avoided?

This should be stated yes if all other interventions in the study population are avoided, or are identical for both control and intervention group (if any).

$\begin{array}{ll}\text { Yes } & 1 \\ \text { No } & 0\end{array}$




\section{Measurement of outcome}

8. Are relevant outcomes measured?

- Results presented of clinical outcome measurements.

$\frac{1}{\text { Nos }} \frac{1}{0}$

- Results presented of other than clinical outcomes ( for example quality of care, quality of life, compliance, therapy/medication, (in)direct costs, etc)

$\frac{\mathrm{Yes}}{\text { No }}-\frac{1}{0}$

- Results presented of process measures ( for example promoting and impeding factors, referral rates, correlation between performance and protocol, admission rates, etc.)

$\frac{\text { Yes }}{\text { No }} \frac{1}{a}$

- Results presented of structure measures ( for example organizational and legal aspects)

$\frac{\text { Yes }}{\text { No }} \frac{1}{0}$

9. Are the outcomes objectively assessed?

This should be answered yes if the authors state explicitly that $>50 \%$ of the primary structure, process and outcome variables are assessed blindly $O R$ that the variables are objective, e.g. length of hospital stay, drug levels as assessed by standardized tests. Primary outcome measures are those variables that correspond to the primary hypothesis or question as defined by the authors.

$\begin{array}{ll}\text { Yes } & 1 \\ \text { No } & 0\end{array}$

10. Is the timing of measurement and follow-up period adequate?

This should be stated yes if the tinning of measurement is identical for all study groups and the final effect measurement is at least one year after allocation of the subjects (for controlled designs) or start of the intervention (for uncontrolled designs).

$\frac{\text { Yes }}{\text { No }} \frac{1}{0}$


11. Are adequate simulation techniques used?

Adequate simulation techniques should be used to extrapolate the major outcomes e.g. (clinical effects, quality of care and costs) of disease management over a longer period of time.

$\frac{\text { Yes }}{\text { No }}=\frac{1}{0}$

\section{Data-analysis and presentation of data}

12a. Is data-analysis performed according to the intention-to-treat principle? (for controlled designs)

When loss to follow-up $\leq 10 \%$ this should be answered yes if results of all allocated patients are presented for most structure, process and outcome measures and for the most important moments of effect measurement irrespective of drop-outs and missing values. When loss to follow up $>10 \%$ this should be answered yes if an alternative analysis that accounts for drop-outs and missing values is performed in addition to the regular intention-to-treat analysis.

$\frac{\text { Yes }}{\text { No }}-\frac{1}{0}$

12b. Is data-analysis performed according to the intention-to-treat principle? (for uncontrolled designs)

When loss to follow-up $\leq 10 \%$ this should be answered yes if a formal test for trend according to intention-to-treat principle was performed. This means that results of all participating patients should be presented for most structure, process and outcome measures and for the most important moments of effect measurement, irrespective of drop-outs and missing values.

When loss to follow up $>10 \%$ this should be answered yes if an alternative analysis that accounts for drop-outs and missing values is performed in addition to the formal test for trend.

$\frac{\mathrm{Yes}}{\text { No }} \frac{1}{0}$

13. Is the presentation of data adequate?

This should be answered yes, if frequencies or means $( \pm S D)$ of the primary structure, process and outcome measures of the study group(s) are presented for the most important moments of measurement.

$\frac{\text { Yes }}{\text { No }} \frac{1}{0}$ 
14. Are adjustments made for confounding variables and/or differences of prognostic indicators at baseline?

This should be answered yes, if a multivariate analysis is performed to adjust for confounding variables and/or differences of prognostic characteristics at baseline.

\begin{tabular}{ll} 
Yes & 1 \\
\hline No & 0
\end{tabular}

15. Are the appropriate analytic techniques applied to the primary outcome measures?

The statistical techniques used must be appropriate to the data. For example nonparametric measures should be used for small ample sizes. Where little statistical analysis has been undertaken, but where there is no evidence of bias, the question should be answered 'yes'. If the distribution of data (nomal or not) is not described, it must be assumed that the estimates used were appropriate and the question should be answered 'yes'.

$\begin{array}{ll}\text { Yes } & 1 \\ \text { No } & 0\end{array}$


$\square$ 


\section{DISEASE MANAGEMENT WITHIN ITS ORGANISATIONAL CONTEXT}

Review towards Components and Organisational Context of Disease Management Programmes throughout the World

L.M.G. Steuten, H.J.M. Vrijhoef, C. Spreeuwenberg, G.G. van Merode 


\section{ABSTRACT}

Objectives: 1) To investigate if the presence or absence of components of disease management is a reflection of (management and incentive structures within) a specific healthcare system; 2) to explore if more complete disease management programmes (DMPs) lead to more or larger improvements in measurable outcomes of care than less complete ones; 3) to investigate if the presence or absence of specific components leads to changes in different types of process or outcome measures.

Design: Systematic literature review.

Methods: The PubMed database (1966-2002) and Cochrane Library (Issue 1, 2002) were searched for studies applying a comparative study design to measure the (cost) effectiveness of DMPs for adult patients with diabetes, asthma or COPD. Relations between healthcare system, presence of components of programmes and effects on process and outcomes measures were tested statistically. The potential influence of management and incentive structures as well as organisational context on design and contents of DMPs were qualitatively described.

Results: Thirty-one studies were included. No statistical significant relationships between the type of healthcare system and either the number of components or presence of a specific component were found. No statistical significant relationship between the number of components and process $(p=0.074)$ or outcomes of care $(p=0.090)$ was found. The components 'collaborative practice models' and 'patient self-management education' are both associated with a positive effect on self efficacy of patients ( $\mathrm{p}$-values of respectively 0.016 and 0.015 ).

Conclusions: There is no direct relationship between healthcare systems and components of disease management. Given the heterogeneity of DMPs, management and incentive structures as well as organisational context of programmes seem to play a major role in designing and operating DMPs. 


\section{INTRODUCTION}

The concept of disease management is used to refer to different forms of healthcare organisation and delivery [1]. Considered from the perspective of organisational contingency theories, which assume that there is no single best way to organize, this is fairly logical.

Disease management is defined by the Disease Management Association of America (DMAA) as 'a system of co-ordinated healthcare interventions and communications for populations with conditions in which patient self care efforts are significant' [2]. The DMAA has also described the components that reflect the ideal or 'full service' disease management programme (DMP): 1) population identification processes, 2) evidence based practice guidelines, 3) collaborative practice models to include physicians and support service providers, 4) patient self management education, 5) process and outcomes measurement, evaluation and management, 6) routine reporting and/or feedback loop [2]. DMPs that consist of only some of these components are regarded as 'disease management support services' [2].

Successful implementation of chronic care improvement models, like DMPs, depends on local conditions in the community and the healthcare system, as well as on the internal operations of each healthcare institution [3]. Notwithstanding the results from research on the effectiveness of DMPs [4-6], poor understanding exists on the influence of organisational factors on the development, the implementation and the success of complete or partial DMPs. Moreover, the fact that there is insufficient and ambiguous evidence concerning the costs and the effects of DMPs $[6]$ makes it even more relevant to explore the relationship between organisational aspects and outcomes of DMPs in more detail. The lack of unambiguous results can be (partly) explained by another implication of the contingency theories, being that any one way of organising is not equally effective under all conditions [7].

Although a given set of circumstances can support many alternative adaptive responses and strategies, specific characteristics of a healthcare system can enlarge or reduce the chance for certain types of DMPs to successfully exist. Management and incentive structures implied by the healthcare system further determine which type(s) of DMPs are actually implemented and how they are operated (Figure 1). Therefore, we hypothesized that the presence or absence of components of DMPs is a reflection of (management and incentive structures within) a specific healthcare system. Additionally, it was explored if more complete programmes lead to more or larger improvements in measurable outcomes of care than less complete ones. Finally, we investigated if the presence of specific components leads to changes in different types of process or outcome measures.

DMPs are targeted at patients with chronic conditions as for these patients in particular coherence of care delivery and cooperation between care providers is important [8]. Since diabetes mellitus, asthma and Chronic Obstructive Pulmonary Disease 


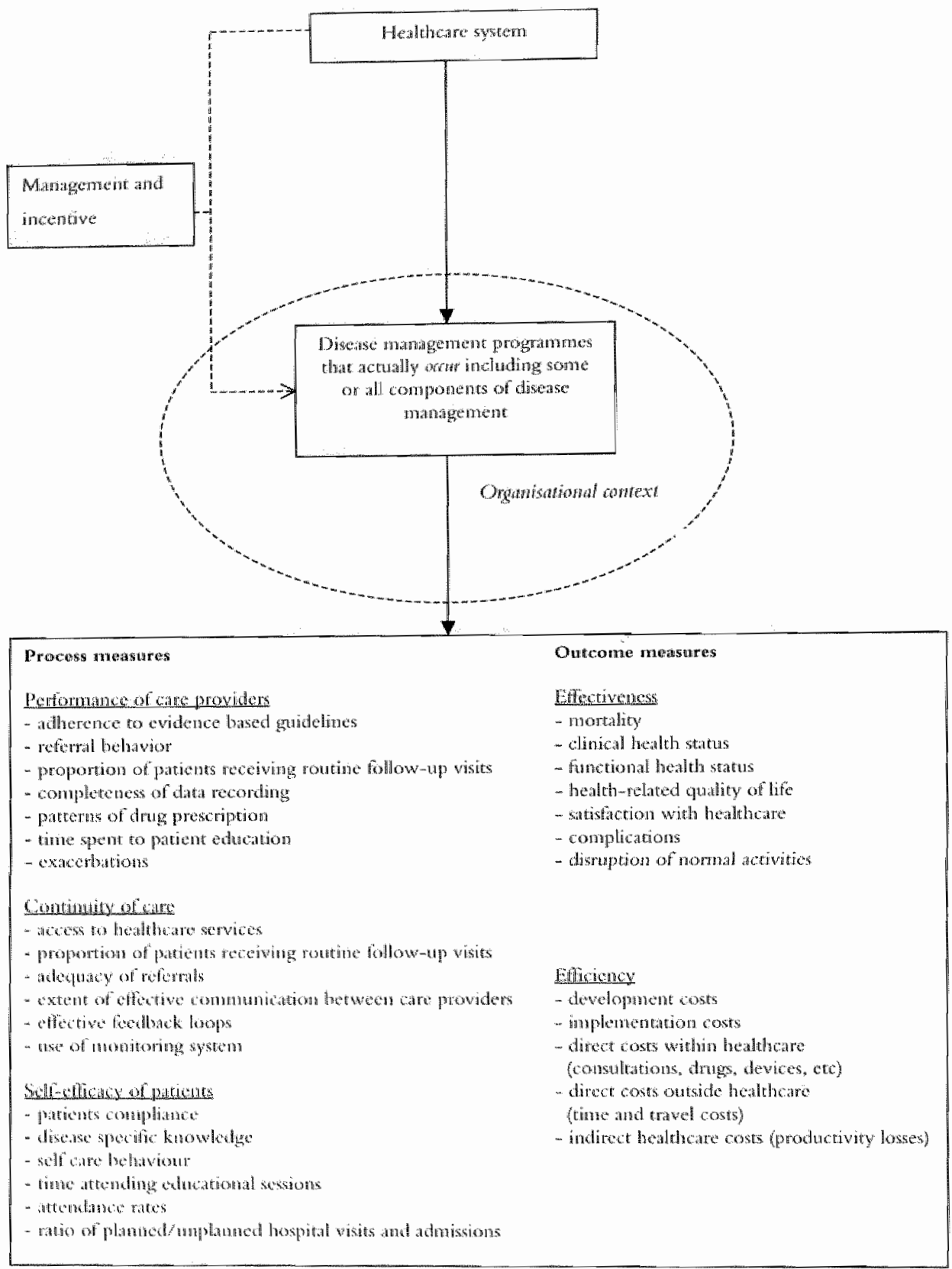

Figure 1: Relation between he:althcare system, management and incentive structures and organisational context of disease management programmes 
(COPD) are regarded suitable for DMPs, this paper focuses on studies of DMP. addressing one of these conditions. In order to test the hypotheses, a systematichterature review of asthma, COPD and diabetes DMPs in an international context, was conducted. This approach was chosen to explore the potential relationships between healthcare systems, components of DMPs and process and outcome measures before starting a more complicated and costly comparative cross national study. An explicit purpose of this study is to direct further empirical research in this relatively young area.

\section{METHODS}

\section{Data sources}

The scientific literature was reviewed to identify studies that evaluated DMPs for patients with asthma, COPD or diabetes mellitus. MEDLINE and Cochrane databases were searched for English, Dutch and German-language articles published between January 1987 en September 2004 (Table 1). Titles of articles and abstracts extracted by the search were reviewed for relevance, and if found to be so, the full-text article was retrieved. Reference lists of the included articles were also reviewed and provided additional relevant citations. To be included in the review, studies had to contain a description of the DMP and report on processes and/or outcomes of care. Moreover, DMPs should be aimed at asthma, COPD and/or diabetes mellitus.

To determine whether a programme could be considered as a DMP, we searched for key words referring to the six components defined by the DMAA [2] (Table 1). The definition of disease management was very strictly applied to reduce the heterogeneity the composition of DMPs as much as possible. Therefore, articles on risk reduction programmes, screening programmes and rehabilitation programmes were excluded, since these do not encompass the whole continuum of care.

\section{Study selection}

Two reviewers (HJMV/LMGS) independently assessed inclusion criteria and methodological quality of studies, using the HTA-DM instrument [9]. This instrument has been developed and validated for the purpose of assessing methodological quality of disease management evaluation studies. Methodological quality was no exclusion criterion since we did not intend to use the value of the outcomes as such, but merely aimed to provide insight in the relation between healthcare system and presence of specific components. Attention was paid to methodological quality as a possible effect modifier in the relationship between components and effects of a DMP. Data 
Table 1: Medical Subjeces Headings and key-words used to identify DMPs

\author{
Medical Subject Headings: \\ armbulatory care \\ case matrigement: \\ comprehensine healthcare \\ continulu of patient cate \\ critical pathowas \\ diseane managemert \\ guidelines: \\ patient care tearn. \\ patent are planing \\ primary healthcart \\ primary nursing carce \\ practice guideline \\ disease AND state AND management AND asthma, COPD or diabetes mellitus \\ disease AND management AND asthma, COPD or diabetes mellitus \\ incegrated $A N D$ care $A N D$ asthnu, COPD or diaberes metlitus \\ coordinated AND care AND asthma, COPD or diabetes mellitus \\ shared AND care AWD asthma, COPD or diabetes andlins \\ Key-words:
}

population identification process, exidence based practice guidelines, qualicy improvement, collaborative practice model, transfer of care, healthcare teams, patient and provider education, self management, process and outcomes measurement, management, toutine reporting, feedback loops, benchmarking.

abstraction was performed independently by the two reviewers using a standardized form. Collected data are: type of healthcare system, presence or absence of disease management components and effects on processes and outcomes of care. Any discrepancies between reviewers were resolved by discussion or referred to the last author (CS). Furthermore, additional information concerning the funancing of the programme, the initiators of the programme and incentives for patients, care providers or healthcare organisations to participate, was collected by contacting the corresponding authors by email or telephone.

\title{
Analyses
}

Figure 1 visualises the relationships that are hypothesized, including the relationships that are tested statistically (uninterrupted arrows). The information that is collected to askess the infuence of mamagement and incentive structures and organisational context was analysed in a more descriptive way since the information on these topics, as collected by means of a systematic review, would never be of satisfying specificity and completeness to allow meaningful statistical testing.

In order to test if there is a relation between the type of healthcare system in a country and the completeness of DMPs operated within that system, as well as the presence of specific disease management components, Kruskall-Wallis (number of components) and Chi-square tests (presence of specific components) were performed. The infor- 
mation concerning financing, initiatives and incentives was analysed in adescriptive way.

It was tested if a statistically significant relationship exists between the total number of components that is present in the DMP and the direction of changes in processes and/or outcomes of care. Processes of care are divided in three domains being 1) performance of care providers, 2) continuity of care and 3) self efficacy of patients. Outcomes are described in terms of effectiveness and efficiency of care. Changes in one of the process or outcomes domains are scored as either positive, negative or no change, regardless of the magnitude of any change. The relations between the total number of components and changes in process and outcome measures were tested with Kruskal-Wallis tests. Chi-square tests were used to test the relation between each of the individual components and any of the process and outcomes measures exists. Statistical tests were performed with SPSS Windows Version 12.0.1. PS.05 was considered statistically significant.

\section{RESULTS}

\section{Description of studies}

Searching the computerised databases, we identified a total of 876 potentially relevant articles (Figure 2). After excluding duplicates and studies clearly not related to the objective of the review, 127 abstracts were retrieved for more detailed evaluation. Screening of references resulted in another 94 potentially relevant articles. On the basis of a full-text review, 190 articles were excluded as not meeting the inclusion criteria. For the majority of excluded papers the intervention under study could not be considered a 'full service" DMP nor a 'disease management support service'. Thirty-one studies were included in the review, of which 10 focused on asthma $[10-19], 20$ on diabetes mellitus [20-39] and one on both diseases [40]. No study on COPD disease management met the inclusion criteria (Table 2).

Most studies originate from the USA $(n=15)$, followed by Europe $(n=12 ; 4$ from the Netherlands, 4 from the United Kingdom, 1 from Germany, 1 from Finland, 1 from Sweden and 1 from Switzerland), Australia $(n=2)$, Canada $(n=1)$ and Taiwan $(n=1)$.

The overall methodological quality of studies was moderate. Four studies scored 70 points or more on a scale from $0-100$ and were considered as having 'good' methodological quality $[12,26,35,38]$, fourteen studies scored between 50 and 69 points and were therefore considered of 'moderate quality $[10,16,19,21,23-26,28,29$, $33,34,37,40]$ while thirteen studies scored between 30 and 49 points and were therefore considered of inferior quality $[13-15,17,18,22,27,30-32,36,39]$. 

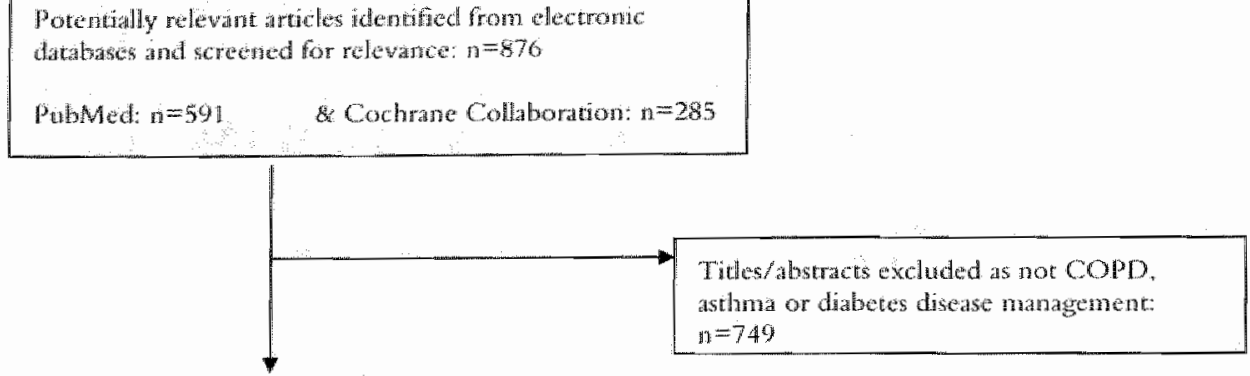

Articles retrieved for more devalce avaltation: $n=127$ COPD: $\mathrm{n}=12$

Asthmi: $n=48$

Diabetes: $n=67$

Poteintially relevant arricles identified from thand searching reference lists: $n=94$

Figure 2: Systematic review flow diagram

\section{Incorporation of components of disease management in practice}

Of all 31 DMPs included, only six reported the presence of all components and were considered 'full service' DMPs, leaving the other 25 DMPs 'support services' (Table 2). Moreover, the components most frequently reported to be present were routine reporting and/or feedback loops $(n=31)$, evidence based practice guidelines $(n=29)$, collaborative practice models $(n=28)$ and process and outcome measurement $(n=28)$. Population identification processes were most frequently absent $(n=17)$. The results per DMP are presented in Table 2 ; in the text below the results per component are presented.

Population identification processes: 14 studies described population identification processes (Table 1) $[14,15,17,20-22,26,28-30,36,38-40]$. Databases of Health Maintenance Organisations (HMOs, insurance companies, pharmacies, hospital clinics, general practices or prospectively compiled registries were used to identify 
Table 2: Presence of components in disease management programmes

\begin{tabular}{|c|c|c|c|c|c|c|c|c|}
\hline \multirow[t]{2}{*}{ Author } & \multirow[t]{2}{*}{ Conntry } & \multirow[t]{2}{*}{ Healdhare system } & \multicolumn{6}{|c|}{ Components } \\
\hline & & & 1 & 2 & 3 & 4 & 5 & 6 \\
\hline "Mihhlhauser et al., 1991 & Gemany & Social insurance & _. & 4 & + & + & + & + \\
\hline "Bratron at al..., 2001 & USA & Market & $\ldots$ & + & \# & - & + & + \\
\hline "Drummond et al., 1994 & uK & $\operatorname{Tax}$ & - & - & + & - & + & tr \\
\hline${ }^{3}$ Lumas et al., 2001 & USA & Market & _- & +4 & + & $*$ & + & + \\
\hline${ }^{14}$ Rossiner et al, 2000 & USA & Market & + & + & + & _- & + & + \\
\hline${ }^{15}$ Tschopp et al, 2002 & Swotzerland & Social insurance & + & + & + & - & + & + \\
\hline 14 Lahdensuo et al 1996 & Finland & $\operatorname{Tax}$ & - & + & + & \# & + & + \\
\hline${ }^{17}$ Zimmer et al., 2000 & USA & Market & + & + & - & H & + & + \\
\hline${ }^{15}$ Mayo er al., 1996 & USA & Market & - & + & + & H & + & + \\
\hline 190 sman et al, 1994 & UK & Tax & - & - & + & H & + & + \\
\hline 20 Vrijhoef et al., 2001 & Netlierlands & Social insurance & + & + & + & - & + & + \\
\hline${ }^{21}$ Sidorov et al., 2002 & USA & Market & + & + & 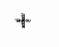 & + & + & + \\
\hline${ }^{22}$ Chion et all, 2001 & Taiwan & Market: & + & + & * & + & + & + \\
\hline${ }^{23}$ DICET 1994 & UK & $\operatorname{Tax}$ & - & 4 & - & - & + & + \\
\hline${ }^{24}$ Hoskins et all., 1994 & Australia & $\operatorname{Tax}$ & $\ldots$ & $*$ & + & - & + & + \\
\hline${ }^{25}$ Dougherty et al., 1999 & Canada & $\mathrm{Tax}$ & - & + & + & + & + & + \\
\hline${ }^{26}$ Donohue et al., 2000 & UK & $\operatorname{Tax}$ & + & + & + & $+\infty$ & + & + \\
\hline${ }^{27}$ Van den Arend et al., 2000 & Netherlands & Social insurance & - & + & + & + & + & + \\
\hline${ }^{28}$ Berringer et al., 1991 & USA & Market & + & + & - & - & - & + \\
\hline${ }^{2 y}$ McCulloch et al., 1998 & USA & Market & + & 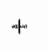 & + & - & + & + \\
\hline${ }^{30}$ Friedman et al., 1998 & USA & Market & + & + & + & + & + & + \\
\hline${ }^{3}{ }^{3}$ Rutten et al., 2001 & Netherlands & Social insurance & - & + & + & - & + & + \\
\hline OOwerland et al., 1999 & Australia & $\operatorname{Tax}$ & - & + & + & $\dot{-}$ & + & + \\
\hline "Piette ex al., 2000 & USA & Market & - & + & + & $\dot{s}$ & - & + \\
\hline 34 Abourizk et all. 1994 & USA & Market & - & + & + & + & - & + \\
\hline${ }^{35}$ Vrijhoef et all., 2001 & Netherliands & Social insurance & - & + & + & + & + & + \\
\hline${ }^{3} k_{2}$ McCulloch et $a l, 2000$ & USA & Market & + & + & + & - & * & * \\
\hline Levetan er al., 1995 & USA & Market & - & + & $\#$ & \# & + & * \\
\hline Aubert alt. 1998 & USA & Market & + & + & $*$ & - & + & H \\
\hline${ }^{34}$ Thorell tet al., 1994 & Sweden & $\operatorname{Tax}$ & + & + & + & $*$ & + & H \\
\hline \multirow[t]{2}{*}{ :HiM Munroe et al., 1997} & USA & Market & + & + & + & + & + & th \\
\hline & & Told 't' & 14 & 29 & 28 & 18 & 28 & 31 \\
\hline
\end{tabular}

* + indicates present; - indicates absent; $1=$ population identification processes; $2=$ evidence based practice guidelines; $3=$ collaborative practice models; $4=$ patient self management education; $5=$ process and outcomes measturement; $6=$ routine reporting and/or feedback loops. 
parients at risk or patients with established diagnoses for asthma or diabetes mellitus. Data on service claims, dispensed medications, labotatory tests, (emergency) hospital admissions, diagnosis, et cetera, were used for this purpose Seventeen studies did not report any form of population identification process $[10-13,16,18,19,23-25,27$, $31-35,37]$.

Evidence based pratice guidelines: the use of evidence based guidelines was reported in 29 studies $[10,11,13-20,22-40]$, of which 22 studies also reported that these guidelines included preventive activities and/or follow-up management with the purpose of reintegration $[10,11,13-17,21-24,26-33,35,36,40]$.

Collaborative practice models: collaborative practice models consisting of a cooperation between primary and secondary care providers, were reported in 28 studies, of which six also described cooperation with health centres that played a mainly supportive role in the disease management programme $[14,15,22,27,32,33]$.

Patient selfmanagement eduation: patient self management education was incorporated in 18 disease management programmes $[10,13,15-19,21,22,25,26,27,30$, $33,34,37,40]$.

Process and purcowes meastrement, evalwation and managenent; all 31 studies reported some kind of evaluation of the DMP. In 28 studies, process and outcome measurements were performed to evaluate the DMP $[10-27,29-32,35-40]$. In three studies, only outcome measurements were used for this purpose $[28,33,34]$. The most commonly used process measurements were promoting and impeding factors, referral rates and admission rates. Outcome measurements were very diverse, including quality of life, patient satisfaction, clinical outcomes, healthcare costs, et cetera.

Routine reporting and for feedback loop: in all 31 DMPs, healthcare outcomes were systematically registered during the project. Twelve studies reported that these outcomes were used to adjust (improve) the DMP (e.g. feedback loop towards the organisational team) $[10,11,18,23,24,26-28,35,38-40]$, while in 18 studies outcomes were benchmarked to the care providers themselves (e.g. feedback towards the healthcare professionals) $[12,14-16,17,20,22,24,27,28-34,36,37,40]$. In six DMPs, only clinical or psychosocial outcomes were benchmarked $[19,21,27,34,37,39]$, whereas in 25 programmes process and/or economic outcomes were also provided $[10-18,20,22-26,28-33,35,38,39]$. The use of information communication technology (ICT) for purposes of data sharing between care providers was reported in five studies $[23,27,29-31]$. They comprised on-line access to patient summaries for care providers involved or scheduled reports of data, results of routine assessments and laboratory results. Benchmarking of patient outcomes using ICT was described in four studies $[14,17,27,34]$. Physicians, for example, were provided with an overview of their patients' laboratory results in relation to the total patient database of all participating physicians and a cumulative annual overview of laboratory results per patients [27]. In another programme, they received feedback 
reports, identifying patients in need of follow-up because of poor outcomes interms of emergency visits, and reports on service claims of their patients at planned intervals [14].

\section{Initiatives, incentives and financing of DMPs}

Nine studies provided information about the initiator of the programme. Five programmes were initiated by the hospital $[10,15,20,22,35]$, one by a $\mathrm{HMO}[30]$, one by a Managed Care Organisation (MCO) [21], one by a Diabetes Care Centre [33], and one by an insurance company [14]. It appeared that in healthcare systems with a social insurance or tax-based management structure, DMPs were initiated by hospitals $[10,15,20,35]$, while all market-oriented American programmes were initiated by $\mathrm{HMO}, \mathrm{MCO}$ s or facilitating healthcare centres $[14,21,30,33]$.

Ten studies described the incentives that were present for patients, healthcare professionals or the healthcare organisation to participate in the DMP $[10,14,15$, $19-22,30,34,35]$. Incentives for patients were increasing independency [10], prevention of complications $[10]$, improved patient outcomes [20], improved quality of care [20], increased patient satisfaction when care was provided by nurse specialists [20], and improved accessibility of care [35]. Incentives for physicians were more effective and efficient delivery of care [20], free continuing education credits [14], discount on malpractice insurance [14], and transfer of tasks to the nurse specialist [35]. The incentive for nurse specialists was the opportunity to profile themselves as specialised care providers, while healthcare organisations experienced an economic incentive. Incentives for patients were only reported in European studies $[20,10,35]$ with a system of social insurance, while incentives for physicians, nurse specialists, healthcare organisations and insurers were reported in European, American, Canadian and Taiwanese studies covering all types of healthcare systems $[10,12,14,15,20,-22,25,33]$. Incentives for physicians and healthcare organisations were both qualitative and financial, while incentives for patients and nurse specialists had a primarily qualitative nature.

From 16 studies, information on the financing of the programme was gathered $[10,11,13,15,17,19-21,23,30,34-38,40]$. Eight DMPs were financed by a third-party payer (e.g. pharmaceutical company, $\mathrm{HMO}$ or MCO) $[10,13,17,19,21$, $33,38,40]$, while three programmes were financed by research and development boards $[23,25,37]$. Five programmes were structurally financed from existing healthcare budgets $[11,15,30,36,38]$ and one programme was financed by a combination of structural and external financing [20]. 


\section{Relating type of healthcare system to presence of components}

No statistical significant relationships between the type of healthcare system and either the number of components $(p=0.451)$ or presence of a specific component ( $\mathrm{p}$-values ranging from 0.080 to 1.000 ) were found.

\section{Relating presence of components to changes in processes and outcomes of care}

No statistical significant relationship between the number of components present and changes in process $(p=0.074)$ or outcomes of care $(p=0.090)$ was found.

With regard to the individual components, it was found that the presence of the components collaborative practice models and patient self management education was associated with a positive effect on self efficacy of patients ( $p$-values of respectively 0.016 and 0.015 ). No other relation was found to be statistically significant.

\section{DISCUSSION}

This review provides more insight into the presence or absence of specific components of DMPs throughout the world, as related to healthcare systems and reported process and outcome measures. Furthermore, it addresses the potential impact of management and incentive structures and organisational context on design and contents of DMPs.

Data of 31 DMPs for patients with asthma or diabetes, with half of the programmes originating from the US and with only six DMPs consisting of all components of disease management, do not show a statistically significant relationship between the type of healthcare system and either the completeness of a DM, as reflected by the number of components present, or the presence or absence of any of the specific components. Also, we could not affirm the hypothesis that a more complete programme would have more or larger effects on processes and outcomes of care than less complete programmes. With regard to the third research question, it was found that the presence of the components collaborative practice models or patient self management education was associated with a positive effect on self efficacy of patients.

Given the relative heterogeneity of DMPs and the lack of a direct relationship between healthcare systems and components of disease management, the management and incentive structures as well as the organisational context of programmes seem to play a major role in designing and operating DMPs. This indicates the applicability of contingency theories when taking an international perspective on DMPs. Although not exhausting, some information on these aspects has been collected and can be used to illustrate this. 
For example, population identification processes are very demanding in terns of time and money and can lead to increased healthcare utilisation in the short term. In more competition-oriented healthcare systems, such as the US healthcare system, population identification processes have the potential to lead to an improved market position and increase the profits for the healthcare plans. However, if the workload of physicians and nurses is already very high in a certain country, this could hinder the introduction of population identification processes [7].

Another example concerns the way in which self management education is incorporated in DMPs. In DMPs in the US, nurses or health educators are involved for the sole purpose of providing self management education. In European programmes, nurse specialists collaborate in multidisciplinary teams to provide education in addition to the delivery of direct patient care. This may be a result of differences in the development of the professions and has implications for the degree of professional autonomy they have.

Because management and incentive structures differ between market-oriented healthcare systems and the more publicly regulated systems, the organisational context of the DMPs varies. In market-oriented healthcare systems, programmes are initiated by third-party payers. In social insurance or tax-based systems, hospitals or care providers initiate disease management themselves. For physicians and healthcare organisations, a combination of qualitative and financial incentives is reported, while incentives for patients and nurse specialists are mainly qualitative. More financial incentives are experienced in market-oriented healthcare systems than in more publicly regulated healthcare systems of, for example, continental Europe and Scandinavia. With regard to this, one should keep in mind that the incentives mentioned mainly provide reasons to start participating in a DMP. Within the organisational context there should also be incentives to continue this participation.

Besides these detailed differences, more fundamental differences between DMPss exist that may be induced by differences in management and incentive structures. Programmes in the US are provided by large enterprises and show a strongly protocolised structure in which a patient enters the programme, receives integrated care, follows some type of educational class and attends strictly scheduled follow-up visits. Non-American DMPs, on the contrary are more loosely organised and based on organisational networks in which the parties involved share responsibilities to a certain extent. However, they may still experience different incentives. In general, it can be said that an 'enterprise" culture is less common in continental Europe. In these countries, there is typically a strong national health service, although the interest of the private sector is increasing.

Concerning the distinction between healthcare systems that was made in this study, it has to be noted that this was made on the macro level. Also within countries, especially large ones, different healthcare systems may exist and variations on a healthcare system are common. 
The finding of statistical significant relations between two components and specific process measures only, can be explained in several ways. Firstly, the operationalisation of changes might not be specific enough, as studies testing the same hypothesis in homogeneous DMPs did show the suggested relationships. For example, the studies of Fleming et al and Jackson et al. do show relationships between organisational variables and good glycaemic control $[41,42]$. Secondly, our finding could imply that the other components of disease management do not have a very specific effect or that any potential specific effect was not measured within the time frame of the studies. Thirdly, our finding might indicate once again that in cvaluating DMPs often not the most logical or sensitive measures are applied given the goal and contents of a programme $[43,44]$. In a previous study, for example, it was found that in ten out of 25 studies towards DMPs aiming to improve efficiency, no indicators for efficiency were evaluated. Finally, due to publication bias, negative effects of disease management could be underreported which might have influenced our results.

The fact that of the few studies we found on COPD disease management programmes none fulfilled the inclusion criteria, indicates that either the search strategy was not appropriate for COPD disease management or that this field is less developed as compared to asthma and diabetes. Nowadays, management of COPD is more focused on interventions such as pulmonary rehabilitation [45], smoking cessation [46] and/or patient self-management [47]. Since these only target one specific part of the care continum, they were not regarded 'disease management' and therefore excluded from this review.

This study indicates that there is a need to perform further research towards the influence of management and incentive structures as well as organisational context of DMPs on the design and operations of DMPs, ultimately leading to specific effects in both process and outcomes of care. With this information DMPs can be fitted into the organisational context while predicting the influence of specific organisational characteristics on healthcare processes and outcomes.

\section{CONCLUSION}

The key finding of this study is that, given the heterogeneity of DMPs and the lack of a direct relationship between heal thcare systems and components of disease management, management and incentive structures as well as organisational context of programmes probably play a major nole in designing and operating DMPs throughout the world. With DMP's being implemented in different countries and the lack of sufficient and unambiguous evidence about the costs and the effects of DMPs [6], investigation of the relationship between organisational aspects and outcomes of DMPs is of utmost relevance. 
These findings indicate the importance of additional research towards the influence of organisational factors on the development, the implementation and the sticeess of DMPs. With disease management initiatives in several countries and the research to its cost effectiveness still in its infancy, we need to uptake a multi-factorial, international approach in identifying the mechanisms to improve chronic disease care.

\section{REFERENCES}

1. Kesteloot K. Disease management. A new technology in the need of critical assessment. Int J Technol Assess Health Care 1999;15:506-519.

2. Disease Management Association of America (DMAA). Dictionary of Disease Management terminology. Washington, DC, 2004.

3. Bodenheimer $T$, Wagner $E H$, Grumbach $K$. Improving primary care for patients with chronic illness. The chronic care model, part 2. JAMA 2002;288:1909-114.

4. Norris SL, Nichols PJ, Caspersen CJ, et al. The effectiveness of disease and case management for people with diabetes. Am J Prev Med 2002;22:15-38.

5. Pogach L, Charns MP, Wrobel IS, et al. Impact of policies ind performance measurement on development of organizational coordinating strategies for chronic care delivery. Am J Manag Care 2004; 10(part2): 171-80.

6. Congressional Budget Office. An anallysis of the literature on disease management programs. Washington, DC, October 13, 2004. Available at http://www.cbo,gov/ftpdocs/59xx/doc5909/10-13-DiseaseMngmnt.pdf. Accessed April 1.5, 2005.

7. Wan TH, Wang BL. Integrated healthcare networks' performance: a growth curve modelling approach. Health Care Manag Sci 2003;6:117-24.

8. Wagner $\mathbf{E H}$. Chronic disease management: What will it take to improve care for chronic illness? Effective Clinical Practice 1998;1:2-4

9. Steuten LMG, Vrijhoef HJM, Van Merode GG, Severens JL, Spreeuwenberg C. The health technology assessement disease management instrument reliably measured methodologic quality of health technology assessment of disease management. J Clin Epidemiol 2004,57:881-8.

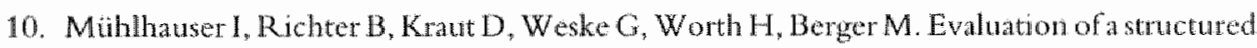
treatment and teaching programme on asthma. J Intem Med 1991;230:157-64.

11. Bratton DL, Price M. Gavin L, et al. Impact of a multidisciplinary day program on disease and healthcare costs in children and adolescents with severe asthma: a two year follow-up study. Pediatr Pulmonol 2001;31:177-89.

12. Drummond $N$, Adbdalla $M$, Buckingham $J K$, et al. Integrated care for asthma: a clinical, social, and economic evaluation. BMJ 1994;308:559-64.

13. Lucas DO, Zimmer LO, Paul JE, Jones D, Liao W, Lashley J. Twwo-Year results from the asthma self-management program: long term impact on health care services, costs, functional status, and productivity. J Asthma 2001;38:321-30. 
14. Rositer LF, Whitehurst-Cook MY, Small RE, et al. The impact of disease management on outcomes and cost of care: a study of low-income asthma patients. Inquiry 2000;37:188-202.

1.5. Tschopp JM. Frey $J G$, Perret $\mathbb{R}$, et al. Bronchial asthma and self-management education: inplenentation of guidelines by an interdisciplinary programme in a health network. Swiss Med Wkly 2002;132:92-97.

16. Lafidensuo $A$, Hahtela $\mathbb{I}$, Herrala J, et al Randomised comparison of guided self management and traditional treatment of asthma over one year. BMJ 1996;312:748-52.

17. Zimmer $\mathrm{LO}$, Almond $\mathrm{MJ}$, Jones $\mathrm{D}$, et al. One-year outcones from a computer based disease management program: the individualized asthma care traning program (LACT). Dis Man 2000;3:65-73.

18. Mayo PH, Weinberg BJ, Kramer B, Richman I. Seibert-Choi OS, Rosen MJ. Results of a program to improve the process of inpatient care of adult asthmatics. Chest 1996;110:48-52.

19. Osman LM, Abdalla MI, Beattie JAG, etal. Reducing hospital admission through computer education for asthma patients. BMJ 1994;308:568-571.

20. VrijhoefHJM., Diederiks JPM, Spreeuwenberg C, Wolffenbuttel BHR. Substitution model with central role for nurse specialist is justified in the care for stable type 2 diabetic outpatients. IAdv Nurs 2001;36:1-10.

21. Sidorov J, Shull R, Tonncavage J, Girolami S, Lawton N, Harris R. Does diabetes disease management save money and improve outcomes? Diabetes Care 2002;25:684-9.

22. Chiou ST, Lin HD, Yu NC, et al. An initial assessment of the feasibility and effectiveness of implementing diabetes shared care system in Taiwan-sonte experiences from I-Lan County. Diabetes Res Clin Practice 2001;54:567-573.

23. Diabetes Integrated Care Evaluation Team. Integrated care for diabetes: climical, psychosocial, and economic evaluation. BMJ 1994;308:1209-12.

24. Hoskins PL, Fowler M, Constantino J, Forrest DIK, Turtle JR. Sharing the care of diabetic patients between hospital and general practitioners: does it work? Diabet Med 1993;10:81-6.

25. Dougherty $G$, Schiffrin A, White D, Soderstrom $L$, Sufrategui M. Home-based managennent can achieve intensitication cost-effectively in type I diabetes. Pediatrics 1999;103:122-8.

26. Donohue ME, Fletion JA, Hook A, at al. Improving foot care for people with diabetes mellitus - a randomized controlled trial of an integrated care approach. Diabet Med $2000 ; 17: 581-87$.

27. Van den Arend IJM. Stolk RP, Rutten GEHM, Schrijvers G. Education integrated into structured general practice care for type 2 diabetic patients results in sustained improvenent of disease knowledge and self-care. Diaber Med 2000;17: 190-7.

28. Berninger R, Shibley MCH, Cary CC, Pugh CB, Powers PAG, Rafi JA. Outcomes of a Community Pharmacy-Based Diabetes Monitoring Program. J Ak Pham Assoc 1991;39:791-7.

29. MeCulloch DK, Price MJ. Hindmarsh M, Wagner EH. A population-based approach to diabetes management in a primary care setting: early results and lessons learned. EffClin Pract $1998 ; 1: 12-22$

30. Friedman NM, Gleeson JM, Kent MJ, Foris M, Rodriguez DJ. Management of diabetes in the Lovelace Health Systems' EPISODES OF CARE program. EffClin Pract 1998;1:5-11. 
31. Rutten GEHM, Maajen J, Valkenburg ACH, Blankestin JG, De Valk HW, The Utrecht Diabetes Project: telemedicine support improves GP care in Type 2 diabetes. Biabet Med 2001:18:459-63.

32. Overland J, Mira M, Yue DK. Diabetes management: shared care of shared neglect. Diabetes Res Clin Pract 1999;44:123-8.

33. Abourizk NN, O'Connor PJ, Crabtree BF, Schnatz JD. An outpatient model of integrated diabetes treatment and education: functional, metabolic, and knowledge outcomes. Diabetes Educ 1994;20:416-21.

34. Piette JD, Weinberger M, McPhee S]. The effect of automated calls with telephone nurse follow up on patient-centered outcomes of diabetes care. Med Care 2000;38:218-30.

35. Vrijhoef HJM, Diederiks JPM, Spreeuwenberg C, Wolffenbuttel BHR, Van Wilderen LJGP. The nurse specialist as main care-provider for patients with type 2 diabetes in a primary care setting: effects on patient outcomes. Int J Nurs Stud 2001;39:441-51.

36. McCulloch DK, Price M, Hindmarsh M, Wagner EH. Improvement in diabetes care using an integrated population-based approach in a primary care setting. Dis Man 2000;3:75-82.

37. Levetan CS, Salas JR, Wilets IF, Zumoff B. Impact of endocrine and diabetes team consultation on hospital length of stay for patients with diabetes. Am J Med 1995;99:22-8.

38. Aubert RE, Herman WH, Waters J, et al. Nurse case management to improve glycemic control in diabetic patients in a HMO. Ann Intern Med 1998;129:605-12.

39. Thorell B, Olsson L, Svardsudd K. Implementation of a structured care programme for diabetes mellitus in a defined population in Mid-Sweden. Diabet Med 1994:11:458-64.

40. Munroe WP, Kunz K, Dalmady-Israel C, Potter L, Schonfeld WH. Economic evaluation of pharmacist involvement in disease management in a community pharmacy setring. Clin Ther $1997 ; 19: 113-23$.

41. Fleming B, Silver $A$, Ocepek-Welikson $K$ et all. The relationship between organizational systems and clinical quality in diabetes care. Am J Manag Care 2004;10:934-44.

42. Jackson $G L$, Yano EM, Edelman D, et al. Veterans Affairs primary care organizational characteristics associated with better diabetes control. Am J Manag Care 2005;11:225-37.

43. Whellan DJ, Cohen EJ, Matchar DB, Califf RM. Disease managencent in healthoure organizations: results of in-depth interviews with disease management decision makers. Am J Man Care 2002;8:633-41.

44. Steuten LMG, Vrijhoef HJM, Severens JL, Van Merode GG, Spreeuwenberg C. Are we measuring what matters in Health Technology Assessement of disease managenent? A systematic review. Int J Tech Assess Health Care (in press).

45. Troosters $\mathrm{T}$, Casaburi $\mathrm{R}$, Gosselink $\mathbb{R}$, Decramer M. Pulmonary rehabilitation in chronic obstructive pulmonary disease. Am J Respir Crit Care Med 2005;172:19-38.

46. Wagena EJ, Van der Meer $\mathbb{R} M$, Ostelo RJWG, Jacobs JE, Van Schayck CP. The efficacy of smoking cessation strategies in people with chronic obstructive pulmonary disease: results from a systematic review. Resp Med 2004;98:805-15.

47. MonninkhofE, Van der Valk P, Van der Palen J, van Herwarden C, Partridge MR, Zielhuis $G$. Self-management education for patienst with chronic obstructive pulmonary disease: a systematic review. Thorax 2003;58:394-8. 
שיח- 


\section{ARE WE MEASURING WHAT MATTERS IN HEALTH TECHNOLOGY ASSESSMENT OF DISEASE MANAGEMENT?}
A Systematic Literature Review
L.M.G. Steuten, H.J.M. Vrijhoef, J.L. Severens, G.G. Van Merode, C. Spreeuwenberg

Based on paper accepted for publication in: Intemational Joumal for Technology Assessment in Health Care 


\section{ABSTRACT}

Objective: To produce an overview of indicators currently used to assess disease management programmes (DMPs) and, based on these findings, provide an evaluation framework with sets of indicators that should be used given the aims and types of DMPs.

Methods: Systematic literatire review

Results: 36 studies met the inclusion criteria. It appeared that a link between aims of DMPs and evaluated structure, process and outcome indicators did not exist in a substantial part of published studies on diabetes and asthma/COPD disease management, especially when efficiency of care was concerned. Furthermore, structure indicators were largely missing from the evaluations although these are of major importance for the interpretation of outcomes for purposes of decision-making. Efficiency of disease management was mainly evaluated by means of process indicators, while the use of outcome indicators was less common. Within a framework, sets of structure, process and outcome indicators for effectiveness and efficiency that should be evaluated to assess each type of DMP, are proposed.

Condusion: The link between aims of DMPs and evaluated structure, process and outcome indicators does not exist in a substantial part of published studies on disease management. The added value of this study mainly lies in the development of a framework to guide the choice of indicators for health technology assessment of disease management. 
Disease management focuses on providing well-integrated care that is intended to maximise quality of care while minimising costs across the continum of care settings $[8,55,58]$. In order to assess to what extent these goals are reached, principles of health technology assessment (HTA) are applied. The most important characteristic of HTA is that it focuses on effectiveness and at least one other aspect of healthcare, as costs, organisational aspects or quality of care, with the aim to provide input to decision-making in policy and practice [5] This implies that several different types of indicators have to be measured in order to provide meaningful, precise and timely information for various stakeholders. The question that is dealt with in this paper is: "Are we measuring what matters when assessing disease management programmes (DMPs) for purposes of decision-making?"

In order to answer this question, an assessment must be made first, to see if there actually is a fit between the general aim of D DMP (e.g. improving quality and/or increasing efticiency of care) and the type(s) of indicators used to evaluate the program.

Previous studies already suggested that a mixture of indicator types - as Donabedian stated, structure, process and outcome indicators [14] - may be more useful in assessing quality of care from various stakeholder perspectives and that attention should be paid to further conceptualisation and operationalisation of quality of care indicators [3].

When assessing the quality of care as delivered within a DMP, one has to realise that a wide variation of programmes exists and these have been implemented within differing organisationall structures in daily practice. This heterogeneity within $D M P s$ - even when these focus on the same disease - not only hinders the understanding of what disease management actually is but also hinders the uniformity in evaluation of the programmes and, consequently, the comparability of study tesults [26]. The Disease Management Association of America (DMAA) formulated a definition of disease management that is now widely accepted. They also acknowledge the fact that there are many differences between programs in terms of their comprehensiveness and focus. Therefore they distinguish the so-called 'full service DMPs' which comprise all elements of disease management as opposed to "disease management support services", that are less comprehensive [13]. Since most DMPs are gradually introduced, very few 'full service DMPs' exist, let alone that they are evaluated rigorously. From the current scientific literature, in general three types of DMPs can be distinguished based on the extent to which they consist of organisational, professional and/or educational interventions [60]. "The choice for specific indicators is expected to be influenced by the type of programme that is evaluated.

What this hiterature review adds to the existing knowledge, is an overview of indicators currently used to assess DMPs. Moreover, a framework is provided suggesting which sets of indicators should be used when taking the aims and types of DMPs into 
account. This framework can be considered as a minimum data set for HTA of disease management. It intends to increase generalisability and comparability of DMP. Within this framework, attention is being paid to the fact that a wide range of programmes is implenented worldwide within different healthcare systems. When the framework is used adequately, the comparability of results of HTA of disease management will improve and the usefulness of study results for policy and practice will increase. Since asthma, COPD and diabetes are among the most common diseases for which DMPs have been developed, the focus of this review will be on these diseases [8].

\section{METHODS}

\section{Systematic literature review}

We reviewed the scientific literature to identify studies that evaluated DMPs designed for patients with asthma, COPD or diabetes. MEDLINE and Cochrane databases were searched for English, Dutch and German-language articles published between January 1987 en September 2004. The following Medical Subject Headings were used: patient care team, patient care planning, primary nursing care, case management, critical pathways, primary healthcare, continuity of patient care, guidelines, practice guideline, disease management, comprehensive healthcare and ambulatory care. Further, "disease state management", "disease management", "integrated care", "coordinated care" and "shared care" in combination with either "asthma", "COPD" or "diabetes mellitus" were alphanumerically searched as title and/or abstract words.

Titles of articles and abstracts extracted by the search were reviewed for relevance and, if found to be so, the full-text article was retrieved. Reference lists of the included articles were also reviewed and provided additional relevant citations. To be included in the review, studies had to contain a description of the DMP, explicitly mention the aim(s) of the programme and provide a description of indicators used. Moreover, programmes should be aimed at asthma, COPD and/or diabetes mellitus. Disease management was defined as: a system of coordinated healthcare interventions and communications for people with conditions in which self care efforts are significant [13]. To determine whether a programme could be considered as a DMP, we searched for key words referring to the six disease management components defined by the DMAA. The key-words were: population identification process, evidence based practice guidelines, quality improvement, collaborative practice model, transfer of care, healthcare teams, patient and provider education, self management, process and outcomes measurement, management, routine reporting, feedback loops, and benchmarking. 
The definition of disease management was very strictly applied to reduce the theterogeneity of the studies as much as possible. Therefore, articles on risk reduction programmes, screening programmes and rehabilitation programmes were excluded since these do not encompass the whole continuum of care. Likewise, evaluations of single components of disease management (e.g., pharmacological treatment, smoking cessation, nutritional advice, self management, patient education) were excluded. Also, paediatric programmes were excluded since in the evaluation of interventions tailored to children specific outcome measures are needed (e.g. from both children and their parents) further increasing heterogeneity in measurement as well as in the programmes themselves. Two reviewers (HJMV/LMGS) independently assessed methodological quality of studies, using the HTA-DM instrument. This instrument has been developed and validated for the purpose of assessing methodological quality of disease management evaluation studies [50]. Methodological quality is scored between 0 to 100 points with a score $<50$ points indicating inferior quality and $\geq 70$ points indicating good quality. The HTA-DM instrument proved to have the best clinimetric characteristics, when applied to disease management evaluation studies, compared to three other common used instruments $[2,18,49]$. Methodological quality was no exclusion criterion since we did not intend to use the value of the outcomes as such. However, based on methodological quality of studies, process and outcome measures were selected to enter the framework.

Data abstraction was performed independently by the two reviewers, using a standardized form. Collected data are: type of DMP, general aim(s) of the program and structure, process and outcome indicators used to evaluate the program. Any discrepancies between reviewers were resolved by discussion or referred to the fifth author.

\section{Classification of the disease management programs}

A programme was classified as 'educational' when the interventions were aimed at self management abilities or disease specific knowledge of patients; "professional' when the interventions focused on changing the performance of care providers or improving their adherence to guidelines; 'organisational' when the interventions interfered in the structure of the primary care process or in any way aimed to improve the continuity of care $[21,60]$.

\section{Classification of indicators}

According to the paradigm of Donabedian, structure indicators are defined as the physical and organisational properties of the settings in which care is provided. Process encompasses all that is done to and for a population of consumers and patients, such as preventive services and measures, diagnosis, treatment, and pallia- 
tive care. Outcomes are the end results of care, i.e. the changes in patient or population health status, life expectancy, quality of life [14] and healthcare costs.

Effectiveness and efficiency are regarded as attributes of quality in healthcare. Effectiveness is defined as the ability to attain the greatest improvements in healthcare now achievable by the best care; efficiency is defined as the amount of resources needed to attain a certain goal. According to Donabedian, this goal should be to lower the cost of care without diminishing attainable improvements in health [15]. For each article included the type (structure, process or outcome) and attribute (effectiveness or efficiency) of indicators were registered.

\section{Providing a taxonomy of indicators and establishing the framework}

An overview of indicators currently used in evaluating DMPs is provided in relation to the aim(s) and type of the program. Based on the indicators used in studies that were considered as having 'good' methodological quality and complementary literature concerning HTA and quality assessment, a framework is provided for evaluation of each type of DMP.

\section{RESULTS}

\section{Description of studies}

The search identified 123,104 references published between January 1987 and September 2004 of which we accepted 6,214 for further screening. After reading titles and abstracts 6,052 papers were excluded for not reporting any form of programme evaluation or focusing on paediatric patients. As a result, 162 full text articles were retrieved for more detailed information while screening of references resulted in another 94 potentially relevant articles. On the basis of a full-text review, 220 articles (86\%) were excluded as not meeting the inclusion criteria. Finally, 36 studies were included in the review, ten of which focused on asthma $[11,19,27,30,34,37,41,45,53,62]$, twenty-five on diabetes mellitus $[1,4,6,7,10$, $12,17,20,23-25,29,35,36,40,42,44,46-48,52,54,56,57,59]$ and one on both diseases [38]. No study on disease management for patients with COPD met the inclusion criteria, mostly for the reason of focusing on rehabilitation only.

The overall methodological quality of studies was moderate. Five studies were considered as having 'good' methodological quality $[4,6,19,56,57]$; nineteen studies scored between 50 and 69 points $[1,7,11,12,17,23-25,27,29,35,37,38,40,41,44$, $47,48,59]$ and were therefore considered of "moderate" quality, while twelve studies were of inferior methodological quality $[10,20,30,34,36,42,45,46,52-54,62]$. 


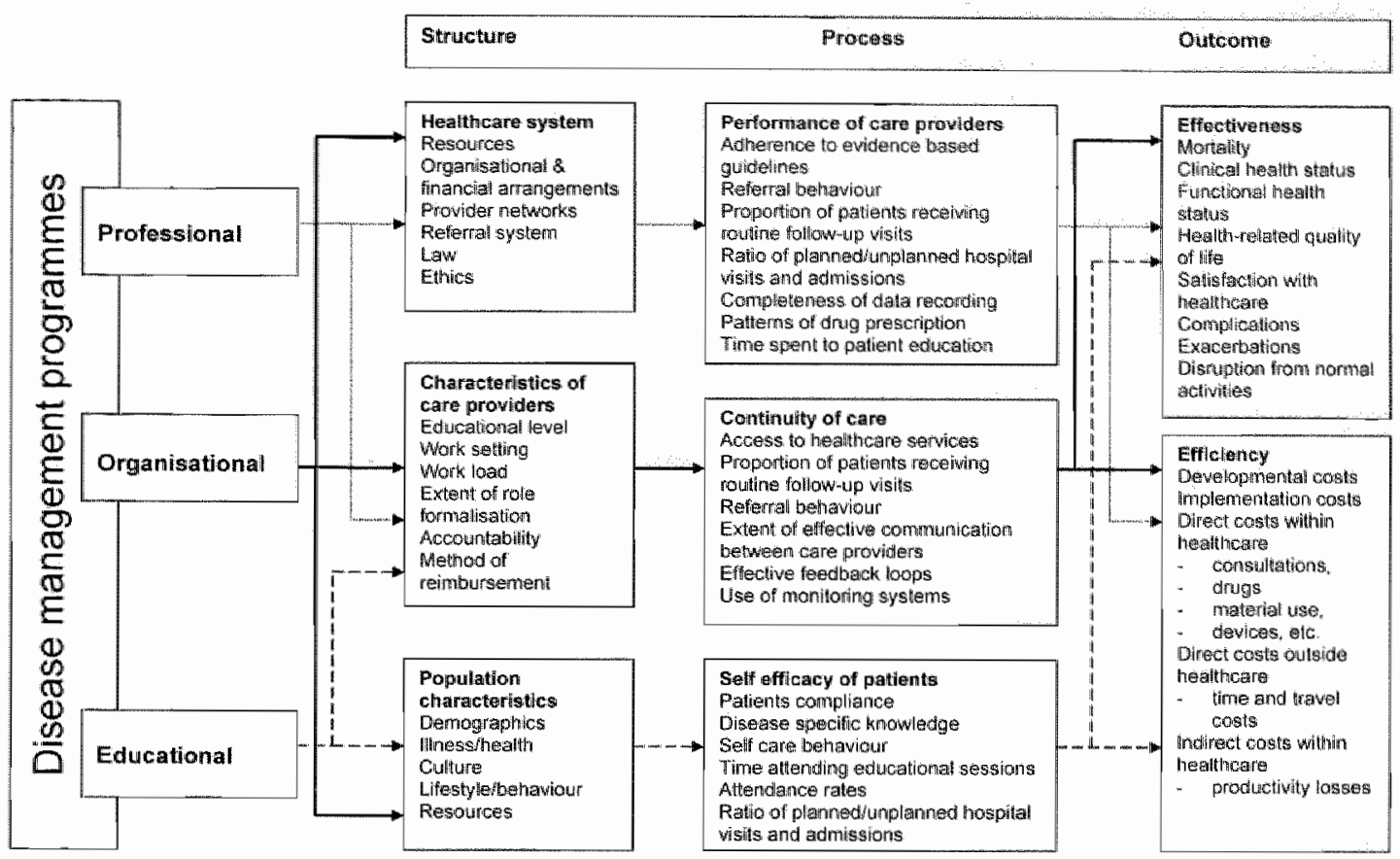

Figure 1: Framework for HTA of disease management

\section{Fit between aim of the DMP and applied indicators}

In three $[29,38,45]$ of the thinty-five $[1,4,6,10-12,17,19,20,23-25,27,29,30,34-38$, $40-42,44-48,52-54,56,57,59,62]$ studies that described "improvement of effectiveness" being (one of) the aim(s) of the DMP, no indicators for effectiveness were actually used in the evaluation; in ten $[1,7,12,20,35,42,44,46,48,52]$ out of twenty-five $[1,4,7,10,12,17,19,20,23,27,29,35,38,41,42,44-48,52,53,56,57,62]$ studies that aimed to improve efficiency, no indicators for efficiency were presented. However." in four $[30,34,36,40]$ out of eleven studies in which no aim to inprove efficiency was formulated $[6,11,17,24,25,30,34,36,37,40,59]$, indicators of efticiency were applied, as was the case for one study [7] in which no intention to improve effectiveness was announced but indicators for effectiveness were presented.

In general, it appears that the use of structure indicators is uncommon. Furthermore, efficiency of disease management is mainly evaluated by means of process indicators; the use of patient outcome indicators to evaluate efficiency is still relatively limited. 


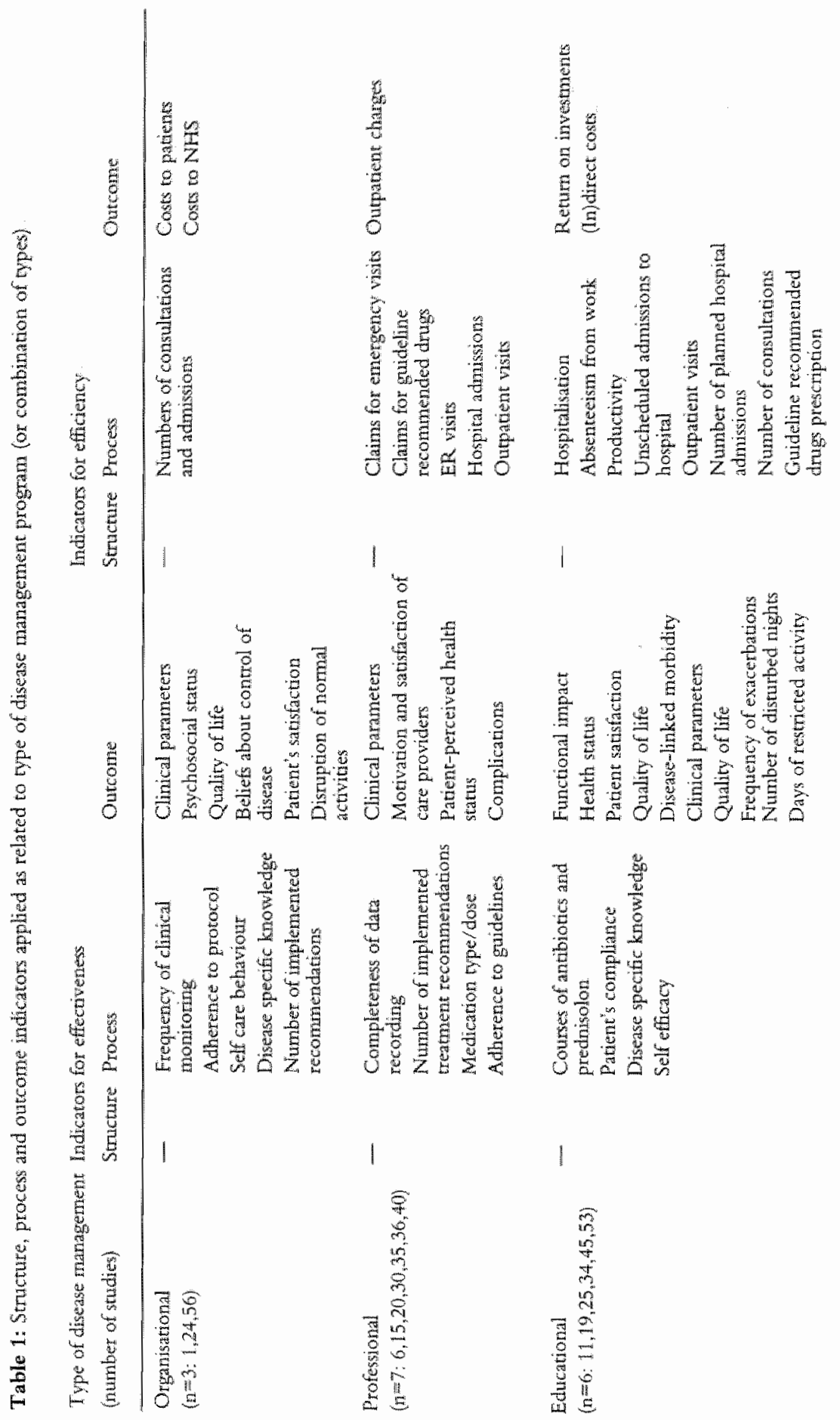




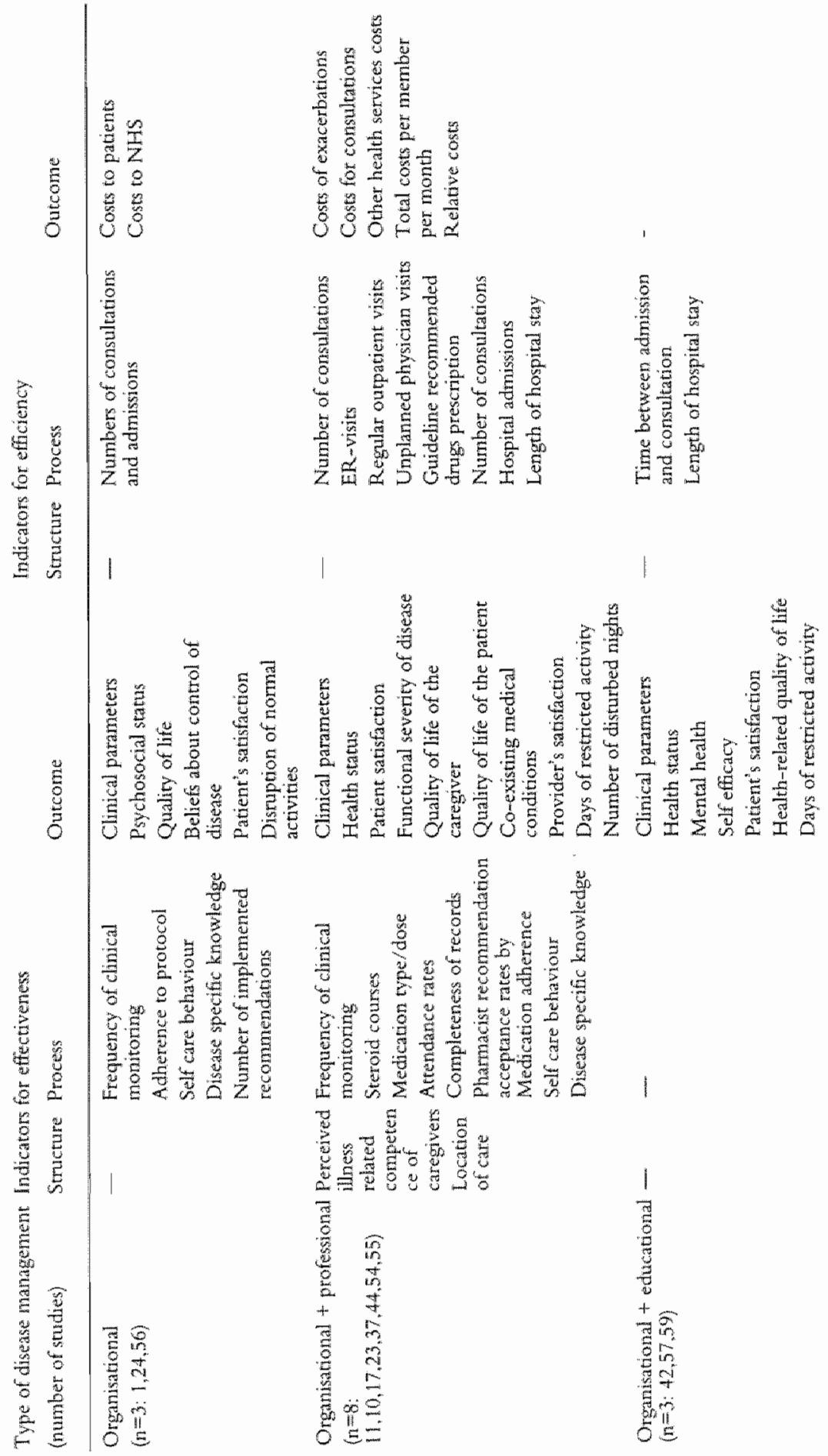




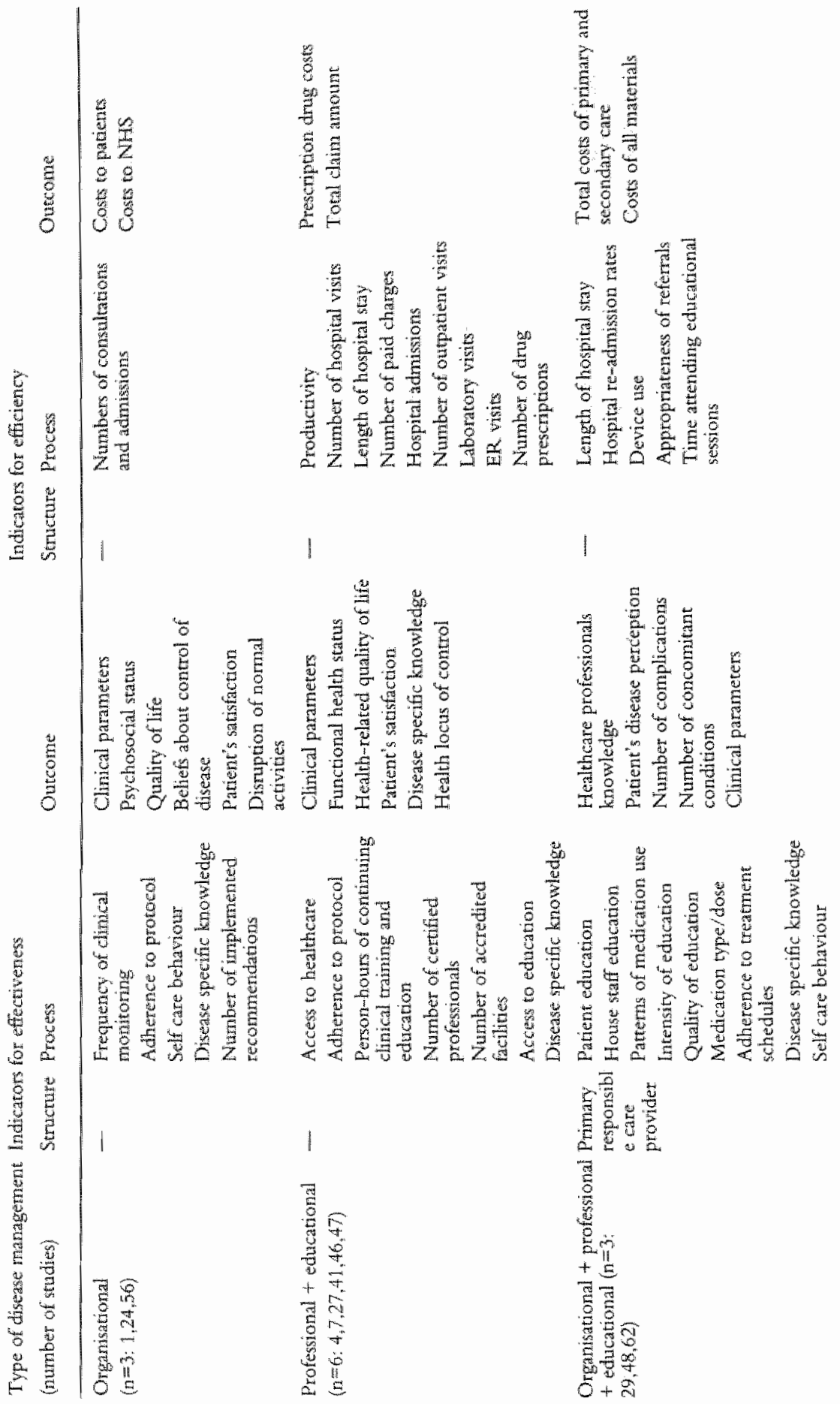




\section{Relation between type of DMP and indicators used}

All (combinations of) types of disease management were present in the included studies. In table 1, an overview is presented of the indicators that were applied as related to these different (combinations of) types. In general, the efficiency of all types of DMPs is evaluated by means of process indicators. Conceming effectiveness, it appears that no process indicators were applied in evaluating DMPs that mainly consist of organisational and educational interventions.

Regarding the specific structure, process and outcome indicators that are reported, it is questionable if actually those indicators are chosen that are expected to be most sensitive to changes caused by the type of interventions applied in the programme. For example, educational interventions are explicitly reported in eighteen studies, while in twelve of these studies $[11,20,25,27,29,38,41,44,47,52,53,62]$ disease specific knowledge has not been used as an indicator for effectiveness.

\section{Establishment of a framework}

An overview is provided of indicators used for the evaluation of each type of DMP as related to the general aim of the program. Specific structure, process and outcome indicators for effectiveness and efficiency are recommended for each type ofDMP in figure 1. When following the arrows, indicating expected direct links between structure, process and outcome indicators, it can be seen that the type of disease management is reflected in the process indicators, while the outcome indicators are the same for all three types of DMPs. The structure indicators also reflect the type of disease management to some extent, but since most DMPs are so-called 'mixed programs', there is some overlap between them.

\section{DISCUSSION}

The art of linking outcomes to organisation and delivery of DMPs, depends on matching the right outcomes with the goals of the organisational arrangements and their conceptualisation and measurement in health services research [43]. This study shows that a link between aims of DMPs and evaluated structure, process and outcome indicators does not exist in a substantial part of published studies on diabetes and asthma/COPD DMPs, especially when efficiency of care is concerned. Concerning the effectiveness of disease management, in 3 out of 35 published studies $(9 \%)$ no fit between aim of the programme and used indicators exists, while for efficiency this is the case in 10 out of 25 studies (40\%). Furthermore, efficiency of DMPs is mainly evaluated by means of process indicators, while the use of outcome indicators is less common. This problem could be overcome by explicitly combining process parameters with outcome parameters as illustrated by Mason et al. [33] 
Since it is hardly ever possible to have one empirical study that gathers all the data needed for an HTA study, the choice for specific structure, process and outcome indicators was expected to be influenced by (or focused upon) the type of DMP that has been evaluated. The data from this review do not support this. Actually, there is hardly any reflection to be found in the content of the specific indicators that are applied, as related to the different types of DMPs. This questions the sensitivity of the chosen indicators to detect (small but) important differences in the effectiveness or efficiency of DMPs.

\section{Structure}

Structure indicators are to a large extent missing from the research literature. Since most DMPs involve a form of process redesign, which is acconpanied by a change in the structure of healthcare, information about the structure of care is essential. There are three types of structure indicators that affect both cost and outcomes and can differ between DMPS: 1) financial arrangements/incentives, 2) site of care delivery and 3) composition/organization of the care delivery team [22]. In order to assess the generalisability and robustness of healthcare outcomes, one should understand to what extent the difference in cost and outcomes is attributable to differences in financial arrangements, differences in the sites of care delivery or differences in the composition and organisation of the care delivery system.

Although the lack of structure indicators might be partly explained by the fact that sometimes process measures also reflect structural characteristics of healthcare, this does not invalidate the observation that in most studies inportant data on the structure of healthicare (either measured by structure or process indicators) are missing.

\section{Process}

In assessing the efficiency ofDMPs, mostly process indicators are used. Two possible reasons for this are: 1) efficiency gain within disease management is commonly attempted by process redesign, therefore assessing process indicators as outcome units seems a logical choice; 2) continuous measurement of indicators is part of the feedback systems that are a component of DMPs itself. For this purpose, indicators are assessed that are relatively easy to measure, which are mostly process indicators. It is supposed that these indicators are then continuously available for assessing the overall efficiency of the program.

An intrinsic advantage of process indicators is that they are more sensitive than outcome indicators to differences in quality of care, that they are easy to interpret and that they are a direct measure of quality of care (32). On the other hand, process indicators are only of value if a robust link to (patient) outcomes has been demonstrated. 


\section{Outcome}

Outcome indicators reflect all aspects of the process of care including those that are not measurable or have not been measured. Moreover, the ultimate goal of HTA of disease management is to express efficiency in terms of patient outcomes. An atraction of outcome indicators is that these are indicators of something important in their own right (32). In other words, not only the number of resources used in executing DMPs but, in addition a valuation of these resources in terms of costs and utilities are necessary for local and national decision-making [16]. For purposes of generalisability, the reporting of units of component resources, disaggregated from their unit costs will help decision makers in other regions or countries to derive valid local costs of implementation by applying local patterns of resource use and prices $[33]$.

\section{Sensitivity, comparability and generalisability}

Currently, results from different DMPs are hard to compare even when the type of disease that is focused upon has been taken into account. Apart from heterogeneity of programs, this is also due to the wide variety within indicators used to evaluate the programs. Therefore, it is suggested that process indicators are chosen that are sensitive to the specific interventions of a determined type of DMP and are associated with the expected changes in outcomes of care [28]. For example, when the DMP primarily focuses on patient education, process indicators should be aimed at, for instance, compliance of patients with scheduled follow-up visits [61]. An increase in compliance indicates a better control of the disease [9], resulting in improved overall health status as well as less complications and costs in the long run $[31,51]$. Outcome indicators, on the other hand, should then be more general for purposes of generalisability and comparability (for example health-related quality of life or morbidity). Furthermore, developmental and implementation costs need to be included for purposes of decision-making, since these costs should not out rule the cost effectiveness of the intervention [33].

\section{Framework}

Theoretically driven inquiries are necessary to link systems and outcomes [43]. Within the presented framework all the before mentioned aspects of evalluating DMPs for purposes of decision-making are integrated to guide the choice of structure, process and outcome indicators. As a result, three sets of structure, process and outcome indicators for each type of disease management are proposed that should guide the selection of indicators to be included in a "minimum data set". "This approach is in itself not new. For diabetes self management education, for example, also an analytical framework has been proposed [39]. However, the fact that the 
framework presented in this study is applicable to all DMPs, regardless of the disease they focus upon, and takes the type of disease management into account, makes it innovative and more useful for purposes of decision-making. To illustrate this: when evaluating a DMP that can be characterised as 'professional', one should at least pay attention to structure indicators related to the healthcare system and characteristics of care providers, process indicators related to performance of care providers and outcome indicators for effectiveness as well as efficiency. In addition, process indicators for continuity of care and self efficacy of patients could be taken into account. Further empirical research is necessary to detect which indicators of this "minimum. data set' are the most valid ones or for which strong links to health outcomes exist.

\section{CONCLUSION}

In order to measure what matters in HTA of disease management one has to realise that many different DMPs exist and have been implemented under varying circumstances. The aim and type of the programme should guide its assessment to produce useful information for policy and practice. When paying closer attention to the type of indicators that are used for evaluating DMPs, a very diffuse picture appears. In HTA of disease management, the link between the aim of the programme and the indicators that are used in evaluating the programme does not exist in a substantial part of published papers, especially when efficiency of disease management is concerned. Furthermore, structure indicators are hardly presented, although these are of major importance for the interpretation of outcomes for purposes of decision-making. Process indicators, on the other hand, are very frequently used for assessing efficiency of disease management. A valuation of these process indicators in terms of costs or utilities, which is often lacking now, would provide more useful information for policy makers and care providers. Also, no reflection of the type of DMP (i.e. professional, organisational or educational) was found in the structure, process or outcome indicators mentioned, while the choice for specific indicators was expected to be influenced by this. Based on the flaws in the current evaluation of DMPs and supported by existing theories on HTA, quality of care measurement as well as decision-making, a framework is presented in which structure, process and outcone indicators are linked. Use of this framework should guide researchers to define a minimum data set that enables to provide relevant and useful information for decision makers in healthcare. 


\section{POLICY IMPLICATIONS}

Decision-making in health and medicine should preferably be based on the best scientific evidence informing us which interventions are worthwhile spending limited resources on. So far, the lack of a consistent framework for HTA of disease management has made comparisons of reported results hardly possible, meaning that much time and money has been spent inefficiently. Research budgets should be reserved for those studies addressing outcomes that have shown to be of added value to decision-making in policy and practice.

\section{REFERENCES}

1. Abourizk NN, O'Comnor PJ, Crabtree BF, Schnatz JD. An outpatient model of integrated diabetes treatment and education: functional, metabolic, and knowledge outcomes. Diab Educ, 1994;20:416-21.

2. Alderson P, Bero LA, Grilli R, et al. Effective Practice and Organisation of Care group. In: The Cochrane Library, Issue 2, 2004. Chichester, UK: John Wiley \& Sons, Lrd.

3. Arah OA, Klazinga NS, Delnoij DMJ, Ten Asbroek AHA, Custers T. Conceptual framework for health systems performance: a quest for effectiveness, quality, and inprovement. Int J Qual Health Care, 2003; 15:377-398.

4. Aubert RE, Herman WH, Waters J, et all. Nurse case management to improve glycaemic control in diabetic patients in a HMO. Ann Intem Med, 1998;129:605-612.

5. Banta D. The development of health technology assessment. Health Policy, 2003;63:121-32.

6. Benjamin EM, Schneider MS, Hinchey KT. Implementing practice guidelines for diabetes care using problem-based learning. Diab Care, 1999;22:1672-78.

7. Berringer $R$, Shibley MCH, Cary CC, Pugh CB, Powers PAG, Rafi JA. Outcomes of a Community Phamacy-Based Diabetes Monitoring Program, I Am Pharm Assoc, $1991 ; 39: 791-7$

8. Bodenhemer $T$, Wagner $E H$, Grumbach $K$. Improving primary care for patients with chronic illness. The chronic care model, part 2. JAMA, 2002;288:1909-14.

9. Bone RC. Goals of asthma management: a step-care approach. Chest, 1996;109(4):1056-65.

10. Chiou ST, Lin HD, Yu NC, et all. An initial assessment of the feasibility and effectiveness of implenenting diabetes shared care system in Taiwan - some experiences from I-Lan County. Diabetes Res Clin Pract, 2001;54:S67-\$73.

11. Cote J, Cartier $A$, Robichaud $P$, et al. Influence on asthma morbidity of asthma education programs based on self-management plans following treatment optimisation. Am J Respir Crit Care Med, $1997 ; 155(5): 1509-14$.

12. Diabetes Integrated Care Evaluation Team (DICET). Integrated care for diabetes: clinical, psychosocial, and economic evaluation. BMJ, 1994;308:1209-12.

13. Disease Management Association of America at www.dmaa.org. Last accessed at 17 May 2005. 
14. Donabedian A. The defuntion of quality and approaches to its assessment. Ann Arbor, Mich: Mealth Administration Press, 1980.

15. Donabedian A. The role of outcomes in quality assessment and assurance. Qual Rev Bull, $1992 ; 18: 356-60$.

16. Donaldson $C$, Mugford $M$, Valk $L$, edk. Evidence-based health economics: from effectiveness to efficiency in systematic treview. London: BMJ Books, 2002.

17. Donohoe ME, Fletton JA, Hook $A$, et al. Improving foot care for people witl diabetes mellitus - a tandomized controlled trial of an integrated care approach. Diabet Med, $2000 ; 17.581-587$.

18. Downs $S$, Black $N$. The feasibility of creating a checklist for the assessment of the methodological quality of both randomised and non-randomised studies of health care interventions. J Epidemiol Community Health 1998,52:377-84.

19. Drummond $N$, Adbdalla M, Buckingham JK, et al. Integrated care for asthma: a clinical, social, and economic evaluation. BMI, 1994;308:559-64.

20. Friednan NM, Gleeson JM, Kent MJ, Foris M, Rodriguez DJ. Management of diabetes in the Lovelace Health Systems" EPISODES OF CARE program. Eft Clin Pract, 1998; 1:5-11.

21. Haggerty JL, Reid RJ, Freeman GK, et al. Continuity of care: a multidisciplinary review. BMJ, 2003:327:1219-21.

22. Hogan AJ. Methodological issues in linking costs and health outcomes in research on differing care delivery systems. Med Care, 1997;35(1) 1):NS96-NS105.

23. Hoskins PL, Fowler M, Constantino J, Forrest DK. Turtle JR. Sharing the care of diabetic patients between hospital and general practitioners: does it work? Diabet Med, 1993;10: $81-86$.

24. Hurwitz B, Goodman $C$, Yudkin J. Prompting the clinical care of non-insulin dependent (type II) diabetic patients in an inner city area: one model of community care. BM], $1993 ; 306(6878): 624-30$.

25. Jaber LA, Halapy H, Fernet M, Tummalapalli S, Diwakaran H. Evaluation of a pharmaceutical care model on diabetes management. An Pharmacother, 1996;30(3):238-43.

26. Kodner DL, Spreeuwenberg C. Integrated care: meaning, logic, applications, and implicarions. IJIC, 2002;2:october-december issue (only electronically available at whw ijic.org)

27. Lahdensuo $A$, Hahtela $T$. Herrala J, et al. Randomised comparison of guided self management and traditional treatment of asthma over one year. BMJ, 1996;312:748-752.

28. Lamb GS. Outcomes across the care continuum. Med Care, 1997;35(11):NS106-NS114.

29. Levetan CS, Salas JR. Wilets IF, ZumoffB. Impact of endocrine and diabetes team consultation on hospital length of stay for patients with diabetes. Am J Med, 1995;99:22-28.

30. Lucas DO, zimmer LO, PaulJE, et al. Two-Year resuls from the asthma self-management progrmm: long term impact on health care services, costs, functional status, and productivity. Asthmin, 2001;38:321-30.

31. Manley $S$. Haemoglobir A 1 - a marker for complications of type 2 diaberes: the experience from the UK Prospective Diabetes Study (UKPDS). Clin Chem Lab Med, 2003;41(9):
$1182-90$. 
32. Mant J. Process versus outcome indicators in the assessment of quality of thealth care. Int Qual Health Care, 2001;13:475-480.

33. Mason J. Freemantle $N$, Nazareth 1, Eccles $M$, Haines A, Drummond $M$. When is it cost-effective to change the behaviour of health professionals? JAMA, 2001;286:2988-92.

34. Mayo PH, Weinberg BJ, Kramer B, et al Results of a program to improve the process of inpatient care of adult asthmatics. Chest, $1996: 110: 48$ - 52 .

35. McCulloch DK, Price MJ, Hindmarsh M, Wagner EH. A population-based approach to diabetes management in a primary care setting: early results and lessons learned. Ef Clin Pract, $1998 ; 1: 12-22$.

36. McCulloch DK, Price M, Hindmarsh M, Wagner EH. Improvement in diabetes care uxing an integrated population-based approach in a primary care setting. Disease Mamagement, 2000;3:75-82.

37. Mühlhauser I, Richter B, Kraut D, et al. Evaluation of a structured treatment and teaching programme on asthma. J Intern Med, 1991:230:157-64.

38. Muntoe WP, Kunz K, Dalmady-Israel C, Potter L, Schonfeld WH. Economic evaluation of phamacist involvement in disease management in a community phamacy setting. Clin Ther, 1997;19:113-23.

39. Norris SL, Nichols PJ, Caspersen CJ, et al. Increasing diabetes self-management education in community settings. A systematic review. Am J Prev Med, 2002;22(45):15-38.

40. O'Connor PJ, Rush WA, Peterson J, Morben P, Cherney L, Keogh C, Lasch S. Contimous quality improvement can improve glycemic control for HMO patients with diabetes. Arch Fann Med, 1996;5(9):502-6.

41. Osman LM, Abdalla MI, Beattie JAG, et al. Reducing hospital admission through computer education for asthma patients. BMJ, 1994;308:568-571.

42. Overland J, Mira M, Yue DK. Diabetes management: shared care or shared neglect. Diabetes Res Clin Pract, 1999;44:123-28.

43. Patrick DL. Finding healthwelated quality of life outcomes sensitve to health-care organization and delivery. Med Care, 1997;35:S49-57.

44. Piette JD, Weinberger M, McPhee SJ. The effect of automated calls with telephone nurse followmup on patient-centered outcomes of diabetes care. Med Care, 2000;38:218-30.

45. Rossiter LF, Whitehurst-Cook MY, Small RE, et al. The impact of disease management on outcomes and cost of care: a study of low-income asthma patients, Inquiry, 2000;37:188-202.

46. Rurten GEHM, Maaijen J, Valkenburg ACH, Blankestijn JG, De Valk HW. The Utreche Dabetes Project: telemedicine support improves GP care in Type 2 diabetes. Diab Med, $2001: 18: 459-63$.

47. Sidorov J, Shull R, Tomeavage J, Girolami S, Lawton N Harris R. Does diabetes disease management sawe money and improve outcomes? Diabetes Carre, 2002;25:684-9.

48. Smith S, Byme G, Shannon WF, et al. The North Dublin Shared Care (DiSC) Project: a profile of current diabetes care in Ireland. Ir Med Joumal, 2001;94:1-8.

49. Standards of Reporting Trials Group. A proposal for structured reporting of randomised controlled trials. JAMA, 1994;272(24):1926-31. 
50. Sturen LMG, WringefHMM. Van Merode GG, Severens JL, Spreenwenberg C. Methodological quality of disease management exalluation studies can best be assessed with the HTA-DM instrument. Cin Epidemio, 2004,57:881-888.

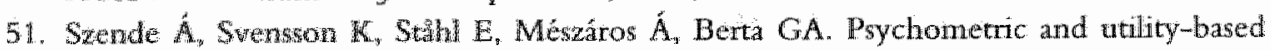
medsures of beath satur of asthmatic patients with different disease control level. Phamazoeconomics, $200 \%: 22(8): 537-47$.

52. Thorell 1 , Otson $L$, Swardsudd $K$. Implementation of a structured care programme for diabetes mellitus in a deffined population in Mid-Sweden. Diab Med, 1994:11:458-464.

53. Tschopp $J M$, Frey $\mathbb{I C}$, Pernet $\mathrm{R}$, al. Bronchial asthma and self-managenent education: implementation of guidelines by an interdisciplinary programme in a thealth network. Swiss. Med Wkly, 2002;132:92-97.

54. Van den Arend IJM, Stolk RP, Rutten GEHM, Schrijwers G. Education integrated into structured general practice care for type 2 diabetic patients results in sustained improvement of disease knowledge and self-care. Diab Med, 2000;17:190-197.

55. Vrijhoef HJM, Spreeuwenberg C, Ejikelberg IMJG, Wolfenbuttel BHR, Van Merode G. Adoption of disease management model for diabetes in the region of Maastricht. BMJ, $2001 ; 323: 983-985$

56. Vrijhoef HJM, Diederiks JPM, Spreeuwenberg C, Wolffenbuttel BHR. Substitution model with central role for nurse specialist is justified in the care for stable type 2 diabetic outpatients. J Adv Nurs, 2001;36:1-10.

57. Vrijhoef HJM, Diederiks JPM, Spreeuwenberg C, Wolffenbuttel BHR, Van Wilderen LJGP. The nurse specialist as nain care-provider for patients with type 2 diabetes in a primary care setting; effects on patient outcomes. Int J of Nurs Stud, 2002;39:441-451.

58. Wagner EH, Austin BT, Von Korff M. Organizing care for patients with chronic illness. Milbank Q, 1996;54:56-8.

59. Weinberger M, Kirkman MS, Samsa GP, Shortliffe EA, Landsman PB, Cowper PA, Simel DL, Feussner JR. A nurse-coordinated intervention for primary care patients with mon-insulinedependent diabetes mellitus: impact on glycemic control and health-related quality of life. J Gen Intern Med, 1995;10(2):111-2.

60. Weingarten SR, Henning IM, Badamgaraw $\mathrm{E}$, et all, Interventions used in disease management programmes for parients with chronic illness - which ones work? Meta-analysis of published reports. BMJ, 2002;235:925-37.

61. Zgibor JC, Rao H, Wesche-Thobaben J, Gallagher N, McWilliams J, Korytkowski MT. Improving quality of diabetes care in primary care practice. I Healthc Qual, $2004,26(4): 14-21$.

62. Zinmer LO, Almond MJ, Jones D, et al. One-year outcomes from a computer-based disease management program: the individualized asthma care training program (ACT). Disease Management, 2000;3:65-73. 


\section{COPD AS A MULTI-COMPONENT DISEASE}

Inventory of Dyspnoea, Underweight, Obesity and Fat Free Mass Depletion in Primary Care

L.M.G. Steuten, E.C. Creutzberg, H.J.M. Vrijhoef, E.F.M. Wouters

Based on paper accepted for publication in:

Primary Care Respiratory Journal 


\section{ABSTRACT}

Aims: to describe the distribution of disease severity in primary care based on airway obstruction, and to assess the extent to which dyspnoea scores, BMI and FFMI contribute to the distribution of COPD severity in primary care.

Design: cross sectional population-based study

Methods: from an outpatient disease management programme, 317 patients with COPD were recruited. Prevalence of moderate to severe dyspnoea, underweight, obesity and FFM-depletion by GOLD stage were measured.

Results: according to GOLD guidelines, $29 \%$ of patients had mild COPD, $48 \%$ moderate, $17 \%$ severe and $5 \%$ very severe. A substantial part of patients classified in GOLD 2 reports severe dyspnoea (28.1\%) and/or suffers from FFM-depletion $(16.3 \%)$. Prevalence of low body weight strongly increases in GOLD 4; prevalence of obesity is highest in stages 1 and 2 .

Condusion: the use of a multidimensional grading system that takes dyspnoea as well as nutritional status of patients with COPD into account is likely to influence the distribution of disease severity in a primary care population. This might have implications for prevention, (non-) medical treatment and estimations of healthcare utilisation in primary care. 


\section{INTRODUCTION}

Chronic obstructive pulmonary disease (COPD) is a disease state characterised by airflow limitation that is not fully reversible. The airflow limitation is usually both progressive and associated with abnormal inflammatory response of the lungs to noxious particles or gases. The most important cause of COPD is a long-term smoking history [1].

COPD causes considerable mortality and morbidity worldwide and is predicted to become the third most frequent cause of death and the fifth leading cause of disability by the year 2020 [2]. Moreover, the condition is often under diagnosed and under treated [3].

The Global Initiative for Chronic Obstructive Lung Disease (GOLD) established a definition as well as a classification system of airway obstruction. Herein, the diagnosis of COPD is confirmed by the Forced Expiratory Volume in one second (FEV $)$ as hallmark of the obstruction. The system then distinguishes five stages of COPD varying from stage 0 for people being 'at risk' to stage 4 for patients with 'very severe COPD' [1]. Although spirometric classification has proven to be useful in predicting health status [4], utilisation of healthcare resources [5], development of exacerbations [6] and mortality in COPD, it is accepted that a single measurement of FEV incompletely represents the complex clinical consequences of COPD. Other risk factors, as the presence of hypoxemia or hypercapnia, a short distance walked in a fixed time, a high degree of functional breathlessness, and a low body mass and/or fat free mass index, are associated with an increased risk of death [7-14].

As in other chronic inflammatory conditions, weight loss and tissue depletion are commonly seen in COPD patients [15]. The occurrence of tissue depletion varies from $20 \%$ in clinically stable outpatients up to $35 \%$ in patients who are eligible for pulmonary rehabilitation. In addition, the selective wasting of fat free mass (FFM) despite relative preservation of fat mass has been reported in COPD patients. Loss of FFM adversely affects respiratory and peripheral muscle function, exercise capacity and health status [16-20]. Moreover, several studies using different COPD populations have convincingly shown that a low body mass index (BMI), low FFM and weight loss are associated with an increased mortality risk $[13,14,21]$. Obesity, on the other hand, is strongly associated with an increase in dyspnoea, both in the general population as in patients with COPD $[22,23]$.

Dyspnoea represents the most disabling symptom of COPD and is a better predictor

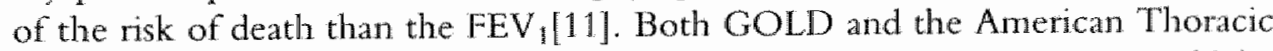
Society (ATS) recommend that a patient's perception of dyspnoea should be included in any new staging system for COPD [24]. The degree of dyspnoea can be measured with the dyspnoea scale of the Medical Research Council (MRC) [25], which correlates with other dyspnoea scales and scores of health status [26,27]. More- 
over, the scale is simple to administer and therefore feasible for application in a primary care setting.

Considering the above and in accordance with the results of the BODE-study [7], it is desirable to pay attention to respiratory, perceptive and systemic aspects in order to produce a composite picture of disease severity of COPD. The BODE-study, however, was performed in a secondary care setting with a group of elderly patients, most of them suffering from severe COPD [7]. This population is not representative for a primary care population. Moreover, despite data describing the prevalence of COPD, the distribution of disease severity in the primary care population is mainly unknown [28].

Therefore, our study aims to: 1) to describe the distribution of disease severity in primary care based on airway obstruction, and 2) to assess the extent to which dyspnoea scores, BMI and FFMI contribute to the distribution of COPD severity in primary care. In addition to the second research question, it has been investigated if there are differences between the proportion males and females suffering from severe dyspnoea, underweight, obesity or depleted FFM within in each GOLD stage. The potential impact of exercise capacity on disease severity in a primary care population was not studied, since it is not feasible to routinely perform the 6-minute walking test in this setting, given the number of patients, the lack of machinery in the GP's office and the limited time of consultation.

\section{METHODS}

Patients were recruited between May 2002 and March 2003 from an outpatient disease management programme that has previously been implemented in the region of Maastricht (NL). At that time, sixteen general practices $(20 \mathrm{GP}$ ) participated in the programme. Inclusion criteria were: diagnosis of COPD based on spirometry, and age $\geq 18$ years. Exclusion criteria were: serious co-morbidity such as lung cancer or congestive heart fallure. Following a well-defined procedure, respiratory nurse specialists evaluated respiratory symptoms and lung function of patients submitted by the $\mathrm{GP}$. This procedure took place in the primary care setting. Diagnosis and definition of severity of COPD was established in accordance with the GOLD guidelines by a core team consisting of a pulmonologist, a GP and a respiratory nurse specialist. GOLD O (= at risk) is diagnosed when patients report chronic cough and sputum production while their lung function is still normal. GOLD 1 (= mild COPD) is defined as $\mathrm{FEV}_{1} / \mathrm{FVC}<70 \%$ but $\mathrm{FEV}_{1} \geq 80 \%$ predicted. GOLD 2 (= moderate COPD) is diagnosed if $50 \% \leq \mathrm{FEV}_{\|}<80 \%$ predicted. GOLD 3 (= severe COPD) is defined as $30 \% \leq \mathrm{FEV},<50 \%$ predicted and GOLD 4 (= very severe COPD) is diagnosed if FEV $<30 \%$ predicted. Patients with a confirmed diagnosis of COPD were included in the study. W/ritten informed consent was obtained from each patient. 


\section{Lung function measurements}

Post bronchodilator FEV 1 was measured according to the American Thoracic Society criteria before and after administration of a bronchodilator (salbutamol, $400 \mu \mathrm{g}$ ) using a hand held spirometer (Vitalograph; Vitalograph Ltd; Buckingham, United Kingdom). Patients were instructed not to use bronchodilators on the day of pulmonary function assessment or at least not within six hours before measurement. Respiratory nurse specialists were especially trained to perform the pullmonary function measurements. Spirometers were calibrated daily. All patients were studied in a sitting position. Data from the flow-volume curve with the highest sum of FVC and $\mathrm{FEV}_{1}$ were used for calculations. $\mathrm{FEV}_{1}$ was expressed as $\mathrm{FEV}_{1} \%$ predicted, based on gender, height and age, using the reference values of the European Respiratory Society [29].

\section{Dyspnoe measurement}

The MRC-scale was used for grading the effect of breathlessness on daily activities. The scale measures perceived respiratory disability by allowing patients to indicate the extent to which their breathlessness affects their mobility. Disability is defined in accordance with the WHO definition of disability being any restriction or lack of ability to perform an activity in the manner or within the range considered normal for a human being' [25]. The MRC dyspnoea scale consists of five statements being: $1=$ "I only get breathless with strenuous exercise'; 2 = 'I get short of breath when hurrying on the level or up a slight hill'; 3 = 'I walk slower than people of the same age on the level because of breathlessness or have to stop for breath when walking at my own pace on the level"; 4 = "I stop for breath after walking 100 meters or after a few minutes on the level'; $5=$ "I am too breathless to leave the house'. Patients select the grade that applies to them. They are considered moderately or seriously disabled due to breathlessness if their MRC score is $\geq 3$ since this is associated with worsening of exercise tolerance, health status and mood state [25].

\section{Anthropometrical measurements}

Measurement of height was made by clinical stadioneter in bare or stocking feet. Body weight was measured with a calibrated precision scale with subjects wearing their nomal clothes but without shoes. To correct for this, $1 \mathrm{~kg}$ of the measured body weight was subtracted for each person. BMI, defined as weight (kilograms) divided by the square of height (meters), was calculated. Patients were considered underweight if their BMI was $\leq 21 \mathrm{~kg} / \mathrm{m}^{2}$, and obese if their BMI was $>30 \mathrm{~kg} / \mathrm{m}^{2}$ [1]. 


\section{Measuring fat free mass}

FFM was measured by means of whole body bioelectrical impedance analysis with the Bodystat 1500 (Bodystat Ltd; Isle of Man, British Isles). Injector electrodes are placed on the dorsal surfaces of the foot and wrist, and detector electrodes are placed between the radius and un (styloid process) and at the ankle (berween the medial and lateral malleoli). The FFM-index (FFMI) was calculated from height $2 /$ resistance and body weight using a regression formulae corrected for COPD. Patients were considered as having a depleted FFM if FFMI $\leq 15 \mathrm{~kg} / \mathrm{m}^{2}$ (women) or $\leq 16 \mathrm{~kg} / \mathrm{m}^{2}$ (men) [30].

\section{Statistical considerations}

Patients were classified by means of lung function (GOLD stage), MRC score, BMI and FFMI. Descriptive statistics were applied in order to identify the prevalence of GOLD stages in a primary care population. Also, the number of patients that, according to their lung function, were classified in GOLD stage 0,1 or 2, but had a MRC-score $\geq 3$, or a BMI $\leq 21 \mathrm{~kg} / \mathrm{m}^{2}$ or $>30 \mathrm{~kg} / \mathrm{m}^{2}$, or a FFMI $\leq 15 \mathrm{~kg} / \mathrm{m}^{2}$ (for women) or $\leq 16 \mathrm{~kg} / \mathrm{m}^{2}$ (for men), were computed. Differences in baseline characteristics between GOLD stages were assessed for statistical significance at $\alpha=0.05$ using independent-samples t-tests for normally distributed data and Mann-WhitneyU-tests for the variables sex and smoking. Potential differences between the proportion males and females, suffering from severe dyspnoea, underweight, obesity or depleted FFM, within each GOLD stage were analysed with Chi-square tests at a 5\% uncertainty level. All analyses were performed using the Statistical Package for Social Sciences (SPSS Inc., Chicago, IL, U.S.A.). All data are presented as means ( $t_{\mathrm{sd}}$ ) unless stated otherwise.

\section{RESULTS}

Of the 355 eligible patients 317 participated (89.3\%). Baseline characteristics of the 317 subjects with a diagnosis of COPD are shown in Table 1 . Twenty-nine percent of the COPD patients were classified as having mild COPD, $48 \%$ as moderate, $17 \%$ as severe and $5 \%$ as very severe. The relative number of females decreased with increasing severity of the disease. The percentage smokers is highest in the group of patients classified in GOLD $2(48.3 \%)$, while the average number of pack years is highest in GOLD $3(40.2 \pm 25.1 \mathrm{yrs})$. The average number of pack years differs between men (32.6 \pm 21.8$)$ and women $(27.3 \pm 15.2)$, this difference being statistically significant $(p=0.034)$ (Students t-test, two-sided with $\alpha=.05$ ).

Table 2 shows the percentage of patients having a MRC score $\geq 3$, a BMI $\leq 21 \mathrm{~kg} / \mathrm{m}^{2}$ or $>30 \mathrm{~kg} / \mathrm{m}^{2}$, or a FFMI $\leq 15 \mathrm{~kg} / \mathrm{m}^{2}$ (women) or $\leq 16 \mathrm{~kg} / \mathrm{m}^{2}$ (men) per GOLD 
Table 1: Baseline characteristics categorised by GOLD stage

\begin{tabular}{|c|c|c|c|c|}
\hline & $\begin{array}{l}\text { GOLD }(n=317) \\
1\end{array}$ & 2 & 3 & 4 \\
\hline$N(0)$ & $93(29.4)$ & $153(48.3)$ & $54(17.0)$ & $17(5.3)$ \\
\hline$M / F$ & $45 / 48$ & $84 / 69$ & $35 / 19$ & $14 / 3$ \\
\hline Age & $56.6( \pm 14.4)$ & $61.8( \pm 13.7)^{\star}$ & $65.7( \pm 11.8)$ & $68.8( \pm 11.5)$ \\
\hline FEV $1 \%$ pred & $91.8( \pm 10.0)$ & $64.7( \pm 8.3)^{\star}$ & $42.3( \pm 4.9) *$ & $25.1( \pm 4.8)^{\star}$ \\
\hline FVC & $118.2( \pm 1.5 .9)$ & $94.4( \pm 18.6)^{\star}$ & $75.3( \pm 17.9)^{\star}$ & $72( \pm 23.6)$ \\
\hline FEVI/FVC & $0.63( \pm 0.1)$ & $0.56( \pm 0.1)^{\star}$ & $0.47( \pm 0.1)^{\star}$ & $0.34( \pm 0.1)^{\star}$ \\
\hline MRC & $1.6 \pm 0.85$ & $2.2( \pm 1.03)^{\star}$ & $2.8( \pm 1.12)^{\star}$ & $3.6(11.11)^{\star}$ \\
\hline $\mathrm{BMI}$ & $26.5( \pm 4.13)$ & $26.7(\mathbb{E} 5.48)$ & $25.7( \pm 4.53)$ & $22.0( \pm 5.31)^{*}$ \\
\hline FFMI & $17.8( \pm 2.4)$ & $17.8( \pm 2.5)$ & $17.6( \pm 2.3)$ & $16.1( \pm 2.5)$ \\
\hline$\%$ smokers & 43.5 & 48.3 & $31.5^{\star}$ & 23.5 \\
\hline Pack years & $23.1( \pm 15.6)$ & $31.5( \pm 18.1)^{\star}$ & $40.2( \pm 25.1)^{\star}$ & $27.1( \pm 15.3)$ \\
\hline
\end{tabular}

* Indicates statistical significant difference between this GOLD stage and the preceding one, tested with an independent-samples t-test or at Mann-Whitney-U test when appropriate $(\alpha=0,05)$.

stage. A substantial part of the patients classified in GOLD 2 reports severe dyspnoea (28.1\%) and/or suffers from FFM-depletion (16.3\%). The prevalence of low body weight increases with $10 \%$ over GOLD stages 1 to 3 , but strongly increases in GOLD 4. The prevalence of obesity is highest in GOLD stages 1 and 2. Significant differences between males and females were found with regard to FFM-depletion in GOLD stage $2(p=0.002)$ and severe dyspnoea in GOLD stage $3(p=0.021)$.

\section{DISCUSSION}

In this study, the distribution of COPD-severity in an outpatient population, as stratified according to GOLD classification system, was assessed. Moreover, the proportion of patients that suffered from severe dyspnoea, underweight, obesity or FFM-depletion, while being classified as having mild to moderate COPD (GOLD 1 and 2), was investigated. Also, gender differences with regard to the prevalence of these measures was studied.

With regard to the first objective of this study, we found that in total $77.8 \%$ of parients had mild or moderate COPD and $22.2 \%$ had severe or very severe COPD, as defined according to GOLD criteria. The distribution of disease severity in primary care as found in this study can well be compared with other studies performed in The Netherlands and the UK. The relatively small number of females in GOLD stages 2, 3 and 4 might be explained by lower prevalence rates of COPD for women as previously 


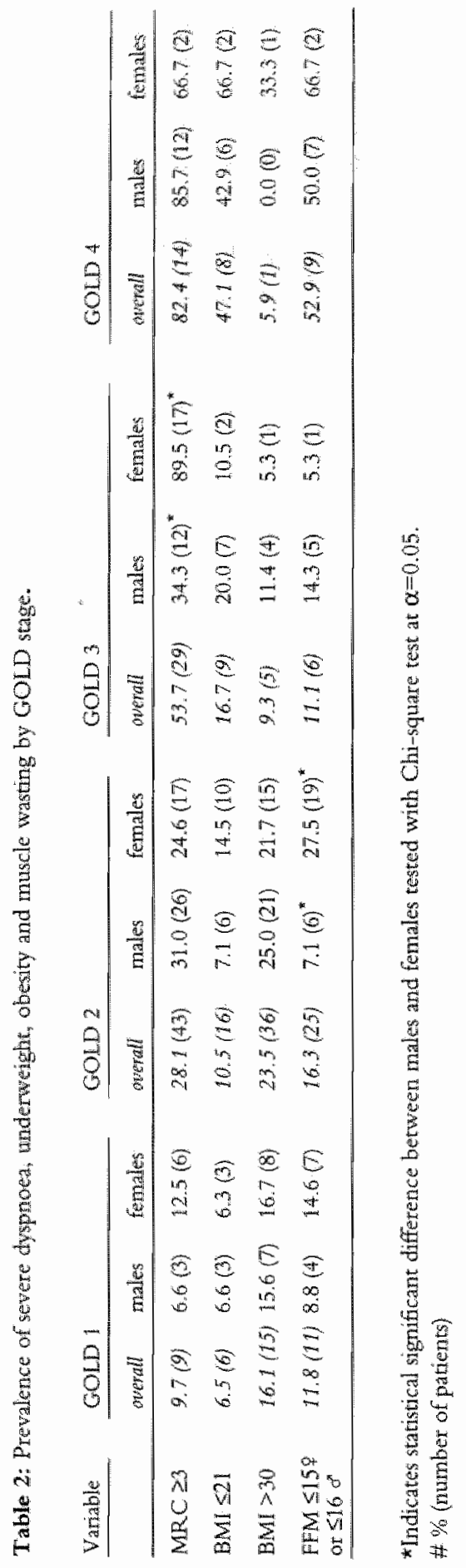


reported by Feenstra et al [31]. Also, this may be influenced by the lower timmber of pack years found for women, as found in this study, or gender differences inoccupational exposures $[32,33]$.

With respect to the second objective, we found that a substantial proportion of primary care patients with mild to moderate COPD reported moderate to severe dyspnoea (mild 9.7\%; moderate $28.1 \%$ ) and / or serious muscle wasting (mild $11.8 \%$; moderate $16.3 \%$. Prevalence of low body weight only strongly increased in patients with very severe COPD while prevalence of obesity was highest among patients with mild to moderate COPD. Gender differences were found with regard to depleted FFM in GOLD stage 2 and severe dyspnoea in stage 3. It needs to be stressed here that the prevalence of FFM-depletion within an outpatient population is normally found to be around $25 \%$ independently from disease severity as compared to the prevalence of $11.8 \%$ to $16.3 \%$ that we found in this study. Consequently, our data are rather underestimating the potential impact of FFM-depletion on distribution of disease severity in primary care than overestimating.

The study results suggest that the use of a multidimensional grading system, that takes dyspnoea as well as nutritional status of patients with COPD into account, is likely to influence the distribution of COPD severity in a primary care population. However, the exact impact of using such a multidimensional system instead of the GOLD criteria is hard to assess because not all necessary data are available in primary care. For example, the multidimensional grading system as proposed by Celli et al. seems difficult to apply in primary care, since data on exercise capacity are generally not available there. Data on FFM, however, are more commonly available and they were shown to be strongly related to exercise capacity $[16,34]$. Measures of BMI, on the other hand, were found to be of relatively less importance in determining disease severity, as has also been reflected in the BODE-index where relatively little weight was attached to changes in BMI [7]. Therefore, more emphasis might be placed on assessing body composition in primary care. It seems worthwhile to include this measure in a multidimensional grading system.

A shift in severity distribution might have implications for prevention, (non-)medical treatment and estimations of healthcare utilisation. Firstly, since the majority of patients in primary care suffers from mild to moderate COPD, they are at risk of deterioration of the disease for instance with increasing age. Also, many of these patients are still current smokers $(43,5 \%$ in mild and $48,3 \%$ in moderate COPD patients). Because smoking cessation reduces the subsequent rate of decline in lung function in people with mild to moderate airflow limitation [35], the chief benefits of this type of intervention is to be expected in these patient groups. A combined strategy of micotine-replacement therapy with counselling or antidepressants (bupropion or nortryptiline) with counselling, in which the physiological as well as the psychological aspects of smoking cessation are treated, was shown to be most effective [36]. 
Secondly, a substantial part of patients classified in GOLD stage 1 or 2 already shows symptoms of moderate to severe disability due to dyspnoea and/or (serious) muscle wasting. Previous studies already suggested that any given $F_{1} V_{1}$ may be associated with a wide range of disability [25], therefore, direct measurements of disability are clearly complimentary in assessing severity of the disease. Moreover, dyspnoea is a better predictor of the risk of death than the $\mathrm{FEV}_{1}$ [11].

Thirdly, both retrospective and prospective studies within several COPD populations provided evidence for a relationship between low BMI and higher mortality rates $[12,13]$ with relative risks ranging from 1.42 in women to 1.64 in men [13]. Furthemore, it has been reported that underweight patients are more dyspnoeic than normal weight patients, partly as a consequence of decreased respiratory nuscle strength. [37]. The functional consequences of being underweight and of FFM-depletion have been reflected in a decreased health status as measured by the St. George Respiratory Questionnaire (SGRQ) [38] and decreased physical functioning. Depletion of FFM caused greater impaiment in the activity and impact scores of the SGRQ than weight loss [20]. The specific relationship between FFM and mortality was first reported by Marquis et al. [39], demonstrating that a small midthigh muscle cross-sectional area and FEV, were found to be the only significant predictors of mortality in patients with stable COPD (mean FEV, $42 \pm 16 \%$ predicted). Recently, more evidence came from Schols at al. showing that FFM (relative risk: $0.90 ; 95 \% \mathrm{Cl}: 0.48,0.96 ; p^{=0.003)}$ is an independent predictor of mortality [14].

Several studies have shown that restoration of the distorted energy balance by nutritional support, in combination with training or revalidation, results in a significant increase in body weight, fat-free mass, respiratory muscle function and even in the immune response $[12,40-44]$. Nevertheless, nutritional support for severely underweight COPD patients may only have limited effect on the recovery of functional exercise abilities, because compliance appears to be difficult [45]. For the obese patients in these GOLD stages, nutritional advice is also worth while since obesity is associated with dyspnoea $[22,23]$.

Overall, the results of this study imply that awareness of dyspnoea and nutritional aspects of COPD is necessary to avoid underscoring of disease severity in primary care. This should be accomplished by integrating simple measurements of dyspnoea and nutritional status in classification systems for disease severity and, subsequently, provide targeted interventions as smoking cessation, exercise training and nutritional interventions as a means of secondary prevention [12]. Furthermore, these findings have implications for the estimation of the future burden of COPD in tems of healthcare utilisation $[3,46]$. Since healthcare utilisation is commonly matched to discriminated stages of disease severity (most frequently the GOLD stages), the estimated amount of healthcare utilisation within a specific disease stage and within a specific time lagneeds to be recalculated when the distribution of patients over these 
disease severity stages changes. Not only patient numbers per severity stage will change, but from previous studies it is also known that underweight as well as depleted FFM are related to higher utilisation of, among others, in-patient services [46]. The relationship between MRC score and healthcare utilisation needs to be investigated more extensively for this purpose. In addition, mortality rates per severity stage need to be adjusted for the impact that dyspnoea, BMI and FFM have on mortality rates.

\section{REFERENCES}

1. Pauwels RA, Buist S, Calverly PMA, Jenkins CR, Hurd SS. Global Strategy for the Diag. nosis, Management and Prevention of Chronic Obstructive Pulmonary Disease NHLBI/WHO Global Initiative for Chronic Obstructive Lung Disease (GOLD) Workshop Summary. Am J Respir Crit Care Med 2001;163:1256-1276.

2. Murray CJ, Lopez AD. Alternative projections of mortality and disability by cause 1990-2020: Global Burden of Disease Study. The Lancet 1997;349:1436-42.

3. Wouters EF. Economic analysis of the Confronting COPD survey: an overview of results. Respir Med 2003;97:S3-14.

4. Ferrer M, Alonso J, Morera J, et al. Chronic obstructive pulmonary disease stage and health-related quality of life. Ann Int Med 1997;127:1072-79.

5. Friedman M, Serby C, Menjoge S, Wilson J, Hileman D, Witek T. Pharmacoeconomic evaluation of a combination of ipratropium plus albuterol compared with ipratropium alone and albuterol alone in COPD. Chest 1999;1 15:635-41.

6. Burrge PS, Calverley PM, Jones PW, Spencer S, Anderson JA, Maslen TK. Randomised, double blind, placebo controlled study of fluticasone propionate in patients with moderate to severe chronic obstructive pulmonary dise ase: the ISOLDE trial. BMJ 2000;320:1297-1303.

7. Celli BR, Cote CG, Marin JM, Casanova C, Montes de Oca M, Mendez RA, et al. The body-mass index, airflow obstruction, dyspnoea, and exercise capacity index in chronic obstructive pulmonary disease. NEJM 2004;350;10:1005-12.

8. Nocturnal Oxygen Therapy Trial Group. Continuous or nocturnal therapy in hypoxemic chronic obstructive pulmonary disease: a clinical trial. Ann Intern Med 1980;93:391-8.

9. The Intermittent Positive Pressure Breathing Trial Group. Intermittent positive pressure breathing therapy of chronic obstructive pulnonary disease: a clinical trial. Ann Intern Med 1983;99:612-20.

10. Gerardi DA, Lovett L, Benoit-Connors ML, Reardon $\rrbracket Z, Z u W$ allack RL. Variables related to increased mortality following outpatient pulmonary rehabilitation. Eur Respir J $1996 ; 9: 431-5$.

11. Nishimura $K$, lzumi $T$, Tsukino $M, O g a T$. Dyspnoea is a better predictor of 5-year survival than airway obstruction in patients with COPD. Chest 2002;121:1434-40. 
12. Schols AM, Slangeril, Volovics L, Wouters EF. Weight loss as a reversible factor in the prognosis of chronic obstructive pulmonary disease. Am J Respir Crit Care Med 1998; 157:1.791-97.

13. Landbo $C_{3}$ Prescott $E$, Lange $P$, Vestbo J, Alindal TP. Prognostic value of nutritional status in chronic obstructive pulmonary disease. An J Respir Crit Care Med 1999;160:1856-61.

14. Schol AMWJ, Broekhuizen R. Weling-Scheepers CA. Wouters EFM. Body composition and mortality in chronic obstructive pulmonary disease. Am J Clin Nutr 2005;82:53-9.

15. Wouters EF, Crewtzberg EC, Schols AM, Systemic effects in COPD. Chest 2002; 121:127S-130S.

16. Barends EM, Schols AM, Mostert R, Wouters EF. Peak exercise response in relation to tissue depletion in patients with chronic obstructive pulmonary disease. Eur Respir J 1997;10:2807-13.

17. Palange P, Forte S, Felli A, Galassetti P, Serra P, Carlone S. Nutritional state and exercise tollerance in patients with COPD. Chest 1995;107:1206-12.

18. Engelen MP, Schols AM, Does JD, Wouters EF. Skeletal muscle weakness is associated with wasting of extremity fat-free mass but not with airflow obstruction in patients with chronic obstructive pulmonary disease. Am J Clin Nutr 2000;71:733-38.

19. Palange $P$, Forte $S$, Onorati $P$, et al. Effect of reduced body weight on muscle acrobic capacity in paticnts with COPD. Chest 1998;114:12-8.

20. Mostert R, Goris A, Weling-Scheepers C, Wouters EF, Schols AM. Tissue depletion and health related quality of life in patients with chronic obstructive pulmonary disease. Respir Med 2000;94:859-67.

21. Schols AM. Nutrition in chronic obstructive pulmonary disease. Curr Opin Pulm Med $2000 ; 6: 110-5$.

22. Berner. YN. The contribution of obesity to dyspnoea in elderly people. Age Ageing $2001 ; 30(6): 530$.

23. Ho SF, O'Mahony MS, Steward JA, Breay P, Buchalter M, Burr ML. Dyspnoea and quality of life in older people at home. Age and Ageing 2001;30:155-9.

24. Definitions, epidemiology, pathophysiology, diagnosis, and staging. Am J Resp Crit Care Med 1995;152:Supp:S78-S83.

25. Bestall JC, Paul EA, Garrod R, Garnham R, Jones PW, Wedzicha JA. Usefulness of the MRC dyspnoes scale as a measure of disability in patients with chronic obstructive pulmonary disease. Thorax 1999;54:581-6.

26. Mahler DA, einberg DH, Wells CK, Feinstein AR. The measurement of dyspnea: contents, interobserver agrement, and physiologic correlates of two new clinical indexes. Chest $1984 ; 85: 751-8$.

27. Hajiro T, Nishimura $K$, Tsukino $M$, Ikeda A, Koyama H, Izumi T. Comparison of discriminative properties among disease-specific questionnaires for meastring health related quallity of life in patients with chronic obstructive pulmonary disease. Am J Respir Crit Care Med 1998;157:785-90. 
28. Hoogendoom M, Rutten-Wan Mölken MPMH, Hoogenveen RT, Van Gentgten MIL, Buist AS, Wouters EFM, Feenstra TI. A dynamic population model of disease progression in COPD. Eur Respir J 2005; 26:223-33.

29. Quanjer PH, Tammeling GJ, Cotes JE, Pedersen OF, Peslin R, Yermalt JC Lung volumes and forced ventilatory Hows. Report Working party Standardisanon of Lung Function Tests, European Community for Steel and Coal; Official Statement for the Europian Respiratory Society. European Respir J 1993;6:5 -40.

30. Creutzberg EC, Wouters EF, Mostert R, Weling-Scheepers CA, Schols AM. Eficacy of nutritional supplementation therapy in depleted patients with chronic obstrucive pulmonary disease. Nutrition 2003;19:120-7.

31. Feenstra TL, Van Genugten MLL, Hoogenveen RT, Wouters EF, Rutten-wan Möken MPMH. The impact of aging and smoking on the future burden of chronic obstructive pulmonary disease. Am I Respir Crit Care Med 2001;164:590-6.

32. Varkey $\mathrm{AB}$. Chronic obstructive pulmonary disease in women: exploring gender differences. Curr Opin Pulm Med 2004; 10:98-103.

33. Le Moual N, Kennedy SM, Kaufinan F. Occupational exposures and asthma in 14,000adults from the general population. Am J Epidemiol 2004;160:1108-1116.

34. Franssen FME, Broekhuizen R, Janssen PP, Wouters EFM, Schols AMWJ. Effects of whole-body exercise training on body composition and functional capacity in nomal-weight patienst with COPD. Chest 2004;125:2021-8.

35. Anthonisen NR. Smoking, lung function, and mortality. Thorax 2000;55:729-34.

36. Wagena E], Huibers MJ, Van Schaijk CP. Therapies for smoking cessation (antidepressants, nicotine replacement and counselling) and implications for the treatment of patients with chronic obstructive pulmonary disease. Ned Tijdsch Geneeskd 2001;145(31):1492-6. (in Dutch)

37. Sahebjani H, Sathianpitayakul E. Influence of body weight in emphysema. Am J Respir Crit Care Med 2000; 161:886-90.

38. Shoup $\mathbb{R}$, Dalsky $G$, Warner $S$, et al. Body composition and health-related guality of life in patients with obstructive airways disease. Eur Respir J 1997;10:1576-80.

39. Marquis $\mathbb{K}$, Debigaré $\mathbb{R}$, Lacasse $Y$, et al. Midthigh muscle cross-sectional ane is a better predictor of mortality than body mass index in patients widh chronic obstructive pulnonary disease. An J Respir Crit Care Med 2002;166:809-13.

40. Exthimion J, Fleming J, Gomez C, Spiro SG. The effect of supplenentary oral nutrition in poorly nourished patients with chronic obstructive pulmonary disease. Am Rev Respir Dis 1988;137:1075-82.

41. Whittaker IS, Ryan CF, Buckley PA, Road JD. The effects of refeeding on peripheral and respiratory muscle function in malnourished chronic obstructive pulmonary disease patients. Am Rev Respir Dis 1990;142:283-88.

42. Rogers RM, Donahoe M, Costantino J. Physiologic effects of oral supplemental feeding in malnourished patients with chronic obstructive pulmonary disease. Am Rev Respir Dis $1992 ; 146: 1511-17$. 
43. Schols AMWJ. Soeters PB, Mostert RM, Pluymers RJ, Frantzen PJ, Wouter EFM. Physiological efects of nutri Crit. Care Med. 152:1268-1274, tional support and anabolic steroids in COPD patients. An J Respir Crit Care Med 1995;152:1268-74.

44. Fuenzalida CHE, Petry TL, Jones PLM, Hambridge HM. The immune response to shor-tem nutritional interwention in advanced chronic obstructive pulmonary disease. An Rev Respir Dis $1990 ; 142: 49-56$.

45. Ferreira IMD, Brooks D, Lacasse $Y$, Goldstein RS. Nutritional support for individuals with COPD: a meta-analysis. Chest 2000;117:672-8.

46. Decramer M, Gosselink R, Troosters T, Verschueren M, Evers G. Muscle weakness is related to utilization of health care resources in COPD patients. Eur Respir 1 1997;10:417-23. 


\section{ASSESSMENT OF ASTHMA AND COPD DISEASE MANAGEMENT PROGRAMMES}

\section{Evaluating and Linking Outcomes Across the Care} Continuum

L.M.G. Steuten, H.J.M. Vrijhoef, G.G. Van Merode, GJ. Wesseling, C. Spreeuwenberg 


\section{ABSTRACT}

Objectives: to assess the impact of a population-based disease management programme (DMP) for adult patients with asthma or COPD on processes, intermediate outcomes and end results of care and to explore how changes in process, intermediate and disease specific outcomes are related to the main outcomes.

Study setting: region of Maastricht (the Netherlands) including university hospital and 16 GP practices.

Study design: pre-post test with 12-months follow up.

Data collection: data on quality of care, self management, health status, health-related quality of life (HRQL), patient satisfaction and healthcare costs are collected from 975 patients, 658 of which have asthma and 317 have COPD.

Principal findings: aspects of quality of care, self care behaviour, smoking status, disease specific knowledge and satisfaction of all patients improved after implementation of the programme. Lung function and health status were not affected by implementation of the DMP. For COPD patients a significant improvement in HRQL was found. For patients with asthma, significant cost savings were measured.

Condusion: organising healthcare for adults with asthma or COPD according to principles of disease management is associated with significant improvements in several processes and outcomes of care delivery within existing budgets. Changes in FEV, (\%pred), self management education, disease specific knowledge, compliance, hospitalisation, medication costs and productivity loss can predict changes in end results of care, which are better suitable for decision-making on macro level. 


\section{INTRODUCTION}

Disease management programmes (DMPs) aim to improve quality of care and reduce healthcare costs $[1,2]$. They seek to identify chronic conditions more quickly and treat them more effectively, thereby slowing the progression of the disease. This is pursued through a combination of enhanced screening, monitoring and education, the co-ordination of care among providers and settings, and standardisation of care using evidence based guidelines $[3,4]$. The assumption is that, for the increasing number of chronically ill patients, better care today will result in better health and less expensive care in the future [4].

In the region of Maastricht (the Netherlands), a DMP for patients with asthma or Chronic Obstructive Pulmonary Disease (COPD) has been implemented. The programme concerns all patients with asthma or COPD registered by a general practitioner (GP), either treated by a GP or a pulmonologist at the outpatient department of the regional (university) hospital. Main features of the programme are central co-ordination, protocolised assessment of lung problems, classification of severity of asthma or COPD, assignment of patients to their GP, a respiratory nurse specialist (RNS) or a pulmonologist, central data collection with yearly feedback and regular training and education of the caregivers. Special attention is given to the role and training of the RNS. The RNSs function as a liaison between the integrated care department of the hospital, the pulmonologists and the GPs. They are employed by and hosted in the hospital, but see patients in the offices of the GPs. Apart from the diagnostic and therapeutic tasks listed in the (inter)national guidelines for pulmonologists and $\mathrm{GPs}$, the RNSs focus on patient education and promotion of self management.

This paper aims to describe the effects of a DMP in terms of process and outcome indicators and to explore if changes in end results of care can be predicted from changes in process and intermediate outcomes.

\section{METHODS}

\section{Patients and setting}

Between May 2002 and March 2003 patients were recruited in the region of Maastricht from 16 general practices (20 GPs) and the outpatient department of the hospital. The region of Maastricht encompasses circa 120.000 inhrabitants, $90 \mathrm{GP}$ s, of which 60 participate in the DMP, and one university hospital. Patients with a diagnosis of either asthma or COPD were invited for participation in the study. Patients with serious co-morbidity, e.g. lung cancer or congestive heart failure were not eligible for inclusion. 


\section{Study design and procedures}

To assess the processes and outcomes of care, a one-group pre-post test design was applied [5]. This design was chosen as the programme was implemented region-wide and a "fair" comparison region could not be found. In all potential comparison regions, innovations were being implemented that would bias the measure of usual care.

The contrast between usual care and the care within the DMP concerns the central co-ordination, the re-assignment of patients and the introduction of the RNS. Within usual care, patients were either managed by the GP (mild to moderate asthma or COPD) or the pulmonologist (moderate to severe asthma or COPD).

After obtaining written informed consent, patients were sent the first questionnaire (see Data collection) and were invited for an initial consultation that was carried out by the RNS within the office of the patients' own GP. During this consultation the RNS performed spirometry, assessed the perceived breathlessness, with the dyspnoe score as developed by the Medical Research Council, as well as wheezing, night time awakening and exacerbations. Based on these data, the core team of care providers within the DMP (GP, pulmonologist and RNS) confirmed or reconsidered the diagnosis. They classified each patient's disease severity and the required intensity of care in accordance with either GOLD [6] or GINA [7] guidelines. This led to a proposal concerning the assignment of the patient. If patients agreed with the proposal, those with intermittent or mild asthma or mild COPD were assigned to the GP, patients with moderate persistent asthma or moderate COPD received quarterly outpatient appointments from the RNS within the practice of the GP, and patients with severe persistent asthma or (very) severe COPD received healthcare from the pulmonologist. All care providers in the DMP were encouraged to follow the guidelines for asthma and COPD management [6-10]. The protocol for care delivery by the RNS was based on the Dutch guidelines for GPs. The scheduled duration of consultations with GP or pulmonologist was not changed. The consultations with the RNSs were scheduled for 30 minutes.

\section{Classification of indicators}

According to the paradigm of Donabedian, structure indicators are defined as the physical and organisational properties of the settings in which care is provided. A process encompasses all that is done to and for a population of consumers and patients, such as preventive services and measures, diagnosis, treatment, and palliative care. Outcomes are the end results of care, i.e. the change in patient or population health status, life expectancy, health-related quality of life (HRQL) and healthcare costs [1 1]. A distinction can be made between outcome indicators that are suitable for decision-making between several (types of) interventions that are aimed at different populations (like HRQL, healthcare costs, patient satisfaction) and 
Table 1: Overview and classification of process and ontcome indicators

\begin{tabular}{|c|c|c|}
\hline Process indicators & Internediate $/$ disease specific outcomes & End resuls of care \\
\hline $\begin{array}{l}\text { Number of planned routine } \\
\text { comsultations }\end{array}$ & Respiratory control & Heality stattus \\
\hline $\begin{array}{l}\text { Number of non-routine } \\
\text { conmiltations }\end{array}$ & Srmoking status & Health-nelared quality of life \\
\hline $\begin{array}{l}\text { Number of patients receiving self } \\
\text { namagement education }\end{array}$ & $\begin{array}{l}\text { Self care behaviour (phywcal activity and } \\
\text { compliance with nedication regunen) }\end{array}$ & Total healdhence costs \\
\hline Co-ordination of care & Disease specific knowledge & Patient sarisfaction \\
\hline \multirow[t]{3}{*}{ Accessibitior of care } & Hospitalisation & \\
\hline & Medication costs & \\
\hline & Productivity losses & \\
\hline
\end{tabular}

disease specific and intermediate outcome indicators [12]. Disease specific outcomes are typically suitable for decision-making concerning interventions for one specific patient population, but they are relatively invaluable beyond this scope. Intermediate outcomes tend to cover only a very specific part of healthcare outcomes, like, for example, compliance. As single indicators, they are less suitable for decision-making on a meso or macro level. However, intermediate outcomes might be very worthwhile in optimising and comparing interventions for specific populations or comparing treatment options at patient level $[12,13]$. In addition, they are often assumed to be related to the more general end results of care as mentioned before. An overview and classification of the indicators used to answer the research questions is presented in table 1.

\section{Data collection}

Data concerning clinical indicators, self care behaviour, disease specific knowledge, compliance, patient satisfaction, quality of care, health status, HRQL and (in) direct costs covered a period of three months before a patient entered the programme and 12 months afterwards. Clinical data (as lung function, frequency and severity of symptoms, level of dyspnoea, number of exacerbations, body weight and fat--free-mass index) were obtained from caregivers' registries. Self care behaviour, disease specific knowledge, compliance, patient satisfaction, quality of care, health status, HRQL and (in)direct costs were measured by postal questionnaires.

Costs were measured retrospectively every three months starting at entry of the programme. All other data were collected immediately prior to entry (T0: reflecting usual care), after six months (T1) and after 12 months (T2). 


\section{Lung function}

Evaluation of lung function was based on spirometry and expressed as changes in postbronchodilator forced expiratory flow in one second $\left(\mathrm{FEV}_{1}\right)$ in percentage of the predicted value, FEV $1 \%$ reversibility as well as the Tiffeneau-ratio (FEV $/ F V C$ ).

\section{Quality of care}

Quality of care was measured with a Dutch instrument called the QUOTE questionnaire (QUality Of care Through patients Eyes) for patients suffering from asthma or COPD. This instrument consists of 32 indicators of quality in healthcare (Cronbach's $\alpha=0.93$ ) [14]. For the purpose of this study only indicators that directly refer to one of the selected process measures were included in the statistical analysis (e.g. co-ordination $[\alpha=0.79]$, accessibility $[\alpha=0.74]$, education concerning medication use $[\alpha=0.74]$ and understandable education concerning non-medical self care $[\alpha=0.81])$.

\section{Self care behaviour and disease specific knowledge}

Measurements of self care behaviour and disease specific knowledge were performed with a validated Dutch instrument [15]. Regarding self care, two dimensions were measured: compliance to the medication scheme and condition-maintenance. Condition maintenance, defined as the extent to which the patient actively works on maintaining a good physical condition, was measured by asking patients whether they participated in active movement during their free time. The answer possibilities of these questions had a five-point scale and were expressed as one overall score. In addition, self-reported smoking status was assessed as an aspect of self care behaviour and measured on a dichotomous scale.

Disease specific knowledge was measured by means of 22 questions about asthma and COPD (Cronbach's $\alpha=0.70$ ) and expressed as the proportion of right answers, transformed into a $0-10$ scale.

\section{End results of care}

Health status was measured with a validated Dutch version of the St. George's Respiratory Questionnaire (SGRQ) [16]. The SGRQ consists of 76 items and measures three components: symptoms, activities and impact. It also yields a total score, ranging from 0 to 100 , with a score of 0 indicating no impairment. Satisfaction of patients with the provided care was graded with a mark (1-10).

The Dutch version of the EuroQol-5D (EQ-5D) was used to measure HRQL. The EQ-5D is a standardised instrument to measure health outcome. It provides a simple 
descriptive profile and a single index value for health status ranging from 0 to 100 , with 0 indicating "worst imaginable health state" [17].

Cost calculations are based on actual resource use, measured with a 15-item questionnaire and verified with administrative data from care prowiders. Direct healthcare costs were calculated using current prices, when available, or tariffs [18]. Productivity losses were measured in terms of sick leave days and calculated using the age-dependent friction cost method. Implementation and overhead costs were calculated by using a bottom-up approach. Collected data on resource use were: number of planned consultations with GP, RNS or pulmonologist, number of consultations with other care providers, amount and type of medication used, number of sick leave days due to asthma or COPD, number of non-routine consultations due to an exacerbation, number and duration of hospital admissions.

\section{Statistical analyses}

All presented analyses were based on intention to treat, while missing response was handlled by using the last observed response (carry forward procedure) [19]. Missing data analysis was performed to assess if any selective loss to follow up or dropping out occurred during follow up.

Differences in process, intermediate and disease specific indicators between the three measurement points were assessed with repeated measurement analysis. For continuous outcome variables multivariate MANOVA analyses were performed, while dichotomous variables were analysed using Cochran's $Q[20]$. Bonferroni correction was applied to adjust for multiple testing. All repeated measurement analyses were carried out for the study population as a whole as well as for separate subgroups as defined by primary responsible care provider (e.g. pulmonologist, RNS and GP) with $\alpha=0.05$.

Before-after comparisons of the end-results of care were analysed using paired-samples $T$-tests (two-sided; $\alpha=0.05$ ) for normally distributed data. Cost data were $\log$ transformed for this purpose.

Since there is incongruence between the unit of allocation (level of care provider) and unit of analysis (patient level), random coefficient regression analysis was applied to analyse the relationship between process, intermediate and disease specific indicators on the one hand and end results of care on the other. A mixed model procedure was performed with differences in patient satisfaction, health status, HRQL and log transformed total healthcare costs as subsequent dependent variables and all differences in process, intermediate and disease specific indicators as independent variables. We modelled a random intercept as determined by the cluster variable 'care provider' and fixed slopes for the regression coefficients. All data processing and analyses were performed using SPSS 12 for Windows. 


\section{RESUITS}

\section{Patient inclusion, assignment and follow up}

One thousand and sixty-rwo patients were found eligible, 975 of which were included in the study $(92 \%$. Of the included patients, $10 \%$ was assigned to the pulmonologist, $65 \%$ to the RNS and $25 \%$ to the GP. Response rates on both quality of care questionnaires and cost questionnaires ranged from $67 \%$ to $96 \%$. Seventy percent of the patients $(n=685$ ) completed 12 -month follow up. The most common reason for dropping out of the study was unwillingness to complete any questionnaire. Patient characteristics at baseline are presented in table 2 .

\section{Missing data analysis}

Patients that were assigned to the GP were less likely to complete data collection as compared to patients that were assigned to the RNS or pulmonologist. Therefore, lung function values of patients who did not complete follow up were on average higher compared to lung function values of patients that completed the follow up questionnaires. Within the GP-subgroup of patients, baseline characteristics of patients with missing data did not differ significantly from baseline characteristics of patients with complete data. This indicates that within the GP-subgroup, no selective loss to follow up occurred.

\section{Lung function}

No significant improvements were found with regard to $\mathrm{FEV}$ (\%pred), FEV, reversibility or FEV / FVC. For patients with COPD, however, also no significant deterioration of the $\mathrm{FEV}_{1}$ (\%pred) was found (Table 3 ).

\section{Quality of care}

The proportion of patients that reported to receive self management education, which was appreciated as "understandable, almost doubled within the first six months after inclusion (from 35\% to $77 \%$; $<0.001$ ), reaching $81 \%$ after 12 months $(p<0.001)$. This effect was mainly driven by the increase in the RNS-subgroup (from $32 \%$ at baseline to $95 \%$ after 12 months; $p<0.001$ ). The proportion of patients reciving regular control of effective medication use increased from $29 \%$ at baseline to $74 \%$ at the end of the study $(\mathrm{p}<0.001)$. Within the RNS-subgroup this increase occurred within the first six months after implementation of the programme; within the GP-and the pulmonologist-subgroups the largest improvements were measured after 12-months follow up. The proportion of patients reporting good accessibility of 
Table 2: Patient characteristics at baseline

\begin{tabular}{|c|c|c|}
\hline Variable & Asthuna $(n=658)$ & $\operatorname{COPD}(1+=317)$ \\
\hline Age (yrs) & $54( \pm 17)$ & $61(14)$ \\
\hline $\operatorname{Sex}(\mathrm{m} / \mathrm{f})$ & $270 / 388$ & $178 / 139$ \\
\hline Current smoker $(\%)$ & $43 \%$ & $40 \%$ \\
\hline Pack years & $19( \pm 17)$ & $38 \cdot( \pm 22)$ \\
\hline FEV1 (onpred) & $89.9( \pm 18.9)$ & $56.2( \pm 17,2)$ \\
\hline FVC (opred) & $105.4( \pm 19.2)$ & $83.7( \pm 18.8)$ \\
\hline Tiffeneaumatio & $0.72( \pm 0.14)$ & $0.51( \pm 0.14)$ \\
\hline FEV1 reversibility & $11.5( \pm 4.8)$ & $4.5( \pm 5,9)$ \\
\hline PEF (\%pred) & $92.3( \pm 24.0)$ & $49.1( \pm 14.3)$ \\
\hline Dyspnoea (MR C-score) & $1.84( \pm 0.96)$ & $2.76( \pm 1.17)$ \\
\hline Body Mass lndex $\left(\mathrm{kg} / \mathrm{m}^{2}\right)$ & $26.4( \pm 4.8)$ & $25.1( \pm 4.9)$ \\
\hline Fat Free Mass Index $\left(\mathrm{kg} / \mathrm{m}^{2}\right)$ & $17.7( \pm 2.2)$ & $17,1( \pm 3.5)$ \\
\hline
\end{tabular}

HAll variables are presented as means $( \pm \mathrm{sd}$ ) unless stated otherwise.

Table 3: Lung function

\begin{tabular}{|c|c|c|c|c|c|c|}
\hline \multirow[t]{2}{*}{ Variable } & \multicolumn{3}{|l|}{ Asthima } & \multicolumn{3}{|l|}{ COPD } \\
\hline & Baseline & 12 months & p-value & Baseline & 12 montlis & p-value \\
\hline $\mathrm{FEV}_{1}$ (\%pred) & $89.9( \pm 21.0)$ & $90.5( \pm 17.2)$ & 0.429 & $56.2( \pm 17.2)$ & $55.2\{ \pm 16.2\}$ & 0.079 \\
\hline $\begin{array}{l}\text { FEV, } \\
\text { reversibility }\end{array}$ & $11.5( \pm 4.8)$ & $12.1( \pm 4.3)$ & 0.119 & $4.5( \pm 5.9)$ & $3.3( \pm 3.5)$ & 0.110 \\
\hline Tiffeneau-ratio & $0.72( \pm 0.14)$ & $0.72( \pm 0.11)$ & 0.714 & $0.51( \pm 0.14)$ & $0.52(-0.12)$ & 0.588 \\
\hline
\end{tabular}

\#All variables are presented as means ( 1 sd) unless stated otherwise.

* Health status measured with the SGRQ: '0' indicates no impaiment; '100' indicates toral impairnent.

care increased from $57 \%$ at baseline to $73 \%$ after 12 months $(p=0.017)$, while the proportion of patients reporting good co-ordination of care increased from $63 \%$ to $77 \%$ within this period $(\mathrm{p}=0.010)$. Patient satisfaction improved from circa 7.0 points at baseline to 7.9 points (scale from $1-1.0)$ after 12 months $(p<0.001$ ).

\section{Self care behaviour and disease specific knowledge}

Compliance with the medication regimen improved from $3.2 \pm 0.7$ to $4.3 \pm 0.7$ (on a $0-5$ scale) after 12 -months follow up $(p<0.001)$. Physical activity increased from $1.9 \pm 1.2$ before implementation of the DMP to $2.4 \pm 1.2$ (on a $0-5$ scalle) after one year $(p=0.024)$. The proportion of smokers decreased significantly with on $4 \%$ 
$(p=0.023)$. Disease specific knowledge improved with one point on a scale from 1 to 10 , from $4.6 \pm 2.2$ at baseline $(p<0.001)$. For all three measurements, the effects were the largest in the RNS-subgroup.

\section{Resource utilisation}

The average number of routine follow up consultations doubled within the first six months after implementation of the DMP (from $0.53 \pm 0.74$ to $0.99 \pm 0.65 ; \mathrm{p}=0.017$ ), indicating that the guidelines, advising one routine consultation per three months, were more closely met than before. In the second half year of follow up, this effect was found to be fairly stable with an average of $0.88 \pm 0.62$ routine consultations per three months ( $p=0.092$ between 6 and 12 month values). This effect was entirely driven by the increase in routine consultations among patients assigned to either the GP or the RNS; the number of routine consultations within the pulmonologistsubgroup did not change. The number of non-routine consultations decreased from $1.00 \pm 0.62$ to $0.72 \pm 0.56$ after 1.2 months $(p=0.004)$. In addition, hospitalisation decreased from $0.10 \pm 0.3$ days per three months before implementation of the DMP, to $0.05 \pm 0.2$ days after one year $(\mathrm{p}=0.031$ ). Again, the decrease was the largest in the RNS-subgroup, while also the timing of the effect differed between subgroups. In the RNS-subgroup a significant drop in hospitalisation was observed within the first six months after inclusion (from $0.11 \pm 0.3$ days to $0.06 \pm 0.21 ; \mathrm{p}=0.033$ ), while in the GP-subgroup a decrease in hospitalisation only became apparent between six and 12 months after inclusion. In the pulmonologist-subgroup no significant effect was found with regard to hospitalisation.

Costs for medication increased within the first six months after inclusion with on average $€ 5$ per three months (from $€ 48 \pm 21$ to $€ 53 \pm 31 ; \mathrm{p}=0.024$ ). In the second half year of follow up, medication costs in the GP- and pulmonologist-subgroups returned to baseline values, while in the RNS-subgroup a further increase of circa $25 \%$ was found $(p<0.001)$.

Within six months after inclusion, the number of sick leave days due to asthma or COPD decreased from $0.22 \pm 0.77$ at baseline to $0.10 \pm 0.14$ day $(p<0.001)$. This effect remained stable in the second half year after inclusion with an average sick leave of $0.12 \pm 0.18$ ( $\mathrm{p}=0.081$ between six and 12 month values). The overall decrease in sick leave days was mainly driven by the effect as observed in the RNS-subgroup. In the GP-subgroup a decrease in sick leave days was also observed between baseline and six months follow up, but this was not significant and partly relapsed in the second half year after inclusion. 


\section{End-results of care}

Patient satisfaction improved from circa 7.0 points at baseline to 7.9 points after one year (scale from $1-10 ; p<0.001$ ). Health status did not change significantly in both patient groups. HRQL improved among patients with COPD (from $0.67 \pm 0.15$ to $0.69 \pm 0.14 ; p=0.021$ ), but not for patients with asthma. In both patient groups, healthcare costs decreased although this was only significant among patients with asthma (Table 4).

Table 4: Changes in end results of care between baseline and 12 months follow up

\begin{tabular}{|c|c|c|c|c|c|c|}
\hline \multirow[t]{2}{*}{ Varable $^{\text {if }}$} & \multicolumn{3}{|l|}{ Asthma } & \multicolumn{3}{|l|}{$\mathrm{COPD}$} \\
\hline & Baseline & 12 months & $p^{y-1}$ ad late & Baseline & 12 montins & $p-$ walhe \\
\hline Paricut satisfaction & $6.99( \pm 0.55)$ & $7.90( \pm 0.88)$ & 0.000 & $7.01( \pm 0.57)$ & $7.94(10.91)$ & 0.000 \\
\hline Health stateus & $34.21( \pm 18.6)$ & $34.03( \pm 19.4)$ & 0.640 & $38.82( \pm 18.3)$ & $37.64( \pm 18.5)$ & 0.119 \\
\hline $\mathrm{HRQL}(\mathrm{EQ}-5 \mathrm{D})$ & $0.72( \pm .16)$ & $0.73( \pm .16)$ & 0.432 & $0.67( \pm .15)$ & $0.69)( \pm .14)$ & 0.021 \\
\hline $\begin{array}{l}\text { Anmeal total } \\
\text { healthodre costs } \\
\text { per patient }(E)\end{array}$ & $766( \pm 648)$ & $698( \pm 633)$ & 0.002 & $1423( \pm 1248)$ & $1381( \pm 1213)$ & 0.093 \\
\hline
\end{tabular}

HWariables are presented as means ( $t$ d) unless stated otherwist

\section{Prognostic factors for end-results of care}

Self management education and disease specific knowledge were prognostic factors for patient satisfaction $(\beta=0.146, C I=0.006 ; 0.284, p=0.04$ and $\beta=0.778$, $\mathrm{Cl}=0.004 ; 1.553, \mathrm{p}=0.049$ respectively). A decrease in the number of non-routine consultations as well as improved lung function in terms of FEV, (\%pred) was associated with improved health status $(\beta=0.992, \mathrm{Cl}=0.045 ; 1.940, p=0.040$ and $\beta=$ $-0.241, \mathrm{CI}=-0.019 ;-0.562, \mathrm{p}=0.023$ ). Changes in HRQL could be predicted from disease specific knowledge $(\beta=1.102, \mathrm{CI}=0.546 ; 1.658, \quad \mathrm{p}<0.001)$, compliance $(\beta=0.039, \quad C I=0.002 ; 0.077, \quad p=0.038)$ and productivity loss $(\beta=-0.009$, $\mathrm{CI}=-0.017 ;-0.001, \mathrm{p}=0.034)$. Changes in total costs could be predicted from hospitalisation $(\beta=0.011, C I=0.02 ; 0.02, p=0.017)$ and productivity losses $(\beta=0.021$, $\mathrm{CI}=0.018 ; 0.023, \mathrm{p}<0.001$ ).

\section{DISCUSSION}

The objective of this study was to assess the impact of a DMP for patients with asthma or COPD on process and outcome measures of care and to explore if changes in process, disease specific or intermediate measures could predict changes in end-results of care. 
The introduction of the DMP is associated with significant improvements in several processes and outcomes of care delivery within the existing budgets. Aspects of quality of care, self care behaviour, smoking status, disease specific knowledge and satisfaction of all patients improved after implementation of the programme. Lung function and health status were not affected by implementation of the DMP. For patients with COPD, a stable FEV 1 (\%pred) during one year after implementation was considered a favourable outcome. Furthermore, for patients with COPD a significant improvement in HRQL was found. Among patients with asthma significant cost savings were measured.

Patients consumed more routine consultations and costs for medication increased. Non-routine consultations, hospitalisation and productivity losses decreased after implementation of the programme, indicating improved disease control. The largest impact was observed within the subgroup of patients that were assigned to the RNS. With regard to the second research question we found changes in self management education and disease specific knowledge to be predictive for patient satisfaction. Furthermore, a decrease in non-routine consultations as well as an increase in $\mathrm{FEV}_{1}$ (\%pred) were associated with improved health status. The level of disease specific knowledge, treatment compliance and productivity loss could predict changes in HRQL. Prognostic factors for total healthcare costs are productivity loss and hospitalisation.

The findings in this study are to some extent consistent with results from other studies [1]. Improved patient satisfaction as well as improvements in process measures has often been reported as a result of DMPs $[1,2,4]$. The finding of significantly decreasing costs as observed among patients with asthma, is less common. To a large extent this might be caused by the fact that varying perspectives are taken on costs, which makes comparison with other studies difficult [4]. Furthermore, power calculations are usually based on one specific clinical parameter as primary outcome, not on healthcare costs. Since costs are typically characterised by relatively high levels of uncertainty [21], often too few patients are included to detect any significant changes on this parameter.

Although a sufficient number of patients was included to detect small changes in patient satisfaction, heal th status, HRQL and healthcare costs, the effects of this study cannot simply be assigned to the DMP, since no parallel control group was available. Theoretically, the effects that were found could also be caused by other changes in healthcare [5]. In this respect, it is important to notice that the observed improvements in almost all process and outcome measures occurred directly after the implementation of the programme (especially in the RNS-subgroup). To our knowledge no other changes in healthcare or specific co interventions occurred during this time period that could have caused improvements of comparable magnitude. For example, the decrease in hospitalisation of $50 \%$ would not be expected given the natural course of either asthma or COPD. More importantly, discharge policy for 
patients with asthma or COPD also did not change during follow up. Furthermore, we observed a decrease of $54 \%$ in the number of sick leave days within six months after implementation of the programme, while an overall decrease in sick leave of 15-18\% was registered between 2002 and 2003 in the Netherlands [22].

An assumption made in this study is that the DMP has equal effects on processes of care for patients with asthma or COPD. Given the natural course of these diseases, this might not be true. However, since the programme did not interfere in the contents of the provided medical treatment, but rather stimulated to use disease specific evidence based treatment guidelines, we strongly believe that within the timeframe of the study no major bias occurred due to this assumption.

We realise that generalisability of study results is difficult when interventions are designed to fit into local healthcare structures. Providing a careful description of the programme and explicitly paying attention to the contrasts with usual care should alleviate this to some extent. Insight into the relation between organisational factors and demographical dynamics on the one hand and outcomes of care on the other would help to assess generalisability more thoroughly and herewith facilitate the decision making process.

Taking all strengths and weaknesses of the study into consideration, the recommendation is to implement DMPs for patients with asthma or COPD, in which respiratory nurse specialists play a key role, on a larger scale. Attention needs to be paid to adequate incorporation of the programme into (local) healthcare structures, as well as a careful description of the processes and function of its components. Further research is needed to investigate the relationship between structure, process and outcomes of healthcare, guiding the choice for indicators to be measured when evaluating DMPs. This should lead to objective information, which is timely available and useful for decision-making on different levels.

\section{CONCLUSION}

In the region under study, redesigning care for adults with asthma or COPD according to principles of disease management was associated with significant improvements in several processes and outcomes of care. Aspects of quality of care, self care behaviour, smoking status, disease specific knowledge and satisfaction of all patients improved after implementation of the programme. Lung function and health status were not affected by implementation of the DMP. Furthermore, for patients with COPD a significant improvement in HRQL was found. Significant cost savings were measured among patients with asthma.

The impact of the programme was largest within the subgroup of patients that were assigned to the RNS. Moreover, it was found that changes in self management education, disease specific knowledge, compliance, non-routine consultations, 
hospitalisation, medication costs and productivity loss could predict changes in end results of care, which are better suitable for decision-making on a macro level.

\section{REFERENCES}

1. Bodenheimer $T$, Wagner $E H$, Grumbach $K$. Improving primary care for patients with chronic illness. The chronic care model, part 2. JAMA 2002;288:1909-14.

2. Ofman JJ, Badamgarav E, Henning JM, Knight K, Gano AD, Levan RK, Gur-Arie S, Ruchards MS, Hasselblad V, Weingarten SR. Does disease management improve clinical and economic outcomes in patients with chronic diseases. Am J Man Care 2004;117:182-92.

3. Disease Management Association of America: www.dmaa.org Last accessed: 14 April, 2005.

4. Holtz-Eakin D. An analysis of the literature on disease management programs. Congressional Budget Office, U.S. Congress, Washington DC 2004. www cbo.gov Last accessed: 14 April, 2005.

5. Cook TD, Cimpbell DT. Quasi-experimentation: design and analysis issues in field settings. Boston, USA: Houghton Mifflin, 1979.

6. Pauwels RA, Buist S, Calverly PMA, Jenkins CR, Hurd SS. Global Strategy for the Diagnosis, Management and Prevention of Chronic Obstructive Pulmonary Disease. NHLBI/WHO Global Initiative for Chronic Obstructive Lung Disease (GOLD) Workshop Summary. Am J Resp Crit Care Med 2001;163:1256-76.

7. Masoli M, Fabian D, Holt S, Beasley R for the Global Initiative for Asthma (GINA) Program. The global burden of asthma: executive stmmary of the GINA Dissemination Conmittee Report. Allergy 2004:59:469-78.

8. Dutch College of General Practitioners http://nhg artsennet.nl/upload/104/standaarden/M26/start.htm Last accessed: 14 April, 2005. [in Dutdi]

9. Dutch College of General Practitioners http://nhg.artsennet.ml/upload/104/stindaarden/M27a/start.htm Last accessed: 14 April, 2005. [in Dutch)

10. Dutch College of General Practitioners hetp://nhg.artsemnet.nl/upload/104/standaarden/M27b/start.litm Last accessed: 14 April, 2005. [in Duthly

11. Donabedian A. The definition of quality and approaches to its assessment. Ann Arbor, Mich: Health Administration Press, 1980. voll 1.

12. Lamb G. Outcomes across the care continuum. Med Care 1997:35(11) Suppl: NS106-NS114.

13. Patrick DL. Finding health-related quality of life outcomes sensitive to health care organization and delivery. Med Care 1997;35(11) Suppl: NS49-NS57.

14. Van Campen C, Sixma HJ, Kerssens JJ, Peters L. Assessing noninstitutionalized asthma and COPD patients" priorities and perceptions of quality of health care. J Asthma $1997 ; 34(6): 531-538$.

15. Deenen ThAM. Patient health-education and self-management: a medical-psychological intervention study on severe asthma and COPD in a high altitude clinic. Dissertation. Rijksuniversiteit Groningen, 1996. 
16. Jones PW, Quirk FH, Baveystock CM. Littlejohns P. A self-complete measure of healh status for chronic aiflow limitation: the St. George Respiratory Questionnaire. Ant Revof Respir Diseases 145:1321-7.

17. The EuroQoL Group. EuroQoL-a new facility for the measurement of health-related quality of life. Health Policy 1990;16(3):199-208.

18. Oostenbrink 1B, Koopmanschap MA, Rutten FFH. [Guidelines for economic exaluations: methods and standard cost prices for economic evaluations in health care. Handleiding voor kostenonderzoek: methoden en standard kostprijzen voor economische evaluaties in de gezondheidszorg. Geactualiseerde versie 2004. Anstelveen: College voor Zorgverzekeringen, 2004. [im Dutch]

19. Hollis $S$, Campbell F. What is meant by intention to treat analysis? Survey of published randomised trials. BMJ 1999;319:670-4.

20. Twrisk JWR. Applied longitudinal data analysis for epidemiology: a practical guide. Cambridge, UK: Cambridge University Press, 2003.

21. Briggs AH, McGray A. Methods in health service research: handling uncertainty in economic evaluations of healthcare interventions. BMJ 1999;319:635-8.

22. Central Office of Statistics: http://statine.cbs.nl/StatWeb Last accessed: 14 April, 2005. fim Dutchl 



\section{A DISEASE MANAGEMENT PROGRAMME FOR PATIENTS WITH DIABETES MELLITUS IS ASSOCIATED WITH IMPROVED QUALITY OF CARE WITHIN EXISTING BUDGETS}

L.M.G. Steuten, H.J.M. Vrijhoef, S. Landewé-Cleuren, N. Schaper, G.G. Van Merode, C. Spreeuwenberg 


\section{ABSTRACT}

Objective: to assess the impact of a disease management programme (DMP) for patients with diabetes mellitus on cost effectiveness, quality of life and self care behavjour.

Methods: quasi-experimental design with two-year follow-up among 473 patients. Intervention: DMP aiming to increase quality of care within existing budgets.

Results: substantial significant improvements in glycaemic control, health-related quality of life (HRQL), compliance and most aspects of self care behaviour were found. No significant changes were measured concerning total costs of care. The probability that the DMP is cost effective compared to usual care is $74 \%$, saving on average $€ 1.18$ per additional life year, while HRQL improved with $5 \%$.

Conchusion: introduction of a DMP for diabetics is associated with improved (intermediate) outcomes within existing budgets. Further research should focus on long-term cost effectiveness, including diabetic complications and mortality in a controlled setting or by using decision-analytic modelling techniques. 


\section{INTRODUCTION}

In the last decade, disease management programmes (DMPs) for patients with diabetes mellitus have gained attention in the belief that redesigning healthcare according to principles of disease management would improve patient outcomes and mitigate costs [1-3]. Thorough evaluation of the impact of DMPs on processes and outcomes of care is important, since the prevalence of cliabetes and the burden of diabetes-related costs on scarce healthcare resources are rising [4].

A population-based DMP, aiming to increase quality of care within existing budgets by integrated care delivery, has been developed and implemented in the region of Maastricht (the Netherlands) [5]. The programme concerns all patients with diabetes type 1 or 2 that are known by the general practitioner (GP), who is the gatekeeper of the Dutch healthcare system. Main features of this programme are: use of evidence based guidelines, central co-ordination of care, assignment of patients to either the GP, diabetes nurse specialist (DNS) or endocrinologist according to complexity of problems, and central data collection with yearly personal feedback. In addition, special attention is given to the role and training of the DNSs. The DNSs, who see patients in the practices of the GPs, function as a liaison between the endocrinologists working in the hospital and the GPs. Apart from the diagnostic and therapeutic tasks listed in the (inter)national guidelines for endocrinologists and GPs, the DNSs pay specific attention to patient education and promotion of self-management.

Until now, many DMPs have been introduced without critical evaluation of the actual value of such programmes. Recently, the US Central Budgetary Office published a report stressing that "to date there is insufficient evidence to conclude that DMPs can generally reduce the overall cost of healthcare services". Most studies do not directly address costs [6], while no significant improvements are shown on outcomes like mortality, hospitalisation, patient satisfaction, patient knowledge, and patient compliance [7]. As a result, decision-making regarding the allocation of scarce resources for this purpose is difficult. Apart from methodological problems in evaluating such comprehensive programmes [8], this is also due to the fact that definitions and components of DMPs vary widely. Failure to recognise this may lead to inappropriate conclusions about cost effectiveness of these programmes [9].

This study reports on the impact of a DMP, for patients with diabetes mellitus, on the cost effectiveness, health-related quality of life (HRQL) and self care behaviour, as compared to usual care, during a period of two years. The uncertainty surrounding the decision to choose the optimal strategy in terms of cost effectiveness is explicitly evaluated in order to support decision-making concerning adoption or rejection of DMPs for patients with diabetes. 


\section{METHODS}

\section{Patients and setting}

The DMP was implemented in the region of Maastricht (the Netherlands) encompassing circa 120.000 mhabitants. Currently, 63 of 90 GPs are taking part in the DMP. Between April 2001 and February 2002, a convenience sample, of nine general practices (12 GPs) and the outpatient department of the hospital, was approached for participation in the study. Subsequently, patients with a diagnosis of diabetes mellitus and aged $\geq 16$ years were invited to participate. Since the programme aimed to cover the entire population of diabetics (including patients with complications and/or co morbidity), only patients with severe co morbidity such as pre-teminal renal failure or carcinoma and/or patients needing dialysis were excluded.

\section{Study design and procedures}

A one-group pre-post test design was applied [10], since the programme was implemented region-wide and a 'fair' comparison region could not be found. In all potential comparison regions, innovations were being implemented that would bias the measure of usual care.

After obtaining written informed consent, all patients (including those treated by the endocrinologist at the outpatient department of the hospital) were invited for an initial consultation, carried out by the DNS within the office of the GP. During this consultation the DNS registered demographic and clinical characteristics of each patient and made an inventory of previous and/or current complications such as, vascular complications, retinopathy, neuropathy, hypertension, etcetera.

Based on these data, a core team (GP, endocrinologist, DNS) confimed or reconsidered the diagnosis. They classiffed disease severity and required intensity of care in accordance with national and international guidelines [11-13], leading to a proposa] concerning the assignment of the patient to either the GP, the DNS or the endocrinologist. If patients agreed with the assignment proposal, those with newly diagnosed diabetes mellitus type 1 or poorly regulated diabetes type 1 or 2 with serious complications or co morbidity were assigned to the endocrinologist. Patients with stable diabetes mellitus using insulin and/or suffering from serious (psychosocial) complications, with which the GP did not have sufficient experience (as judged by the GP), received quarterly outpatient appointments with the DNS within the practice of the GP. All other patients were assigned to the GP.

A multidisciplinary disease management protocol was developed based on (inter)national guidelines for diabetes managennent $[11-13]$. All care providers involved in the DMP were encouraged to follow this protocol, herewith increasing 
uniformity in treatment policy. The contrast between usual care and the care by the DMP concemed central coordination, uniform treatment policy, re-assigninent of patients, introduction of the DNS in this role and structural feedback. Within usual care, patients were either managed by the GP or the endocrinologist, while no structural feedback systems existed.

\section{Data collection}

As indicators of effectiveness, several clinical parameters, HRQL and self care behaviour were measured. Also, data on resource use were collected to assess the direct and indirect costs of care [14].

Data collection covered a period of six months before patients entered the programme and 24 months afterwards. Laboratory data $\left(\mathrm{Hb}_{4 c}\right.$, blood pressure, cholesterol, etcetera) and clinical data were obtained from caregivers' registries. All other data were collected by means of postal questionnaires. Resource use was measured retrospectively every six months, starting at entry of the programme. Clinical data, laboratory data as well as data on HRQL and self care behaviour were collected immediately prior to entry (TO) and after 24 months (T1).

\section{Outcome measures}

The main clinical outcome measure was change in glycaemic control, defined as the change in glycated haemoglobin level $\left(\% \mathrm{Hb}_{1 c}\right)$. Glycaemic control was evaluated as the proportion of patients with good $\left(\mathrm{HbA}_{1 c}<7.0 \%\right)$, moderate $(7.0 \%$ $\left.\leq \mathrm{HbA}_{1 c}<8.5 \%\right)$ or poor control $\left(\mathrm{HbA}_{1 c} \geq 8.5 \%\right)[13]$. Clinical status was further determined by systolic and diastolic blood pressure, Body Mass Index $\left(\mathrm{kg} / \mathrm{m}^{2}\right)$, total cholesterol concentration and high density lipoprotein. All laboratory measures were performed by standard techniques in one laboratory.

HRQL was measured with a Dutch version of the SF-36. SF-36 scores range between 0 and 100 , with a higher score indicating a better health related quality of life $[15,16]$. In addition, a Visual Analogue Scale (VAS), a single-item measure of quality of life, was applied. Self care behaviour of patients was measured using the Self care Behaviour Checklist (SCBC), a validated Dutch diabetes-specific instrument [17]. The SCBC comprises four domains: dietary advice, self-control of glucose levels, physical activity and self-performed foot control. Scores for each domain were computed (range 0-5). Compliance with medication schemes, also scored on a five-point Likert scale, was measured with three items referring to the extent to which patients adhere to the scheme and take either more or less medication than prescribed. Scores were computed as the sum score of the three items (range 3-15). 


\section{Statistical analysis}

All presented analyses were based on intention to treat, while missing response was handled by using the last observed response (carry forward procedure) [18]. Before-after comparisons were analysed using paired-samples $T$-tests and Wilcoxon signed ranks tests (wo-sided; $\alpha=0.05$ ) where appropriate. Post-hoc subgroup analyses were performed to assess the relative contribution of each patient group, as assigned to one type of care provider (GP, DNS, endocrinologist), to the overall effect of the programme. All data are presented as means ( $t$ sd) unless stated otherwise, Data processing and analyses were perforned using SPSS 12 for Windows.

\section{Economic evaluation}

The economic evaluation was carried out from a societal perspective, meaning that all healthcare costs related to diabetes were included in the analysis. Cost calculations were based on actual resource use, measured with a 15 -item questionnaire and verified with administrative data from care providers. Direct healthcare costs were calculated using current prices, when avalable, or tariff $[19]$. For costs of medication, cost prices, as provided in the Dutch Pharmacotherapeutic Compass, were applied. Productivity losses were measured in terms of sick leave days and calculated using the age-dependent friction cost method [20]. Overhead costs comprise costs for the employment of a medical and project coordinator, continumg education of the DNSs, costs of an administrative support office, maintenance costs of the electronic patient record system, telephome and travel costs of the DNSs and salary costs of the unit leader. Not included in this analysis were costs concerning informal care provided by family members, long-term disability and premature death, since information on these paraneters was not avaliable. The number of quality-adjusted life years ( $Q A L Y s$ ) was adopted as outcome measure for effectiveness as it incorporates both effects on survival and quality of life in a single index [21]. QALYs are the arithmetic product of the life duration and the quality of life score (using VAS-scores), meaning that one year of life with a VAS-score of 0.60 would result in 0.60 QALYs produced. Since the follow up was limited to two years, the product of the VAS-score times the duration of life up to two years represents the QALYs produced for each subject.

The difference in number of QALYs generated by the two strategies, i.e. usual care and DMP, and the difference in overall costs were used to produce the cost/QALY ratio. This value, being the ratio of two differences that each may not have a nomal distribution, has an unknown sampling distribution. Therefore, it is necessary to estimate the sampling distribution around the point estimate using non-parametric methods. This is employed by bootstrapping 1,000 further hypothetical incremental cost/QALY ratios based on the original data pools from all patients. For this, the whole of the costs and QALY data pools are repeatedly re-sampled (at random, 300 
times) to produce new estimates of mean costs and QALYs for both strategies. The resulting estimates of the differences in costs and QALYs are plotted on the costeffectiveness plane [22]. This plot provides an empirical estimate of the sampling distribution of the cost/QALY ratio and can be used, for instance, to determine the probability that the DMP will provide an increase in QALYs at lower costs. This probability is calculated by the proportion of estimates ending-up in the southeast quadrant, indicating an increase in QALYs at lower costs. Subsequently, it is determined whether or not the DMP is considered cost effective. This firstly depends on its absolute cost effectiveness ratio and secondly on the most expensive cost effectiveness ratio that a decision maker would consider to be a reasonable investment. If the highest or 'ceiling' cost effectiveness ratio that a policy maker is willing to accept for a new DMP is known, the proportion of bootstrap estimates equal to or below this ratio will represent the probability that the intervention is cost effective according to the policy maker's definition. Since the ceiling value (lambda) of the cost effectiveness ratio is not known, this process is repeated for a range of possible ceiling ratios and expressed by the cost effectiveness acceptability curve [23].

\section{Sensitivity analysis}

The following input parameters were univariately varied to assess the robustness of the findings: 1) consultations costs, 2) medication costs, and 3) costs for hospitalisation. Two-year follow up values of consultation, medication and hospitalisation costs were varied with $\pm 20 \%$ percent. Subsequently, productivity losses were excluded from the analysis to address the insurance perspective.

\section{RESULTS}

\section{Patient inclusion and response rates}

Based on GP and hospital registries, 521 patients were found eligible, 473 of who agreed to participate in the study (91\%). The mean age of patients was 69 years; the average duration of diabetes $9.8 \pm 6.8$ years. Half of the patients were male, $67 \%$ had diabetes type 2 and $23 \%$ were current smokers. Of the included patients, $12 \%$ was assigned to the endocrinologist, $34 \%$ to the DNS and $54 \%$ to the GP. Although this assignment was altered substantially after two years, with $11 \%$ of the patients assigned to the endocrinologist, $66 \%$ to the DNS and $23 \%$ to the GP, the results of these patients were subscribed to the initial assignment group (intention to treat).

Clinical data were available for $82 \%(n=386)$ of the patients after a 24 -month follow up. Data from questionnaires were available from 319 patients at $T=0(67 \%)$ and 245 patients at $\mathrm{T}=1(52 \%)$. The two main reasons for not returning the questionnaires 
were unwillingness to complete any questionnaire (also directly at the start of the stady) and loss of interest. Patients that did not respond to the questionnaires were more likely to be assigned to the $G P(p<0.05)$, had on average lower $H B A_{1}$ values $(\Delta-0.7 \pm 0.02 ; p<0.05)$ and the duration of diabetes was as $1.5 \pm 0.03$ years shorter $(\mathrm{p}<0.05)$.

\section{Clinical parameters}

Mean $H$ b $A_{1}$ of all patients, being $7.5 \pm 1.3$ at baseline, had improved significantly with $-0.2 \pm 1.2(\mathrm{p}<0.001)$ after 24 months (Table 1$)$. The proportion of patients with poor glycamic control decreased with $15 \%$, while the proportion of patients with moderate control increased with $40 \%$. The $25 \%$ decrease in the proportion of patients with good glycamic control (Table 1) is the result from the decrease in glycaemic control among patients assigned to the GP. This deterioration in glycamic control was the main reason for re-assigning a substantial part of these patients to the DNS. In general, total cholesterol and HDL-level decreased significantly, as did systolic and diastolic blood pressure. No significant changes in BMI were observed in any of the subgroups.

\section{Health-related quality of life}

VAS-scores increased significantly from $5.4 \pm 2.4$ at baseline to $5.8 \pm 1.5(p=0.002)$. This effect was mainly driven by the large improvement within the DNS-subgroup

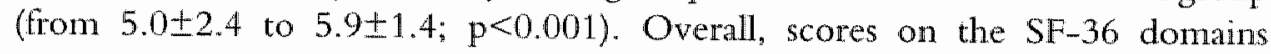
increased from $65 \pm 16$ to $70 \pm 8(\mathrm{p}<0.001)$. The largest improvement was found on the domain 'general health' (from $54 \pm 11$ to $63 \pm 12 ; \mathrm{p}<0.0001$ ); the smallest on the domains 'role limitation physical' and 'physical functioning' (both $\Delta+2$; $p>0.05$ ).

\section{Self care behaviour and compliance}

Scores for compliance, dietary adherence, glucose self-control and foot control improved significantly with, on average, $15 \% \pm 6 \%$ on the Likert scalles. Scores for physical activity did not change. Improvements with regard to compliance and foot control were mainly driven by the improvements in the DNS-subgroup (compliance $\Delta+11 \%, p=0.000 ;$ foot control $\Delta+24 \%, p=0.000$ ).

\section{Costs and cost-utility}

Overall, the number of diabetes-related consultations with GPs and endocrinologists decreased while more (routine) consultations with the DNS took place. Among the patients assigned to the DNS, this led to a significant rise of consultation costs. 


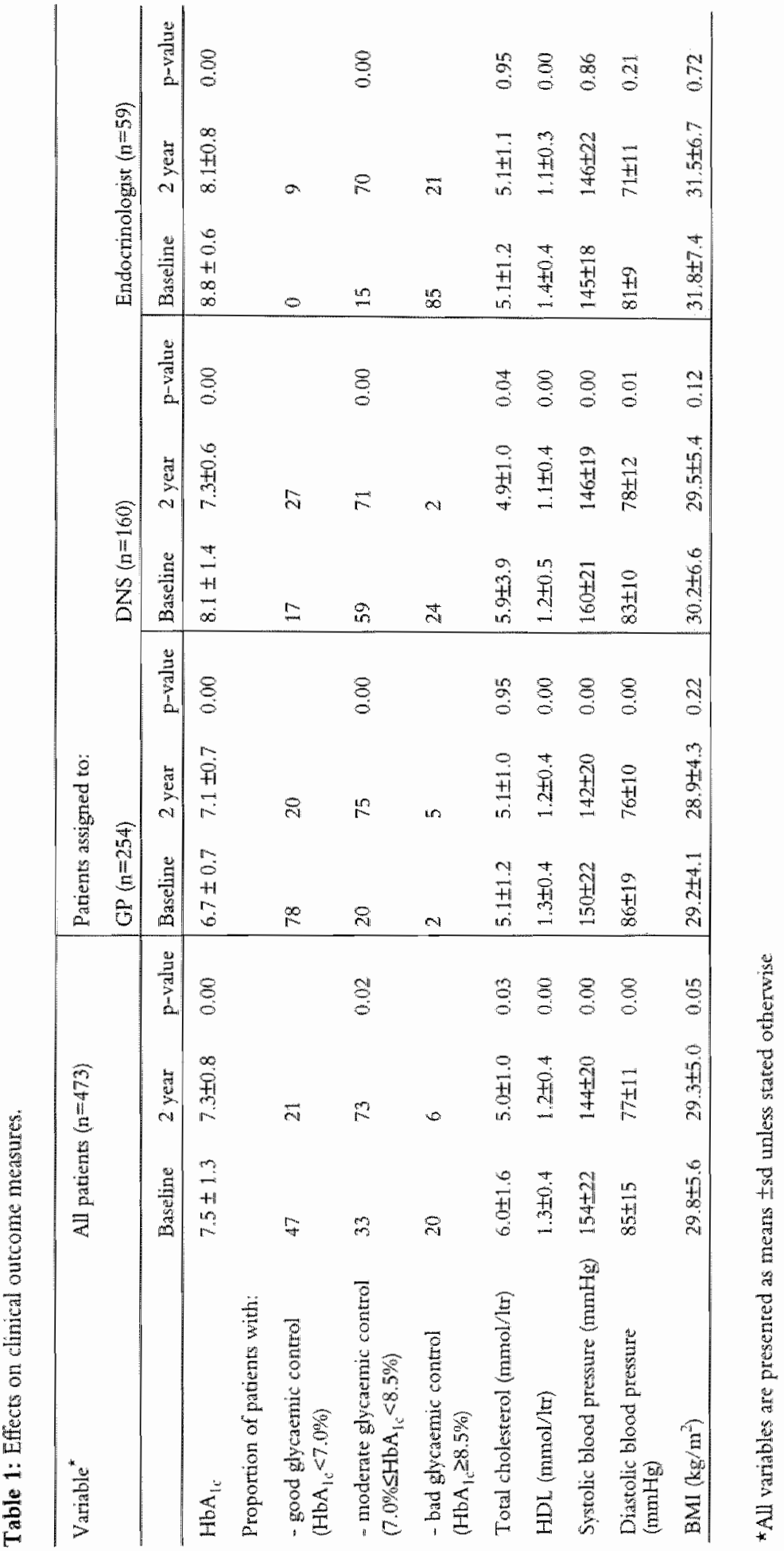




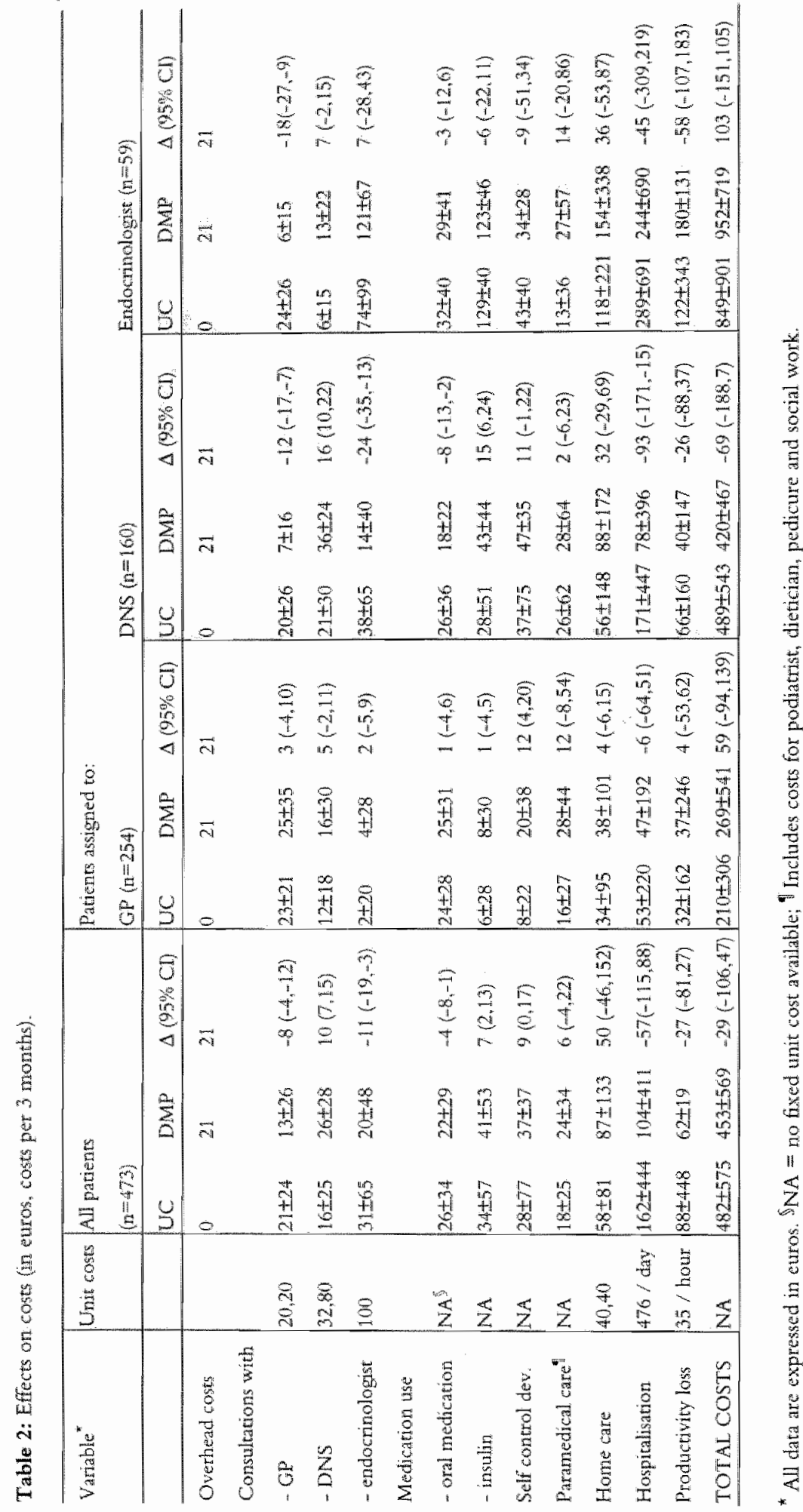


Patients assigned to the GP started to use more self care devices. Patients assigned to the DNS used less oral medication but more insulin. Additionally, a $54 \%$ decrease in hospitalisation costs was found within the DNS-subgroup. Total costs did not change significantly within the two-year period (Table 2).

The cost effectiveness plane in figure 1 shows that the DMP is the dominant strategy in $74 \%$ of the bootstrap simulations, saving on average $€ 118$ per patient per year while HRQL increases with $5 \%$. Furthermore, cost effectiveness planes for each subgroup, as defined by assignment, are presented in Figures $2-4$. These planes show how each subgroup contributes to the overall effect of the DMP. It can be seen that within the DNS-subgroup the least uncertainty concerning cost effectiveness exists (Figure 3). The cost effectiveness acceptability curve in Figure 5 indicates that, when policy makers are willing to pay $€ 3,000$ for an additional QALY, the probability that the DMP is cost effective increases from $74 \%$ to circa $90 \%$.

\section{Results sensitivity analysis}

The DMP remained the most cost-effective strategy in all sensitivity analyses. Decision uncertainty surrounding overall cost effectiveness was most sensitive to changes in productivity losses, followed by consultation costs and cost for hospitalisation. Decision uncertainty was the least sensitive to changes in medication costs. After excluding productivity losses from the analysis, the percentage of bootstrap simulations that indicates the DMP to be dominant compared to usual care decreased from $74 \%$ to $64 \%$, suggesting that the benefits of the DMP extend beyond the healthcare system.

\section{DISCUSSION}

The objective of this study was to assess the impact of a DMP for patients with diabetes mellitus on cost effectiveness, HRQL and self care behaviour, as compared to usual care, during a two-year period. In general, the introduction of the DMP is associated with improvements in glycaemic control, except for patients assigned to the GP. Although room for improvement was limited in this subgroup of patients, given their relatively low values of $\mathrm{HbA} 1 \mathrm{c}$ at baseline $(6.7 \pm 0.7 \mathrm{~mm} \mathrm{Hg})$, the deterioration of glycaemic control was still worrying and led to re-assignment of a substantial part of the patients from the GP to the DNS.

Furthermore, both VAS and SF-36 scores showed a significant improvement in HRQL. Overall, compliance and self care behaviour improved after introduction of the DMP, except with regard to physical activity. This might be explained by the relatively high mean age of the study population. Total costs did not change signifi- 


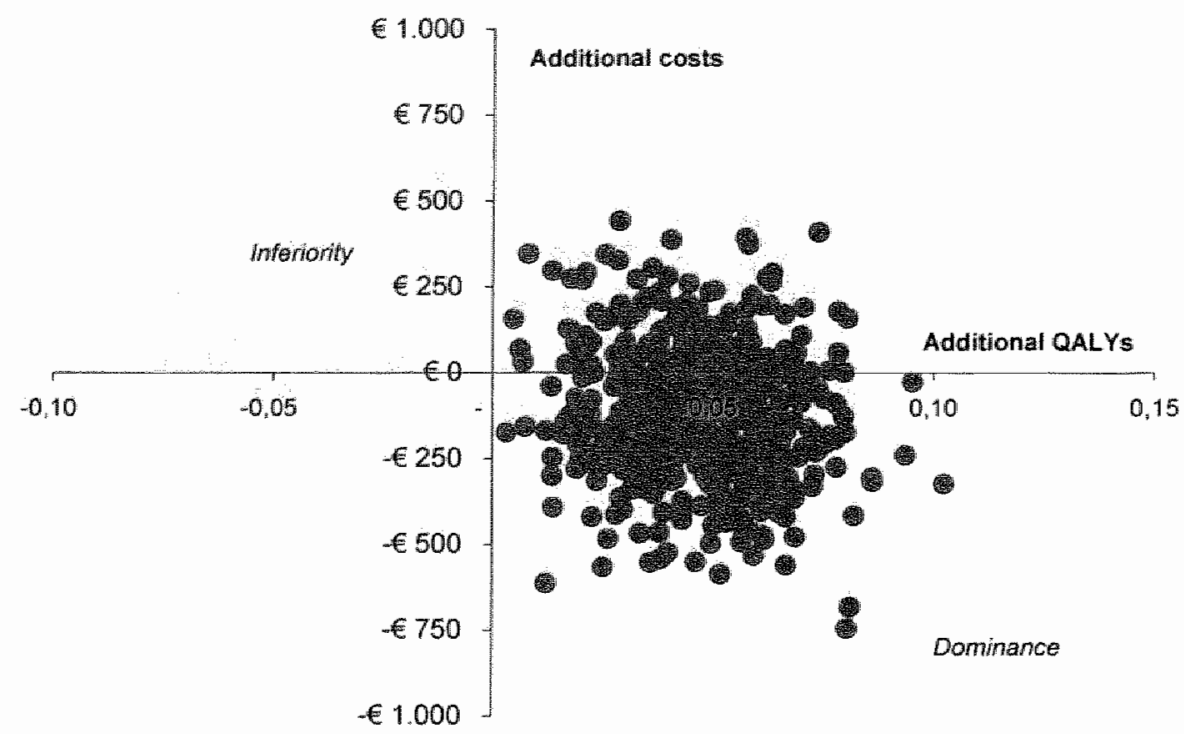

Figure 1: Cost effectiveness plane of usual care versus diabetes disease management

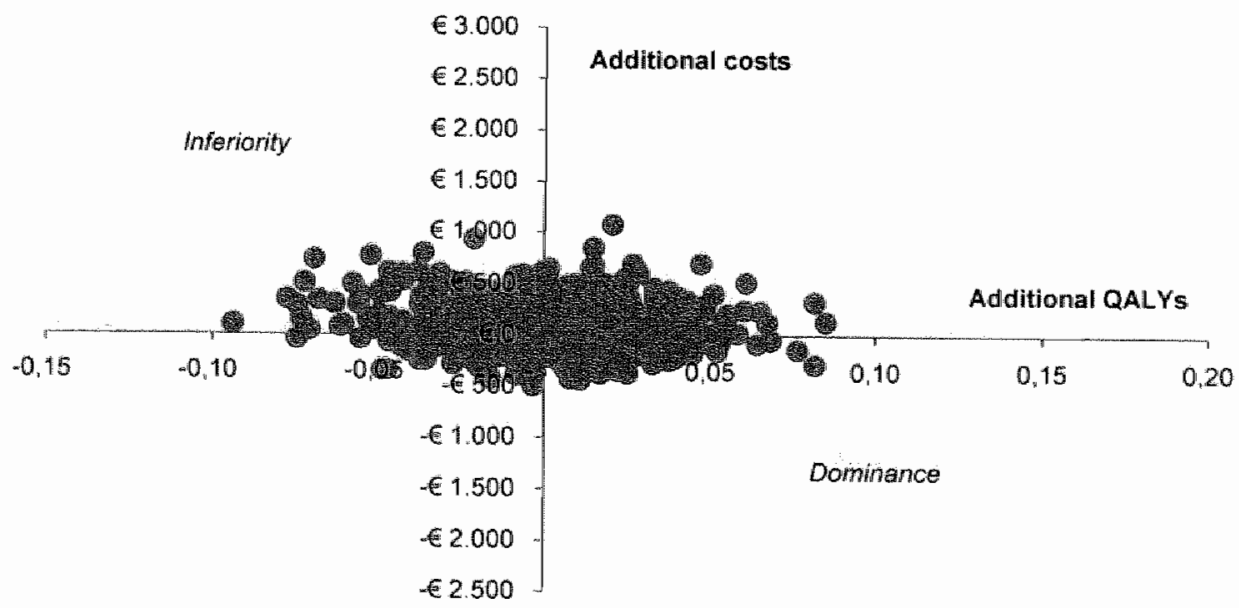

Figure 2: Cost effectiveness plane for GP subgroup only 


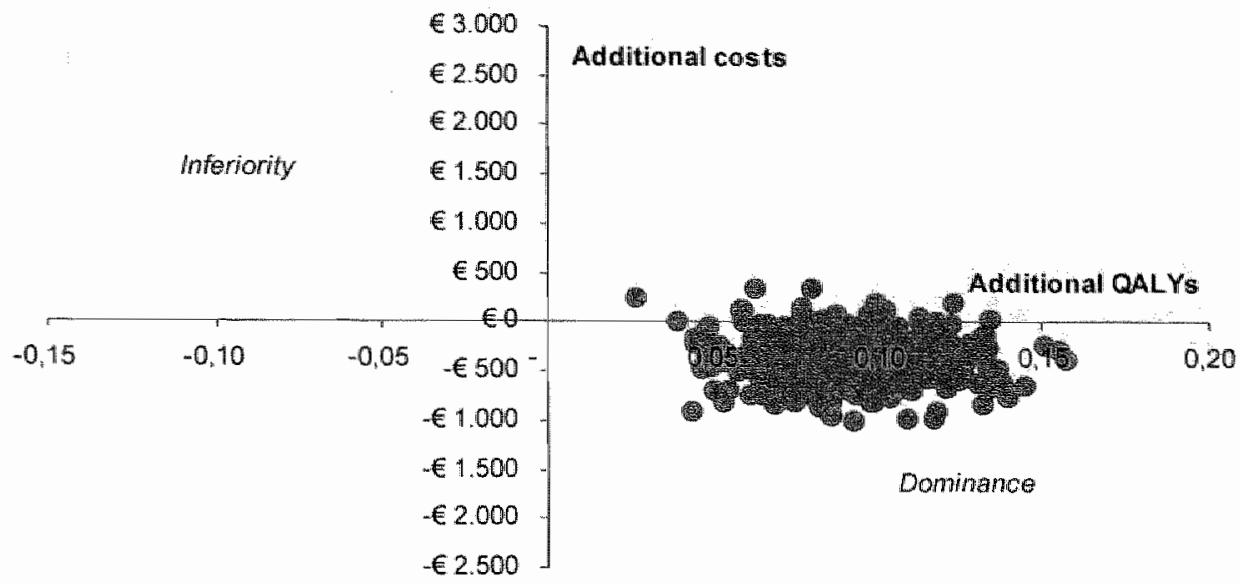

Figure 3: Cost effectiveness plane for DNS-subgroup only

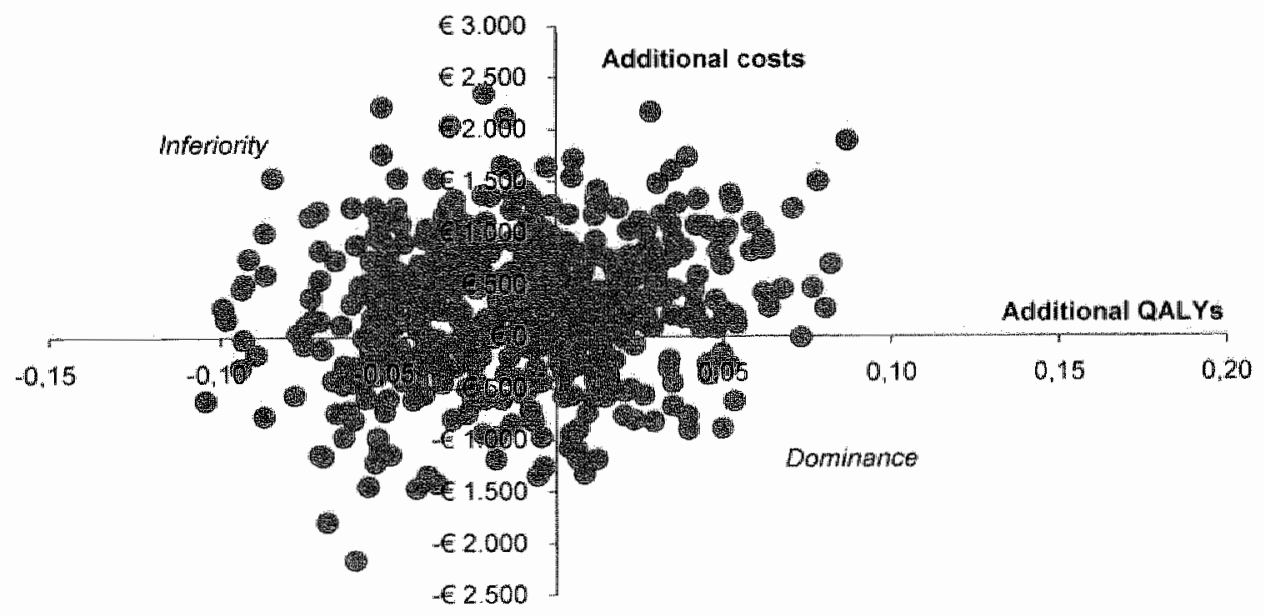

Figure 4: Cost effectiveness plane for endocrinologist subgroup only 


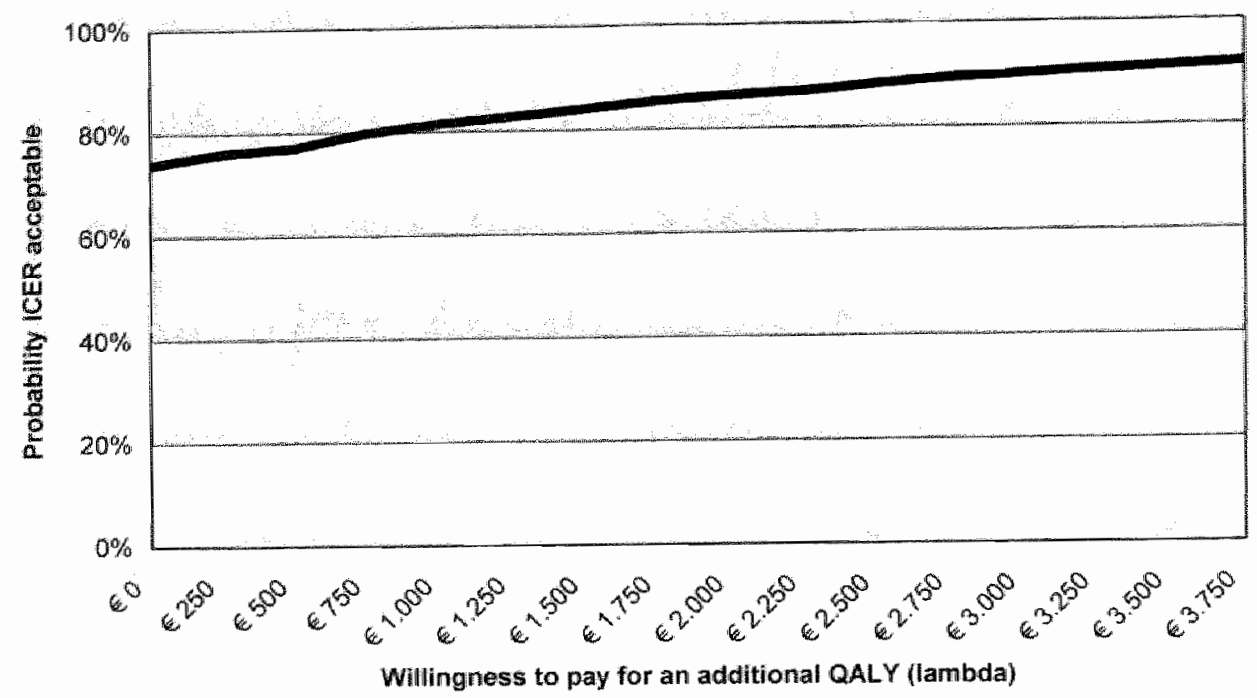

Figure 5: Cost effectiveness acceptability curve

cantly within the two-year period, although hospitalisation costs in the DNS-subgroup were significantly lower.

Since the SF-36 was not devised for use in economic evaluations [24], the VAS scores, representing the most conservative estimations of HRQL gained, were used to analyse cost utility in terms of costs per QALY. The DMP proved to be the "dominant' strategy in $74 \%$ of simulations, meaning that there is a probability of $74 \%$ that the disease management strategy for patients with diabetes improved HRQL while saving money as compared to usual care. When taking the results on the other outcome parameters into account, the DNS-subgroup seems to benefit the most from the introduction of the DMP. This is an important finding with regard to decision-making, since the stratification of the patient population by disease severity and the key-role of the DNS within the collaborative practice model are the most important differences with usual care. The increased attention to patient education and promotion of self-management probably plays an important tole herein, as does the combination of nursing and medical skills of the nurses. Also, adherence to the protocol is highest within the DNS-group, which might further explain the beneficial effects found among these patients. Although the DMP under study can not yet be considered a 'full service' DMP as defined by the Disease Management Association of America [25], it is already cost effective by intervening in the process of care 
Given the limitations of the study design, however, no causal relationship between the introduction of the DMP and the observed changes in costs and effects of eare can be demonstrated. Since no comparable parallel control group was available, the results of this study might be biased by, for example, regression to the mean [27]. Without underestimating the power of this phenomenon, we are confident that the observed results can, at least to a large extent, be attributed to the introduction of the DMP. Regression to the mean, for example, would have biased the results in all patients; not only of those patients that were assigned to the DNS in which the largest changes were observed. Also, no co interventions that could interfere with our measurements (e.g. changes in discharge policy, introduction of screening programmes or availability of new drugs) occurred during the study period. Furthermore, given the magnitude of the observed changes in, for example, glycaemic control, self care behaviour and an average decrease in hospitalisation costs of $54 \%$ among patients assigned to the DNS, we believe this cannot be explained by the natural course of the disease or by (inter)national trends. Another concem of this study is the missing values. Although response and completion rates were common for longitudinal studies with chronically ill, the missing data selectively affect measurements within the disease management strategy. However, since patients with missing data were more likely to be those patients having relatively high $\mathrm{HRQL}$ and lower costs, i.e. patients assigned to the GP, the estimates of costs and effects of the DMP are underestimated, if anything.

Considering the constraints of this study, it is recommended to implement DMPs in which nurse specialists play a key-role on a wider scale and focus further research on the long-term cost effectiveness of DMPs, including diabetic complications and mortality, in either a controlled setting or by using decision-analytic modelling techniques.

\section{CONCLUSION}

The introduction of a DMP for patients with diabetes mellitus is associated with improvements in several outcome measures within existing budgets. Except for patients assigned to the GP, glycaemic control improved significantly as did HRQL, compliance and most aspects of self care behaviour. No significant changes were measured concerning total costs, although a $54 \%$ decrease in hospitalisation costs within the DNS-subgroup was measured. With regard to cost effectiveness, the disease management strategy proved dominant compared to usual care in $74 \%$ of bootstrap sinulations, saving on average $€ 118$ per additional life year, while HRQL increased with $5 \%$. 


\section{REFERNCES}

1. Wagner EH. Chronic disease management: what will it take to improve care for chronic illness? Eft Chin Pract 1:2-4, 1998.

2. Bodenhemer. $T$, Wagner $E$, Grumbach $K$. Improving primary care for patients with chronic illnes: the chronic care model. JAMA 288:1775-9, 2002.

3. Bodenheiner $T$, Wagner $E$, Grumbach $K$. Improving primary care for patients with chronic illwess: the chronic care model, part 2. JAMA 288:1909-14, 2002.

4. Zhang P, Engelgau MM, Norris SL, Gregg EW, Narayan KM. Application of economic analysis to diabetes and diabetes care. Ann Intern Med 140:972-9, 2004.

5. VrijhoefH], Spreeuwenberg C, Eijkelberg IM, Wolfenbuttel BH, Van Merode GG. Adop tion of disease management model for diabetes in region of Maastricht. BMJ 323:983-5, 2001.

6. Holkz-Eakin D. An analysis of the literature on disease management programs. Washington, DC, U.S. Congressional Budget Office, 2004. Available from http://www.cbo.gov Accessed 9 August 2005.

7. Kuight $\mathrm{K}$, Badamgarav $\mathrm{E}$, Henning JM et al. A systematic review of diabetes disease management programs. Am J Manag Care 11(4):242-50, 2005.

8. Steuten LM, Vrijhoef HJ, Van Merode GG, Severens JL, Spreeuwenberg C. The Health Technology Assesment-Disease Management instrument reliably measured methodologic quality of health technology assessments of disease management. J Clin Epidemiol 57:881-8, 2004.

9. Ouwens M, Wollerheim H, Hermens R, Hulscher M, Grol R. Integrated care programmes for chronicaly ill patients: a review of systematic reviews. Int J for Quality in Health Care 17:141-146, 2005.

10. Cook TD, Campbell DT. Quasi-experimentation: design and analysis issues in field settings. Chicago, Rand McNally College Publishing, 1979

11. American Diabetes Association (ADA). Clinical practice guidelines 2003. Diab Care 26(Suppl 1):S1-\$156, 2003.

12. Dutch College of General Practitionets /Nederlands Huisartsen Genootschap/. Available from http://uhg.artsemet nl/upload/104/standarden/M01/std.htm Last accessed: 9 August 2005. [in Duth]

13. Dutch Diabetes Federation Federlandse Diabetes Federatiol. Available from http://www.diabetesfederatie.nl/publicaties.htm Last accessed: 9 August 2005. fin Duthl

14. Steuten LMG, Vrijhoef HJM, Severens $\mathrm{IL}$, Van Merode GG, Spreeuwenberg C. Are we measuring what matters in Health Technology Assessment of diseatse management? Int J Tech Ass Health Care, in press.

15. WareJEJr, Sherboume CD. The MOS 36-item short form health survey (SF-36). I. Conceptual franework and item selection. Med Care 30:473-83, 1992.

16. Aaronson NK, Muller M, Cohen PD, et al. Translation, validation, and norming of the Dutch language version of the SF-36 Health Survey in community and chronic disease populations. J Clin Epidemiol 5: $: 975-81,1998$. 
17. Pennings-Eerden van der LJM. Self-care behaviour in the treatment of diabetes niellitus. Theory, assessments and determinants of self-care behaviour and diabetes edncation Dissertation, Utrecht, The Netherlands, University of Utrecht, 1992.

18. Hollis $S$, Campbell $F$. What is meant by intention to treat analysis? Survey of published randomised controlled trials. BMJ 319:670-4, 1999.

19. Oostenbrink JB, Koopmanschap MA, Rutten FFH. Guidelines for econonic evaluations: methods and standard cost prices for economic evaluations in health care. [Handleiding voor kostenonderzoek: methoden en standaard kostprijzen voor economische evaluaties in de gezondheidszorg. Geactualiseerde versie 2004.] Amstelveen. The Netherlands, Health Insurance Council, 2000. [in Dutch]

20. Koopmanschap MA, Rutten FF, Van Ineveld BM, Van Roijen $\mathbb{L}$. The friction cost method for measuring indirect costs of disease. J Health Econ 14:171-89, 1995.

21. Drummond MF, O'Brien B, Stoddart GL, Tormance GW. Methods for the econonic evaluation of health care programmes. New York, Oxford Univensisy Press, 1997.

22. Briggs $\mathrm{AH}$, Wonderling DE, Mooney $\mathrm{CZ}$. Pulling cost-effectiveness analysis up by its bootstraps: a non-parametric approach to confidence interval estimation. Health Econ $6: 327-40$, 1997.

23. Fenwick E, Claxton K, Sculpher M. Representing uncertainty: the role of cost-effectiveness acceptability curves. Health Econ 2001;10(8):779-87.

24. Brazier]. The Short-Fom 36 (SF-36) Health Survey and its use in pharmacoeconomics evaluation. Pharmacoeconomics 7(5):403:15, 1995.

25. Disease Management Association of America (DMAA). Available from http://www.dmaa org Last accessed: 9 August, 2005.

26. Weingarten SR, Henning JM, Badangaraw $E$, et al. Interventions used in disease management programmes for patients with chronic illness - which ones work? Meta-analysis of published reports. BMJ 325:925-32, 2002.

27. Linden A, Roberts N. A user's guide to the disease management literature: recommendations for reporting and assessing program outcomes. Am J Man Care 11:113-20, 2005, Table 1: Effects on clinical outcome measures. 


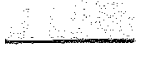




\section{A PROBABILISTIC DECISION MODEL TO ASSESS THE LONG-TERM COST UTILITY OF A DISEASE MANAGEMENT PROGRAMME FOR PATIENTS WITH ASTHMA}

L.M.G. Steuten, S.J. Palmer, H.J.M. Vrijhoef, G.G. Van Merode, C. Spreeuwenberg, J.L. Severens 


\section{ABSTRACT}

Objective: To assess the long-term cost utility of a disease management programme for adults with asthma as compared to 'usual care' by means of a decision-analytic model.

Design: A clinical trial was performed over a 15-month period in order to collect relevant data concerning the costs and effects of the disease management programme as compared to usual care. These data were used to inform the development of a probabilistic decision-analytic model in order to estimate the five-year impact of the programme beyond follow-up.

Main outcome measure: A societal perspective was adopted, with outcomes assessed in terms of costs per quality-adjusted life year.

Results: The disease management strategy is associated with a gain in quality-adjusted life years compared to the usual care strategy $(2.7 \pm 0.2$ vs $3.4 \pm 0.8)$ at lower costs $(€ 3,302 \pm 314 v \leq € 2,973 \pm 304)$, thus leading to dominancy. Including productivity costs in our analyses even strengthens this finding. The probability of disease management to be the more cost effective strategy is $76 \%$ at a societal willingness-to-pay of $€ 0$ for an additional quality-adjusted life year. A probability of $95 \%$ is reached at a willingness-to-pay of $€ 1000$ per additional quality-adjusted life-year. Condusions: Organising healtheare for adults with asthma in accordance to principles of disease management has a high probability to be cost effective. The programme is associated with a gain in quality-adjusted life years at lower costs. When productivity costs are included, the cost savings achieved using the disease management programme are even higher. This indicates that the benefits from the programme extend beyond the patient and the healthcare system and can also benefit employers. 


\section{INTRODUCTION}

The economic burden of asthma is considerable in terms of both direct medical costs and indirect costs [1]. A disproportionate amount of asthma related costs are a consequence of unsuccessful asthma control [2]. When the level of asthma control increases, the health-related quality of life of patients improves [3]. Disease management programmes (DMPs) that aim to improve astima control by emphasizing co-ordinated, comprehensive care along the continuum of care and across healthcare delivery systems are expected to improve quality of life of patients and lower the economic burden of the disease $[4,5]$.

After positive experiences with a diabetes DMP in the region of Maastricht, the Netherlands [6], a comparable programme for patients with asthma was developed and implemented in this region. Maastricht is located in the southern part of the Netherlands and contains a population of approximately 120,000 people, 90 general practitioners (GPs) and one hospital that functions as a regional as well as a teaching hospital.

By integrating care, the DMP aims to continuously improve the quality of care within existing budgets. One of the main components of the programme encompasses the transfer of care from the medical specialist and the GP to a respiratory nurse specialist. This form of process redesign comprises the assignment of patients to one member of a multidisciplinary team of care providers. Patients are identified from databases of participating GPs and the hospital. 'The assignment is based on disease severity as defined in accordance with the international asthma guidelines (GINA). If patients agreed, those with intermittent or mild asthma were assigned to the GP, those with moderate persistent asthma to the nurse specialist, and patients with severe persistent asthma to the pulmonologist. Respiratory nurse specialists (RNSs) independently provide protocolised care to the patients assigned to them, within the office of the GP. Tasks of the RNS are concerned with direct patient care (medical history taking, physical examination, interpretation of spirometric measurements and laboratory tests, administration and assimilation of findings), organisation and co-ordination of care for individual patients (identification of shortcomings in care, referral to and communication with care providers), and advancement of expertise (education of patients, themselves and other care providers). If complications or other problems arise, the RNS consults the GP or the pulmonologist. During office hours, the RNS is the first care provider to contact for patients assigned to her/him. The main differences compared to the "usual care" strategy are the extent to which the co-ordination is centralised and the position of the nurse specialist as a liaison between primary and secondary care. Within usual care, patients are either managed by the GP (mild to moderate asthma) or the pulmonologist (moderate to severe asthma), while the responsibility for co-ordination of care lies with the patient and their GP. 
If resources are to be allocated efficiently, then the value of using these resources in alternative ways needs to be made explicit. In order to assess whether the DMP for adults with asthma is an appropriate use of scarce healthcare resources, it is necessary to compare the costs and consequences of the programme with those of usual care in terms of their associated costs and health outcomes [7]. Historically, DMPs have had difficulty demonstrating their financial value using statistically rigorous methods $[8,9]$. Several reasons for this have been suggested, including the relatively high levels of uncertainty around cost estimates and the fact that the major benefits of DMPs are expected to occur in the long term $[8,10]$. An increasingly common approach to assess cost-effectiveness of healthcare interventions and to assist in complex decision making is to use decision-analytic modelling techniques $[11,12]$. Decision analysis provides an explicit, quantitative and systematic approach to combining data on a range of effectiveness, resource use and value parameters to assist decision-making under conditions of uncertainty. The primary benefit of using modelling in this study is that it facilitates the extrapolation of data beyond the time horizon of the clinical trial that was undertaken previously. This approach is important if the impact of disease management on the long-term costs and outcomes of asthma patients is to be effectively captured by the analysis. Although there may be potential concerns about the use of simulation models (e.g. due to a lack of transparency), there is still a need to make informed decisions with or without direct evidence from well designed trials that covered the relevant time horizon to incorporate long-term effects [11]. In this case, due to the limited period of follow-up provided by the clinical trial, there is a clear role for modelling in linking the short-term results from the trial to a more appropriate time horizon for the economic analysis.

Therefore, the primary objective of this paper is to describe the expected long-term cost utility of a DMP for adults with asthma as compared to "usual care' by means of a decision-analytic model.

\section{METHODS}

\section{Overview}

A clinical trial was performed over a period of 15 months in order to collect relevant data conceming costs and effects of the DMP. For many conditions, particularly chronic ones, the resource implications and effects on patients' health occur over many years. It is thus important that an economic assessment has a time horizon that is consistent with the duration of these effects. As such, the need for extrapolation is often necessary. In order to estimate the impact of the programme beyond the study period, a probabilistic simulation model has been developed. The purpose was to assess the cost utility of the DMP over a period of five years. The rationale for this 
Table 1: Data sources, instrunnents used and time of measunement for each paraneter of interest.

\begin{tabular}{|c|c|c|}
\hline Parameter & Data sontre and /or instrument & Time of measurement \\
\hline Clincal data (symptoms, PEF) & Medical patient record & Every thee months \\
\hline Uailines: QALY & Written questionnaire - EQm 50 & Every six months \\
\hline \multicolumn{3}{|l|}{ Resource use: } \\
\hline (not) routine consultations & Written cost questionnaire & Exery three months \\
\hline $\begin{array}{l}\text { medication use } \\
\text { (reyular/ emengency) }\end{array}$ & Written cost questionhaure & Every threa months \\
\hline hospitallisation (yes/no) & Writcen cost questionnaire & Every three months \\
\hline lengith of stay & Written cost questionmatre & Every the months \\
\hline number of sick leave days & Written cost questionduare & Every three months \\
\hline
\end{tabular}

time horizon lays in the assumption that, within this period, the DMP will not alter substantially due to changes in the organisation of healthcare or major changes within the evidence based guidelines on which the DMP is heavily based.

\section{Data source}

Data from which the model inputs were derived came from a clinical trial using a pre-post test design. Between May 2002 and March 2003 patients were recruited from 16 general practices (20 GPs) and the outpatient department of the hospital. Patients, aged $\geq 18$ years, with a GP diagnosis of asthma were eligible for the study. Patients with co morbidity such as lung cancer or congestive heart failure were excluded. Data on clinical parameters, quality of life, direct and indirect costs were collected during three months before the DMP was implemented, and every three to six months afterwards for a total period of one year (see Table 1). This design was chosen because the programme was implemented region wide and a 'Fair' comparison region was difficult to find. The reason for this was that, in all potential comparison regions, innovations were being implemented that would bias the measures of usual care. Examples of these innovations include shared care arrangements, physician assistants working in primary care, or the implementation of specific self-management programmes.

\section{Development of the model}

In order to assess the cost utility of the DMP in the long term, a Markov model was developed. Markov models define a disease in terms of a set of clinically and economically important health states to which both costs and effects are attributed [13]. Determined by the natural course of the disease and the influence of medical and 
other interventions, theoretical patients will move between these health states, accruing costs and treatment benefits in each health state over a predefined period of time. Because of the costs they incur, asthma exacerbations that require intervention by a healthcare professional are a central consideration in the model structure [14]. The structure of the model was based on a previously published model developed by Price and Briggs [14]. The asthma model was developed using Microsoft Excel $2000^{\circledR}$

\section{Model structure: Markov health states}

In accordance with the asthma model of Price and Briggs [14], five mutually exclusive health states were defined: 'successful control', 'sub optimal control', 'primary care managed exacerbation', 'hospital managed exacerbation' and 'all causes death'. 'Successful control' has been defined using the Global Initiative for Asthma (GINA) goals of asthma management [15]. Their definition of 'well-controlled' was applied to the health state 'successful control' in this model. This means that patients should not experience nighttime awakening due to asthma, emergency hospital visits, and exacerbations or treatment related adverse events causing a change in asthma therapy. In addition, patients were required to meet at least two of the following criteria: symptoms on $\leq 2$ days per week, rescue bronchodilator used on $\leq 2$ days per week and total weekly use $\leq 8$ puffs, and morning peak expiratory flow $\geq 80 \%$ predicted. Patients were classified as being in the health state 'sub optimal control' when they reported less than acceptable asthma control (e.g. their health state did not meet the criteria for 'successful control') but their level of symptoms did not warrant any immediate intervention by a healthcare professional [14].

A 'primary care managed exacerbation' was defined as a situation in which a patient is managed in a primary care or outpatient setting by a healthcare professional for the treatment of an asthma exacerbation [14]. In the DMP under study, the location of treatment was at the GP's office for patients assigned to the GP or the RNS and the outpatient department of the hospital for patients assigned to the pulmonologist. A 'hospital-managed exacerbation' was defined as a situation in which a patient experiences an asthma exacerbation, which requires an admission to the hospital. For some patients the management of the exacerbation will take place in the emergency room, after which they will be sent home; for others an inpatient stay will be required [14]. Since the mean length of hospital stay in our patient data was 11 days, the cycle length of the model was set to a two-week period.

The 'all causes death' state in this model represents an absorbing state from which patients cannot move after they have entered. This state comprises all asthma related and unrelated mortality. A specific 'asthma death state' was not included since we did not expect that the DMP would have a direct impact on asthma mortality rates considering the five-year time frame of the analysis. 


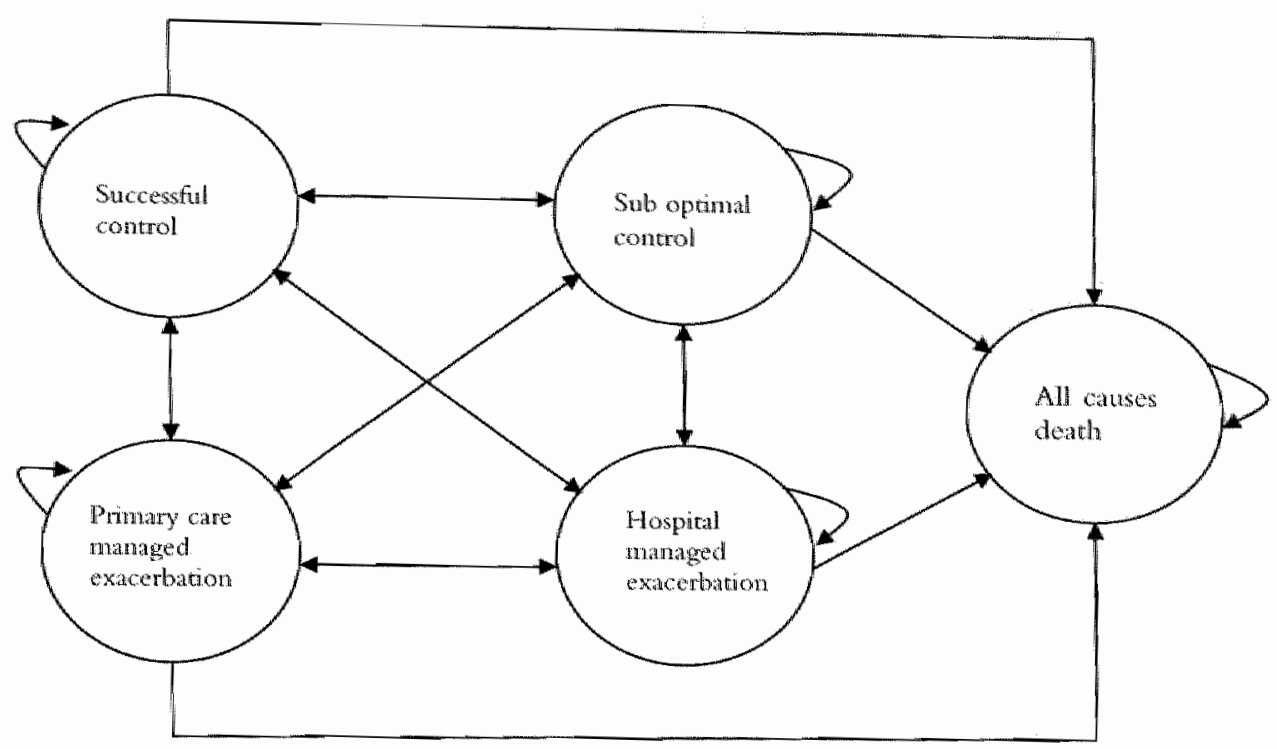

Figure 1: Markov model health state diagram showing the possible transitions between different health states in patients with asthma

The likelihood of a transition between two health states is expressed by the transition probability. The model allows for movement of patients from one state to any other, except from the "all causes death' state, which is the absorbing state (see Figure 1).

\section{Data inputs: transition probabilities}

Transition probabilities were calculated by dividing individual patient data from each strategy (e.g. disease management versus usual care) into bi-weekly segments. After the health state was defined for each patient in each cycle, transitions from one state to another were counted for every individual patient, and the total for all patients in each strategy was calculated. For transitions that had a 'zero count' in the observed data an uninformative prior was employed, which resulted in adding 'one' to all of the observed transition counts [14]. This was done, since it was assumed to be inappropriate to assign a zero probability to any transition allowed for in the model. An observed 'zero count' does not mean that a transition is impossible; merely that it is rare.

The transition probability from any state to the 'all causes death' state was calculated using the standardised age-dependent death rate form the Central Office of Statistics in the Netherlands, being 0.00013 (bi-weekly) for individuals between 45 en 54 years of age [16]. The reason for this is that the follow-up of the study was considered 
too short and the sample size $(n=658)$ too small to provide reliable data on death rates. For each strategy, transition probabilities for surviving patients moving between the disease states are presented in Table 2 .

\section{Data inputs: resource utilisation and costs}

Each health state is associated with specific costs that are considered from a societal perspective. Cost calculations are based on actual resource use as measured with a 15-item questionnaire and verified with administrative data from care providers. Collected data on resource use are: number of planned consultations with GP, RNS and pulmonologist, number of non-routine consultations due to an exacerbation, amount and type of maintenance and emergency medication used, number and duration of hospital admissions, number of sick leave days due to asthma.

Data collected in the three-month pre-measurement period represent resource utilisation within usual care. To avoid problems with dependency between repeated post-measurements and to control for seasonal effects on the patient level, only the 12-month data were used to represent resource utilisation within the DMP. Since patients from different GP practices entered the programme gradually over a period of ten months, both pre- and post-measurement data collection was carried out across all seasons controlling for a seasonal effect at the group level. With this approach, learning costs that can potentially be caused by inefficient provision of care at the start of the programme are ignored. To compensate for this, a sensitivity analysis was performed wherein total health care costs of the disease management programme were increased with $10 \%$.

Costs of medications were calculated using a 2004 price base (in euros) taken from the Dutch Pharmacotherapeutic Compass 2004 [17]. Costs for consultations with GPs or medical specialists, emergency stay and hospital inpatient stay were derived from the Dutch guidelines for economic evaluations [1.8] and were adjusted to 2004 price levels using the inflation index of the Dutch Central Office for Statistics [16]. Since no tariffs exist for consultations with the RNS, these costs were calculated using a bottom-up approach by applying the activity based costing method [19]. For this, a detailed investigation was made of the frequency and duration of all operations of the nurse. These were costed using the standard prices for each activity. In addlition, overhead costs were included. These costs comprise costs for the employment of a medical and project coordinator, the continuing education of the RNSs, the costs of an administrative support office, the maintenance costs of the electronic patient record system that the RNSs use, telephone and travell costs of the RNSs and the salary costs of the unit leader. Although in a different role, RNSs were previously employed in the healthcare system. Therefore, their training costs were not considered as developmental costs for the programme. Since most programme-specific 
Table 2a: Transition probabilities for usual care strategy (bi-weekly data)

\begin{tabular}{|c|c|c|c|c|}
\hline $\begin{array}{l}\text { Usual care To: } \\
\text { From }\end{array}$ & $\begin{array}{l}\text { Successful } \\
\text { control }\end{array}$ & $\begin{array}{l}\text { Sub-optimal } \\
\text { control }\end{array}$ & $\begin{array}{l}\text { Primary care } \\
\text { managed } \\
\text { exacerbation }\end{array}$ & $\begin{array}{l}\text { Hospiral managed } \\
\text { exacerbation }\end{array}$ \\
\hline Successful control & 0.956 & 0.024 & 0017 & 0.003 \\
\hline Sub optimal control & 0.1 & 0.885 & 0.014 & 0.001 \\
\hline $\begin{array}{l}\text { Primary care managed } \\
\text { exacerbation }\end{array}$ & 0.031 & 0.225 & 0.576 & 0.168 \\
\hline $\begin{array}{l}\text { Hospital managed } \\
\text { exacerbation }\end{array}$ & 0.08 & 0.442 & 0.149 & 0.329 \\
\hline
\end{tabular}

Table 2b: Transition probabilities for disease management strategy (bi-weekly data)

\begin{tabular}{lllll}
\hline Disease management To: & $\begin{array}{l}\text { Successful } \\
\text { control }\end{array}$ & $\begin{array}{l}\text { Sub-optimal } \\
\text { control }\end{array}$ & $\begin{array}{l}\text { Prinuary care } \\
\text { managed } \\
\text { exacerbation }\end{array}$ & $\begin{array}{l}\text { Hospital managed } \\
\text { exacerbation }\end{array}$ \\
\hline Successful control & 0.972 & 0.016 & 0.010 & 0.002 \\
Sub optimal control & 0.300 & 0.691 & 0.008 & 0.001 \\
$\begin{array}{l}\text { Primary care managed } \\
\text { exacerbation }\end{array}$ & 0.146 & 0.156 & 0.568 & 0.130 \\
$\begin{array}{l}\text { Hospital managed } \\
\text { exacerbations }\end{array}$ & 0.222 & 0.341 & 0.228 & 0.209 \\
\hline
\end{tabular}

costs have a continuous nature, they are captured within the overhead costs and herewith included in the analysis.

Productivity losses were measured in terms of sick leave days and costed using the age-dependent friction costs method as recommended by the authors of the Dutch guidelines for economic evaluations [18]. The underlying premise of this costing method is that within a production process all people are replaceable. As a result, productivity losses only occur in the period needed to fill the gap in the production process (e.g. friction costs period) due to the fact that less production is realised or that additional costs have to be made to keep the production at a certain level. In the Netherlands, this friction cost period is stated to be a period of four months [18]. Consequently, the costs for the period of sick leave that endured more than 123 days were assigned a zero-cost. All costs are discounted at a $4 \%$ discount rate [18]. The direct and indirect cost data for each strategy are presented in Table 3.

\section{Data inputs: health outcomes}

In order to capture the health effects of the DMP, it is necessary to quantify the impact on life expectancy and health-related quality of life. One of the most widely 
Table 3: Costs (E) associated with speciffe parameters and costs per health state for usual care and disease mandgement (three monthly data)

\begin{tabular}{|c|c|c|c|c|c|c|c|}
\hline \multirow[b]{2}{*}{ Variable } & \multirow[b]{2}{*}{ Distribution* } & \multicolumn{3}{|l|}{ Usual care } & \multicolumn{3}{|c|}{ Disease management } \\
\hline & & Mean (SE) & Apton & Beta & Mean (SE) & Apha & Beta \\
\hline $\begin{array}{l}\text { Routine } \\
\text { consultations }\end{array}$ & Gamma & $9.5(1.9)$ & 25.0 & 0.4 & $10.5(1.5)$ & 490 & 0.2 \\
\hline $\begin{array}{l}\text { Non-routine } \\
\text { consultations }\end{array}$ & Gamma & $26.2(6.4)$ & 16.7 & 1.6 & $180(4.9)$ & 13.4 & 1.3 \\
\hline $\begin{array}{l}\text { Regular } \\
\text { medication }\end{array}$ & Gamma & $28.2(7.8)$ & 13.1 & 2.2 & $29.8(6.2)$ & 23.1 & 1.3 \\
\hline $\begin{array}{l}\text { Emergency } \\
\text { medication }\end{array}$ & Ganmma & $8.6(1.2)$ & 51.4 & 0.2 & $7.8(1.1)$ & 50.3 & 0.2 \\
\hline $\begin{array}{l}\text { Hospital inpatient } \\
\text { care }\end{array}$ & Ganuma & $1376.8(141.8)$ & 943 & 14.6 & $1131.2(145.3)$ & 60.6 & 18.7 \\
\hline Productivity losses & Ganmma & $112.0(16.2)$ & 47.8 & 2.3 & $41.6(10.7)$ & 15.1 & 2.8 \\
\hline \multicolumn{8}{|l|}{ Henllin state } \\
\hline $\begin{array}{l}\text { Successfull } \\
\text { control }\end{array}$ & Ganima & $37.7(11.2)$ & 11.3 & 3.3 & $40.3(12.5)$ & 10.4 & 3.9 \\
\hline$-\mathrm{GP}$ & & $35.1(9.6)$ & 9.1 & 3.2 & $28.2(11.8)$ & 5.7 & 4.9 \\
\hline -RNS & & $35.6(10.5)$ & 13.3 & 2.9 & $42.4(11.9)$ & 127 & 3.3 \\
\hline -pulmonologist & & $56.7(19.8)$ & 8.1 & 6.9 & $55.7(18.1)$ & 9.5 & 5.9 \\
\hline $\begin{array}{l}\text { Sub optimal } \\
\text { control }\end{array}$ & Gamma & $102.3(48.7)$ & 4.4 & 23.2 & $68.9(33.1)$ & 4.3 & 15.9 \\
\hline$-G P$ & & $91.3(42.7)$ & 3.5 & 22.7 & $54.11(31.0)$ & 3.0 & 17.8 \\
\hline -RNS & & $99.8(48.2)$ & 4.8 & 22.0 & $66.6(29.4)$ & 5.1 & 13.0 \\
\hline -pulmnonologist & & $145.5(67.8)$ & 4. 1. & 33.4 & $121.2(63.1)$ & 3.7 & 32.9 \\
\hline $\begin{array}{l}\text { Primary care } \\
\text { matlaged }\end{array}$ & Gamma & $184.5(53.1)$ & 12.1 & 15.3 & $107.7(37.9)$ & 8.1 & 13.3 \\
\hline exacerbation & & $145.7(43.44)$ & 11.3 & 12.9 & $94.0(36.1)$ & 68 & 13.9 \\
\hline$-\mathrm{GP}^{*}$ & & $1909(52,1)$ & 13.4 & 142 & $98.1(32.4)$ & 9.2 & 10.7 \\
\hline $\begin{array}{l}\text {-RNS } \\
\text {-puilmonologist }\end{array}$ & & $241,3(83.7)$ & 8.3 & 29.0 & $206.1(77.2)$ & 7.1 & 28.9 \\
\hline $\begin{array}{l}\text { Hospital managed } \\
\text { exacerbation }\end{array}$ & Gamma & $1673.3(182.9)$ & 83.7 & 20.0 & $1280.5(153.7)$ & 69.4 & 18.4 \\
\hline$-G \mathbb{P}$ & & $1153.1(136.4)$ & 71.5 & 16.1 & $1048.1(141.6)$ & 54.8 & 19.1 \\
\hline RNS & & $1690.4(183.7)$ & 84.7 & 20.0 & $1168.5(139.9)$ & 69.8 & 16.7 \\
\hline -pulnonologist & & $2861.0(288.2)$ & 98.5 & 29.0 & $2578.3(273.3)$ & 89.0 & 29.0 \\
\hline
\end{tabular}

* Parameters of distribution $(\alpha, \beta)$ solved using methods of momedats fitting, using the mean (SE) derived from the trial datin.

HA Gammin distribution is constrained on the interval zero to positive infinity. 
used approaches that combines these two atributes into a composite measure of health is the 'quality-adjusted life year'-approach (QALY) [11].

In this study, the QALYs, associated with disease management and usual care, were assessed using the EuroQol (EQ-5D) instrument [20]. The EQ-5D questionnaire is a standardised generic instrument for measuring health-related quality of life. The EQ-5D provides a single preference weight (also described as a utility) for each health state in the model. These values can be used as quality-adjustment weights to turn at profile of health states over time into QALYs. With the exception of the 'death' state, all health states are assigned a specific utility value obtained from the underlying dataset. For the disease management strategy, only the 12-month follow-up data on quality of life were used.

The number of QALYs relating to a health outcome is expressed as the value given to a particular health state multiplied by the length of time spent in that state. The utilities assigned to each health state are presented in Table 4 . Within the model a discount rate of $4 \%$ was applied [18].

\section{Perspective}

From a societal perspective, all costs and benefits related to the DMP should be included when performing an economic evaluation. For a cost utility analysis this means that all effects that are not captured in the estimation of QALYs should be included in the costs [21]. However, since there is some debate about how productivity costs would have to be included in cost utility analyses $[22,23]$, we present our analyses both with and without productivity costs included in the numerator of the cost effectiveness ratio. The analysis without productivity costs has been considered as the base case. An advantage of this is that we can also address the distributional consequences that occur when productivity costs are one of the driving factors of the cost savings of the DMP. In the Netherlands, as in many countries, health insurance companies do not benefit from savings in productivity costs, but are responsible for paying the healthcare claims of their enrolees. If no savings occur in the direct healthcare costs, there may be limited incentive for them to invest in DMPs.

\section{Probabilistic sensitivity analysis}

Probabilistic sensitivity analysis (PSA), using second order Monte-Carlo simulation techniques, was employed to handle uncertainty in the model by obtaining distributions of costs, health outcomes and the resulting cost-effectiveness estimates. The benefit of propagating distributions through the model, instead of using a single point estimate, is that the cost-effectiveness results indicate the uncertainty surrounding the decision, rather than the uncertainty surrounding a single input [24]. For this purpose, distributions were fitted to the transition probabilities and parameters eval- 
Table 4: Utilites associnted with each health state in asual care and disease management

\begin{tabular}{|c|c|c|c|c|c|c|c|}
\hline \multirow[t]{2}{*}{ Health state } & \multirow[t]{2}{*}{ Distribution * } & \multicolumn{3}{|l|}{ Usual care } & \multicolumn{3}{|c|}{ Disiase management } \\
\hline & & Mean (SH) & Alpha & Beta & Mean (SE) & Alpha & Beta \\
\hline \multirow{5}{*}{$\begin{array}{l}\text { Suceestul } \\
\text { control } \\
\text {-GP } \\
\text { - RNS } \\
\text {-pulmonologist }\end{array}$} & \multirow[t]{5}{*}{ Buted } & $0.75(0.03)$ & 155.50 & 51.83 & $0.80(0.03)$ & 141.42 & 35,36 \\
\hline & & & & & & 81.12 & 21.56 \\
\hline & & $0.77(0.0 .4)$ & 84.46 & 25.23 & $0.79:(0.04)$ & 133.66 & 29.34 \\
\hline & & $0.75(0.03)$ & 155.50 & 51.83 & $0.82(0.03)$ & 160.56 & 62.44 \\
\hline & & $0.70(0.03)$ & 162.63 & 69.70 & $0.72(0.03)$ & & \\
\hline $\begin{array}{l}\text { Salb optimal } \\
\text { control }\end{array}$ & \multirow[t]{4}{*}{ Byeta } & $0.73(0.03)$ & 159.14 & 58.86 & $0.74(0.02)$ & 355.20 & 124.80 \\
\hline$-G \mathrm{P}$ & & $0.77(0.03)$ & 159.14 & 58.86 & $0.73(0.03)$ & 159.14 & 58.86 \\
\hline$-R N S$ & & $0.72(0,03)$ & 160.56 & 62.44 & $0.75(0.02)$ & 350.81 & 116.94 \\
\hline -puthonologist & & $0.69(0.04)$ & 91.55 & 41.13 & $0.71(0.03)$ & 164.72 & 66.06 \\
\hline $\begin{array}{l}\text { Prinary cane } \\
\text { managed } \\
\text { exacerbarion }\end{array}$ & \multirow[t]{4}{*}{ Betat } & $0.67(0.02)$ & 369.67 & 182.08 & $0.71(0.04)$ & 90.66 & 37.03 \\
\hline \multirow{3}{*}{$\begin{array}{l}-G \mathrm{P} \\
\text {-RNS } \\
\text {-pulnonologist }\end{array}$} & & $0.71(0.02)$ & 364.76 & 148.99 & $0.69(0.04)$ & 91.55 & 44 11.13 \\
\hline & & $0.66(0.02)$ & 369.60 & 190.40 & $0.73(0.04)$ & 89.20 & 32.99 \\
\hline & & $0.62(0.03)$ & 161.68 & 99.10 & $0.67(0.05)$ & 58.58 & 28.86 \\
\hline $\begin{array}{l}\text { Hospital managed } \\
\text { exacerbation }\end{array}$ & \multirow[t]{4}{*}{ Bite tal } & $0.66(0.04)$ & 91.91 & 47.35 & $0.63(0.05)$ & 58.11 & 34.13 \\
\hline$-G P$ & & $0.69(0.0 .4)$ & 91.55 & 41.13 & $0.62(0.06)$ & 39.96 & 24.49 \\
\hline$-\mathrm{RN} S$ & & $0.65(0.04)$ & 91.77 & 49.42 & $0.64(0.05)$ & 58.34 & 32.82 \\
\hline mulmonologist & & $0.60(0.05)$ & 57.00 & 38.00 & $0.57(0.06)$ & 38.24 & 28.85 \\
\hline
\end{tabular}

* Parameters of distribution $(\alpha, \beta)$ solved using methods of moments fitting using the meane (SE) derived from the trial data.

Heta distribution is constrained on the interval zero to one.

uating resource use, number of sick leave days and utilities. The volume and quality of the information available, for each of these inputs, is reflected in the probability distribution assigned to these estimates, in which little or poor information is represented by assigning a diffuse distribution.

Once these distributions were fitted, the PSA randomly selected values from each of the parameter distributions, and evaluated the model results for that combination of parameter values. This process was repeated 5000 times to obtain a representative range of cost and effect pairs for the two strategies and hence a distribution of incremental costs and effects (QALYs). These estimates were then presented graphically on a cost effectiveness plane, to show the estimated joint distribution of incremental costs against incremental effects. To avoid potential problems with interval estimates for incremental cost effectiveness ratios (ICERs), net benefit analysis was performed 
[25]. This involves the calculation of a net benefit (NB) statistic, for each of the 5000 simulations, from the formula:

$$
N B=\lambda \Delta e-\Delta c
$$

where $\lambda$ is the societal willingness-to-pay for one additional unit of effect and $\Delta c$ and $\Delta c$ are the incremental differences in effectiveness (QALYs) and costs, respectively. A positive monetary net benefit indicates that a strategy is cost effective for a given value of $\lambda$. A cost effectiveness acceptability curve [26] is obtained by plotting the proportion of the 5000 simulations that have positive net benefits as a function of $\lambda$.

\section{Fitting distributions}

Transition probabilities are continuous parameters with values constrained between zero and one. Although beta distributions are commonly employed to characterise uncertainty in transition probabilities when the branching probability is dichotomous (only two potential transitions from each health state), this does not apply to the transition matrix in this five state model. The transition probabilities from one state to another were therefore assumed to follow a Dirichlet distribution, which is the multinomial equivalent of the beta distribution $[27,28]$.

Costs are a mixture of resource use and unit costs and are constrained to be zero or positive. This suggests the fitting of a gamma distribution to represent uncertainty in cost data, since this distribution is also constrained on the interval zero to positive infinity. Uncertainty in the gamma distribution is characterised by two parameters Gamma $(\alpha, B)$. The parameters of the gamma distribution were solved using analytic methods (method-of-moments) [29]. Method-of-moments fitting involves equating the mean and SE observed in the trial data to the expressions for the mean and SE of the gamma distribution. The parameters of the gamma distribution $(a, B)$ can then be solved analytically. The gamma distributions are reported in Table 3 . Utility parameters (the quality weights in this study), represent slightly unusual parameters in terms of their range. The theoretical constraints on utility parameters are negative infinity at the one end (representing the worst possible health state) and 1 at the upper end (representing perfect health). However, since the utility data obtained from the patients in the trial indicated that values less than zero were implausible, a beta distribution was used to reflect uncertainty in this input. Using a similar approach to that applied to the cost data, method-of-moments was again used to derive the two parameters of the beta-distribution $\sim \operatorname{Beta}(\alpha, B)$.

\section{Sub group analyses}

In addition to the main analysis comparing the disease management strategy with usual care, a series of separate subgroup analyses were undertaken for each of the three patient groups assigned to the GP, the RNS or the pulmonologist. The purpose of these subgroup analyses was to gain more insight in the relative contribution of each 
patient group to the overall cost utility of the disease management strategy. Although the same model structure was applied as that used for the main analysis, each of the subgroup analyses was analysed using subgroup-specific input data.

\section{RESULTS}

\section{Patients and response rates}

Of the 707 patients that were eligible for the study, 658 participated $(93.1 \%)$. Of the included patients, according to their disease status, $10 \%$ were assigned to the pulmonologist, $65 \%$ to the RNS and $25 \%$ to the GP. Response rates on both quality of life questionnaires and cost questionnaires were moderate to high (ranging from $55 \%$ to $96 \%$ ) as was the availability of clinical data (ranging from $80 \%$ to $100 \%$ ). The most common reason for dropping out of the study was unwillingness to fill out any questionnaire. Other reasons were having problems with the Dutch language $(n=10)$, moving away $(n=7)$ or illiteracy $(n=4)$.

Patients that were assigned to the GP were less likely to complete data collection as compared to patients that were assigned to the RNS or pulmonologist. Therefore, lung function values of patients not completing follow-up were on average higher as compared to patients completing all questionnaires. Also, patients with missing data had significantly less pack years of smoking than patients with complete follow-up. Within the GP-subgroup of patients, baseline characteristics of patients with missing data did not differ significantly from baseline characteristics of patients with complete data. This indicates that within the GP-subgroup, no selective loss to follow-up occurred.

\section{Markov model results}

The differences in transition probabilities between usual care and disease management show that the probability of moving into one of the exacerbation states is lower in the disease management strategy while the probability for moving back towards the health state 'successful control' is higher compared to usual care. Overall, costs for routine consultations and regular medication increased after implementation of the DMP, while costs for non-routine consultations, emergency medication, hospital stay and lost productivity of the patients decreased. Overhead costs amounted to 6101 per patient per year. Quality of life improved as demonstrated by a gain of 0.69 QALYs within five years.

The results for the base case model show that the disease management strategy led to a gain in QALYs compared to the usual care strategy (usual care $2.7 \pm 0.2 v$ s. disease management $3.4 \pm 0.8)$, at lower costs $(€ 3,302 \pm 314$ vs. $€ 2,973 \pm 304)$ over a period of 


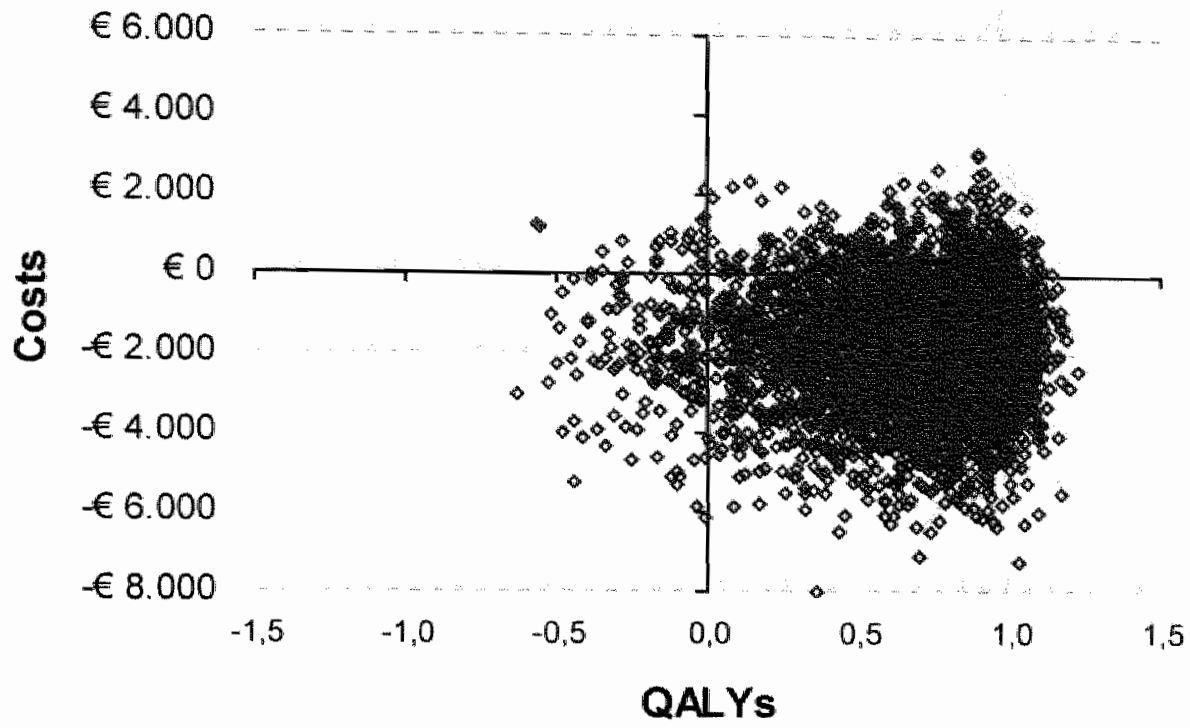

Figure 2: Incremental cost-effectiveness plane comparing disease management with ususal care (results of 5000 Monte Carlo simulations): base case model

five years. Hence, based on a comparison of mean costs and QALYs, the disease management strategy dominates usual care, i.e., it is more effective and less costly. When productivity costs are included, the finding of dominancy is even strengthened (costs usual care $€ 3,833 \pm 410$ ws. costs disease managenent $€ 3,242 \pm 241$; difference in QALYs remains 0.69).

\section{Probabilistic sensitivity analysis}

\section{Base case results}

The results of the PSA for the base case model are graphically presented in Figure 2 This figure shows the results of 5000 simulations on the cost effectiveness plane. The $x$ - and $y$-axes divide the graph into four quadrants, that represent the following scenarios for the DMP in comparison with usual care (clockwise from the northeast quadrant): (i) more effective and more costly; (ii) more effective and less costly (dominancy); (iii) less effective and less costly, and (iv) less effective and more costly (inferiority). For the majority of simulations ( $76 \%)$, the disease management strategy is associated with increased benefits and lower costs compared to usual care.

However, there is also a proportion of simulations that lies in the northeast quadrant $(22 \%)$, indicating a gain of QALYs at higher costs for the disease management strategy. The remaining $2 \%$ of simulations ended up in one of the western quadrants 


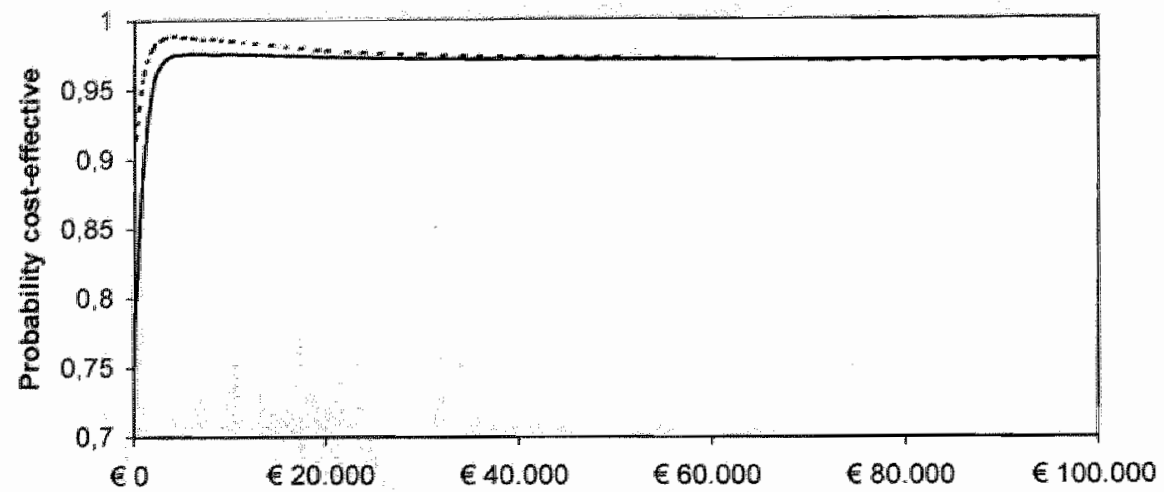

Inct. productivitiy

Willingness to pay for one additional QALY

Excl productivity

Figure 3: Cost-effectiveness acceptability curves for the disease management strategy comparing the base case model and the model including productivity costs

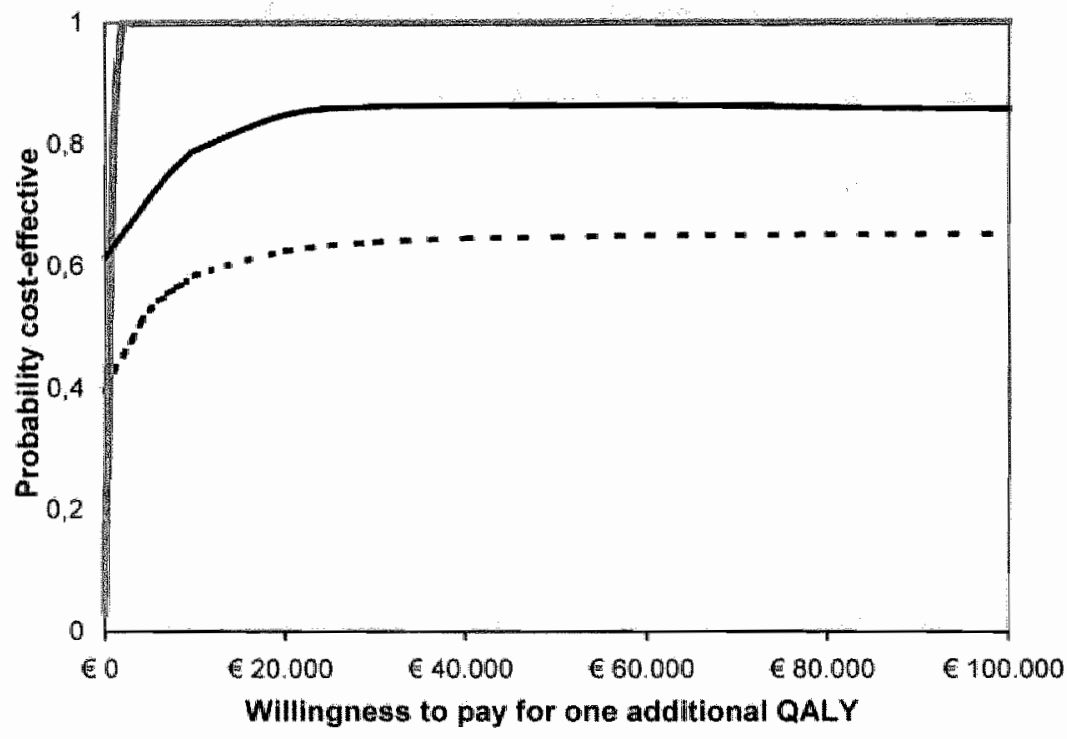

- - GP-subgroup RNS-subgroup MS-subgroup

Figure 4: Cost-effectiveness acceptability curves for each subgroup

indicating a loss of QALY's at either lower (1.5\%) or higher costs (0.5\%) as compared to usual care. Clearly, if the gain in outcome is achieved at a higher cost, then the critical issue that determines whether the disease management strategy is deemed cost effective is how much (if any) the decision maker is prepared to pay for an additional unit gain in health outcome (e.g. QALY). 
To better understand the uncertainty around the point estimate of the incremental cost-effectiveness ratio (ICER), a cost-effectiveness acceptability curve (CEAC) whas plotted based on the 5000 simulations already calculated, using the net benefits approach described before. The result of the CEAC incorporates the uncertainty within the model in relation to both the estimates of mean costs and QALYs, and the maximum willingness-to-pay for an additional QALY. Figure 3 shows that if decision makers are willing to pay approximately $€ 1000$ for an additional QALY, the disease management strategy will be the more cost effective strategy in this patient population in $95 \%$ of the simulations.

\section{Results including productivity costs}

The results of the PSA, for the model that includes productivity costs, show that $90 \%$ of the simulations indicate dominance for the disease management strategy and that this $90 \%$ certainty is reached without any additional investments. The accompanying cost effectiveness acceptability curve is presented in Figure 3.

\section{Sensitivity for learning costs}

After increasing total health care costs of the base case analysis with $10 \%$ to account for learning costs, the DMP remains dominant in $64 \%$ of simulations. At a willingness to pay of $€ 3000$ per additional QALY this probability increases to $91 \%$.

\section{Results sub group analyses}

For patients assigned to the RNS, the disease management strategy is associated with a gain in QALYs $(+1.2 \pm 0.05)$ at higher costs $(+€ 757 \pm 612)$. The expected costs and outcomes for patients assigned to the pulmonologist $(+0.2 \pm 0.38$ QALY; $-€ 3,687 \pm 6,378)$ or the $\mathrm{GP}(+0.1 \pm 0.2 \mathrm{QALY} ;+€ 23 \pm 1,020)$ seem to remain largely the same after implementation of the DMP. In addition, the CEACs of these subgroups indicate that there is much more uncertainty around the cost effectiveness ratio as compared to the RNS-subgroup, which shows a steep rise when the willingness-to-pay for one additional QALY increases. The CEACs of the GP- and pulmonologist-subgroups only rise gradually given higher values for lambda (Figure 4). The same pattern of effect is seen when productivity costs are included.

\section{DISCUSSION}

The DMP under study is associated with a gain in QALYs at lower costs in the management of a population of adult asthmatics, compared to usual care. Given the current information, the probability that disease management is the more cost effective strategy is $76 \%$ at a societal willingness-to-pay of $€ 0$ for an additional QALY. 
reaching $95 \%$ certainty at a willingness-to-pay of $€ 1000$ per additional QALY. The finding of dominancy remains when accounting for learning costs that might have been missed in the base case analysis.

The result is mainly driven by the increase in asthma control that is gained within the disease management strategy. In the DMP, patients who are better controlled continue to be better controlled than in usual care. Also, patients experiencing exacerbations or being in a state of 'sub-optimal control' are more likely to be successfully controlled again. From the subgroup analyses, it can be concluded that the relative contribution to the observed gain in QALYs is highest within the RNS-subgroup, while the major part of the overall cost savings seems to occur from the pulmonologist subgroup. However, uncertainty around costs is relatively high in this subgroup as well as in the overall analysis, which might be due to the fact that only data of three-month measurement periods were used to inform the model. Furthermore, costs for patients that are assigned to the RNS are found to increase, which is mainly due to higher consultation costs. This implicates that the protocol should be followed very strictly with regard to the assignment of patients to the RNS. Patient that do not necessarily require intensification of care, e.g. patients with intermittent or mild asthma, should be taken care of by the GP, not the RNS. Also, it is recommended to critically evaluate the protocol to optimise care for patients assigned to the RNS, for example with regard to duration and frequency of consultations.

Although any adoption decision should be made by policy makers, an intervention that produces results of this magnitude would generally be considered to be extremely cost effective [14].

There are, however, some limitations to this study that need to be taken into account when interpreting these results. First of all, because a non-controlled, quasi-experimental study design was used, no causal relationship between the introduction of the DMP and the observed changes in costs and effects could be demonstrated. Since a comparable parallel control group is lacking, the results from this study might be biased by, for example, regression to the mean. However, regression to the mean would have biased the results in all patients, not selectively affecting utilities in patients assigned to the RNS or costs for patients assigned to the pulmonologist. Secondly, measurement periods of three months are quite vulnerable to bias caused by, for example, seasonality or coincidently high or low estimates of certain parameters. In order to check if our data are likely to be biased, we sought for literature to compare our findings. Although not optimally comparable due to different settings (Hungary ws. The Netherlands), the most recent published study of HRQL of patients with asthma measured with the EQ-5D [30], suggested a mean score of 0.70 in usual care, which is quite comparable to our findings within usual care being an overall average of 0.72 . Concerning costs, Schermer et al. found annual direct costs within usual care to be circa $€ 400$ per patient in the Netherlands, excluding costs for hospital admissions or emergency room visits [31]. Our estimate of overall direct 
costs within in the usual care strategy lies, with $€ 660$ per patient per year, teasonably higher, given that we did include costs for hospital or emergency room adnissions. Another similarity between our study and the study of Schermer et al. was found witli regard to indirect costs. Both studies showed a substantial reduction in sick leave or limited activity days after implementing a DMP that has a strong self-management component [this study] or guided self-management in primary care [31].

Another source of potential bias are the missing values that mainly occurred within the follow-up period. As a result, they selectively affect measures of the disease management strategy. However, since patients with missing data were more likely to be those patients with relatively good asthma control, i.e. patients assigned to the GP, the estimate of costs effectiveness of the disease management strategy is more likely to be underestimated than overestimated.

One of our model"s undoubted strengths is the comprehensive PSA component, which enables the estimation of the joint uncertainty around incremental costs and effects, and the construction of CEACs using net benefit analysis. Another strength of the presented model is the use of the QALY construct as a generic measure of effectiveness, permitting its value to be assessed in a wider healthcare context [11]. A limitation of the presented model is that, as in all Markov models, transition probabilities are considered constant over time [12], which in reality will not be the case. Since there is a lack of studies reporting long-term effects of DMPs [32] for asthma, data informing the magnitude and direction of any adjustment of those probabilities over time are scarce. Consequently, it is difficult to introduce intermediate health states that would allow for time dependent transitions within the existing Markov model structure. Another limitation of the model is that it does not allow patients to switch between primary responsible care providers (e.g. between subgroups as presented), which in reality is possible. Allowing for this transition possibility would increase the complexity of the model enomously. Since only $3 \%$ of patients permanently switched from one primary responsible care provider to another within the 12 months follow-up period of the clinical trial, this simplification is unlikely to significantly bias the results.

Another issue that needs attention is the perspective on costs and outcomes that was taken in this study. The base case model, taking into account the distributional consequences (e.g. who is paying for better healthcare and who is taking the benefits) leads to the conclusion that the DMP is associated with cost savings. When the productivity costs for patients are considered to be covered within the QALY measures, and friction costs (e.g. employer and society costs) are captured in the numerator of the ratio, a more societal perspective is addressed resulting in even more cost savings associated with the disease management strategy. This indicates that employers will also experience benefits in terms of decreasing sick leave costs for employees with asthma. The first recommendation following from the results of this study is to implement DMPs for adults with asthma, in which the RNS plays a key-role, on a larger scale. 
Secondly, scenario studies should be done to optimise the current DMP and assess the generalisability of the results. For example, the number of consultations per year with the RNS as well as the length of each consultation can be varied within the model to explore the extent to which this influences the overall cost effectiveness of this DMP. By varying parameters that reflect more structural characteristics of the programme, the cost utility could be estimated in a different organisational context. For example, parameters reflecting the position and tasks of the RNS or the consequences of the reimbursement system for patients, insurers and employers could be altered.

\section{CONCLUSION}

This study reports on one of the first probabilistic decision-analytic models to assess the cost utility of a DMP for adults with asthma in the long term. We conclude that the presented DMP for adults with asthma is associated with a gain in QALYs at lower costs as compared to usual care. When productivity costs are included, the cost savings are even higher, indicating that also employers may benefit from the programme. Based on these results, it is recommended to implement DMPs in which nurse specialists play a key-role on a wider scale.

One should continue to look critically at the different programmes that currently exist in order to develop the optimal DMP that fits within the organisational context of the region in which it is implemented. Furthermore, the methodological quality of disease management evaluation studies is still limited and needs continuous attention $[9,10]$. The application of decision-analytic modelling techniques might be a step in the right direction.

Funding: the development of the decision-analytic model at the University of York (UK) has been supported by a grant from the Netherlands Organization for Scientific Research (NWO).

Acknowledgements: the Team for Economic Evaluation and Health Technology Assessment, within the Centre for Health Economics of the University of York, has been invaluable in teaching the principles and practical applications of decision-analytic modelling techniques and in providing critical feedback during the actual development of this decision-analytic model. The authors accept full responsibility for the views expressed in this paper as well as any errors or inaccuracies. 


\section{REFERENCES}

1. Masoli M, Fabian D, Holt S, Beasley R for the Global Initiative for Asthm (GINA) Progran. The global burden of asthma: executive summary of the GINA Dissenination Committeo Report. Allergy 2004;59:469 78 .

2. Bames PJ, Johnsson B, Klim JB. The costs of asthma. Eur Respir J 1996;9:636-42.

3. Szende Á, Svensson K, Stahl E, Mészáros Á, Berta GA. Psychometric and utility-based measures of health status of asthmatic patients with different disease control level. Phamacoeconomics $2004 ; 22(8): 537-47$.

4. Ellrodt $G$, Cook DJ, Lee J, Cho $M_{x}$ Hunt D, Weingarten S, Evidence based disease management. JAMA 1997;278:1687-92.

5. Bodenheimer $T$, Wagner $\mathbb{E} H$, Grumbach $\mathbb{K}$. Improving care for patients with chronic illness: the chronic care model, part 2. JAMA 2002;288:1909-14.

6. Vrijhoef HJM, Spreeuwenberg C, Eijkelberg IMJG, Wolfenbuttel BHR, Van Merode G. Adoption of disease management model for diabetes in the region of Maastricht. BMJ 2001:323:983-5.

7. Drummond MF, O'Brien B, Stoddart G, Torrance G. Methods for the economic evaluation of health care programs. Oxford: Oxford University Press, 1997.

8. FetterolfD, Sidorov J. Disease management program evaluation guide. Washington: Disease Management Association of America, 2004.

9. Linden A, Adams JL, Roberts N. Using an empirical method for establishing clinical outcome targets in disease management programs. Dis Man 2004;7(2): 93-101.

10. Steuten LMG, Vrijhoef HJM, Van Merode GG, Severens JL, Spreeuwenberg C. The Fllealth Technology Assessment - Disease Management instrument reliably measured methodologic quality of health technology assessment of disease management. J Clin Epidemiol $2004,57: 881-8$.

11. Drummond MF, McGuine A, editors. Economic evaluation in health care: merging theory with practice. Oxford: Oxford University Press, 2001.

12. Hunink MGM, Glasziou PP, Siegel JE, et al. Decision making in health and medicine: integrating evidence and values. Cambridge, England: Cambridge University Press, 2001.

13. Briggs AH, Sculpher M. An introduction to Markov modeling for economic evaluation. Pharmacoeconomics 1998;13:397-409.

14. Price MJ, Briggs AH. Development of an economic model to assess the cost-effectiveness of asthma management strategies. Pharmacoeconomics 2002;20(3):183-94.

15. National Institutes of Health. Global Initiative for Asthma. Pocket guide for asthma management and prevention. National Institutes of Health, National Heart, Lung and Blood Institute, 1998 Nov, Publication No. 95-3659B.

16. Central Office of Statistics: www.cbs.nl/nl/publicaties/publicaties/algemeen/statistischjarboek/a-26-2004.pdf [ir Duth] Last accessed: 22 Novenaber 2004.

17. Phamacotherapeutic Compass: htep:/ www fk.cvz.nl/ Last accessed: 12 January 2004, fit Dutdil 
18. Oostenbrink JB, Koopmanschap MA, Rutten FFH. Handleiding voor kostenonderzoek, methoden en richtijuprijzen voor economische evaluaties in de gezondheidszorg. Amstelween: College voor Zorgwerzekeringen, 2000. [in Dutch]

19. Ross TK. Analysing health care operations using ABC. I Health Care Finance $2004,30(3): 1-20$.

20. The EuroQoll Group. EuroQol-a new facility for the measurement of health-related quality of life. Health Policy 1990;16(3):199-208.

21. Johannesson $M$. Avoiding double counting in pharmacoeconomic studies. Pharmacoeconomics 1997;11(5):385-8.

22. Weinstein MC, siegel JE, Garber AM, et al. Productivity costs, time costs and health-related quality of life: a response to the Erammus group. Health Econ 1997;6:505-10.

23. Brouwer WBF, Koopmanschap MA, Rutten FFH. Productivity costs in cost-effectiveness analysis: numerator or denominator: a further discussion. Health Econ 1997,6: 511-14.

24. Claxton K, Sculpher M, Drummond M. A rational framework for decision-making by the National Institute For Clinical Excellence (NICE). The Lancet 2002;360:711-715.

25. Stinnett AA, Mullahay J. Net health benefits: a new framework for the analysis of uncertainty in cost in cost-effectiveness analysis. Med Decis Making 1998;18:S65-S80.

26. Van Hout BA, AL MJ, Gordon GS, et al. Costs, effects and C/E-ratios alongside a clinical trial. Health Econ 1994;3:309-319.

27. Gelman A, Carlin JB, Stern HS, et al., editors. Bayesian data analysis. London: Chapman \& Hall, 1995.

28. Briggs AH, Ades AE, Price MJ. Probabilistic sensitivity analysis for decision tress with multiple branches: use of the Dirichlet distribution in a Bayesian framework. Med Decis Making 2003;23:341-50.

29. Briggs A, Goeree R, Blackhouse G, O'Brien B. Probabilistic analysis of cost-effectiveness models: choosing between treatment strategies for gastroespohageal reflux disease. Med Decis Making 2002:22:290-308.

30. Szende A, Svensson K, Stah E, Meszaros A, Berta GY. Psychometric and utility-based measures of health status of asthmatic patients with different disease controll level. Pharnacoeconomics 2004;22(8):537-47.

31. Schemer TR, Thoonen BP, Van den Boom G, et al. Randomized controlled economic evaluation of asthma selif-management in primary health care. Am J Resp Crit Care Med $2002 ; 166: 1062-72$.

32. Linden A, Adams JL, Robetts N. Evaluating disease management program effectiveness: an introduction to time-series analysis. Dis Man 2003;6(4):243-55. 


\section{GENERAL DISCUSSION}




\section{INTRODUCTION}

The main goal of this thesis was to evaluate the effects and resource implications of disease management programmes (DMPs) for patients with diabetes mellitus, asthma or COPD. This chapter summarises the main findings from the individual studies. General conclusions are drawn with regard to methodological aspects of HTA of disease management, the influence of organisational structures on design and performance of programmes and the impact of DMPs on costs and quality of care for patients with diabetes, asthma or COPD. Methodological strengths and limitations of the presented studies are discussed, while the implications of this research for policy and practice as well as recommendations for further research are described at the end of this chapter.

\section{GENERAL CONCLUSIONS}

Against the background of an increasing burden of chronic diseases on today's healthcare systems and the specific needs of chronically ill patients, redesign of the healthcare system is considered of utmost importance [1-3]. By organising healthcare according to principles of disease management it is aimed to meet the needs of these patients, while safeguarding the affordability of good quality healthcare now and in the future $[4,5]$.

In order to assess to what extent DMPs meet the expectations with regard to their presumed effectiveness and efficiency, methodological challenges need to be uptaken. First of all, it was concluded that existing instruments to assess methodological quality of HTA of disease management could be improved by introducing new items that are worthwhile from a decision-making perspective, while other items were considered as less relevant. Secondly, this research revealed a need to pay more attention to organisational structure indicators, in order to predict the influence of specific organisational characteristics on disease management processes and outcomes, and to optimise the design of the programmes. Thirdly, we concluded that due to a lack of comparable data on programme effectiveness and efficiency, paucity of information exists that is scientifically justified and useful for decision-making purposes. An analytical framework for HTA of disease management was proposed to contribute to further research.

With regard to the organisational research questions the following conclusions were drawn. No statistically significant relationship can be demonstrated between the type of healthcare system and the design of a programme, as reflected in the completeness of programmes or the presence of specific components. Also, the hypothesis that a more complete programme would have more or larger effects on processes and outcomes of care than less complete programmes could not be affirmed. The pres- 
ence of a collaborative practice model or patient self management educationas component(s) of a DMP was found to be associated with a positive effect on self-effcacy of patients.

Concerning the diabetes, asthma and COPD programmes that have been implemented in the region of Maastricht, we conclude that redesign of care delivery according to disease management principles is associated with improvements in quality of care within the existing budget restraints. In the long term, the DMP for patients with asthma showed to have the highest probability of being cost effective (90\%) as compared to usual care. It was recognised that changes in clinical guidelines underpinming the programmes, might lead to changes in the assignment of patients to care providers, inducing new prevention and treatment strategies and potentially influencing resource utilisation. Finally, the use of decision-analytic modelling techniques to extrapolate data beyond the follow-up period and explicitly evaluate decision uncertainty, proved to be a useful tool in HTA of disease management.

\section{METHODOLOGICAL CONSIDERATIONS}

Within this research a variety of research methods has been applied, being systematic literature reviews, pre-post test studies and decision-analytic modelling studies. Several methodological considerations arise from each of the applied methods. Subsequently, the strengths and weaknesses of the methods are discussed and a reflection on potential bias of the results is provided.

\section{Systematic literature reviews}

Systematic reviews am to identify relevant studies in a particular topic area, appraise their quality and summarise their results using a scientific methodology [6]. Assessment of methodological quality of studies being reviewed is regarded as one of the key components of a systematic review $[7,8]$. The methodological quality of HT A of disease management has been critically evaluated, before undertaking the systematic reviews.

Before starting expensive, large scale studies, a systematic review was used to direct empirical research by generating hypotheses that are derived from all current available evidence on the subject. This immediately leads to the weakness of any systematic review: the impossibility to detect all available relevant studies. Delays in publication and failure to publish non-significant or negative results introduce publication bias into systematic reviews [9]. Bias can also be caused by sub optimal search strategies and exclusion of non-English publications [1.0]. Due to different definitions of 'disease management' and its features [11], our search strategy was likely to be biased by terminology. To improve comparability and prevent further bias, we 
subscribed to search strategies of previously published systematic reviews towards disease management as much as possible [12-15]. Not only English-language publications were searched for; also studies written in Dutch and German language were eligible for inclusion. Still, in both reviews only a few studies concerning COPD were identified. This might indicate that our search strategy was not appropriate for COPD disease management. Another explanation might be that only a few DMPs for patients with COPD exist. Management of COPD is often aimed at pulmonary rehabilitation [16], smoking cessation [17] and/or patient self management [18]. Since these interventions only cover one specific part of the care continuum or focus on one aspect of care delivery, they were not regarded 'disease management programmws' in the way we conceptualised these. Furthermore, stratification procedures of interventions for patients with COPD were not comparable to ours and many studies solely focus on patients with severe COPD [19]. Especially with regard to COPD programmes, the results from the systematic reviews should be interpreted carefully and substantiated with further empirical data.

\section{Using a pre-post test design for programme evaluation}

Several limitations need to be taken into account when interpreting the results of the progranme evaluations. From a traditional perspective on causation, the use of a pre-post test design is not ideal given the nature of the main research question. Studying the impact of an intervention on effectiveness and efficiency of care requires a research design that allows for drawing valid causal inferences. Preferably, subjects are randomly allocated to the intervention or comparator, while both are standardised and kept constant during the trial. Multiple causation and contingent causes create problems in the evaluation of DMPs [20], for which hardly any satisfying solution exists.

Our choice for a pre-post test design is an attempt to apply the most rigorous research design as possible, while observing the effects of complex programmes in their natural environment: an observational study, observing both the processes and outcomes of usual care and disease management strategies, without forcing daily practise into a standardised setting.

Since the use of a pre-post test design did not allow us to demonstrate a causal relationship between the introduction of the DMP and the observed changes, the burden of proof was turned around. To our knowledge, no other changes in healthcare delivery or specific co interventions occurred during the observation period that could explain improvements of a comparable magnitude.

Another consequence of the pre-post test design is that measurements are compared over time and are thus vulnerable to 'regression to mean' [21]. As a result of regression to the mean, changes in measurements can mistakenly be attributed to a treatment effect, although it is actually caused by chance. When considering our results against 
the background of regression to the mean, two issues need to be stressed. Firstly, regression to the mean would cause the highest measurements to decrease, the lowest to increase and the measurements most close to the population mean to stay fairly constant. This does not apply to the changes as observed in our studies. Secondly, we derived representative samples from the total population of patients with asthma, COPD or diabetes. Herewith, the study population was heterogeneous at baseline with regard to parameters of interest, as disease severity and resource utilisation. Also, study populations were reasonably large. Therefore, the first measurement was not likely to be so different from the population mean.

Finally, regression to the mean is not likely to have a selective effect on particular parameters, assuming that deviation from the mean is comparable among parameters. Thus, regression to the mean would have biased the results in all patients, not selectively affect utility values of patients assigned to the respiratory nurse and cost estimates of patients assigned to the pulmonologist, as pointed out in chapter 8. Without underestimating the power of this regression to mean, we are confident that the observed results can at least to a large extent be attributed to the introduction of the DMPs.

\section{Measurements and instrumentation}

HTA aims to provide input to decision-making in policy and practice by assessing interventions on their effectiveness and at least one other aspect of care $[22,23]$. Until recently, evaluations of disease management have not been of great help to decision makers [5]. Diversity in applied indicators is one of the main reasons for this [24]. Therefore, a framework for evaluating DMPs has been developed. Since DMPs affect structures, processes and outcomes of care delivery, the paradigm of Donabedian [25] was adopted as the basis for operationalisation of the indicators. The framework should guide researchers in defining a minimum data set that enables them to provide relevant and useful information for decision-making in healthcare. Which of the suggested indicators is chosen as the primary outcome depends on: 1) the perspective that is taken on costs and effects, 2) the type of stakeholder at whom the information is targeted (the 'audience") and 3) the timeframe of the study. From a societal perspective, incremental overall healthcare costs/quality-adjusted life year (QALY) are considered as the outcome of primary interest. Health insurers, however, might prefer direct healthcare costs or general health status of the patients as more important. Physicians might value specific clinical data (e.g. $\mathrm{HbA}_{1}$, or respiratory control) as the most important indicators, while policy-makers could prefer QALYs since these are comparable across different diseases. When the timeframe of the study is limited, indicators that are relatively sensitive to changes in care delivery (i.e. process or intermediate measures) are preferred over less sensitive indicators as general health status or health-related quality of life (HRQL). When applying the 
proposed framework to the evaluation of the asthna, COPD and diabetes DMPs, it can be seen that most structure, process and outcome indicators that are mentioned in the framework are addressed by our studies. The emphasis that is placed on a specific type of indicator depends on the purpose of the evaluation and the nature of the research questions, reflecting the perspective, the 'audience" and the timeframe of the study.

The clinical data used in this study were obtained from caregivers" registries. It was found that data collection of patients cared for by the nurse specialist was more complete than data collection of the other care providers. The same observation was made by Vrijhoef (2001), who investigated the effects on quality of care when tasks are transferred from physician to nurse specialist [26]. To this regard it needs to be recognised that nurses, GPs and medical specialists do not use the same (electronic) patient record system, which is likely to affect the completeness of data collection. Less complete data might result in relatively more uncertainty surrounding costs and effects of care, herewith hindering decision-making.

To address a societal perspective, direct and indirect costs are collected. Furthermore, analyses were performed excluding productivity losses, herewith reflecting the insurance perspective. Costs were calculated in accordance with the Dutch guidelines for economic evaluations [27]. Resource use was measured by means of a previously tested, disease specific booklet [26] and verified with administrative data from care providers. The validity and reliability of retrospective questionnaires to measure resource utilisation can be discussed. The question that arises is whether using such questionnaires leads to valid results, because a potential for recall bias exists in all studies in which historical self-reported information from respondents is used $[28,29]$. Alternatives sources to obtain these data that are less vulnerable to recall bias, are cost diaries or routine databases from insurers, hospitals or pharmacies. Although data from insurers may seem the most reliable, they are not equipped to provide detailed information on resource use due to budget or capitation paid systems. There is also a lack of visibility into the medical consumption that is not covered by the patient's insurance as well as the input from informal care givers $[30,31$. . The multiplicity of providers involved in chronic care delivery further limits the feasibility of data collection on resource use. Compared to questionnaires, diaries have been reported to offer several advantages in terms of feasibility and validity $[30,32-36]$, since they provide information prospectively over a period of time, resulting in a minimum recall bias [30]. However, containing a cost diary for a long period of time indicates a substantial workload for participants, which can result in missing data [37]. A study towards the precision and accuracy of a retrospective self-administered questionnaire on sick leave revealed that $95 \%$ of the reported data matched the registered data perfectly when the recall period was limited to two and four weeks. This percentage decreased to $87 \%$ and $57 \%$ for recall periods of respectively two and six 
months. However, no systematic positive or negative differences between registered and reported data were found [28].

In administering self-reported questionnaires for measuring resource utilisation we were able to collect all relevant data on medical consumption whether or not covered by insurance companies. The recall periods of respectively three and six months seem quite long given the decrease in accuracy after two months [28]. This increases uncertainty regarding the estimates, but does not cause systematic errors in either a positive or negative direction. It also needs attention that the accuracy of recall might be affected by the aging of the population during follow-up. Especially in our study of diabetes disease management, where the mean age ( $t$ sd) of patients at baseline was relatively high $(69.3 \pm 12.3$ years), this might have affected our findings.

Finally, since the pre measurement period in both studies was shorter than the post measurement period (three vs. twelve months for asthma and COPD; six months vs. two years for diabetes) the pre measurement data were multiplied to estimate resource utilisation for a longer term (e.g. one or two year). This approach is only valid when large numbers of respondents participate [38]. Given the magnitude of our samples ( $n=473$ for diabetes and $n=975$ for asthma and COPD) the validity of the multiplicated data seems reasonable. However, as long as no threshold is known for the number of patients that is needed to justify this approach, the validity remains debatable.

\section{Sample sizes and completeness of data collection}

The samples in this study can be considered as 'opportunity samples' since sample size was defined by the number of participating GPs, the criteria for inclusion and the willingness of patients to participate. Sample size was not defined by power calculation, because no particular outcome measure was considered as the primary outcome of interest. Different stakeholders may perceive different outcomes to be of nost importance. Furthermore, defining the minimal important difference is already considered as arbitrary when only one stakeholder, for example the physician, is at stake. Several factors may influence the perception of minimal important difference, including 1) the therapy's side effects, inconvenience and expense, 2 ) the severity of the health outcome that the treatment is attempting to prevent, 3) the physician's training and their experience with the therapy and 4) the mothod co elicit the minimal important difference, such as relative versus absolute risk reduction methods [39]. As a result, we cannot exclude the possibility that we incorrectly accepted that no difference between the strategies exists with regard to certain estimates. Due to the relatively large uncertainty around cost estimates [40], this outcome measure is considered to be most vulnerable to such an error.

Response and completion rates within both studies were moderate to high, varying from $52 \%$ after two year follow-up in the diabetes study to $96 \%$ at baseline within the 
study towards asthma and COPD. Although these figures are rather good for longitudinal studies with chronically ill [26], the missing values selectively affected measurements of the disease management strategy. In both studies; patients assigned to the GP were less likely to complete data collection as compared to patients assigned to the nurse specialist or medical specialist. However, no selective loss to follow-up within the subgroup of patients assigned to the GP was found. As a result, patients with missing data had on average higher values of $\mathrm{HRQL}$, showed better disease control, and reported lower costs than patients with complete follow-up. Estimates of costs and effects of the disease management strategy are therefore more likely to be underestimated than overestimated.

\section{Reliability of data and generalisability of results}

Estimates of health-related quality of life and costs were compared to data from other studies towards asthma, COPD or diabetes, to assess the reliability of our findings. This was considered important since the pre measurement periods were relatively short and therefore vulnerable to bias caused by coincidently low or high estimates.

Overall, our estimates of HRQL and costs were reasonably comparable with data from other studies. Our estimates of HRQL as established with the SF-36 were slightly lower than the EQ-5D scores found by Redekop et al. (0.65 vs.0.67 for patients aged between 60 and 69 years) [41], while the baseline VAS scores as measured by Vrijhoef et al. were identical to our baseline estimates on the VAS [42]. The baseline cost estimates from our diabetes study were comparable to the estimates of Redekop et al. When excluding productivity costs we found baseline costs to be $€$ 788 per six months, while Redekop et al. estimated these to be $€ 755$ for patients aged between 60 an 69 [43].

Although not optimally comparable due to different settings (i.e. Hungary vs. The Netherlands), the most recent published study on HRQL in patients with asthma, as measured with the EQ-5D, suggested a mean score of 0.70 in usual care. This estimate is comparable to our finding of 0.72 [44], given that disease severity in our study was lower. Concerning asthma related costs, Schermer et al. found annual direct costs within usual care to be circa $€ 400$ per patient in the Netherlands [45]. This estimate did not include costs for hospital admissions or emergency room visits. Given that we did include costs for hospitalisation, our estimate of overall direct costs within usual care lies with $€ 660$ per patient per year reasonably higher.

Furthermore, the impact of the 'Maastricht' DMPs was compared with results of other programmes as described in literature reviews on disease management $[4,5,12$, 141. In general, these reviews reveal that 1) DMPs show greater improvements in processes of care and intermediate outcomes than in end results of care $[4,14] ; 2)$ the effectiveness of programmes varies between diseases $[4,14]$; 3) there is only limited evidence that DMPs save money $[4,5,14,15]$, and 4 ) the long-term impact on 
outcomes is still unknown [5]. When considering our results against this background, many similarities but also some differences are observed.

A similarity is that the introduction of DMPs in the region of Mastricht, is associated with improvements in several process measures as, adherence to guidelines (e.g. increase in number of routine consultations), better co-ordination and improved accessibility of care. Also, significant improvements in intermediate outcomes, as self management behaviour and disease specific knowledge, were found. Less common findings were observed with regard to end results of care. First of all, clinical outcomes improved significantly after introduction of the programmes. Hospitalisation as well as the number of non-routine consultations decreased among patients with asthma or COPD. Since hospital admissions and non-routine consultations generally result from asthma "attacks" or COPD exacerbations, this implicates an increase in disease control. For patients with diabetes, glycaemic control inmproved significantly as did other laboratory results. In terms of costs per additional QALY, all programmes were considered to be cost effective in comparison to usual care, although the magnitude of savings per additional QALY varied per disease. In the short term, cost savings were only found to be statistically significant for the asthma programme.

A strength of this research is the application of methods to estimate the longuterm resullts of the programmes jointly with decision uncertainty. We bellieve that decision-making, based on information resulting from a decision-analytical model, as presented in chapter 8 , is more straightforward and less arbitrary than making a decision based on the results of the more traditional analyses presented in chapter 6 . Although our findings are to a large extent comparable with other findings, it is recognised that generalisability of results from economic evaluations is limited by a number of factors $[46,47]$. In discussing the extent to which the results of our research hold true for another population and/or in a different context, we focus on the location in which the study was undertaken. Firsty, the location in which the programmes have been implemented is quite unique in the Netherlands. The combined function of the University Hospital Mastricht, being both a regional as well as a teaching hospital, is not comparable to any other hospital in the Netherlands. Secondly, there is a relatively long tradition of working with nurse specialists and (forms of) integrated care in this region. Learning costs that are due to less efficient care delivery at the start of such innovations are therefore limited. Thirdly, unit costs are often higher in an academic setting $[27]$ and also resource utilisation and effectiveness of care delivery might differ [46]. A fourth factor that often limits generalisability of study results is that data are collected under standardised conditions that do not reflect every day care delivery [47]. The latter does not apply to our research.

There are several methods to enhance generalisability of economic evaluations using patient-level data or decision-analytic modelling. In the following, we describe some of them and discuss to what extent they have been applied in our study. Firstly, 
patients included in studies should reflect normal clinical caseloads. By formulating relatively few exclusion criteria and including patients with varying disease severity we aimed to safeguard this. Secondly, resource data should be reported separately from unit costs. This has only partly been done. In the study towards asthma and COPD disease management, resource use in combination with overall healthcare costs has been reported, while for information on unit costs we referred to the Dutch guidelines for economic evaluation [27]. In the diabetes study, unit costs, tota] healthcare costs and costs for specific types of care (e.g. costs for consultations, hospitalisation costs and medication costs), were provided. Herewith, it is possible to derive estimates of resource use from the presented data and use these to calculate costs in other settings. In the decision-analytic model, we presented cost inputs per health state and by type of resource used, again referring to the Dutch guidelines for economic evaluations for information on unit costs. Although these approaches might not be optimal, the relative difference between costs of usual care and disease management can still be used to estimate potential cost savings in other settings, since unit costs were considered constant in the evaluation. Thirdly, multilevel analysis has been proposed as a means to address the degree of clustering in cost and effectiveness data across different trial locations [48]. Since our study encompassed only one tria] location as such, this approach was not applicable to enhance generalisability. Finally, since our research merely observed the care delivery processes before and after implementation of the programmes, hereby accepting incidental deviations from the protocol as they occur in every day healthcare, we believe that out data provide a fairly good reflection of the potential benefits of DMPs as employed in daily practise.

\section{Statistical considerations}

As in all pragmatic trials, missing values due to "loss to follow-up" have the potential to selectively affect one of the treatment strategies. In pre-post test studies, this is most likely the intervention that is assessed in the post measurement period. To protect against systematic differences between comparison groups, intention to treat analysis should be applied. The suggested method for handling missing responses is carrying the last observed response forward [49]. This conservative method has been applied in both the diabetes as well as the asthma and COPD study.

Furthermore, the occurrence of error due to incongruence between the unit of allocation and the unit of analysis has to be considered. This error is likely to occur in evaluations of interventions that aim to improve quality of care [50] and leads to an increase of the apparent precision of estimates [48,51]. Since some components of the DMP are directed to the care providers (e.g. provider feedback, changes in case load as a result of the allocation procedure), while outcomes are analysed at the patient level, clustering of patients within care providers needs to be taken into account. Patients treated by one particular care provider are not as independent from each 
other, as they are from patients that are treated by another care provider. Ignoring this 'intra provider correlation' might result in incorrect acceptance of the alternative hypothesis [51]. Multilevel analysis has been performed in analysing the relationship between changes in processes and intermediate outcomes on the one hand, and changes in end results of care on the other. We found that accounting for clustering of patients within care providers did not influence the precision of estimates. This might explained by the fact that only some components of the DMP were aimed at care providers, while other components were directly aimed at patients. Further support was found in a study of Redekop et al, showing that only $1.6 \%$ of variation in HRQL was explained by differences between care providers, while $94.6 \%$ was explained by variation at the patient level [41]. Therefore, further analyses were performed using standard statistical methods for repeated measurements, taking the dependency between pre and post measurement into account. Were appropriate, Bonferroni correction was applied to correct for multiple testing [48].

\section{Decision-analytic considerations}

The application of decision-analytic techniques enabled us to assess the magnitude of uncertainty surrounding this decision. This facilitated more straightforward decision-making, while the costs of failing to select to most cost effective strategy could be measured in terms of resources and health benefit forgone [52].

The use of modelling techniques enabled us to combine data from different sources. Next to our empirical data, mortality estimates from a secondary data source were used. Herewith, a decision-analytic Markov model was informed, estimating the long-term cost utility of a DMP for patients with asthma. One of the strengths of our approach was the separation of decision uncertainty from parameter uncertainty $[53,54]$. The joint uncertainty surrounding the inputs that are used to calculate the net benefit has been reflected in uncertainty surrounding the outcomes by making the model fully probabilistic. To our knowledge, this is one of the first probabilistic decision models estimating the long-term impact of a DMP.

Naturally, there are also some drawbacks of modelling studies that cannot be ignored here. First of all, models are by definition unable to perfectly represent the complexity of reality [55]. In our model for example, patients were unable to switch between care providers, which in reality is possible. Allowing for this transition possibility would increase the complexity of the model enormously. Since only $3 \%$ of patients switched from one care provider to another during the trial period, this simplification was unlikely to systematically bias the results.

Furthermore, models are often considered "black boxes", while validation is challenging when no comparable long-term data are available. Therefore, providing sufficient detail on the model's inputs, assumptions and algorithms is of utmost importance to judge its validity $[56,57]$. In our model, for example, transition proba- 
bilities were assumed constant over time, which in reality will not be the case. Given the "no-memory" characteristic of Markov models, the only way to deal with changing transition probabilities over time, for example induced by the occurrence of certain events (e.g. an exacerbation), is to define intermediate health states [58]. However, without sufficient long-term data to inform these transitions, only more uncertainty would be introduced into the model when attempting to account for this. Since the time horizon of the model was limited to five years, multiplication of potential bias caused by this was considered to be fairly limited.

\section{RECOMMENDATIONS}

\section{Recommendations for policy and practice}

First, recommendations that follow directly from the conclusions of this research will be proposed. Hereafter, recommendations targeted to specific components of the "Maastricht' DMPs will be presented. Finally, more generall recommendations with regard to design and organisation, education, legislation and financing of disease management will be done. Whenever these recommendations do not follow directly from our research, reference is made to other studies that substantiate the recommendation.

The results of this study suggest that it is beneficial to deliver healthcare according to the principles of disease management for patients with asthma, COPD or diabetes. Not only patients benefit from the disease management strategy, also health insurers and even employers experience advantages of better quality of care for chronically ill. Continuous monitoring and optimisation of programmes is considered necessary, since the processes of care and the resulting cost effectiveness of the programmes are likely to be influenced by, for example, changes in underlying guidelines. Moreover, the long-term impact of the programmes should be considered when deciding about adoption or rejection of these innovations instead of short-term results, since the largest benefits are shown to occur in the long term.

Several recommendations can be done to further optimise the 'Maastricht' DMPs. The population-identification processes that are employed within the programmes are currently based on GPs' and hospital registries. Since it is widely recognised that many patients with COPD, asthna and diabetes remain undiagnosed until complications arise, it is recommended to intensify efforts for identifying 'high risk' patients [59-62]. Herewith, development of the disease might be prevented, while early detection of the disease can prevent or slow down further deterioration of the patient's health status. Moreover, early detection has shown favourable effects in 
patients, while it is not by definition associated with an increase in healthcare costs [62-64]. Systematic primary prevention of chronic illness is currently not a part of the DMPs, although previous studies show, for example, that nurse specialists can also credibly detect COPD in its early onset among undiagnosed patients and patients "at: risk' for COPD [65]. Further exploration of the opportunities to include primary prevention within the programmes is recommended. With regard to prevention of complications and exacerbations, the programmes have proved to be rather eftective, especially for patients assigned to the nurse specialist.

Evidence based practice guidelines are at the heart of the "Maastricht' DMPs. Adherence to these guidelines and to the multidisciplinary care protocol, which was based upon them, is of utmost importance to guarantee cost effective care delivery in the future. As can be seen from the results in chapter 8 , care delivery for patients with asthma that are assigned to the nurse specialist is highly effective, but also slightly more expensive than care delivery in usual care. This implicates that, in the case of asthma, the protocol should be followed very strictly with regard to the assignment of patients to the respiratory nurse specialist. Patients that do not necessarily require intensification of care should be taken care of by the GP. Although care delivery by the diabetes nurse specialist was found to be less expensive and more effective than care delivery in usual care (chapter 7), this does not justify the conclusion that all. patients with diabetes should be taken care of by the nurse. Patients with low disease complexity, but substantial co morbidity, are preferably taken care of by their GP. For complicated issues related to diabetes, the GP can then consult the nurse specialist, if necessary.

Although provider adherence to guidelines improved after introduction of the DMPs, continuous monitoring and feedback is required to further encourage the adherence among all parties involved. For patients assigned to the nurse specialist, it was found that following the guidelines more closely pays off in better quality healthcare.

The collaborative practice model, as represented by the core team of $\mathrm{GP}$, medical specialist and nurse specialist, was considered as one the critical success factors of our programmes, although its effectiveness cannot be separated from the other components. The so-called "QUATTRO-model" [66] that describes the co operation between GP, medical specialist, nurse specialist and community nurse, has been instrumental for this. Given the increased attention to and evidence for effective lifestyle programmes, including physical fitness and nutritional advice [67-69], further collaboration with paramedics and other support services should be established.

To conclude, general recommendations with regard to design and organisation, education, legislation and financing of DMPs will be described.

Firstly, existing management and incentive structures in a particular region need to be considered carefully when designing a programme and planning its implementa- 
tion. If a programme does not 'fit' its environment, it will not work optimally and might not fulfil the expectations properly. With regard to the design of DMPs, the chronic care model as proposed by Wagner et al., might be instrumental as a starting point $[2,70]$. Although the chronic care model and 'disease management' are perceived as being two different concepts in the United States [71], the Dutch operationalisation of the concept 'disease management' [72] suits the characteristics of the chronic care model to a large extent. In fine-tuning the programme to fit a certain organisational context, the use of system dynamics modelling is proposed. Although there is limited experience in Western Europe with the application of this technique to $\mathrm{DMPs}$, internationally, the results are promising [73]. System dynamics modelling aims to provide insight into the potential consequences of a specific DMP to be implemented. Herewith, it supports decision-making concerning design and implementation with quantitative information. Furthermore, it has the ability to compare the potential success of different implementation strategies as well as the impact of various combinations of interventions that might be included in the programme. Since it also evaluates the differential impact on affected parties, it provides the opportunity for stakeholders to assess the potential return on investment beforehand [73].

Another important issue that needs to be discussed is the education of nurses and physicians. Within the last couple of years, different institutions developed several educational courses for new professionals like nurse specialists, physician assistants and practice nurses. Clarity with regard to the core tasks of each of these professionals is necessary to maintain transparency in functions. Moreover, since many of these nurses focus on specific patient populations and work in prinary care, there is a threat that primary care becomes too fragmented again, especially for chronic patients with co morbidity. An adapted form of the joint consultation system [74-76], wherein the GP, medical specialist and/or nurse specialist form a core team, might be a solution for this. In addition to the attention for the training of nurse specialists, physicians also need to be prepared better for working within multidisciplinary teams. All care providers should be aware that variations in the organisation, goals, culture, leadership and team characteristics are associated with the perceived effectiveness of healthcare teams and their success in making meaningful system changes [77]. Working in healthcare teams means that responsibilities need to be specified. When applying a team approach, it seems reasonable that that all care providers can be hold responsible for the care delivered by them. Where healthcare domains overlap, explicit agreements need to be made about responsibilities. Otherwise, shared care might become shared neglect. Legislation needs to reflect daily practice, in which the nurse specialist gained autonomy as compared to traditional care and performs tasks that belonged to the domain of the physician. For the patient it should be clear which care provider is ultimately responsible for the delivery of care. From a focus group interview with patients, it was found that they consider the nurse specialist to be 
competent to independently prescribe drugs in the domain of their specific expertise. They would prefer the nurse to authorise referrals or prescriptions instead of requiring authorisation form the GP [78]. In the Netherlands adaptation of legislation would require amendments to the Individual Healthcare Professionals Act (Wet Beroepen Individuele Gezondheidszorg), the Medical Treatment Act (Wet Geneeskundige Behandelings Overeenkomst) and the Law on Medicines (W ap de Geneesmiddelen-voorziening). Moreover, conflicting legislation on European level should be identified [79].

Finally, the pricing system that is currenty implemented in the Netherlands, the so-called Diagnosis Treatment Combinations-system (Diagnose Behandel Combinaties), should not only focus on diagnosis-treatment combinations within a certain institution, but also across institutions to facilitate cost effective innovations in healthcare such as DMPs. Apart from attention to collaboration along the care continuum, there should also be room to include 'new' elements of care, such as telemonitoring and transfer of tasks, within the pricing system.

\section{Recommendations for further research}

Several recommendations for further research arise from this thesis. The first recommendation is to obtain further insight into the type of uncertainty surrounding the cost utility of the DMPs. From our data it seems that part of this uncertainty is caused by variability in patient pathways along the care continuum. Unnecessary variability in patient pathways incurs additional costs and might be the result of sub optimal steering towards optimisation of care processes within the DMPs [80].

If uncertainty around the cost utility of the DMPs can indeed be characterised as variability, then target costing can be used to re-engineer the healthcare chain and the organisation of the programmes. In target costing, the cost of a new service is no longer an outcome of the service design process; it becomes an input into the process [81]. Furthemore, the value and costs of quality management and/or engineering of programmes can be addressed by applying target costing. As a result, programmes can be re-designed to assure optimal quality of care for a predefined price.

A second recommendation for further research concerns the influence of management and incentive structures as well as organisational context on the net health benefit of programmes. In many western countries, increased market forces in the healthcare system led to changes in management and incentive structures. This may affect design and cost effectiveness of programmes. Moreover, information on the relation between structures, processes and outcomes of care, may lead to a better understanding of the impact of a particular DMP on processes and outcomes of care, given the context in which it has been implemented. It is proposed to apply system dynamics modelling to further investigate this. 
Thirdly, we recommend using decision-analytic modelling in economic evaluations in order to estimate long-term cost utility including the effects on complications, exacerbations and mortality. A fourth recommendation for further research on this topic would be to include cost estimates of time spent by informal caregivers as well as houschold costs that are induced by living with a chronic disease.

Finally, it is recommended to apply value of information analysis in order to assess the expected value of further information (EVPI). If the costs of further research exceed the EVPI, the decision to either adopt or reject the new technology should be made, based on the probability that the technology is cost effective. If the EVPI for the population of current and future patients exceeds the costs of further research, it is potentially cost effective to acquire more information [52]. The value of reducing the uncertainty around each of the inputs cam also be established, herewith prioritising further research by identifying those inputs for which more precise estimates are most valuable. This simultaneously directs the design of further research: some parameters to be further investigated might require experimental design, while others can best be assessed by long-term observational studies. Also, the expected value of sample information can be established in a comparable way, informing the required sample sizes of further research (either for a technology as a whole or for specific model inputs) without being dependent on the arbitrary rules of statistical inference. It is proposed to develop a decision-analytic model that includes data on structure parameters and is suitable to employ value of information analysis, so that the value of further information can also be assessed given a certain organisational context.

\section{REFERENCES}

1. Wagner $\mathrm{EH}$, Austin BT, Von KorfHM. Organizing care for patients with chronic illness. Millbank Q 1996;74:511-4.

2. Wagner EH. Chronic disease management: What will it take to improve care for chronic illness? Eff Clin Pract 1998;1:2-4.

3. Bodenheimer $T$, Wagner $E H$, Grumbach $K$. Improving care for patients with chronic illness. JAMA 2002;288:1775-9.

4. Bodenheimer T, Wagner EH, Grumbach K. Improving primary care for patienst with chronic illness. The chronic care model, part 2. JAMA 2002;288: 1909-14.

5. Holtz-Eakin D. An analysis of the literature on disease management programmes. Congressional Budget Office, U.S. Congress, Washington DC, 2004. www.cbo.gov Last accessed July $27,2005$.

6. Khan KS, Kunz R, Kleijnen J, Antes G. Systematic reviews to support evidence-based medicine: how to review and apply findings of health care research. London: Royal Society of Medicine Press Ltd, 2003.

7. Jadad AR, Moore RA, Carroll D, et al. Assessing the quality of reports of randomized clinical trials. Controlled Clinical Trials 1996:17:1-12. 
8. Moher D, Jadad AR. Nichol G, Penman M. Tugwell P, Walsh S. Assessing the quality or randomized controlled trials. Controlled Clinical Trials 1995;16:62-73.

9. Muir Gray JA. Evidence-based healthcare: how to make health policy and management decisions. Edinburgh: Churchill Livingstone, 2001.

10. Moher D, Fortin P, Jadad AR, et al Completeness of reporting trials published in languages other than English: implications for consuct and reporting of systematic reviews. The Lancet $1996 ; 347: 363-6$.

11. Kodner DL, Spreeuwenberg C. Integrated care: meaning, logic, implications and applications: a discussion paper. IylC 2002;2 www.ijic.ong Last accessed. July $28,2005$.

12. Norris SL, Nichols PJ, Caspersen Cl et al. The effectiveness of disease and case management for people with diabetes. A systematic review. Am J Prev Med 2002;22(Suppl 4):15-38.

13. Weingarten $S R$, Henning JM, Badamgaraw $E$, et al. Interventions used in disease management programmes for patients with chronic illness - which ones work? Meta-anallysis of published reports. BMJ 2002;235:925-37.

14. Ofman JJ, Badamgarav E, Henning JM et al. Does disease management improve clinical and economic outcomes in patients with chronic diseases? A systenatic review. Am J Med 2004 Aug 1;117:182-92.

15. Knight $\mathrm{K}$, Badamgarav E, Henning IM et al. A systematic review of diabetes disease management programs. Am J Manag Care 2005;1 1:242-50.

16. Troosters $T$, Casaburi $R$, Gosselink R, Decramer $M$. Pulmonary rehabilitation in chtonic obstructive pulmonary disease. Am J Resp Crit Care Med 2005;172:19-38.

17. Wagena EJ, Van der Meer RM, Ostelo RJWG, Jacobs JE, Van Schayck CP. The efficacy of smoking cessation strategies in people with chronic obstructive pulmonary disease: results from a systematic review. Resp Med 2004;98:805-15.

18. MonninkhofE, Van der Valk $P$, Van der Palen J, Van Herwarden $C$, Partridge MR, Zielhuis G. Self-management education for patienst with chronic obstructive pulmonary disease: a systematic review. Thorax 2003,58:394 8.

19. Wouters EFM. Management of severe COPD. Lancet 2004;364:883-95.

20. Cook TD, Campbell DT. Quasi-experimentation: design and analysis issues for field setkings. Chicago, Rand McNally College Publishing Company, 1979.

21. Morton V, Torgerson DJ. Regression to the mean: treatment effect without the intervention. I Eval Clin Pract 2005;11:59-65.

22. Banta D. The development of Health Technology Assessment. Healtin Policy 2003:63:12:1-32.

23. Platform HTA. Stimulering HTA in Nederland. Raad woor Gezondsheidsonderzoek, Den Hagg, 2001. [in Dwth]

24. Villagra V. Strategies to control costs and quality: a focus on outcomes research for disease management. Med Care 2004:42(Suppl 4):II124-30.

25. Donabedian A. The definition of quality and approaches to its assessment. Ann Arbor, Mich: Health Administration Press, 1980. 
26. Vrijhoef HJM. Is it justifiable to treat chronic patients by nurse specialists? Evaluation of effects on quality of care. Dissertation. Universiteit Maastricht, Maastricht, The Netherlands, 2002.

27. Oostenbrink ]B, Koopmanschap MA, Rutten FFH. [Guidelines for economic evaluations: methods and standard cost prices for economic evaluations in health care]. Handleiding voor: kostenonderzoek: wethoden en standard kostprijzen voor economische evaluaties in de gezondheidszorg. Geactualiseerde versie 2004. Amstelveen: College voor Zorgverzekeringen, 2000. [in Dutch]

28. Severens JL, Mulder ]. Laheij RJF, Verbeek ALM. Precision and accuracy in measuring absence from work as a basis for calculating productivity costs in The Netherlands. Soc Sc Med 2000;51:243-9.

29. Raphael K. Recall bias: a proposal for assessment and control. Int J Epidemiol $1987 ; 16: 167-70$.

30. Goossens MEJB, Rutten-van Mölken MPMH, Vlaeyen JWS, Van der Linden SMJP. The cost diary: a method to measure direct and indirect costs in cost-effectiveness research. J Clin Epideniol 2000;53:688-95.

31. Drummond MF, O'Brien B, Stoddart GL, Torrance GW. Methods for the economic evaluation of health care programmes. New York: Oxford University Press, 1997.

32. Freer CB. Self-care: a thealth diary study. Med Care 1980;18:853-61.

33. Freer CB. Health diaries: a method of collecting health information. I R Coll Gen Pract $1980 ; 30: 279-82$.

34. Verbrugge LM. Health Diaries. Med Care 1980;18:73-95.

35. Carp FM, Carp A. The validity, reliability and generalizability of diary data. Exp Aging Res 1981;7:281-96.

36. Norman GR, McFarlane AH, Streiner DL, Neale K. Health diaries: strategies for compliance and relation to other measures. Med Care 1982;20:623-9.

37. Goossens MEJB, Rutten-wan Mölken MPMH, Kole-Snijders AMJ, Vlaeyen JWS, Van Breukelen G, Leidl R. Health economic assessment of behavioural rehabilitation in chronic low back pain: a randomised clinical trial. Health Econ 1998;7:39-51.

38. Van Roijen L, Essink-Bot ML, Koopmanschap MA, Bonsel GJ, Rutten FFH. Labor and health status in economic evaluation of health care. The health and labor questionnaire. Int J Technol Assess Health Care 1996;12:405-15.

39. Van Waltaven C, MahonJL, Moher D, Bohm C, Laupacis A. Surveying patients to determne the minimal important difference: implications for sample size calculation. J Clin Epidemiol $1999 ; 52: 717-23$.

40. Rittenhouse BE, Dulisse B, Stinnett AA. At what prive significance? The effect of price estimates on statistical inference in economic evaluation. Health Econ 1999:8:213-9.

41. Redekop WK, Koopmanschap MA, Stolk RP, Rutten GEHM, Wolffenbuttel BHR. Niessen LW. Health-related quality of life and treatment sarisfaction in Dutch patients with type 2 diabetes mellitus. Diab Care 2002;25:458-63. 
42. Vrijhoef HJM, Diederiks JPM, Spreeuwenberg $C_{i}$ Wolfenbuttel BHHR, Van Wideren LJGP. The nurse specialist as main care-provider for patients with cype 2 diabetes in a primary care setting: effects on patient ontcomes. Int J Nurs Studies 2002;39:441-51.

43. Redekop WK, Koopmanschap MA, Rutten GEHM, Wolftenbuttel BHR, Stolk RP, Niessen LW. Resource consumption and costs in Dutch patients with type 2 diabetes mellitus. Results from 29 general practices. Diab Med 2002;19:246-53.

44. Szende A, Svensson K, Stahl E, Meszaros A, Berta GY. Psychometric and utility-based measures of health status of asthmatic patients writh different disease control level. Pharmacoeconomics. 2004;22:537-47.

45. Schemer TR, Thoonen BP, Van den Boom $G$, et all. Randomized controlled economic evaluation of asthma self-management in primary healch care. Am J Resp Crit Care Med. 2002;166:1062-72.

46. Sculpher MJ, Pang FS, Manca A, et al. Generalisibility in economic evaluation studies in health care: a review and case studies. Health Technol Assess 2004;8(49) www.york.ac.uk Last accessed: July 31, 2005.

47. Steuten LMG, Van Merode GG, Spreeuwenberg $C$, Vrijhoef HJM. Brug tussen onderzoek en beleid: toepassing van Health Techmology Assessment op disease management. TSG 2004;82:118-20. fim Dutchl

48. Twisk JWR. Applied longitudinal data analysis for epidemiology: a practical guide. Cambridge, UK: Cambridge University Press, 2003.

49. Hollis $\mathrm{S}$, Campbell $\mathrm{F}$. What is meant by intention to treat anallysis? Survey of published randomised trials. BMJ 1999;319:670-4.

50. Renders CM. Interventions to improve the quality of diabetes care in primary care. Dissertam tion. Vrije Universiteit Amsterdam, Amsterdam, The Netherlands, 2001.

51. Divine GW, Brown T, Frazier LM. The unit of analysis error in studies about physicians' patient care behaviour. J Gen Int Med 1992;7:623-9.

52. Claxton K, Sculpher M, Drunmond M. A rational framework for decision making by the National Institute for Clinical Excellence (NICE). Lancet 2002;360:7 1-5.

53. Briggs AH, McGray A. Methods in heall th service tesearch: handling uncertainty in economic evaluations of healthcare interventions. BMJ 1999;319:635-8.

54. Claxton K, Neumann PJ, Araki S, Weinstein MC. Bayesian value-of-intormation analysis. An application to a policy model of Alzheimer's disease. Int J Technol Assess Health Care $2001: 17: 38-55$

55. Drummond M, McGuire A. Economic evaluation in health care: merging the ory with practice. New York: Oxford University Press, 2001.

56. Philips $Z_{x}$ Ginnelly L, Sculpher M, et al. Review of for good practice in decision-analytic modelling in health technology assessment in health technology assesment. Health Technol Assess 2004;8:1-158.

57. Nuijten M], Pronk MH, Brorens MJ, er al. Reporting forniat for economic evaluation. Part 11: Focus on modelling studies. Pharmacoeconomics 1998;14:259-68.

58. Briggs A, Sculpher M. An introduction to Markov modelling for economic evaluation. Pharmacoecononics 1998; 13:397-409. 
59. Van Schayck CP, Chavannes NH. Detection of asthma and Chronic Obstructive Pumonary Disease in primary care. Eur Resp J 2003;39:16s-22s.

60. Tinketman D, Corsello P. Chronic Obstructive Pulmonary Disease the impact occurs earlier than we think. Arn J Man Care 2003;9:767-71.

61. Moscato $G$, Galdi $\mathbb{E}$, Perfett L. Early detection of occupational asthma and reactive airways dysfunction syndrome. Monaldi Arch Chest Dis 2000;55:66-9.

62. Adrianse MC, Dekker MJ, Spijkeman et al. Health-related quality of life in the first year following diagnosis of type 2 diabetes: newly diagnosed patients in general practice compared with screning-detected patients. The Hoorn Screening Study. Diab Med 2004;21:1075-81.

63. Icks A, Rathmann W. Haastert B, etal. Cost effectiveness of type 2 diabetes screening: from recently published studies. Gesundheitswesen 2005;67(Suppl 1):167-71.

64. Van den Boom G, Rutten-van Mölken MP, Folgering H, van Weel C, Van Schayck CP. The economic effects of screening for obstructive airways disease: an economic analysis of the DIMCA program. Prev Med 2000;30:302-8.

65. VrijhoefH], Diederiks JP, Wesseling GJ, Van Schayck CP, Spreeuwenberg C. Undiagnosed patients and patients at risk for $\mathrm{COPD}$ in primary health care: early detection with the support of non-physicians. J Clin Nurs 2003:12:366-73.

66. Beusmans $G$, Crebolder H, Van Ree J. Zorg woor chronisch zieken. Praktijkverpleegkundigen breed inzetten. Med Cont 2001;56:259-62. [in Dutch]

67. Mensink M, Blaak EE, Corpeleijn E, Saris WH, De Bruin TW, Feskens EJ. Lifestyle intervention according to general recommendations improves glucose tolerance. Obes Res $2003 ; 11: 1588-96$.

68. Franssen FN, Broekhuizen P, Janssen PP, Wouters EF, Schols AM Effects of whole-body exercise training on body composition and functional capacity in nomal-weight patients with COPD. Chest $2004 ; 125: 2021-8$.

69. Schols A. Nutritional modulation as part of integrated management of chronic obstructive pulmonary disease. Proc Nutr Soc 2003;62:783-91.

70. Wagner ED. Elements of the chnonic care model, www improvingchroniccare.org/change/ model/components Last accessed: Aug 1, 2005.

71. Casalino LP. Disease management and the organization of physician practice. JAMA $2005,293: 485-8$.

72. Vrijhoef HJM, Steuten LMG. Innovatieve zorgconcepten op een rij: disease management (1). TSG 2005;83:305-6. fin Dutchl

73. Homer J, Hirsch $G$, Mimiti M, Pierson M. Models for collabonation: how system dymamics helped a conmunity organize cost-effective care for chronic illness. System Dynamics Rev $2004 ; 20: 199-222$

74. Vierhout WP, Knottnerus JA, Van Ooij A, et al. Effectiveness of joint consultation sessions of general practitioners and orthopaedic surgeons for locomotor-system disorders. Lancet $1995 ; 346: 990-4$.

75. VlekJFM, Vierhout WPM, Knotmerus A, et al. A randomised controlled trial of joint consultations with general practitioners and cardiologists in primary care. $\mathrm{Br} J$ Gen Pract $2003 ; 53 ; 108-12$. 
76. Schulpen GJC, Vlek JFM, Vierhout WPM, Wesselingh-Megens AM, Crebolder HIMJ. The win-win consultation: transmurale collaboration between specialist and general practitioners. Med Cont 2002,57:423-5. [im Dwrh]

77. Shortell SM, Marsteller JA, Lin M, et al. The role of perceived team effectiveness in improving chronic illness care. Med Care 2004;42:1040 8.

78. Steuten $L_{n}$ Frederix M, Vrijhoef B, Van Merode GG, Spreeuwenberg C. Patiènten tevteden over diabetesverpleegkundige, TVZ 2003;113:48-51. [in Dmith]

79. Raad voon de Volksgezondheid en Zorg (RVZ). Juridische aspecten van taakherschikking in de gezondheidszorg. Zoetermeer: Raad voor de Volksgezondheiden Zorg, 2002. [in Duth]

80. Van Merode F, Molema H, Goldschmidt H. GUM and six sigma approaches positioned as deterministic tools in quality engineering. Accred Qual Assur 2004;10:32-6.

81. Van Merode F. A prelude of the 2004 Antwerp Quality Conference: targets and target values - integrating quality management and costing. Accred Qual Assur 2004;9:168-71. 


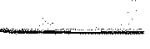




\section{SUMMARY}

The purpose of this thesis was to assess if disease managenent programmes (DMPs) for patients with asthma, Chronic Obstructive Pulmonary Disease (COPD) or diabetes mellitus improve quality of care within the existing budgets. Principles of Health Technology Assessment (HTA) and decision-analysis have been applied to explicitly support decision-making with regard to disease management.

In Chapter 2, the usefulness of three existing instruments for assessing methodological quality of HTA of disease management has been examined. This was done because HTA of disease management has some specific characteristics, as compared to regular clinical trials, that might not be addressed properly in the existing instruments. Using these instruments would then lead to incorrect assessment of the methodological quality of HTA of disease management.

In all existing instruments, items were found that are not applicable to HTA of disease management, such as blinding of patients and care providers. Other issues, like adequate use of modelling techniques to assess the long-term impact of DMPs, were missing. Furthermore, the existing instruments did not provide a reliable way to assess methodological quality when several types of indicators (i.e. structure, process and outcome indicators) were measured within studies. Subsequently, a new instrument to assess the methodological quality of HTA of disease management was constructed and validated. This tailor-made instrument (called the HTA-DM instrument) showed to be a reliable instrument with regard to Spearman ranking correlation, test-retest reliability and interrater reliability. The HTA-DM instrument is useful for both (randomised) controlled and observational designs.

The relation between DMPs and their organisational context has been described in Chapter 3. By means of a systematic literature review it was investigated if the type of health care system (i.e. market, tax or social insurance) intuences the completeness and contents of a programme. No statistically significant relationship between the type of health care system and the completeness of a DMP, or the presence of any specific components could be demonstrated. The hypothesis that a more complete programme would have more or larger effects on processes and outcomes of care than less complete programmes could not be affirmed. The presence of a collaborative practice model or patient self-management education was associated with a positive effect on self efficacy of patients.

An overview of the indicators that are currently used to assess DMPs has been presented in Chapter 4 . We assessed if there was actually a fit between the general aim(s) of a DMP (e.g. improving quality and/or increasing efficiency of care) and the 
type(s) of indicators used to evaluate the programme. In a substantial part of published studies on disease management no link exists between the aim(s) of the programme and the structure, process and outcome indicators that were evaluated. Although of major importance for the interpretation of outcomes and generalisability of results, structure indicators are largely missing from the analysis. Efficiency of disease management programmes was mainly evaluated by means of process indicators, while outcome indicators were commonly applied to assess effectiveness. Furthermore, no reflection of the type of DMP (e.g. organisational, professional or educational) was found within the structure, process and outcome indicators mentioned. A framework has been developed, in which structure, process and outcome indicators are linked. This framework should guide researches to define datasets that are suitable for a certain DMP to be assessed, while promoting the collection of comparable and useful information for decision-makers in healthcare.

In Chapter 5 the results of a cross-sectional study towards the distribution of COPD disease severity in primary care are presented. It was found that, according to the guidelines of the Global Initiative for Chronic Obstructive Pulmonary Disease (GOLD), $29 \%$ of the patients had mild COPD, $28 \%$ moderate, $17 \%$ severe and $5 \%$ very severe. A substantial proportion of patients with mild to moderate COPD suffer from moderate to severe dyspnoea and/or serious muscle wasting. Also, prevalence of obesity was found to be relatively high among these patients. It was concluded that the use of a multidimensional grading system, which assesses systemic as well as respiratory expressions of COPD, would influence the distribution of disease severity in a population of COPD patients. This has implications for prevention, (non) medical treatment as well as estimations of healthcare utilisation.

The short-term results of the DMP for adults with asthma or COPD are presented in Chapter 6. We concluded that organising health care according to principles of disease management is associated with significant improvements in several processes and. outcomes of care within the existing budgets. Quality aspects of care, self care behaviour, smoking status, disease specific knowledge and satisfaction of all patients improved after implementation of the programme. Lung function and health status were not affected by implementation of the DMP. Patients consumed more routine consultations and costs for medication increased. Non-routine consultations, hospitalisation and productivity losses decreased after implementation of the programme. This indicates an improved disease control. For patients with COPD, a significant improvement in health-related quality of life (HRQL) was found. Significant cost savings were measured among patients with asthma. Overall, the impact of the programme was the largest in patients that were assigned to the respiratory nurse specialist. Furthermore, we found that changes in intermediate outcomes predict 
changes in end results of care, which are better suitable for decision-making on a macro level.

The short-term results of the DMP for patients with diabetes are presented in Chapter 7. Clinical effectiveness, as expressed by glycaemic control, improved significantly after two years of follow up, except for patients assigned to the GP. Overall, compliance, most aspects of self care behaviour and HRQL improved significantly. No significant changes were observed in the total costs of care. Patients that were assigned to the diabetes nurse specialist benefited most from the introduction of the programme. There is a probability of $74 \%$ that the disease management strategy dominates the usual care strategy. In the disease management strategy, on average $€ 118$ per patient per year is saved, while HRQL increases with $5 \%$. When policy makers are willing to pay $€ 3000$ for an additional quality-adjusted life year (QALY), the probability that the diabetes programme delivers "value for money' rises from $74 \%$ to $90 \%$.

The five-year impact of the DMP for patients with asthma was estimated by means of a probabilistic decision-analytic Markov model, as reported in Chapter $\mathbf{8}$. The results of the Markov model showed that HRQL improved, as demonstrated by a gain of 0.7 QALYs within five years. Costs decreased with $€ 329$ per patient. These results are mainly driven by the increase in asthma control that is gained in the disease management strategy. In the DMP, patients who are better controlled continue to be better controlled than in usual care. Also, patients experiencing exacerbations or being in a state of 'sub optimal control' are more likely to be successfully controlled again.

With regard to decision uncertainty we found a probability of $76 \%$ that the disease management strategy leads to increased benefits at lower costs, compared to usual care. When policy makers are willing to pay $€ 1000$ for an additional QALY, the probability that disease management will be the most beneficial strategy increases to $95 \%$. Including productivity costs in the analysis even strengthens the finding that disease management dominates usual care: $90 \%$ of the simulations indicate the DMP to be cost saving without any investment for incremental QALYs. For patients assigned to the respiratory nurse specialist, the disease management strategy is associated with a gain in QALYs at slightly higher costs. The expected outcomes for patients assigned to either the GP or the pulmonologist seem to remain largely the same after implementation of the DMP. Within these subgroups also more uncertainty around the cost utility ratio exists, as compared to the subgroup assigned to the respiratory nurse specialist.

An overview of the most important results of the DMPs, as presented in chapters 6,7 and 8 , is provided in Table 1. 
Table 1: Owerview of most inportant results of the disease management programmes as compared to usual care

\begin{tabular}{|c|c|c|c|c|c|c|c|}
\hline Chalpter & Diserise & $\begin{array}{l}\text { Disedse } \\
\text { control }\end{array}$ & $\begin{array}{l}\text { Health-related } \\
\text { gitidity of life }\end{array}$ & $\begin{array}{l}\text { patient } \\
\text { salisfaction }\end{array}$ & $\begin{array}{l}\text { Self } \\
\text { managentent } \\
\text { knowiledge }\end{array}$ & $\begin{array}{l}\text { Total } \\
\text { healthicare } \\
\text { cosits }\end{array}$ & $\begin{array}{l}\text { Probability that DMP } \\
\text { is cost effective from at } \\
\text { societal perspective }\end{array}$ \\
\hline $6 / 8$ & asthryat & + & $=$ & + & $+1+$ & - & $90 \%$ (long-term results) \\
\hline 6 & COPD & + & + & 4 & $+y+$ & $=$ & na (in preparation) \\
\hline 7 & $\begin{array}{l}\text { diabetes } \\
\text { mellitus }\end{array}$ & + & + & na & $+/$ na & $=$ & $74 \%$ (short-term results) \\
\hline
\end{tabular}

+ statistically significant improvenent; - statistically significant decrease; = equivalent outcome; nat = not applicable 


\section{SAMENVATTING}

Het doel van deze studie is te beoordelen of disease management programma"s voor patiënten met astma, chronisch obstructieve longaandoening (COPD) of diabetes mellitus, de kwaliteit van zorg verbeteren binnen de bestaande budgetten. Principes van Health Technology Assessment (HTA) en beslisanalyse zijn toegepast om besluitvorming rondom disease management programma's te onderstetnen.

In Hoofdstuk 2 wordt de bruikbaarheid van verschillende instrumenten ter beoordeling van de methodologische kwaliteit van disease management evaluatie studies bekeken. Een resultaat hiervan is de ontwikkeling en validering van een nieuw instrument dat specifiek bedoeld is voor de beoordeling van de methodologische kwaliteit van. HTA van disease management. In de bestaande instrumenten bleken items te zijn opgenomen die niet toepasbaar zijn op HTA van disease management, terwijl andere items, zoals het adequat gebruik van modelleringtechnieken teneinde de impact van een programma op langere termijn te beoordelen, ontbraken. Verder was het met de bestaande instrumenten niet mogelijk om methodologische kwaliteit op een betrouwbare manier te beoordelen wanneer meerdere indicatoren worden gemeten in evaluatiestudies. Het voorgestelde instrument (het zogenoemde HTA-DM instrument) geeft een betrouwbare beoordeling van methodologische kwaliteit, zoals bleek uit de Spearman rangcorrelatie, test-hertest betrouwbaarheid en tussen-beoordelaar betrouwbaarheid. Het HTA-DM instrument is niet alleen toepasbaar op gerandomiseerde studies, maar ook op quasi-experimenteel en observationeel onderzoek.

In Hoofdstuk 3 wordt een systematische literatuurstudie nar organisatie aspecten van disease management programma's beschreven. De resultaten toonden geen significante relatie aan tussen het type gezondheidszorgsysteem enerzijds en de compleetheid van een programma of de aanwezigheid van specifieke componenten van disease management anderzijds. De veronderstelling dat een meer compleet programma leidt tot betere resultaten, kon op basis van de beschikbare gegevens niet worden bevestigd. Verder werd vastgesteld dat de anwezigheid van de componenten 'samenwerkingsmodel" of 'zelfmanagement interventies voor patiënten', leidt tot verbeteringen in zelfzorggedrag van patiënten.

Een overzicht van indicatoren die momenteel gebruikt worden om disease management programma's te beoordelen, wordt gepresenteerd in Hoofdstuk 4. Het bleek dat ergeen eenduidigheid bestaat betreffende de keuze voor indicatoren ter evaluatie van een programma. Er is onderzocht of er een match bestaat tussen de dockn van een disease management programma (d.w.z verbeteren van effectiviteit en/of efficiëntie 
Wan zorgy en het type indicatoren dat gebruikt is om het programma te evalueren. In en substanticel deel van gepubliceerde evaluaties van disease management programma's bleek geen link te bestaan tussen de doelen van het programma en de geevalueerde structuur-, proces-en uitkomstindicatoren. Ondanks het feit dat informatie over structuurind catoren wan groot belang is voor interpretatie en generalisatie van ondexzoeksresultaten, worden deze nauweliks meegenomen in de evaluatie van programma"s. Efficiẻntie van disease management programma's wordt doorgans geèvalueerd op basis wan procesindicatoren, terwijl de effectiviteit van programma's voornamelijk wordt beoordeeld aan de hand van uitkomstindicatoren. Verder bleek het type disease management programma (d.w.z. organisationeel, educatief of professioneel) geen invloed te hebben op de keuze voor specifieke structuur-, proces- en uitkonstindicatoren. Op basis van de resultaten werd een raamwerk ontwikkeld waarin structuurm, proces- en uitkomstindicatoren aan elkaar worden gerelateerd. Dit ramwerk geeft richting aan verder onderzoek en dient als ondersteuning bij het kiezen van indicatoren voor de evaluatie van een disease management programma.

In Hoofdstuk 5 worden de resultaten van een transversale studie naar de verdeling wan ziekte-ernst in een populatie patiënten met COPD in de eerstellijns gezondheidszorg, weergegeven. Er werd gevonden dat wanneer patienten op basis van Iuchtwegobstructie (zoals gedefinieerd door de Global Initiative for Chronic Obstructive Pulmonary) worden ingedeeld in ernstcategorieën, $29 \%$ kan worden geclassificeerd als mild COPD, $28 \%$ als matig COPD, $17 \%$ als ernstig en $5 \%$ als zeer ernstig COPD. Verder bleek dat een aanzienlijk deel van de patiënten met mild of matig COPD aangaf matige tot ernstige kortademigheid te ervaren. Daarnaast werd gevonden dat een deel van de patiënten met mild of matig COPD reeds an ernstig selectiefverlies van spiermassa ten opzichte van lichaamsgewicht lijdt (spierdepletie), terwijl ook de prevalentie van obesitas relatief hoog is in deze patientencategorieër. Op basis van deze gegevens werd geconcludeerd dat een multifactorieel classificatiesysteem, dat zowel systemische als respiratoire expressies van COPD beoordeelt, de ernstverdeling van COPD in een eerstelinspopulatie zal doen veranderen. Dit kan gevolgen hebben voor (secundaire) preventie, medische en niet-medische behandeling van patiënten alsook schattingen van zorggebruik in deze populatie.

De korte termijn resultaten wan het disease management programma voor mensen met atstma of COPD, worden gepresenteerd in Hoofdstuk 6. Er wordt gecondudeerd, dat het organiseren van zorg volgens de principes van disease management is. geassocieerd met significante verbeteringen in processen en witkomsten van zorg binnen de bestaande budgetten. Aspecten van kwaliteit van zorg, zelfzorggedrag, rookstatus, ziektespecifieke kennis en tevredenheid van alle patiënten verbeterde na implementatie van het programma. Verder nam het aantal controle consulten en 
medicatiegebruik van patiënten toe. Het aantal ongeplande consultaties (d.w.z. consultaties als gevolg van een plotselinge verslechtering van de gezondheidstoestand), ziekenhuisopnames alsook productiviteitsverliezen nam af. Dit impliceert een verbeterde controle over de aandoening. Longfunctie en gezondheidstoestand werden niet beïnvloedt door implementatie van het disease management programma. Bij patiënten met COPD werd een significante verbetering in ziektegerelateerde kwaliteit van leven gevonden. In de groep patiënten met astma werd een significante kostenbesparing waargenomen. In het algemeen bleek de impact van het disease management programma het grootst te zijn in de groep patiënten die werd toegewezen aan de gespecialiseerde longverpleegkundige. Tenslotte bleken veranderingen in intermediaire uitkomstmaten voorspellend te zijn voor eindresultaten van zorg, welke beter geschikt zijn voor besluitvorming op macroniveau.

In Hoofdstuk 7 worden de korte termijn resultaten van het disease management programma voor patiënten met diabetes mellitus beschreven. Het bleek dat de klinische effectiviteit van zorg, uitgedrukt in de mate waarin de bloedglucose gecontroleerd is, twee jaar na invoering van het programma significant was verbeterd. Dit gold echter niet voor patiënten die waren toegewezen aan de huisarts. Verder bleken na invoering van het programma de ziektegerelateerde gezondheidstoestand, therapietrouw alsook de meeste aspecten van zelfzorggedrag significant te zijn verbeterd. De totale kosten van zorg bleven gelijk. Patiënten die werden toegewezen aan de gespecialiseerde diabetesverpleegkundige profiteerden het meest van de invoering van het disease managenent programma.

Er werd berekend dat er een kans van $74 \%$ is dat het disease management progranma traditionele zorg 'domineert' door gemiddeld $€ 117$ per patiënt jaar te besparen terwijl ziektegerelateerde kwaliteit van leven met $5 \%$ verbeterd. Wanneer beleidsmakers bereid zijn om $€ 3000$ per additionele QALY te betalen, er een kans is van $90 \%$ dat het disease management programma 'value for money' oplevert.

De lange termijn impact van het disease management programma voor patiënten met: astma werd geschat met behulp van een probabilistisch Markov model. Dit is beschreven in Hoofdstuk 8 . De resultaten van deze simulatiestudie laten zien dat over een periode van vijf jaar de ziektegerelateerde kwaliteit van leven verbetert met 0.7 QALYs, terwijl de kosten afnemen met $€ 329$ per patiënt. Deze resultaten worden voomamelijk veroorzaakt door een verbeterde controle over de aandoening zoals gemeten na invoering van het disease management programma. Patiënten die hun astma goed onder controle hebben, blijken deze controle vaker vast te houden, terwijl patiẻnten die exacerbaties ervaren of suboptimale controle over de aandoening hebben een grotere kans hebben om weer in een toestand van succesvolle controle terecht te komen. Wat betreft beslissingsonzekerheid werd er een kans van $76 \%$ gevonden dat het disease management programme leidt tot 
verbeterde ziektegerelateerde kwaliteit van leven tegen lagere kosten, in vergelijking met de zorg zoals die voorheen geleverd werd. Wanneer beleidsmakers $€ 1000$ over hebben voor een extra QALY, neemt deze kans toe tot $95 \%$. Het includeren van productiviteitskosten in de analyse, waarmee een meer maatschappelijk perspectief op de economische evaluatie wordt geworpen, versterkt de bevinding dat het disease management programma de traditionele zorg dommeert: $90 \%$ van de simulaties geeft aan dat het disease management programma kosten bespaart, zonder dat enige investering voor additionele QALYs wordt verondersteld. De subgroepanalyses, zoals gebaseerd op de toewijzing van de patient aan de huisarts, gespecialliseerd longverpleegkundige of longarts, leiden tot inzicht in de relatieve bijdrage van elk van deze stibgroepen aan de kostenutiliteit wan het programma als geheel. Voor de patienten die zijn toegewezen aan een gespecialiseerde longverpleegkundige wordt geschat dat het programma leidt tot een verbeterde ziektegerelateende kwaliteit van leven tegen iets hogere kosten, terwijl de verwachte uitkomsten voor patienten toegewezen aan huisarts of longarts grotendeels gelijk blijven. In deze laatste twee subgroepen bestaat echter ook meer onzekerheid betreffende de kostenutiliteitsratio, vergeleken met de subgroep patiënten die is toegewezen aan gespecialiseerde verpleegkundige.

Een overzicht van de belangrijkste effecten wan de onderzochte disease management programma's, zoals beschreven in Hoofdstuk 6,7 en 8, wordt weergegeven in Tabel 1.

Tabel 1: Owerzicht van de belangrijkste effecten van de onderzochte disease management programma's in vergelijking rot traditionele zorg

\begin{tabular}{|c|c|c|c|c|c|c|c|}
\hline Hoofdstak & Aandowening & $\begin{array}{l}\text { KJininche } \\
\text { tuithomsten }\end{array}$ & $\begin{array}{l}\text { Ziektegere- } \\
\text { lateerde } \\
\text { kwalliteit } \\
\text { wan leven }\end{array}$ & $\begin{array}{l}\text { Patrènt } \\
\text { tewredentheid }\end{array}$ & $\begin{array}{l}\text { Zelfinana- } \\
\text { gernenit } \\
\text { ziekterpe- } \\
\text { cifieks: } \\
\text { kennis }\end{array}$ & $\begin{array}{l}\text { Totale } \\
\text { kosten: } \\
\text { van zorg }\end{array}$ & $\begin{array}{l}\text { Kans dat hel diseast } \\
\text { managemert } \\
\text { programma kosten- } \\
\text { effetief is (wanut } \\
\text { maatschappelijk } \\
\text { persectief) }\end{array}$ \\
\hline $6 / 8$ & istrnat & + & $=$ & $H$ & $+1+1$ & - & $90 \%$ (lange temnin) \\
\hline 6 & COPD & + & + & + & $+f+$ & $=$ & $\begin{array}{l}\text { the (in } \\
\text { voorbereiding) }\end{array}$ \\
\hline 7 & $\begin{array}{l}\text { diaberes } \\
\text { muallimus }\end{array}$ & + & + & nb & th $/$ nib & $=$ & $74 \%$ (korte lerminn) \\
\hline
\end{tabular}

+ statistisch significante verbetering; - statistisch significante afname; = equivalente uitkomst; nb = nict betlenend 


\section{DANKWOORD}

Na vier jaar met veel plezier aan dit boekje te hebben gewerkt, is het af Het is dan ook de hoogste tijd om iedereen, die op de een of andere manier een bijdrage heef geleverd an de totstandkoming ervan, heel hartelijk te bedanken.

Allereerst een bijzonder woord van dank aan mijn promotoren Cor Spreeuwenberg en Frits van Merode. Van het begin af aan hebben jullie mij alle vrijheid gegeven in het verder uitwerken en vormgeven van dit onderzoek. Daarnast kon ik altijd rekenen op snelle en adequate begeleiding. Ondanks jullie overvolle agenda's kreeg ik doorgaans binnen 24 uur (!!) reactie op mijn schrijfsels. Voor vartraging hoefde ik dus niet bang te zijn (en voor een adempauze overigens ook niet). Het meest ben ik echter geinspireerd door jullie eigenzinnigheid, durf en doorzettingsvermogen. "From guts to glory" is op jullie bijzonder van toepassing.

Als mijn dagelijks begeleider en co-promotor is Bert Vrijhoef onmssbar geweest bij de totstandkoming van dit proefschrift. Bert, ik zal moeten wolstaan met een 'bedankt voor alles" om dit dankwoord qua lengte binnen de perken te houden. Het was (en is) prettig samenwerken met jou. Ik ben dan ook blij dat onze samenwerking een vervolg krijgt. Dit geeft je trouwens ook de kans om eindelijk eens met die beloofde aardbeientaartjes uit Gronsveld op de proppen te komen!

Zonder de mensen die de disease managenent programma's hebbengemaakt tot wat ze nu zijn, was mijn onderzoek niet mogelijk geweest. Dank aan Hans Fiolet, Geert-Jan Wesseling, Miel Wouters, Leonie van Son, Marianne Frederix, Nicolaas Schaper, Sabine Landewé-Cleuren, alle gespecialiseerde verpleegkundigen, huisartsen en de secretariaten disease management. Ik heb ontzettend wael bewondering voor hetgeen jullie bereikt hebben met de disease management programma"s. Gelukkig hoefde ik slechts de data te verzamelen en de analyses te doen. Een speciaal woord van dank gaat uit naar de gespecialiseerde verpleegkundigen, die mij hebben laten meelopen met hun spreekuren en zonder wie ik maar half zo veel data had kunnen verzamelen. Ik ben er trots op dat we nu samen naar internationale congressen gatn on de mooie resultaten die we hebben bereikt wereldkundig te maken.

Alle patienten die hebben deelgenomen an het onderzoek ben ik zeer erkentelijk voor het invullen van de vragenlijsten en kostenboekjes. Voor het invoeven van en paar duizend vragenlijsten, screeningsformulieren, jaarcontroles en kostenboekjes bedank ik alle student-en onderzoeksassistenten (Simone Bleeker, Karien Croezen, Jerome Lacroix, Wendy Altobello, Eefe Kouters, Dany Simon, Joyce Janssen, 
Steven en Maarte). Hopelijk word ik nooit aansprakelijk gesteld voor eventuele muisarmen.

Further, I would like to acknowledge everybody who supported my modelling work and/or facilitated my working visit at the Centre for Health Economics, University of York. Besides my supervisors, these are Mark Sculpher, Steve Palmer, Hans Severens and Amold van Alphen. Professor Sculpher, many thanks for having me as your guest at CHE. Steve, without your endless patience, my asthma model would still not run. Thanks for helping me out, not only during my stay in York but also afterwards. Hans, bedankt voor je kritische beoordeling van verschillende manuscripten. Arnold wil ik speciaal bedanken voor het à la minute tevoorschijn 'toveren' van drie extra pc's, zodat ik mijn simulaties toch binnen enkele weken i.p.v. enkele maanden kon draaien.

Alle collega's van de sectie $Z W-V W$ wil ik bedanken voor hun inhoudelijke input tijdens het refereren, de vele vrolijke noten (met name 'Waterloo' en 'Dr. Bernhard') en het ongekend slap geouwehoer op (onder andere) vrijdagmiddag. Degenen die in de afgelopen vier jaar een kamer moesten delen met mij (Bert, Hanneke, Benigna, Ilonca en Patricia), wil ik vragen hoe ze het in hemelsnaam hebben uitgehouden?? In elk geval bedankt voor alle gezelligheid, 'social talk' en de gesprekken over zaken die ik hier niet durf te benoemen (parental advisory), maar die in géén geval tot algemeen geaccepteerde 'social talk' gerekend kunnen worden. Ik zal niks doorvertellen, op voorwaarde dat jullie dat ook niet doen!

Naast de collega's bij ZW verdienen Hanneke en Irma van de vakgroep BEOZ een speciale vermelding in dit dankwoord. Imma, met jou is het altijd gezellig! Bedankt voor je betrokkenheid, de nodige relativering en je fantastische ondersteuning in het bestuur van de alumnivereniging (mast je eigen taken hierin). Wanneer gaan we weer een weekendje naar Brussel? Han, enkele jaren gelleden kwam je binnendenderen bij ZW en al snel bleek dat wij een 'pittig setje' zijn (als collega's wel te verstanj, Geweldig dat ik met jou onbeperkt over simulatiemodellen en statistiek kan zaniken, zonder dat je in slaap valt. Sterker nog, je kletst me er (bijna) uit! Bedankt voor alle praktische hulp, betrokkenheid en de vele hilarische momenten waarbij regelmatig "de bodem utut mien boks" viel. Zoals jij altijd zegt: "great minds think alike'... al is het maar over hangop. Ik vind het super dat je mijn paranimf wilt zijn; ik hoop alleen dat je drie kwartier je mond kan houden.

Sylvie, al vanaf de middelbare school ben jij mijn liefste vriendinnetje. Geweldig dat je je vakantieplannen aampast om mijn paranimf te zijn. Door al het academisch geklets heen, zie jij mij toch altijd gewoon als "die andere blonde van Boshoven". Ik voel me gesteund doordat jij op P-day achter me staat (en, zoals afgesproken, een oogie op Han houdt ;-) 
Lieve pap, mam en Maartje, jullie wil ik bedanken voor het geduld waarnee jullie mijn verhalen telkens (opnieuw) hebben aangehoord. Paps, desystematusche namier waarop jij bijvoorbeeld onze studentenkamers inrichtte (met op schaal getekende figuurtjes, waarmee je op papier de mogelijkheden verkende alvorens met meubels te gaan slepen), staat model voor mijn werk nu. Mam, van jou heb ik niet alleen de 'looks', maar vooral ook een flinke dosis competitiedrang en koppigheid geërfd. Zonder eigenschappen van jullie beiden was dit proefschrift nooit tot stand gekomen. Bedankt voor jullie onvoorwaardelijke steun. Maartje, wij hebben meer gemeen dan onze kapsels doen vermoeden. Al kan ik je levensweg niet altijd volgen, ik ben er hartstikke trots op dat jij mijn zus bent! Het kaftontwerp is mede het resultaat van jouw creativiteit. Super bedankt daarvoor.

Lieve Steven, op geheel eigen wijze heb je mij de afgelopen jaren gesteund. Als geen ander wist je mij met beide benen op de grond te zetten, wanneer ik weer eens ongeremd doordraafde, volslagen onredelijk was of in de put meende te zitten. Al kan ik je onmogelijk genoeg bedanken, vanaf vandaag is het 'payback-time': stoffer, blik en kookboek zijn hiervoor al aangeschaft!

$\mathrm{Nu}$ is het tijd voor een feestje... 


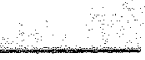




\section{CURRICULUM VITAE}

Lotte Steuten was born in Weert, the Netherlands, on April 27, 1979. After finishing secondary school (VWO) at the Bisschoppelijk College in Weart, she started to study Health Care Sciences at Maastricht University. She chose for the specialisation of Health Care Studies, when this educational programme was offered for the first time. During this specialisation, she spent three months at Arizona State University (USA). There, she investigated the development, implementation and evaluation of disease management programmes in the United States. From that moment, her interest in scientific research in general, and disease management in particular, was excited. In September 2001 she received her master's degree in Health Care Sciences after finishing her thesis about the participation of Dutch general practitioners in disease management programmes. Immediately after that, she started working as a PhD-student at the Department of Health Care Studies of Maastricht University. In addition, she studied Dutch Law at Mastricht University, from 2002 until 2003. Her research towards health technology assessment of disease management was performed under supervision of professor Spreeuwenberg, professor Van Merode and dr. Vrijhoef. In 2004, she was hosted for three months at the Centre for Health Economics of the University of York (UK). During this period, she improved her skills in advanced decision-analytic modelling under supervision of professor Sculpher. Her PhD-research resulted in this dissertation.

Starting from September 2005, she is appointed as a post-doctoral researcher on a "Talent for the Future'-grant from the Faculty of Health Sciences. Her future research is aimed at the optimisation of disease management programmes and the further improvement of scientific research on this subject. 


\section{LIST OF PUBLICATIONS}

\section{International refereed journals}

Stentw LMG, Vrijhoef HJM, Severens JL, Van Merode GG, Spreeuwenberg C. Are we measuring what matters in Health Technology Assessment of disease management? A systematic litenature review. Int J Tech. Assess Health Care 2006;20(1) (in press).

Stowten LMC, Creutzberg EC, Vrijhoef HJM, Wouters EFM. COPD as a multicomponent disease: inventory of dyspnoea, underweight, obesity and fat free mass depletion within primary care. Prim Care Respir I (in press).

Steuten LMG, Römers R, Frambach K, Van Son L, Wesseling GJ, Wouters EFM. Assessment of a disease management program for patients with asthma or COPD. Eur Respir ] 2005;26(Suppl 49):195.

Steuten LMG, Vrijhoef HJM, Van Merode GG, Severens JL, Spreeuwenberg C. The Health Technology Assessment-Disease Management instrument reliably measured methodologic quality of health technology assessments of disease management. J Clin Epidemiol, $2004,57: 881-88$.

Steuten LMG, Wouters EFM. Impact of dyspnoea scores, body mass index and fat free mass on distribution of disease severity in COPD. European Respiratory Joumal 2004;24(Suppl 48):689s.

Van Merode GG, Steuten LMG, Vrijhoef HJM, Spreeuwenberg C. Disease management in The Netherlands. Eur J Public Health 2002;12(4):11.

Steuten LMG, Vtijhoef HIM, Spreeuwenberg C, Van Merode G. Participation of general practitioners in disease management - experiences from the Netherlands. IJIC 2002;1(5). (electronically available from www.ijic,org)

\section{National journals}

Stenten LMG. Disease management programma bij astma of COPD boekt tesultaat. Evidence Based Practice 2005;3(3):14-15.

Vrijhoef HJM, Steuten $L M G$. Innowatieve zorgconcepten op een rij: case managenent (3). TSG $2005 ; 83(7): 446-7$.

Vrijhoef HJM, Stertor LMG. Innovatieve zorgconcepten op een rij: managed care (2). TSG $2005 ; 83(6): 384-5$.

Vrijhoef HJM, Stcten LMG. Innovatieve zorgconcepten op een rij: disease management (1). TSG 2005;83(5):305-6.

Stuten LMG, Van Merode GG, Spreeuwenberg C, Vrijhoef HJM. Brug tussen onderzoek en beleid: toepassing van Health Technology Assessment op disease management. TSG $2004 ; 82(2): 118-20$.

Stewten $L M G_{\|}$Vrijhoef HJM, Van Merode GG, Severens JL, Spreeuwenberg C. Assessing the methodological quality of disease management evaluation studies. Verpleegkunde 2004;19(2):151-2. 
Stewten $L M G$, Frederix M. Vrijhoef HJM, Van Merode GG, Spreeuwenberg C. Patuenten tevreden over transmurale diabetesverpleegkundige. TvZ 2003;6.48-5.

Steuten LMG, Vrijhoef HJM, Van Merode GG, Spreeuwenberg C. Gespecialiseerde verpleegkundige speelt sleutelrol in disease management. Verpleegkunde 2003;18(4):270-1.

Presentations at conferences and symposia

Steuten $L M G$, Sales $T$. Disease management programma's voor mensen met astma of COPD: positieve effecten op kerte én lange termijn. CAHAG Conferentie, Urtecht 2006.

Stewten $L M G$, Römers $\mathbb{R}$, Van Son L, Wesseling G). Wouters EFM. Assessing the impact of a disease management programme for patients with asthma or COPD on process and intermediate outcomes of care. European Respiratory Society, Copenhagen, Denmark 2005.

Stemten LMG, VrijhoefHJM, Spreeuwenberg C, Van Merode GG, Severens JL. Does the (evaluation of the) Maastricht disease management program for asthma and COPD break new ground? Invitational Conference Disease Management, Mastricht 2004.

Steutef LMG, Vrijlhoef HJM, Spreawenberg C, Van Merode GG, Severens JL. Development of a decision-analytic model to assess the cost-utility of a disease management programme for patients with asthma. DMAA $6^{\text {th }}$ Annual Leadership Forum, OHando (FL), US 2004

Stewten $L M G$, Wouters EFM. Impact of dyspnoea scores, body mass index and far free mass on distribution of disease severity in COPD. European Respiratory Society, Glasgow ، UK 2004.

Stenten LMG, Van Son L, Salles $T$, Römers R. Wouters EFM. Impact of dyspnoea scores, body mass index and fat free mass on distribution of disease severity in COPD. IPCR G Conference, Glasgow, UK 2004 [poster].

Sicuten $L M G$, Vrijhoef HJM, Van Son L, Wesseling GJ, Wouters EFM, Spreeuwenberg C. Disease management for asthma and COPD. European Respiratory Society, Vienna, Austria 2003 [poster].

Steuten $L M G$, VrijhoefHJM, Van Merode GG, Spreeuwenberg C. Assessment of imethodological quality of health technology assessment of disease management. Intermational Society of Technology Assessment in Health Care, Canmore, Canada 2003 [poster].

Sfeuten LMG, Vrijhoef HJM, Van Merode $\mathrm{GG}_{*}$ Spreeuwenberg C. Verpleegkundige speelt sleutelrol in disease management. Vlaams-Nederlands Wetenschappelijk Congres - Desugns en Dilemma's, Nijmegen 2003.

Stcuten LMG, Vrijhoef HJM, Severens JL, Van Merode GG, Spreeuwenberg C. Assessing the methodological quality of disease management evaluation studies. The $4^{\text {th }}$ European Conference in Nursing Science, Mastricht 2003.

Stcuten LMG, Molema JJW, Gielkens-Hidegh BM, VrjhoefHJM. Disease management model voor: de astma en COPD zorg. Symposium BZE VII - De verplecgkundige gat transmuraal. Maastricht 2003 [poster].

Stenten LMG, Vrijhoef HJM, Van Merode GG, Wolffenbuttel BHR, Sprexwwenberg C. Nurse specialists playing a key-role in diabetes disease management. The $3^{\text {rd }}$ European Doctoral Conference in Nursing Science, Berlin, Germany 2002. 
Stcuten LMG, Vrjhoef HJM, Wesseling G], Wouters EFM, Spreewwenberg C. Haalbaarheid van Wet toewijzen wan patienten met astma of COPD aan een primair verantwoordelike zorgverlener binmen en disease management model. Een kwaliteitsvolle eerste lijn-Derde Eerstelinssymposium, Antwerpen, Belgiẻ 2002.

Steute LMG Vrijhof HJM, Koolen Y. Wesseling GJ, Wouters EFM, Spreeuwenberg C. Feasibillty of the assignment of patients with asthma or COPD to general practitioner, respiratory nuirse, of pulmonologist. Respiratory Diseases in Primary Care - World IPCRG Conference, Ansterdam 2002.

\section{Grants and prizes}

"Talent for the Future" "-grant of the Faculty of Health Sciences, Maastricht University; "Philipsen Award for Best Publication 2004" of the Care And Public Health Research Institute (CAPHRI);

NWO travel grant for internship at the Centre for Health Economics, University ofYork, UK. 